\title{
Livelihood Strategies and Employment Structure in Northwest Pakistan
}

\author{
Dissertation \\ to obtain the Ph. D. degree \\ in the Faculty of Agricultural Sciences, \\ Georg-August-University Göttingen, Germany
}

presented by

\section{Mohammad Asif Khan}

born in Shabqadar, Pakistan

Göttingen, January 2008 
D7

1. Name of supervisor: Prof. Dr. Dr. Winfried Manig

2. Name of co-supervisor: Prof. Dr. Stefan Sperlich

Date of oral examination: January 23, 2008 


\section{ABSTRACT \\ Livelihood Strategies and Employment Structure in Northwest Pakistan}

\section{Mohammad Asif Khan}

In this study, the livelihood strategies and changes in employment structure in Northwest Pakistan are explored from a household perspective. The study combined socio-economic longitudinal survey data that had been collected previously twenty years apart (in 1967 and 1987) with quantitative data collected 18 years later (in 2005), retrospectively tracing events and changes during that period. The universe of the research are six rural villages in the district Peshawar Northwest Pakistan. The basic survey in addition to revealing the current livelihood strategies also focused on changes in the occupational structures of the rural households during that period. The census type basic survey of 2825 households, followed by subject-specific special survey of 120 households, revealed that non-agricultural employment is an important livelihood strategy practised by rural dwellers. However, most of the non-farm employment consists of informal casual wage jobs and low rewarding petty trade. The poverty in the area is wide-spread, deepseated and severe and is accompanied by a certain degree of inequality among the rural households. The logistic regression on poverty was also used to ascertain the determinants of poverty. Comparing the employment structures with previous surveys conducted in the same villages, the analyses revealed the increasingly important role of the non-farm economy in the area with farming becoming increasingly marginalized. The study also analyses the diversity of livelihood strategies of the rural people living in the six villages in Northwest Pakistan. There is great diversity in the non-farm occupations, but the majority are survival oriented. Descriptive statistics along with diversity indices revealed the distribution patterns of employment and livelihood strategies across the study villages. The results from the logit model showed that the households' asset endowment has a significant effect on the households' choice of livelihood diversification strategies. Similarly, the multinomial logit model revealed, with respect to the household employment decisions, the importance of individual, household and community related variables such as education, age, household size, working members and location. It is the larger households with senior household heads who have some education which are generally found to be involved in relatively high-return, formal-sector occupations. Older household heads with smaller workforces at their disposal tend to continue practising pure tenancy. The implication of the study is that the rural non-farm sector needs its due share in development policies as it has the potential to uplift the rural areas. More precisely, the informal sector that is the main source of survival for the rural poor is in urgent need of support. 


\section{ZUSAMMENFASSUNG}

\section{Existenzgrundlagenstrategien und Beschäftigungsstruktur in Nordwest Pakistan}

\section{Mohammad Asif Khan}

In dieser Arbeit werden die Existenzgrundlagenstrategien und Veränderungen in den Beschäftigungsstruktur in Nordwest Pakistan aus der Perspektive der Haushalte untersucht. Die Arbeit verband sozioökonomische und Langzeitstudiendaten, die in einem Abstand von 20 Jahren 1967 und 1987 gesammelt wurden, mit quantitativen Daten aus dem Jahr 2005 (also 18 Jahren später). Rückblickend wurden die Veränderungen erforscht, die während dieser Zeit stattfanden. Die statistische Gesamtmasse bestand aus sechs ländlichen Dörfer in dem Distrikt Peschawar in Nordwest Pakistan. Die Grundbefragung konzentrierte sich auf die Veränderungen in den Berufsstrukturen in den ländlichen Haushalten während dieser Zeit sowie auf das Aufdecken der gegenwärtigen Existenzgrundlagenstrategien. Die zensusähnliche Grundbefragung von 2825 Haushalten, die durch 120 Haushalten ergänzt wurde anhand einer themenspezifischen Spezialbefragung, stellte fest, dass die nichtlandwirtschaftliche Beschäftigung eine wichtige Existenzgrundlagenstrategie für die Bewohner ländlicher Gegenden ist. Die Mehrzahl der nichtlandwirtschaftlichen Beschäftigungsverhältnisse bestand aber aus bezahlten informellen Gelegenheitsarbeiten und Kleinhandel mit einer niedrigen Gewinnspanne. Die Armut im Untersuchungsgebiet, in der ein gewisser Grad an Ungleichheit zwischen den ländlichen Haushalten herrscht, ist weitverbreitet, tief verwurzelt und drastisch. Die logistische Regression über Armut wurde auch benutzt um die Determinate von Armut festzustellen. Indem die Analyse die Beschäftigungsstrukturen mit Daten von früheren Studien verglich, wurde die an Wichtigkeit zunehmende Rolle der nichtlandwirtschaftlichen Ökonomie in der Region festgestellt, wobei die Landwirtschaft zunehmend marginalisiert wird. Weiterhin untersucht die Studie die Diversifikation der Existenzgrundlagenstrategien der ländlichen Bevölkerung in den sechs Dörfern in Nordwest Pakistan. Es gibt eine große Diversifikation in den nichtlandwirtschaftlichen Berufen, aber die Mehrheit der Berufe ist subsistenzorientiert. Beschreibende Statistiken zusammen mit Diversifikationsindikatoren enthüllten die Verteilungsmuster der Beschäftigung und Existenzgrundlagenstrategien in den untersuchten Dörfern. Die Ergebnisse des Logitmodels zeigen, dass die Ausstattung für die Auswahl der Diversifikationsstrategien der Existenzgrundlagen der Haushalte sehr wichtig ist. Auf ähnlicher Weise zeigte das multinominale Logitmodel, wie wichtig Variablen sind, die sich auf die Charakteristika individueller Haushalte und der Gemeinschaft beziehen, wie Bildung, Alter, Größe des Haushalts, Anzahl der arbeitenden Mitglieder des Haushaltes sowie der Standort für die Entscheidungen der Haushalte hinsichtlich Beschäftigung. Es sind die größeren Haushalte mit älteren Mitgliedern als Haushaltvorsteher mit 
etwas Bildung, die relativ hochbezahlte Beschäftigungen in dem formalen Sektor ausüben. Ältere Haushaltsvorsteher, die weniger Arbeitskräfte zu Verfügung haben, neigen dazu, reine Pachtverhältnisse zu unterhalten. Die Implikation der Studie ist, dass der ländliche nichtlandwirtschaftliche Sektor mehr Einfluss in der Entwicklungspolitik braucht, da der Sektor das Potenzial hat, die ländlichen Regionen zum Aufschwung zu verhelfen. Genauer gesagt braucht der informelle Sektor, der den Hauptüberlebensbereich der Armen in ländlichen Gebieten darstellt, dringend Unterstützung. 


\section{ACKNOWLEDGEMENTS}

This dissertation would not have been possible without the assistance of many individuals. I am deeply indebted to Prof. Dr. Dr. Winfried Manig for his valuable guidance through out the PhD program. I would also thank Dr. Stefan Schwarze for his suggestions and discussions on the econometrics models used in the study. My honorable co-supervisor, Prof. Dr. Stefan Sperlich, head of Econometrics Department Goettingen University, also deserve special thanks for providing noble guidance during my research work. I would like to express cordial gratitude to Prof. Dr. Bernhard Brümmer at Department of Agricultural Economics and Rural Development, Goettingen Universiuty for his sincere cooperation.

Many people contributed to the field surveys in the six research villages in Northwest Pakistan. First, I would like to recognise the assistance of Tahir Mahmood and Inayatullah Jan at the Department of Agricultural Economics and Rural Development, Goettingen University in making data available. Yet we wouldn't have come far without our four field enumerators, namely Sajid Islam, Hamid Khan, Naseem Khan, and Fazle-Subhan.

My thanks go to Julia Johannsen, Christina Seeberg-Elverfeldt, and Rico Ihle for their useful comments. Special commendations go to Mr. Kenneth Muller for his kind cooperation. Research funding from the Volkswagen Foundation Germany is gratefully acknowledged.

Last but not least, we are indebted to the staff of all the public institutions that is, health facilities and government schools we visited for welcoming us to their facilities and being cooperative, open and forthcoming in every way. I thank the people of all the six villages for admitting us into their villages and treating us with kindness and hospitality. This study would not have been possible without the enthusiasm and continuous support we received from the households in the study villages.

Keeping the most important to the last, I would like to thank my loving and affectionate parents, Yar Mohammad Khan \& Shawar Begum (Babi) for giving me a sound stimulating upbringing. I owe to my dear brothers and sisters, Sajid Khan, Kashif Khan, Sadaf, \& Adeeba an immense debt for their constant and unconditional support and unceasing confidence in my abilities to accomplish this task. Finally, my wife Khatia, without you I would never have made it.

Mohammad Asif Khan

Goettingen, January 2008 


\section{CONTENTS}

Abstract $i$

Zusammenfassung ii

Acknowledgements iv

Contents $v$

List of Tables $\quad x$

List of Figures xii

List of Boxes xii

List of Pictures xii

List of Appendices xii

Glossary xiii

Acronyms and Abbreviations $\quad x V$

1. INTRODUCTION 1

1.1 Background 1

1.2 Problem Statement 2

1.3 Objective of the Study 5

1.4 Research Questions and Hypotheses 6

$\begin{array}{lll}1.5 & \text { Purpose of the Study } & 7\end{array}$

$\begin{array}{lll}1.6 & \text { Outline of the Study } & 7\end{array}$

2. THEORETICAL AND CONCEPTUAL FRAMEWORK 9

2.1 Understanding the Concept of Livelihood 9

2.2 Rural Employment Structure: Trends and Patterns in Non-agricultural Activities 10

2.2.1 Division of Non-agricultural Activities on Productivity Basis 10

2.2.2 Division of Economic Activities on Sectoral, Functional, and Spatial Basis $\quad 10$

2.3 Intrahousehold Resource Allocation 12

$2.4 \quad$ Significance of Poverty in Employment Opportunities 13

2.5 Defining and Theorizing Household Strategies 17

2.5.1 Framework for Livelihood Survival Actions 17

2.5.2 Multiple Employment: As a Livelihood Strategy 19

2.6 Rural Household Livelihood Diversification-Conceptual Issues 21 
2.6.1 Non-farm Employment: Demand-pull or Distress-push Diversification 22

2.6.2 Rural Non-farm Diversification: Urban-led or Agriculture Driven 25

2.7 Determinants of Occupational Choices 27

2.7.1 Education and Skills $\quad 27$

2.7.2 Household Composition 29

2.7.3 Role of Gender $\quad 30$

2.7.4 Role of Credit and Financial Capital (assets) 31

2.7.5 Role of the Infrastructure $\quad 32$

2.7.6 Rural Town Development and Role of Government 33

2.7.7 Social Capital Dimension of Access to the Non-Farm Economy 35

$\begin{array}{lll}2.7 .8 & \text { Land Ownership } & 35\end{array}$

2.8 Transformation and Changes in Rural Employment Structure 37

2.8.1 Institutions and Their Role in Livelihood 38

2.8.2 Institutional Change $\quad 39$

2.8.3 Past Studies in Changes in Rural Employment Structures 40

2.9 Conceptual Framework 43

2.9.1 Framework for Cross-sectional Consideration of Empoyment Structure 43

2.9.2 Framework for Trend in Rural Empoyment Structure 45

3. METHODOLOGY AND FIELD RESEARCH INSTRUMENTS

3.1 $\quad$ Field Research Instruments $\quad 50$

3.1.1 Basic Survey $\quad 50$

$\begin{array}{lll}3.1 .2 & \text { Special Survey } & 51\end{array}$

3.2 Demarcation of the Household Categories 52

3.3 Selection of the study villages 55

$3.4 \quad$ Unit of Study and Sampling Frame $\quad 57$

$3.5 \quad$ Selection of households $\quad 58$

$\begin{array}{lll}3.6 & \text { Sampling Weight }\end{array}$

3.7 $\quad$ Survey Time and Response Rate $\quad 61$

3.8 Data Processing $\quad 62$

3.9 Analytical Methodology Applied to the Research Questions 63

3.9.1 Research Methodology for Income Generating Strategies and Livelihood Diversity 64

3.9.1.1 Methodology for Diversification Strategies across Households and Villages 64

3.9.1.2 Household Diversity Indices $\quad 64$

3.9.1.3 Logistic Regression for Household Diversity 66

3.9.2 The Analysis of Agriculture and Urban-led Influences in Non-farm Employment 67

3.9.3 Methodology for Measuring Poverty in the Area 68

3.9.3.1 Determination of Headcount Index, Poverty Gap, and Severity Index 68

3.9.3.2 Estimation Methodology: Logit Regression for Determinants of Poverty 69 
3.9.4 Estimation Methodology for Multinomial Logit Model: Factors Influencing Occupational Choices

3.9.5 Measuring Changes in Employment Structure in the Study Villages over the Years

\section{RESEARCH SITES}

4.1 Research Setting: North West Frontier Province

4.2 Profile of District Peshawar

4.3 Natural Conditions of District Peshawar

4.4 Description of the Study Area $\quad 82$

4.4.1 Extension Villages $\quad 83$

4.4.2 Landlord, Tenant, and Labourer Villages $\quad 83$

4.4.3 Tribal Villages

5. EMPIRICAL ANALYSES

5.1 The Asset Status of Livelihood in the Surveyed Villages in Northwest Pakistan

5.2 Human Capital in the Study Area

5.2.1 Household Size

5.2.2 Literacy and Skills

5.3 Labor Endowment at Household Disposal

5.4 Female Economic Activity in the Study Area

5.5 Land Access and Tenure

5.6 Livestock Ownership in the Area

\section{HOUSEHOLD LIVELIHOOD DIVERSIFICATION AND STRATEGIES IN THE STUDY AREA}

6.1 Diversification Strategies according to Household Structure 102

6.2 Diversification Strategies according to Household Categories across the Villages 104

6.2.1 Households with Only Farming as Livelihood Strategy 104

6.2.2 Households with the Strategy of Combining Farming with Non-farming Activities 105

6.2.3 Households with Only Non-agricultural Activities as Livelihood Strategy 106

6.3 Household Strategies: Empirical Application of Chayanov Model 106

6.4 Simpson, Shannon and Dissimilarity Indices of Household Diversity 107

6.5 Multivariate Analysis For Household Diversity 109

6.5.1 Descriptive Analysis for Logit Model on Household Diversity 109

6.5.2 Results: Determinants of Diversification 
7. LIVELIHOOD OUTCOME: PROFILE OF POVERTY IN THE AREA

7.1 Household Income Distribution

7.2 Poverty Indices for the Rural Households in the Research Area 117

7.3 Poverty Related Indicators Across the Study Villages 119

$\begin{array}{lll}7.4 & \text { Inequality in the Study Area } & 122\end{array}$

$\begin{array}{lll}7.5 & \text { Empirical Results for Determinants of Poverty } & 126\end{array}$

7.5.1 Descriptive Statistics for Logistic Regression on Poverty 126

7.5.2 Econometric Results on Poverty Correlates 128

\section{FACTORS AFFECTING OCCUPATIONAL CHOICES}

8.1 Empirical Results: Multinomial Logit Regression 134

$\begin{array}{lll}8.2 & 134\end{array}$

8.3 Diagnostics Tests for Multinomial Logit Model 137

$\begin{array}{lll}\text { 8.3.1 Independence of Irrelevant Alternatives } & 137\end{array}$

8.3.2 Tests for Combining Dependent Categories 139

$\begin{array}{ll}\text { 8.3.3 Collinearity Diagnostics } & 140\end{array}$

8.4 Factors Affecting Labor Participation: Results and Discussion of Multinomial Logit Model 141

8.4.1 Role of Human Capital in Labor Participation 143

8.4.2 Role of Household Assets in Labor Participation 145

8.4.3 Role of Geographical Location and Infrastructure in Labor Participation 145

9. CHANGES IN THE EMPLOYMENT STRUCTURE 147

9.1 Changes in the Demography and Education over Time in the Study Villages 147

9.2 Changes in the Farm Structures in the Villages 149

9.2.1 Pattern of Livestock Rearing in the Study Villages 152

9.2.2 Changes in Crop Production Patterns 153

9.3 Occupational Pattern in the Research Area: A Comparative Perspective 154

$\begin{array}{lll}\text { 9.3.1 Agricultural Labours in the Study Villages } & 159\end{array}$

9.3.2 Casual Labours, Self Employment and Petty Trade 161

9.3.3 Patterns of Rural Migration 163

$\begin{array}{lll}\text { 9.3.4 Formal Sector Jobs } & 164\end{array}$

9.4 Changes in Institutions Organizing Non-agricultural Employment 165

9.4.1 Changes in the Labour Organization in the Study Area 165 
10. CONCLUSION

10.1 Summary and Conclusion

10.2 Policy Implications

REFERENCES

175

APPENDICES

189 


\section{LIST OF TABLES}

Table 1. Selection of Households for the Special Survey 59

Table 2. Sampling Statistics of the Surveyed Villages in Northwest Pakistan 61

Table 3. Comparison of Agricultural Related Statistics between Pakistan and NWFP 79

Table 4. Socio-economic Characteristics across the Six Villages in Northwest Pakistan 84

Table 5. Household Size Classification in the Survey Villages, 2004/05 90

Table 6. Distribution of the Household Working Members according to their Occupations 99

Table 7. Household Members with Main Occupations in the Survey Villages, 2004/05 94

Table 8. Farm Area, Cultivated Area, and Number of Farms in the Survey Villages, 2004/05 98

Table 9. Percentile Distribution of the Farms According to Size Categories and Household Categories in the Surveyed Villages, 2004/05 99

Table 10. Significance of Livestock Production in the Surveyed Villages, 2004/05 101

Table 11. Household Income Diversification Strategies in the Study Area, 2004-05 103

Table 12. Distributions of Households in the Study Area according to their Diversification 105

Table 13. Correlation between Dependency Ratio and Household Output per Worker 107

$\begin{array}{ll}\text { Table 14. Diversity Indices for Household Categories } & 108\end{array}$

Table 15. Summary Statistics of Logit Model on Household Diversity 110

Table 16. Logit Analysis of Factors Affecting Household Diversification in the Study Area 111

Table 17. Correlation among Variables used in Logit Model for Household Diversity 112

Table 18. Collinearity Diagnostics for Logit Model on Household Diversity 112

Table 19. Correlation Matrix of Proportion of Non-Farm Workers and its Determinants 113

Table 20. Socio-economic Indicators Conveying Urban Effect across Villages Categories 114

Table 21. Percapita Monthly Household Income by Income Quartile 115

$\begin{array}{ll}\text { Table 22. Poverty Indices for the Research Villages } & 118\end{array}$

Table 23. Poverty Indices for Household Categories 119

Table 24. Various Socio-economic Poverty Related Indicators in the Study Area 121

Table 25. Intercorrelation Matrix of Poverty Related Variables in the Study Area 122

Table 26. Household Wealth Inequality in Terms of Gini Coefficient across the StudyArea 123

Table 27. Summary Statistics for Logistic Model on Poverty 127

Table 28. Binary Logistic Regression on Poverty in the Study Villages 129

Table 29. Odd Ratio and Marginal Effects for Logit Model on Poverty 131

Table 30. Robustness of Logistic Regression at Different Level of Poverty 132

Table 31. Collinearity Diagnostic for Poverty Model 133

Table 32. Summary Statistics of Variables Used in Multinomial Logit Model 135

Table 33. Summary Statistics of Variables in Multinomial Logit Model 137

Table 34. Hausman Test for Assumption of Independence of Irrelevant Alternatives 139 
Table 35. Small-Hsiao Tests of IIA Assumption for Multinomial Logit Model

Table 36. Wald and LR Tests for Combining Alternatives

Table 37. Collinearity Diagnostics for Variables used in Multinomial Logit Model

Table 38. Multinomial Logit Regression for Occupational Categories

Table 39. Odd Ratios for Multinomial Logit Regression for Household Occupations

Table 40. Demographic and Other Structural Changes over the Years in the Surveyed Villages in North-west Pakistan

Table 41. Transition in Household Farm Related Statistics over the Years

Table 42. Changes in Farm Area, Cultivated Area, and Number of Farms in Study Area

Table 43. Changes in the Livelihood Strategies of the Rural Household (Data in Percent) 155

Table 44. Distribution Trend of the Household Workers in Different Occupational Fields 156

Table 45. Changes in the Household Members Occupations over the Years 


\section{LIST OF FIGURES}

Figure 1. Labor Force and its Share in GDP over the Years in Pakistan 3

Figure 2. Three-way Classification of Economic Activities 11

Figure 3. The Business Environment in Pakistan 15

Figure 4. Different Forms of Multiple Employment in Developing Countries 20

Figure 5. Welfare Gains Through Distress-push and Demand-pull Labour Shifts 24

Figure 6. Population Pyramid of Pakistan, 1998

Figure 7. Conceptual Framework of the Study 44

Figure 8. Processes Behind Institutional Change 47

Figure 9. The 'Pattern Model' Showing Basic Elements of Socio-economic System 48

Figure 10. Delimitations of the Household Categories for the Study Villages 54

Figure 11. Criteria for the Selection of the Villages for the Surveys in Northwest Pakistan 56

Figure 12. Climatic Conditions in the Study Area 82

Figure 13. Distribution of Agricultural Labors across the Research Area, 2004/05 93

Figure 14. Percapita Monthly Household Income Distribution 116

Figure 15. Comparison of Income across Farming and Non-agricultural Households $\quad 124$

Figure 16. Lorenz Curve for Different Household Categories in the Study Villages 125

Figure 17. Changes in Farm Size in the Study Area since 1986-87 151

Figure 18. Changes in Household Livestock Ownership over the Years 153

Figure 19. Changes in Hired Agricultural Labour in the Study Area 160

\section{LIST OF BOXES}

Box 1. Poverty and Inequality Profile in Pakistan 16

Box 2. Reasons for Promoting Non-farming Sector 26

\section{LIST OF PICTURES}

Picture 1. Socio-economic Conditions in the Study Villages in Northwest Pakistan 87

Picture 2. Self-employment in the Study Villages 162

\section{LIST OF APPENDICES}

Appendix 1. Map of North West Frontier Province (NWFP), Showing its Districts 190

Appendix 2. Changes in the Employment Structures in the Study Area 191

Appendix 3. Location of the Study Areas in Northwest Pakistan 192

Appendix 4. Basic Survey Questionnaire of All Rural Households 193

Appendix 5. Content Outline of Special Survey Questionnaire 195 


\section{GLOSSARY}

Arbab

Charsadda

High School

Hindko

Hujra

Ijara

Jerab

Katcha Kor

Khan

Qanat

Khandey

Kharif

Khazana

Kor

Malik

Mardan

Matric

Middle School

Naib Nazim

Nazim

Pakka

Primary School

Pukhtunwali

Pashto

Purdah

Rabi

Rickshaw

Ring road

Rupee
Title used by landlords in the study villages Gulbela and Kochian in Northwest Pakistan

A town in Charsadda District, around 17 miles from Peshawar. It was once the administrative center of Gandhara civilization

Ninth and tenth school years

A regional language spoken in Peshawar, Hazara, Punjab and Kashmir by an estimated 7 million people

A covered meeting place, frequented by the male village population and a pillar of Pukhtun society

Fixed rent for land

0.5 acres

Mud House

Title for landowner

Underground canals

Region/part of village

Summer cropping (mid April to mid October)

Village near Peshawar, Pakistan famous for its Khazana sugar mill

Pashto word for 'House'

Landowner

A district in NWFP, famous for archaeological site 'Takht Bhai'

Ten years school completion

Sixth to eighth school years

Deputy mayor

Mayor

Brick made house

First to fifth school years

Pathan code of honour

Dominant language in the North West Frontier Province of Pakistan and Afghanistan

Seclusion and veiling of women

Winter cropping (mid October to mid April)

Auto Rickshaw or tuctucs, a two-stroke engine vehicle

A road constructed around the Peshawar city

Pakistani currency (1 Euro $=78$ rupees in 2004-05) 
Tribal Area

Ustakar

Zakat

Zamindar

Zilla Council
Controlled by federal government in Pakistan, it comprise seven Agencies namely Khyber, Kurram, Bajaur, Mohmand, Orakzai, North, and South areas of Waziristan and five F.Rs (Frontier Regions) namely F.R Peshawar, F.R Kohat, F.R Tank, F.R Bannu and F.R D.I. Khan

Village artisans and service workers who have a special service relationship with the village population and mostly paid in kind for their services after crop harvest

Islamic concept of tithing and alms. As an obligation, Muslims must pay 2.5 percent of their wealth to specified categories in society when their annual wealth exceeds a minimum level (nisab)

Farmer (zamin = land)

District Council 


\section{ACRONYMS AND ABBREVIATIONS}

\begin{tabular}{|c|c|}
\hline $\mathrm{BBC}$ & British Broadcasting Corporation \\
\hline BHU & Basic Health Unit \\
\hline $\mathrm{Chi}^{2}$ & Chi-Square \\
\hline $\mathrm{CNG}$ & Compressed Natural Gas \\
\hline EU & European Union \\
\hline GDP & Gross Domestic Product \\
\hline $\mathrm{HH}$ & Household \\
\hline $\mathrm{HHH}$ & Head of Household \\
\hline IDS & Institute of Development Studies, Agricultural University Peshawar, Pakistan \\
\hline IIA & Independent of Irrelevant Alternatives \\
\hline ILO & International Labour Organization \\
\hline IMF & International Monetary Fund \\
\hline IRE & Institut für Rurale Entwicklung (Institute of Rural Development, Goettingen) \\
\hline LR & Likelihood Ratio \\
\hline $\mathrm{LU}$ & Livestock Unit, one LU matches roughly to a large cattle unit assuming beef cattle \\
\hline M1 & Peshawar-Islamabad Motorway \\
\hline MMA & Muttahida Majlis-i-Amal (MMA), an alliance of six religious parties that ruled the \\
\hline & North West Frontier Province from 2002-2007 \\
\hline MNLT & Multinomial Logit \\
\hline NGO & Non-Governmental Organization \\
\hline NIE & New Institutional Economics \\
\hline NWFP & North West Frontier Province \\
\hline OECD & Organisation for Economic Co-operation and Development \\
\hline $\mathrm{R}^{2}$ & Coefficient of Variation \\
\hline RNAE & Rural Non-Agricultural Employment \\
\hline RNFE & Rural Non-Farm Economy \\
\hline Rs. & Pakistani currency (at the time of investigation one Euro = Rs. 78) \\
\hline SPSS & Statistical Package for Social Sciences \\
\hline TE & Township Enterprises \\
\hline $\mathrm{UN}$ & United Nations \\
\hline VIF & Variance Inflation Factor \\
\hline WAPDA & Water and Power Development Authority \\
\hline
\end{tabular}




\section{INTRODUCTION}

\subsection{Background}

Livelihood is the central concept in this study which can simply be considered as having adequate stocks and flows of food and cash for an active and healthy life. In planning and carrying out activities, people use a variety of strategies with livelihood security and well being as the desired outcomes. There are three possible clusters of such strategies pursued by the rural household to construct their livelihood (SCOONES, 1998, p. 9). They may obtain their livelihood from agriculture by applying the processes of intensification/extensification; or they diversify to a range of non-farm economic activities; or they migrate temporarily or permanently. Though, in most cases the rural dwellers make use of a combination of these strategies to avoid risks and at the same time achieve their desirable outcomes. These desirable livelihood outcome demands assets which are not merely means through which they make a living, these assets also give meaning to the person's world. At the same time a livelihood becomes sustainable when it can cope as well as recover from stresses and shocks (Ibid., p. 5).

Rural areas in developing countries, where diverse income generating activities are carried out typically present a dismal picture. Health, educational ${ }^{1}$ and other social services are not adequate. Rural infrastructure, including roads, telecommunications, water, and waste management, is in need of upgrading. In addition, there is inadequate support for businesses in the form of information and mutual organization. Along side with these dismal conditions, labor force is growing rapidly, but employment opportunities are not keeping pace. As land available for expansion of agriculture becomes increasingly scarce, non-farm employment must expand if deepening rural poverty is to be avoided. A growing number of studies (ISLAM, 1997; REARDON et al., 2000; BARRETT et al., 2001b; JANVRY \& SADOULET, 2001; LANJOUW, 2001; REARDON et al., 2001; START, 2001; BUCHENRIEDER, 2005b) indicate that the non-farm sector has the potential to increase rural employment and improve income distribution. Expanding opportunities in rural areas outside of agriculture also may help stem the migration of rural dwellers to the cities and slow the spread of urban congestion. As urban industries are unlikely to absorb the rapidly

\footnotetext{
${ }^{1}$ For instance, a large part of the labour force in Pakistan is illiterate. In 2003-04 around 48 percent of the population 10 years of age and above was illiterate of which males were 36 percent and females 60 percent. The figure in rural areas was significantly higher at 44 and 73 percent respectively. Less than 10 percent of new entrants to the labour force possess any formal training (AMJAD, 2005, pp. 392-93).
} 
increasing labor force, hence it is up to the more labor-intensive rural non-farm sector to absorb excess labor and diversify income sources (MANIG, 2006).

Rural nonfarm ${ }^{2}$ employment is the major source of income for rural households in low income countries accounting for around 40 percent of their income (REARDON et al., 2001). However, majority of these diversified nonfarm activities are the equivalent of "subsistence farming" suffering with low productivity, low-wage, instability, and low-growth potential (REARDON et al., 2000; LANJOUW, 2001; REARDON et al., 2001; BARRETT et al., 2005).

\subsection{Problem Statement}

The common view of rural economy among Pakistani policymakers is that it is confined only to agriculture. However, there is a growing evidence that rural sector is much more than just farming (MANIG, 1991). For instance, the share of agriculture in Pakistan's GDP reduced to almost 23 percent in 2006 compared with 29 percent in 1982 (see Figure 1). Keeping the same trend, in the last few decades, the rural labor market also steadily changed ${ }^{3}$. Within the rural nonagricultural sector, four subsectors construction, service, manufacturing and commerce, are more important (ARIF et al., 2000). About the major trends in these activities, there is a consistent growth in service sector. The share of this sector in total non-agricultural employment increased from 20 percent in 1968-69 to about 25 percent in 2005-06. An increase was also observed in construction and trade sectors over the years. In contrast, the share of manufacturing in total nonagricultural employment falls from 39 percent in 1968-69 to 14 percent in 2005-06 (ARIF et al., 2000; GOVERnMENT OF PAKISTAN, 2005b). Overall employment structure represents a shift away from commodity production to services orientation of the rural non-agricultural economy (ARIF et al., 2000). These changes show a clear trend on part of the rural dwellers to switch towards non-farm employment. This study seeks to challenge this farming focused vision of

\footnotetext{
${ }^{2}$ The terms "off-farm", "non-farm", "nonagricultural", "nontraditional”, etc. routinely appear in seemingly synonymous ways revealing the inconsistency and confusion in literature regarding non-agricultural terminology (BARRETT et al., 2001b). However, in current study nonfarm means activity outside agriculture (own-farming plus wage employment in agriculture), hence in wage or salaried employment, manufacturing, and services.

${ }^{3}$ Pakistan's canvas is large: its population is double that of Germany and it covers an area of around 0.8 million square kilometers. With a population that recently passed the $\mathbf{1 6 0}$ million mark, making Pakistan the sixth most populous nation on earth. Pakistan is still predominantly rural; about 68 percent of her people live in some 45,000 villages spread over 0.97 million square kilometers of variegated terrain (KHAN, 2007). Almost 44 percent of the labor force is engaged in agriculture sector (GOVERNMENT OF PAKISTAN, 2005b) while only 16 percent of the total 45 million workforce in Pakistan have jobs in the formal private sector (WORLD BANK, 2007a).
} 
Pakistani policy makers on the basis that it overlooks the direction and trajectory of change in the rural Pakistan and, therefore, also ignore the emerging non-farm sector.

Figure 1. Labor Force and its Share in GDP over the Years in Pakistan

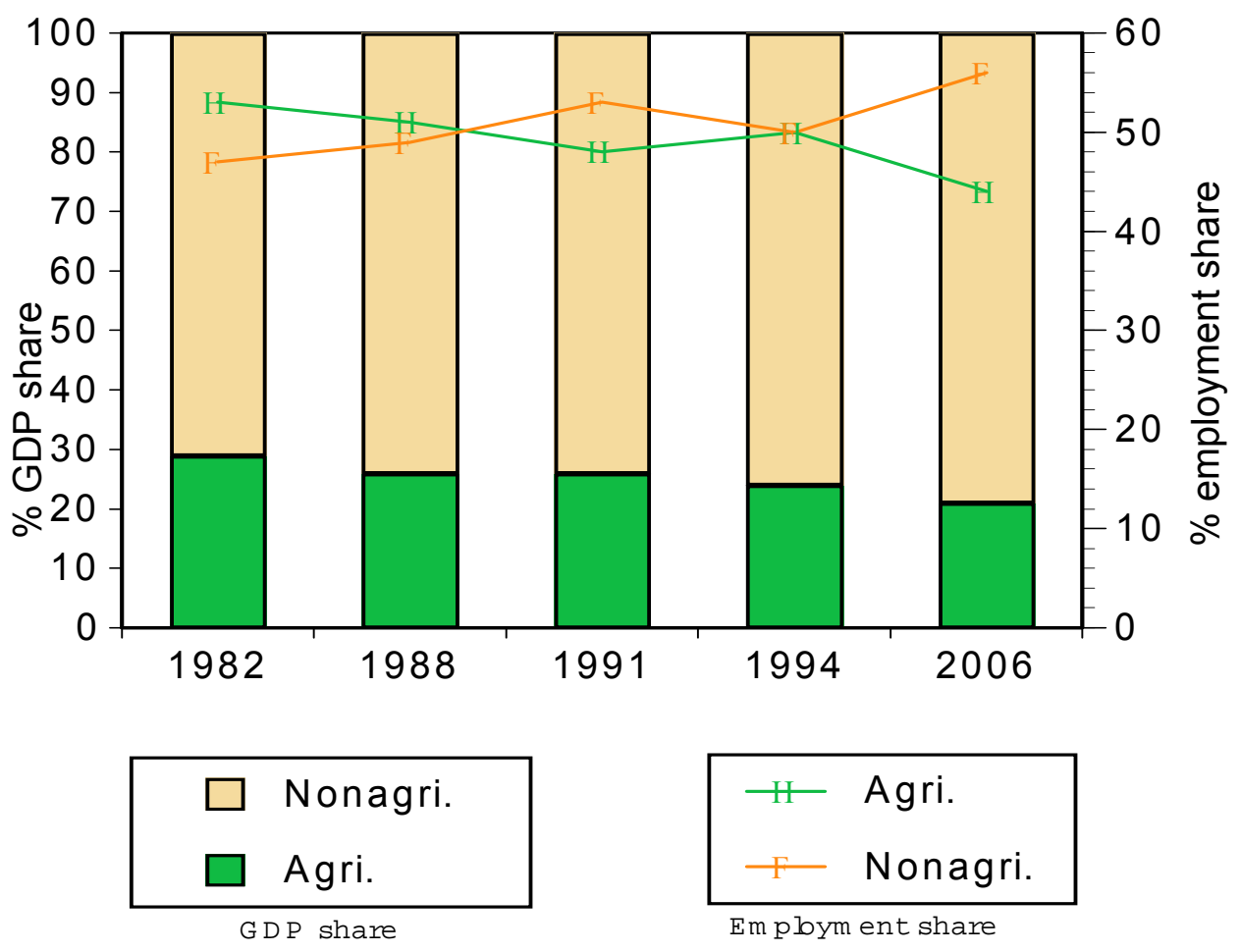

Source: Various labor force surveys of Pakistan

Livelihoods in the rural Pakistan as stated before are becoming increasingly divorced from farming and, at the same time there is an ever rising growth and expansion of non-farm opportunities (MANIG, 1991; RIEKEN, 1994; KUROSAKI \& KHAN, 2006). However, what is striking about rural Pakistan is the proliferation of informal sector ${ }^{4}$ mostly self-created low-skill wage employment or petty trade. Majority of these activities are survival based showing their fragile asset based situation. Thus the dwellers of rural Pakistan, to achieve their desirable livelihood outcomes are not only facing the institutional constraints but also lack the required assets to overcome them (ALBRECHT, 1976; MANIG, 1991; RIEKEN, 1994). However, little is known about how rural dwellers become engaged in various occupations? What strategies they are applying for

\footnotetext{
${ }^{4}$ The informal economy in Pakistan is characterized in most cases by low incomes, low productivity, and hazardous working conditions (AMJAD, 2005).
} 
living, and why? In addition, we need to know what dictate an individual decision to engage in a particular economic activity.

The argument pursued in this thesis is that not only are non-farm activities becoming central to rural livelihoods in Northwest Pakistan but also that an increasing number of rural households have no commitment to farming whatsoever (ALBRECHT, 1976; RIEKEN, 1994). It is not, therefore, just a question of weighting and balance, but of a more profound transition from one way of making a living to another. Despite the ever-growing size of the non-agricultural employment, little attention has been paid to analyze the very facets of non-agricultural employment. For instance, one of the most under-studied areas in informal sector in Pakistan is the daily wage labourers, as they have no voice in development policies. While a small handful of studies (Mohnhaupt, 1971; MANig, 1991; RIEKEN, 1994; IlAHI \& JAFAREY, 1999; LefERVRE, 1999; ARIF et al., 2000) have examined the non-agricultural employment, we are not aware of any studies examining non-agricultural employment longitudinally ${ }^{5}$ and quantitatively ${ }^{6}$ in rural Northwest Pakistan. Understanding of the socio-economics of rural Pakistan cannot be complete without an understanding of these economic activities for which neither consistent analyses nor statistical data exist. Hence, this study contributes, from the perspective of Pakistan and the rural North-western region in particular, to the debate on the effectiveness of promoting non-farm employment in an underdeveloped region. The study selected district Peshawar as it depicts the North West Frontier Province. The district comprised of people from almost all the major rural and urban areas of the province with their varied socio-economic environment.

The analysis of household livelihood strategy and employment structure is the focus of this study conducted in six villages of District Peshawar NWFP, Pakistan. The basis of the current study is two research projects conducted in 1967/68 and 1986/87 by Institute of Rural Development, Georg-August University Goettingen Germany in collaboration with Institute of Development Studies (IDS), NWFP Agricultural University Peshawar Pakistan. It all started in 1967-68, as part of a training and research project carried out by the former Institute of Foreign Agriculture at Georg-August University Goettingen, Germany under the guidance of Prof. FRITHJOF KUHNEN. A

\footnotetext{
${ }^{5}$ The study using a semi-longitudunal approach will consider the changes in employment structure across the six study villages. The current occupational structure in the study area will be compared with the earlier work of MoHNHAUPT, 1971; MANIG, 1991; and RIEKEN, 1994 to trace the process of change over time.

${ }^{6}$ Some qualitative studies on non-farm wage and business sectors in rural Northwest Pakistan appeared in a few monographs (MoHNHAUPT, 1971; ALBRECHT, 1976; RIEKEN, 1994). However, these earlier works focused on qualitative aspects without giving due attention to quantitative analysis. As these studies deals with 1970s and 1980s and hence outdated ignoring the profound changes in the 1990s and early 2000, including structural adjustment, trade liberation, infrastructure, and technology change. Therefore, an update of knowledge on rural employment and specially non-farm sector is needed and the present study is going to fill this knowledge gap.
} 
series of studies were made on the problems of rural and agricultural development in the six villages of rural Northwest Pakistan. In 1986-87, again under the initiative of Prof. F. Kuhnen the same six villages were resurveyed. This time the aim was to analyze the institutional change processes ${ }^{7}$ in these rural areas.

Economic rural structures undergo changes continually and understanding these changes in a given area would enhance the chances for a better-formulated development policy intervention ${ }^{8}$ (MANIG, 1991). However, studies of rural employment determinants using mainly national surveys can obscure wide variations in stages of economic development at the regional or local levels. An empirical study, such as the one presented here, offers the advantage of knowing the potential for and constraints on non-farm rural activities expansion.

\subsection{Objective of the Study}

The main objective of this empirical study is to analyze livelihood strategies and employment structure in Northwest Pakistan. More precisely the study is aims at the following objectives:

- To analyse livelihood strategies and diversification of households in Northwest Pakistan;

- To identify the factors responsible for participation in different occupations;

- To examine the household assets (human, social, physical, natural and financial), crucial to realize any livelihood outcome; and

- To make a comparative analyses of the changes in employment structure in the study area.

\footnotetext{
${ }^{7}$ The institutional adjustment processes were analysed in areas of land tenure and farming system, credit systems, capital formation, marketing and extension services, non-agricultural employment, the organization and management of irrigation, and the local tax system (MANIG, 1991).

${ }^{8}$ Over the past decades, the government of Pakistan has initiated several development programmes aimed at rural services and employment (SATTAR, 2004). However, there is a lack of consistency and homogeneity in policies as depicted by the mostly short sighted and politically oriented policies initiatives in the recent past such as:

a) Prime minister's five point program in 1985-88;

b) People's works program from 1988 to 1990;

c) Tameer-a-Watan program 1990-1993;

d) People's work program 1993-1997;

e) Tameer-a-Watan program 1997-1999; and

f) Khushhal Pakistan program, 2000 to date.
} 


\subsection{Research Questions and Hypotheses}

According to the objectives outlined in the previous section, the study is devoted to address the following research questions $(\mathrm{Q})$ with possible hypotheses.

Q1: What are the income generating strategies adopted by rural households in the research area? Is there any big difference among the pattern of these strategies performed by the rural people in the six villages?

H1: The households are engaged in various income generating activities and there is a significant difference in the pattern of these activities across the six villages.

H2: Majority of the households in the research area are engaged in survival strategies for their livelihood.

Q2: Whether the non-agricultural ${ }^{9}$ activities in the research area agriculture led or urban induced?

H3: The livelihood activities of the household members living closed to the urban centre are less induced by agriculture than those living in remote villages.

Q3: What is the role of household's endowment with capitals (human, natural, financial, physical \& social) to the outcome of their livelihood strategies in terms of well-being?

H4: Household assets (Human, natural, financial, physical \& Social) are differently endowered across the research area resulting in poor and non-poor households.

Q4: What determines household participation in various income earning livelihood activities in the research area?

H5: Household decision to engage in various income earning activities is influenced by individual, household and community level variables.

\footnotetext{
${ }^{9}$ All economic activities other than cultivation, rearing of livestock, and agricultural labour are considered as nonagricultural.
} 
Q5: What are the major structural changes in the employment structure in the study area?

H6: There have been major structural changes in the employment structure in the six research villages during the last four decades with increasing proportion of households in nonagricultural employment.

\subsection{Purpose of the Study}

The finding is expected to be of importance for a number of reasons. Firstly, they would reveal the factual position regarding the livelihood income generating strategies at the micro level (household) and highlight the rational of rural population equipped with different mix of assets to avail themselves of the prevailing economic opportunities. Secondly, the finding would provide the background information to be used as a basis for further research in the area and improve knowledge base on livelihood income generating strategies.

\subsection{Outline of the Study}

The balance of the thesis is organized as follows. Chapter 2 concerns an extensive review of literature. Rural employment structure, poverty, distress-push and demand-pull aspects of nonfarm employment are some of the important topics discussed here. A review of determinants of non-farm employment is provided based on the available literature. The chapter culminates the objectives and motivation of study into a conceptual framework.

Chapter 3 is devoted to the research methodology. After a brief description of the field research instruments, the chapter explains the logic behind categorization and selection of households in the area. The concept of household is also explained here. An important issue discussed here is the sampling and sampling weights. The details of survey timing, response rate, and data processing are discussed next. This is followed by the description of the analysis procedures and variables adopted for analysis. The descriptive methodology for household diversification strategies is first given followed by diversity indices of Shannon, Simpson, and Dissimilarity. The estimation methodology behind household diversity using a logistic regression is also provided. Next, the theory behind the FOSTER, GREER and THORBECKE, 1984 set of poverty indices are introduced. The section discusses all the three indices used in the study: the head-count, poverty 
gap, and squared poverty gap. An occupational choice model is developed within a multinomial logit model framework, which is based on the theory of random utility maximisation. Finally, the last section of the chapter concerns with measuring changes in the employment structure in the study villages over the years.

Chapter 4 begins with a discussion of North West Frontier Province and it capital, Peshawar. A brief introduction of the six research villages is also provided here. Chapter 5 outlines the description and profile of household assets across the six research villages. Specifically, human capital, household size, education, labour force participation, land, and livestock ownership are discussed in details.

Results of the study starts with Chapter 6 with analysis of household diversification strategies. Besides analysing the household livelihood diversity descriptively and through a set of diversity indices, the chapter also apply CHAYANOV model of household strategies. A multivariate regression analysis try to answer the factors behind household diversification strategy.

Poverty and its various dimensions is the theme of Chapter 7. Besides presenting the incidence, depth, and severity of poverty, the chapter also identify the major determinants that influence poverty in the research area. The rural household income distribution is followed by details of poverty indices in the study area. A description of extent of inequality in the area is also given through Gini coefficient and Lorenz curve. The final section provides the results and discussion of a logit model of poverty in the area.

Chapter 8 provides findings from multinomial logit model on the factors affecting household activity participation, a procedure never applied in any study in the area. In the penultimate chapter, we present the change processes observed in the household employment structure in the area. A comparison of the present employment structure with previous studies conducted in the area is descriptively made. Finally, some general conclusions and implications are suggested in Chapter 10. 


\section{THEORETICAL AND CONCEPTUAL FRAMEWORK}

This chapter focuses on how various authors and authorities have defined the concepts involved in this research. The topics that have been covered in the following sections include the concept of livelihood, livelihood assets, division of economic activities, strategies, livelihood diversification, role of institutions in livelihood, and changes in rural employment structure.

\subsection{Understanding the Concept of Livelihood}

This section is structured around the concept of rural livelihood. Livelihood entails various means of supporting life and meeting individual and community needs. It can be expressed in cash, kind, or both, as well as human, social, and natural capital (Delali et al., 2005; ElLIS, 1998). For instance Chambers and Conway, 1991 considered livelihood as "comprises the capabilities, assets (...) and activities required for a means of living; a livelihood is sustainable which can cope with and recover from stress and shocks, maintain or enhance its capabilities and assets, and provide sustainable livelihood opportunities for the next generation (...)." Similarly, DE HAAN \& ZOOMERS, 2005 citing WALLMANN, 1984 outlined the frontiers of livelihood in the following words:

Livelihood is never just a matter of finding or making shelter, transacting money, getting food to put on the family table or to exchange on the market place. It is equally a matter of ownership and circulation of information, the management of skills and relationships and the affirmation of personal significance ...... and group identity. The tasks of meeting obligations, of security, identity and status, and organizing time are as crucial to livelihood as bread and shelter.

Livelihood as a dynamic and holistic concept is not just a matter of material well-being, but rather it also includes non-material aspects of well-being. In the words of BEBBINGTON, 1999 cited in DE HAAN \& ZOOMERS, 2005:

A person's assets, such as land, are not merely means with which he or she makes a living: they also give meaning to that person's world. Assets are not simply resources that people use in building livelihoods: they are assets that give them the capability to be and to act. Assets should not be understood only 
as things that allow survival, adaptation and poverty alleviation: they are also the basis of agents' power to act and to reproduce, challenge or change the rules that govern the control, use and transformation of resources.

\subsection{Rural Employment Structure: Trends and Patterns in Non-agricultural Activities}

\subsubsection{Division of Non-agricultural Activities on Productivity Basis}

Non-agricultural activities can be broadly divided into two groups of occupations: high labour productivity/high income activities and low labour productivity activities which serve only as a residual source of employment - a "last-resort" source of income (LANJOUW, 2001). These latter activities are common among the very poor and earnings are often very low. Such employment may nevertheless be important from a social welfare perspective for several reasons:

a) Off-farm employment income may serve to reduce aggregate income inequality;

b) Where there exists seasonal or longer-term unemployment in agriculture, households may benefit even from low non-agricultural earnings; and

c) For certain sub-groups of the population who are unable to take part in the agricultural wage labour market, notably women in many parts of the developing world, nonagricultural incomes offer some means to economic security.

A sizeable share of manufacturing sector in developing countries is unregistered; take for instance the ILO, 2003 Country Employment Policy Review document on Pakistan that states:

The unregistered sector has a capital labour ratio and productivity, which is lower than that of the registered sector by a factor 7 . Consequently its wage rates are also much lower, and in addition being unregistered is not protected by any social legislation on the workers' right to welfare, security or organization. Approximately 40 percent of the unregistered sector in manufacturing is also based on self-employment and on family labour.

\subsubsection{Division of Economic Activities on Sectoral, Functional, and Spatial Basis}

The rural economic activties as a whole and non-agricultural sector in specific are heterogenous. However, it can be broadly distributed on three basic criteria; functional basis, sector, and space 
wise classification (BARRETT et al., 2001b). Figure 2 depicts this three-way classification of economic activities. Starting with their sectoral basis, a distinction between farming and nonfarming activities bring the following most basic classification of economic activities:

a) Primary: agriculture, mining and other extractive;

b) Secondary: manufacturing; and

c) Tertiary: services

Figure 2. Three-way Classification of Economic Activities

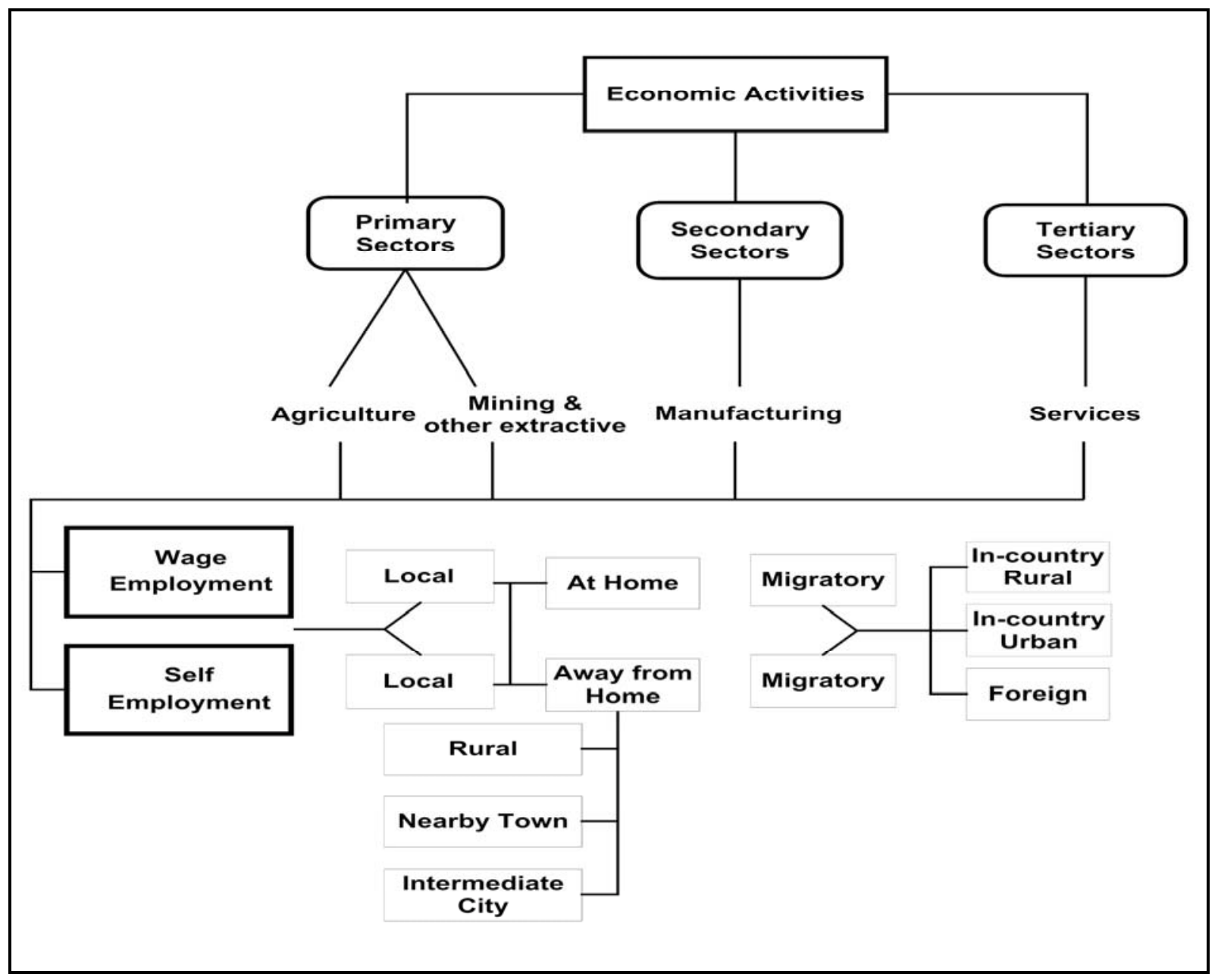

Source: Adjusted after BARRETT et al. 2001a,; 2001 b.

The sectoral classification is concerned only with the nature of products and types of factors used in the production without noticing the location, scale, or the functional aspects of jobs (BARRETT et al., 2001b). Followed by sectoral assigned activities, there exists a functional classification. 
The functional classification displays a continuum from "clearly wage-employment" (i.e. involving a wage or salary contract), through a grey area where an activity could be classified as either wage- or self-employment, to "clearly self-employment" (for example entrepreneurial activity). Given a sectoral and functional classification of an activity, there is finally a spatial categorization. Here again are two broad categories with some important subcategories (see Figure 2).

A spatial study in four villages of Madhya Pradesh, India revealed that the urban villages had more non-agricultural activities than those in the rural villages. Hence, it is expected that intensification of agro-based industries can help create more non-agricultural employment among rural people (GAURAHA, 1996, p. 417). A similar research conducted in the rural farm households in Honduras using national income and expenditure survey from 1993-94 highlighted the role of non-agricultural income. Non-farm wage labour was geographically concentrated in small rural towns and in the industrial free zones located in the northern region, while selfemployment was particularly developed in the Southern region (RUBEN \& VAN DEN BERG, 2001).

The local versus in-country versus foreign distinction has several advantages. It allows one to judge how dependent the household is on the local economy. Important practical issues arise in assigning a given activity to one of the above categories. For instance, a household can be a rural (located in the countryside) but its activities may be a mix of urban and rural. There is a need for distinguishing between the location of residence of the earner and location of the activity.

\subsection{Intrahousehold Resource Allocation}

Most studies, with some exceptions, treat the internal decision-making processes within the household as a 'black box'; so rather little attention has traditionally been paid to what happens within the household - such as how the decisions are made and how resources are allocated among household members (FUWA et al., 2006, p. 376). As suggested by FuWA et al. 2006, some aspects of intrahousehold ${ }^{10}$ resource allocation are of potential importance for at least two reasons. First, it will reveal who and where the poor are as some households considered above

\footnotetext{
${ }^{10}$ Work both inside and outside the home is considered by the New Home Economics as emerging from a 'home production function.' This utility which is attached to every activity outside and inside the home, including leisure, determines the time allocated to each task. The household production function is also the decisive factor in the gender division of labour (ACHARYA, 1998, p. 153).
} 
the poverty line ${ }^{11}$ may still contain household members whose standard of living falls below the poverty line because of intrahousehold inequality in resource allocation. Second, the way household members assign resources among themselves could potentially affect the effectiveness of policy interventions (FUWA et al., 2006, p. 376).

The quality of work opportunities - low wages, precarious working conditions, and insecure job tenure - is a crucial constraint to improving the livelihoods, especially since labor is poor people's greatest asset (HAAN, 2000). The supply of this only asset to rural labor markets does not need any complementary physical capital on their part (MDUMA \& WOBST, 2005).

Time is also an important resource over which they still keep control and use it in their strategies for survival (MEINDERTSMA, 1997). CHAYANOV, 1966 through his model of the peasant economy centered on time allocation approach and later BECKER, 1976 using New Household Economics model highlighted household utility maximization through time family was willing to grant to different activities. Nevertheless, for time spent at work, according to CHAYANOv, 1966 has never been greater $(43 \%)$ than the time spent at leisure $(57 \%)$.

\subsection{Significance of Poverty in Employment Opportunities}

Poverty is multidimensional ${ }^{12}$ with a wide range of factors are seen as determinants of poverty, like lack of access to income-earning opportunities; policy biases; lack of services and infrastructure; population pressure; climatic shocks; the marginalization of women; institutional failure to ease rural people's access to the skills, education, and health needed for escaping poverty; lack of freedom, knowledge, and women's empowerment (ROVERE et al., 2006). The question arises how poverty struck response with lack or limitations of these determinants. They response in multiple way like specialization, intensification of farming, diversification of activities, migration, or exiting from farming (ROVERE et al., 2006).

\footnotetext{
${ }^{11}$ MOLLY ORSHANSKY, an economist working for the Social Security Administration, developed the poverty line in the early 1960s, and the US federal government adopted it as an official threshold. For finding out poverty lines, the ORSHANSKY approach is a compromise between nutritional and income-based methods. Its calculation is simple. First find the minimum spending needed to satisfy nutritional needs, then gross up this figure by an appropriate proportion to allow for non-food expenditure needs. Hence, the Orshansky approach considers the social as well as a biological dimension of poverty (MACPHERSON \& SILBURN, 2000, p. 9).

${ }^{12}$ Poverty is multi-dimensional in essence, as it encompasses not only income for the satisfaction of basic needs but also causal factors like human, physical, environmental, social, and political capital as a means of achieving income. Poverty expresses itself in multi-dimensional outcomes, being stipulated by the socioeconomic, cultural, institutional, and political environment (ZELLER et al., 2006, p. 48).
} 
BAulch \& MCCulloch, 2002, p. 171 citing MALIK, 1993 and JOEKES et al., 2000 also stated that based on evidence from household surveys, the national income accounts, and other sources there is a long-term downward trend in the incidence, depth, and severity of poverty in Pakistan until 1988. During this period, three main factors apparently contributed in the poverty reduction- strong agricultural performance, pro-poor public spending policies, and remittances from the more than 2 million Pakistanis who went to work abroad.

Since the late 1980s, the implementation of structural adjustment programmes under the guidance of international monetary institutions to deal with the external and internal imbalances in the economy raised the incidence of poverty (BAULCH \& MCCULLOCH, 2002; GERA, 2007). A report of WORLD BANK, 2007b also highlights the dismal picture of rural Pakistan where nearly 35 million people remain poor (almost 80 percent of Pakistan's poor), and rural poverty rates in 2004-05 were still at levels approximating those of the 1990s (for a comparison of poverty in Pakistan between 2000-01 and 2004-05, see Box 1).

Besides, the prevalence of widespread poverty, in the recent years nevertheless, there are encouraging figures emerging out of Pakistan like 8.4 percent GDP growth in 2006-07, foreign reserves touching 15 billion mark, remittances reaching all time high to 5 billion dollars and a tremendous increase in stock market and exports. That's why a recent world bank report comparing countries across the globe for business environment put Pakistan on top in the South Asia (WORLD BANK, 2007a). The report ${ }^{13}$ states:

"Pakistan ranks relatively well in starting a business-both globally and regionally. Reforms in the early part of the decade cut start-up time by half. Startup now takes 24 days, 8 days less than the South Asian average (32 days) and less than Bhutan (62 days), Sri Lanka (50 days), Bangladesh (37 days) and In-

\footnotetext{
${ }^{13}$ However, this report also highlights some area of concern regarding business conditions in Pakistan (Figure 3). For instance, starting up business in Pakistan need a high number of procedures (11) compared to Bangladesh (8), Nepal (7) and Sri Lanka (8). In the region, only India requires this much procedures. Further, Pakistan's procedures are cumbersome, require considerable documentation and involve six different agencies - the registrar of companies at the Securities and Exchange Commission, the Central Board of Revenue, the local tax authority, the Employees Social Security Institution, the Employees Old Age Benefits Institution, and the Inspector in the Department of Labor of the provincial government - and a visit to a specifically designated bank. Costs are 25 percent higher in Karachi than in other cities. The report further states:

"By removing the stamp duty requirement in 2004, Faisalabad, Lahore, Sialkot and Peshawar all eliminated 1 procedure, 1 day and considerable cost -16 percent of income per capitafrom the start-up process. Start-up time does not vary significantly across cities, with 2 more days required to register with the Registrar of Companies in Quetta than in Faisalabad, Lahore, Sialkot and Peshawar."
} 
dia (35 days). The cost is 21 percent of income per capita, well below the South Asian average of 47 percent, and compares favourably to all regional averages apart from those of the OECD (5\%) and Europe and Central Asia (14\%). Like all South Asian countries except for the Maldives, Pakistan does not impose a minimum capital requirement."

Figure 3. The Business Environment in Pakistan

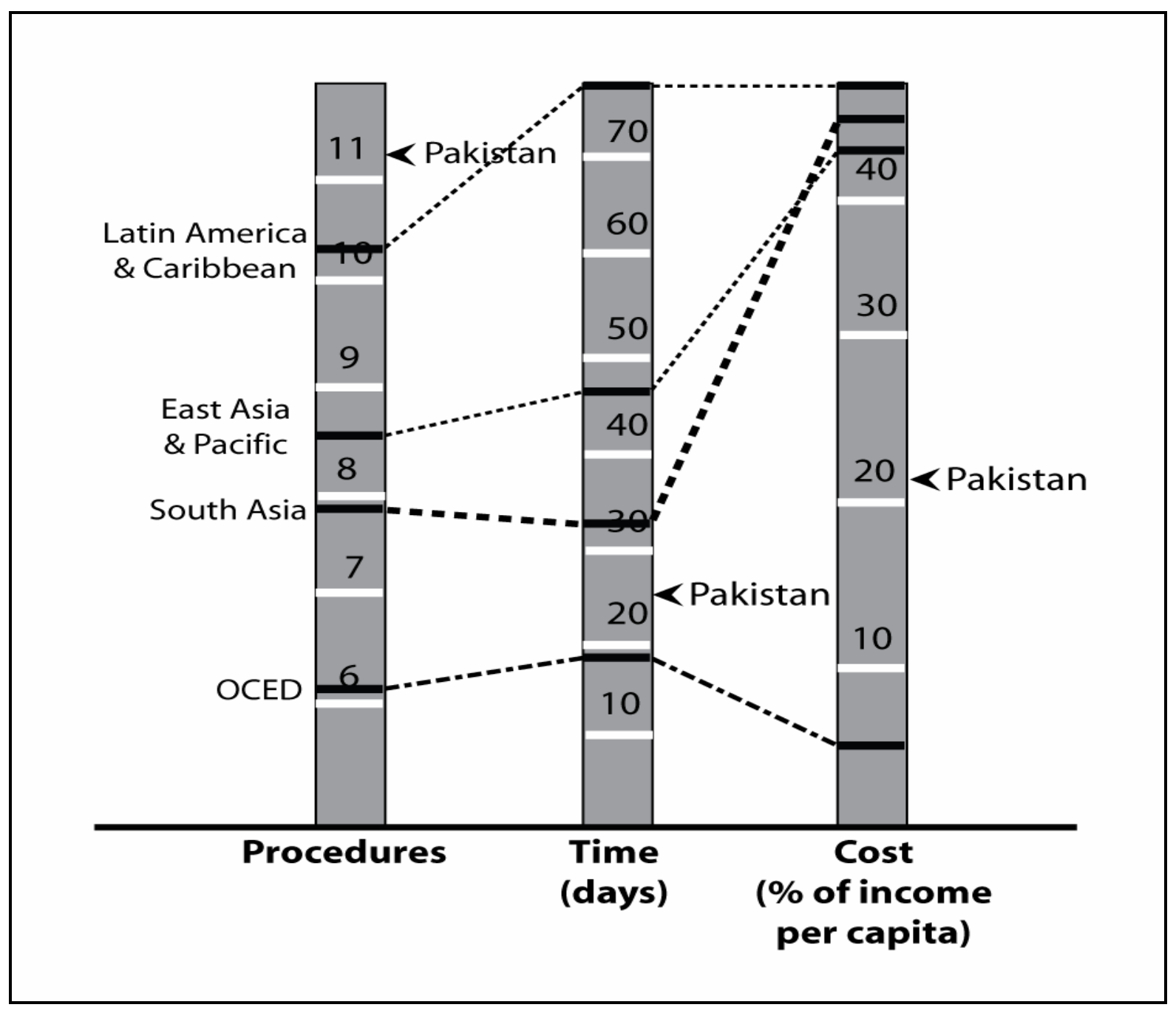

Source: WORLD BANK, 2007a. 
(a) Trends in poverty profile in Pakistan

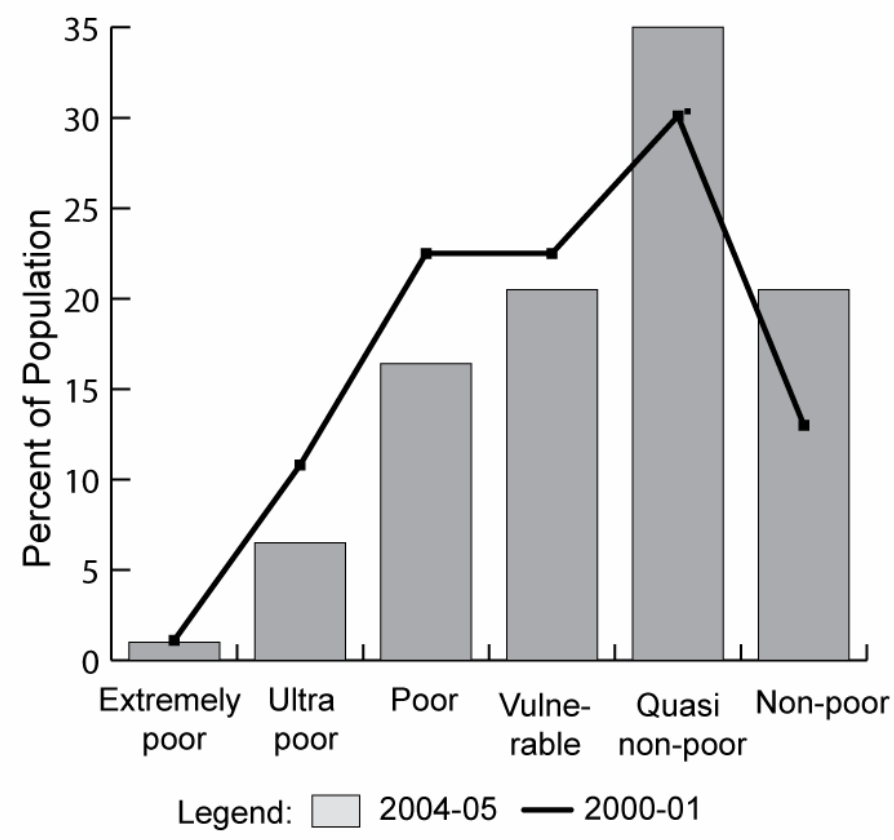

(b) Household in bottom $40 \%$ of rural per capita expenditure in Pakistan

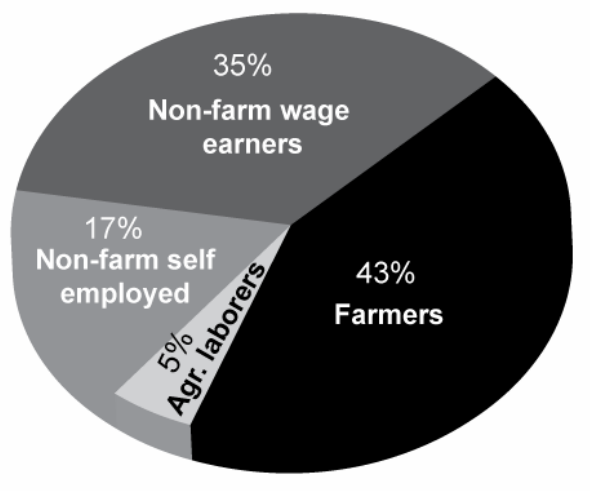

Poor defined as those households in the bottom 40 percent of rural per capita expenditure distribution shows that slightly more than half of non-farm households $(52 \%)$ in rural Pakistan are poor (see Graph $\mathrm{b}$ in Box 1). Farmers (including both owners and tenants) account for nearly 43 percent of the rural poor households in 2004-05. Within the non-farm sector, rural poor are more concentrated in wage employment (35\%) while share of self-employment (mostly petty trade) is around 17 percent. Highly unequal distribution of land is a major reason behind the prevalence of large proportion of rural poverty in Pakistan. For instance, nearly 37 percent of the rural households own land and majority $(61 \%)$ of those with land own fewer than five acres, or 15 percent of total land. Due to this highly skewed land distribution most of the gains from farming sector accrue to landlords (highincome farmers). As evidence from a comparative analysis of Economic Surveys in Pakistan (see Graph a in Box 1), the proportion of all poor categories declined significantly except the extremely poor who remained almost identical in the two survey periods of 2000-01 and 2004-05. Similarly, the population classified as quasi-non-poor and non-poor have increased in 2004-05 relatively to 2000-01. This drop in the poverty can be explained by increased job creation in this period. Since 2003-04 and until the first half of 2005-06, 5.82 million new jobs have been created against an average job creation of 1.0-1.2 million yearly (GOVERNMENT OF PAKISTAN, 2006).

Source: GOVERnMENT OF PAKISTAN, 2006; WORLD BANK, $2007 \mathrm{~b}$. 


\subsection{Defining and Theorizing Household Strategies}

This section aims to define strategies as according to EMIGH, 2001 in existing literature reviews, though excellent, describe empirical uses of the concept, strategy, not its theoretical underpinnings. BourdiEU, 1990 mentioned in EMIGH, 2001 considered strategies as "the sequence of ordered and oriented actions" that are directed to maintain or increase household social and economic position without necessarily to be household objectives. Thus besides being a product of rational and conscious decision-making behaviour, there will also be elements of unconsciousness behind household strategies. Similarly for CHAYANOV, 1966 strategies ${ }^{14}$ are based on the idea that households allocate labor on the basis of the households' needs, the size and composition of their labor force, and the drudgery of such labor. Workers in households with a high dependency ratio work more hours and produce a higher output than workers in households with a low ratio of consumers to workers. So, in households with many consumers, workers work long hours to provide for their dependents.

Rural livelihoods are not limited just to income derived solely from economic activities but it is a holistic way of looking on their livelihood strategies. SCOONES, 1998 considered agricultural intensification/extensification $^{15}$, livelihood diversification and migration as the three core livelihood strategies. Pluri-activity is also a potential livelihood strategy on part of the rural people when the farm does not provide an enough amount of income to the peasant families or when there are opportunities in non-farm sector (UPTON, 1999; DHARMAWAN, 2001). All these concepts related to household strategies are documented in details in the following two sections.

\subsubsection{Framework for Livelihood Survival Actions}

This section begins with an overview of 'coping' and 'adaptive' strategies followed by listing various categories of survival strategies as formulated by DHARMAWAN, 2001; HERBON, 1988; and MANIG, 1997. Coping refers to situation where a household is food insecure, whereas adaptive is used when a household is food secured and tends to pursue a strategy persistently (AHMED et al., 2002). Coping strategies are actually the bundle of poor people's responses to declining food availability and entitlements in abnormal seasons or years (BELAY et al., 2006). Considering livelihood diversification, coping strategies are distinguished from risk strategies by

\footnotetext{
${ }^{14}$ It is to noted that CHAYANOV does not himself use the term strategy and so, provides no definition (EMIGH, 2001).

${ }^{15}$ The agricultural intensification is labor-led while extensification is capital-led.
} 
whether the diversification occurred after or before a 'shock', and thus whether the actions are reactive rather than pro-active (ELLIS, 1998). Under normal situation according to HERBON, 1988, 1994; MANIG, 1997; and DHARMAWAN, 2001 the peasant households usually pursue the following strategies to secure their livelihood:

a) Acquisition strategies: Household strategies striving for acquiring the accumulation of resources including all activities concerning utilization of resources endowed and provided by the nature (e.g., land, water, plants, air, and sun-shine);

b) Allocation strategies: The utilisation of acquired resources by making a certain organisation and applying specific resources management at household level. Hence, the disposition of material and immaterial resources within a household in a way that it can be used optimally to meet human needs. Under this strategy, one categorises the application of land, labour, knowledge or skill, and power or ability to fulfil human requirements;

c) Transformation/Production strategies: Strategies aim at converting an acquired resource into another form of useful energy sources that can be used to fulfil human needs;

d) Social relation strategies: Social networks are structured to secure human existence.

e) Consumption strategies: The creation of disposable energy by converting an acquired or saved resources into cash necessary for purchasing something for consumption; and

f) Reproduction strategies: The maintenance and consolidation of all elements that are necessary for a better living.

Considering the structural components within strategies, ZOOMERS, 1999 based on her study of rural livelihoods in the Bolivian Andes classified four types of strategies: accumulation, consolidation, compensatory and security. Applied mostly by recently married couples and families with young children, accumulation is a way to prepare for future expansion aimed at creating a minimum resource base. Some of these socially upward mobility strategies include migration, land acquisition, and labour recruitment. Once this upward mobility is achieved comes the consolidation strategies, where the wealthy households invest in items like short term land improvement to stabilize and improve the household's well-being and quality of living. Compensatory or survival oriented strategies are in response to sudden shocks like crop failure or loss of labour power. These includes migration, economizing, selling assets, borrowing, bartering or in some cases relying on family social security. Security strategies like multiple cropping, multitasking, sharecropping, stockpiling, and exploring non-agricultural opportunities are common responses to ecologically harsh areas. 


\subsubsection{Multiple Employment: As a Livelihood Strategy}

One important pathway towards livelihood sustainability involves avoidance of long-term dependency on only one or two income sources (BLOCK \& WEBB, 2001). Multiple employment or pluri-activity, which constitutes an important source of income for rural household in securing their financial requirement, refers to household that engage in economic activities in addition to farming their own land and animals. Pluri-activates can be classified as:

a) Employment on other farms, e.g., hired farm labour;

b) Para agricultural actives, e.g., food processing on own farm;

c) Other non agricultural activities on the farm, e.g., furniture making; and

d) Off farm activities, e.g., wage labour.

Multiple employment in farm households in rural Pakistan according to KUHNEN, 1985, on the basis of family structure, farm structure and economic structure, can take any of the below mentioned five different forms (see Figure 4 for a quick overview).

a) Individual income combination: When cultivators of small farms take up off-farm employment (rural labour) as a main occupation or as a sideline permanently or seasonally. Both of these activities are usually carried out by a single person creating problems of work adjustment and for this reason the second occupation is normally carried out locally.

b) Household or Family Income Combination: A situation when several male members (sons) take permanent non-agricultural employment locally or in distant places. Thus, the migration of workers to Arab countries and their investment in land, farm machinery, transport and trade back home brought about an economic and social advancement for their families.

c) Extended Family Economy: Extended family emerges when there is a close economic and social support contact between urban family (nuclear family) and their farm members in rural areas. The urban family members provide financial as well as labour support while in return the rural family (usually parents) offers basic foodstuffs usually for sentimental reasons. 
d) Remigration of Urban Population Groups: It is usually a case of non-farmers taking up agriculture as second profession. Reasons may be available or inherited landed property, rural residence place, and in few cases tax aversion by bureaucrats through investment in land.

e) Division of Labour: It emerges within the household in remote areas as there are few farm opportunities. Specialization emerges as activities are distributed according to age, skill and inclination resulting in professions like tailoring, mason, technician etc.

\section{Figure 4. Different Forms of Multiple Employment in Developing Countries}

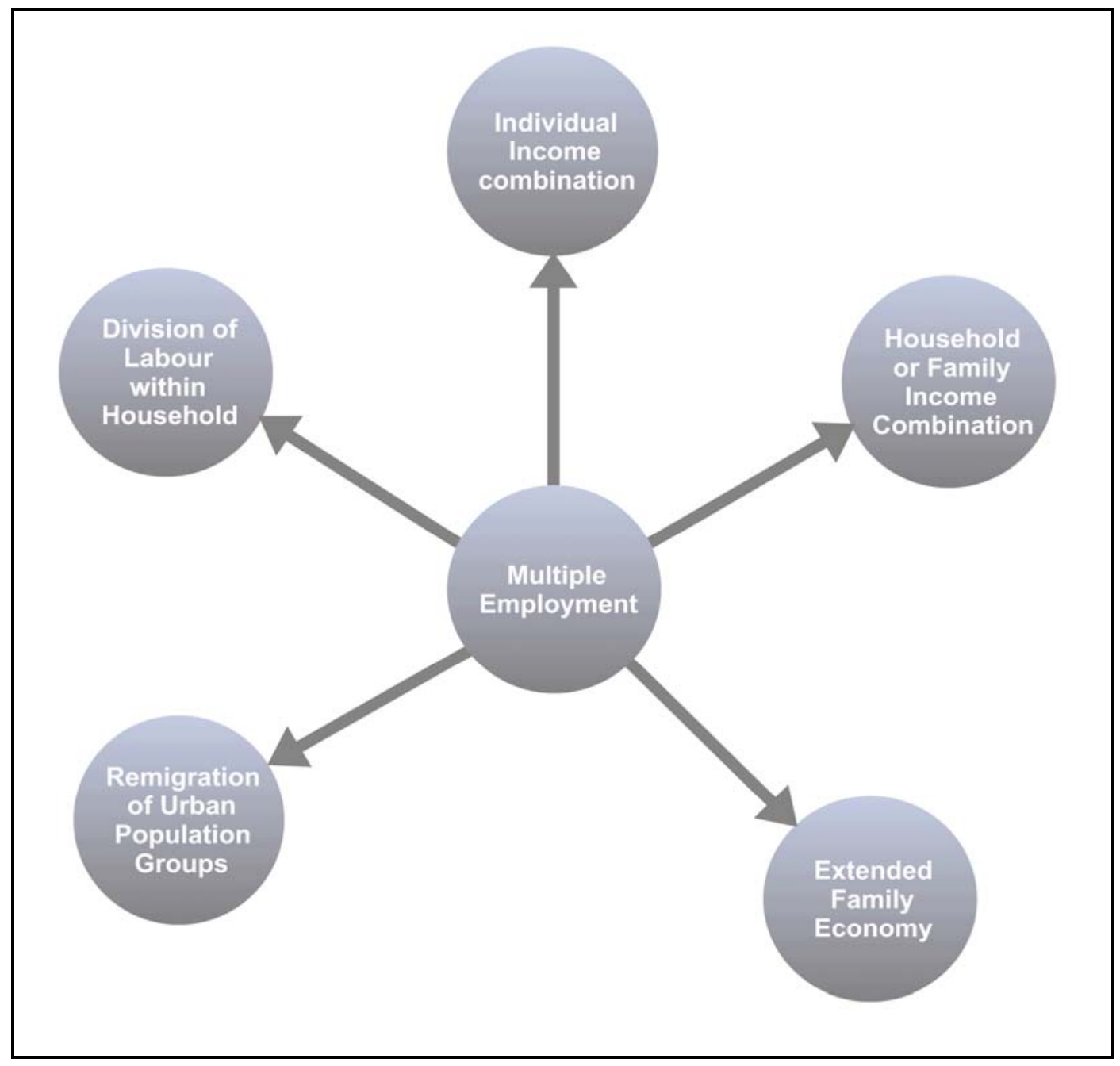

Source: Modified after KUHNEN, 1985.

The prevalence of multiple employment is either due to failure of the farm to provide an adequate amount of income to the peasant families or the rapid growth of non-agricultural sector 
bringing new employment opportunities to them (UptON, 1996; DHARMAWAN, 2001). Hence, agriculture is no longer necessarily a characteristic function for rural areas mainly due to it marginalization. Therefore, one must admit the fact that activities outside farming proper are vital to the livelihoods of all households as it is, in most rural contexts, not that easy to disentangle 'farming' from activities which are 'non-farm', since a household's livelihood is, in fact, a complex and organic whole made up of different activities on the part of different members, which together form a jigsaw which - ideally - fits tightly together (OVERBEEK et al., 2000).

\subsection{Rural Household Livelihood Diversification-Conceptual Issues}

The livelihood becomes diversified when rural households build an increasingly diverse portfolio of activities and assets to survive and improve their living standards (ELLIS, 2000). However, this diversification in developing countries is survival oriented than accumulation (ELLIS, 2000; KRISHNA, 2006). The mainstream household economic theory by considering diversification as a rational economic behaviour adopted in given circumstances of constraints ${ }^{16}$ and opportunities can serve to analyse the rural household diversification behaviour (ELLIS, 1998, 2000; ELLIS \& Mdoe, 2003; Ellis \& FREEMEN, 2004). It considers rural households as free choice makers in assigning their labour and material resources to alternative activities in response to the comparative returns of these engagements. Under perfectly competitive assumptions, the simple economic rule that governs household labour allocation decisions is that an effort invested in any activity increases until the marginal return to its resource use equals that of alternative occupations. The optimal point of the division of household time among various competing alternative activities is achieved at equilibrium where their marginal returns are ultimately equalised (BERHANU et al., 2007).

Differences in resource endowments (land, labour, capital) and access to markets and institutions are the facial expressions for diversity among rural households. These aspects are closely related, since households with more resources and wealth are usually better positioned to acquire market access and can offer the required safeguards to participate in social networks. Even so there is still diversity in the portfolio of activities and income composition among households with similar endowments and access to market. Diversity amongst seemingly homogenous

\footnotetext{
${ }^{16}$ Rural households' resource allocation decisions are basically constrained by conditions of livelihood asset endowments and related socio-political and institutional factors (MÖLLERS \& BUCHENRIEDER, 2005, p. 28).
} 
household types according to RUBEN \& PENDER, 2004 appeared to be the result of a broad range of additional factors like:

a) a multitude of subjective elements sometime labelled as 'enterprise styles',

b) life cycle criteria,

c) social hierarchy,

d) tradition, and

e) goals related to income and consumption, wealth and status, and efforts and risk

Combining farm and non-farm activities is a major source of diversity among rural households emerging out of the time-varying nature of agricultural work enabling farmers to engage in subsidiary jobs (RUBEN \& PENDER, 2004). Income diversification is important for ex ante risk management and ex post coping with adverse shocks, thus reducing income variability and enabling consumption smoothing overtime. The dilemma in front of poor households is that while they would most need income diversification, they are less able to become engaged in better paid jobs due to entry and investments barriers (FAFCHAMPS \& QUISUMBING, 1999) resulting in their concentration in low paid refuge jobs (BARRETT et al., 2001a; RUBEN \& PENDER, 2004; BARRETT et al., 2005; BUCHENRIEDER, 2005a; KIM, 2005).

\subsubsection{Non-farm Employment: Demand-pull or Distress-push Diversification}

Some households are pushed to diversify their activities because of external shocks (lack of cash, credit or location) while some are pulled into more paid jobs (SCOONES, 1998; ELLIS \& FREEMEN, 2004). The welfare model of rural non-farm diversification considers labor shifts from agriculture to non-farm sector induced by demand-pull and distress-push forces as beneficial to households and society as a whole (MÖLLERS \& BUCHENRIEDER, 2005). Following the assumptions of rationality and full information, the model suppose the demand-pull wage to be higher while distress-push wage to be lower relative to wage rate in agriculture sector (see graph a in Figure 5). There exhibits two labor supply curves (S1 \& S2) to accommodate for: (a) differences in individual capital assets of household members employed at a farm, and (b) variation in these household members opportunity costs regarding their labor contribution to agriculture.

It is to be noted that some household members due to high shifting costs (lack of capital assets

and institutions) work at less rewarding distress-push curve (S1) while others with better capital 
assets offer their labor at more attractive demand-pull supply curve (S2). So these high shifting costs are decisive in prohibiting household members to move to demand-pull strategy. The average wage rate in agriculture is below the equilibrium wage because of disguised unemployment $^{17}$ in this sector. The point where labor supply curve (S1) touches the demand curve for labor in agriculture (D1), representing the difference between distress-push wage rate and the labor supply curve $(\mathrm{S} 1)$, yield the maximal acceptable labor shifting costs. Because of high shifting costs it is impossible for the household members to jump to better yielding labor supply curve S2; so they have to stay at S1. Nevertheless, some members with low opportunity costs regarding their farm labor contribution can still raise the aggregate household welfare (increased household income) by working at a wage lower than that in farm sector. Graphically, the difference between the area with a plus sign (wage gain by working as farmer) and the area with minus sign (wage loss by moving out of farming) shows the welfare gain for the household as a whole (graph a in Figure 5).

The labor supply curve (S2) shows not only those in agriculture but also the potential workers in the better paid non-farm sector (demand-pull). This curve (S2) is the result of marginal productivity of labor in the demand-pull sector minus the shifting costs (transaction costs) of moving out of agriculture to this better paid non-farm sector (see graph b Figure 5). The point where the S2 touches demand-pull wage rate shows zero shifting costs. However, the labor movement from agriculture to non-farm sector (demand-pull) is possible only as long as the difference between the wage rate in these two sectors is larger than the shifting costs (see shaded triangle for welfare gains from this labor movement in graph b Figure 5). Simply, there will be labor movement to demand-pull sector, if:

(Demand-pull wage rate - Wage rate in agriculture) $>$ Shifting costs

The moment the shifting costs become higher than this difference in wages between the agriculture and non-farm sector (demand-pull) the labor shifts stop. However, this shifting is beneficial for agriculture as those remaining in this sector have now not only higher productivity but also better wages reducing the incentive to move to non-farm sector (see dotted line in Figure 5).

\footnotetext{
${ }^{17}$ The aggregate agriculture income is divided among all the household members although some members will not be working and adding to aggregate value added (MöLLERS \& BUCHENRIEDER, 2005, p. 28).
} 
Figure 5. Welfare Gains Through Distress-push and Demand-pull Labour Shifts

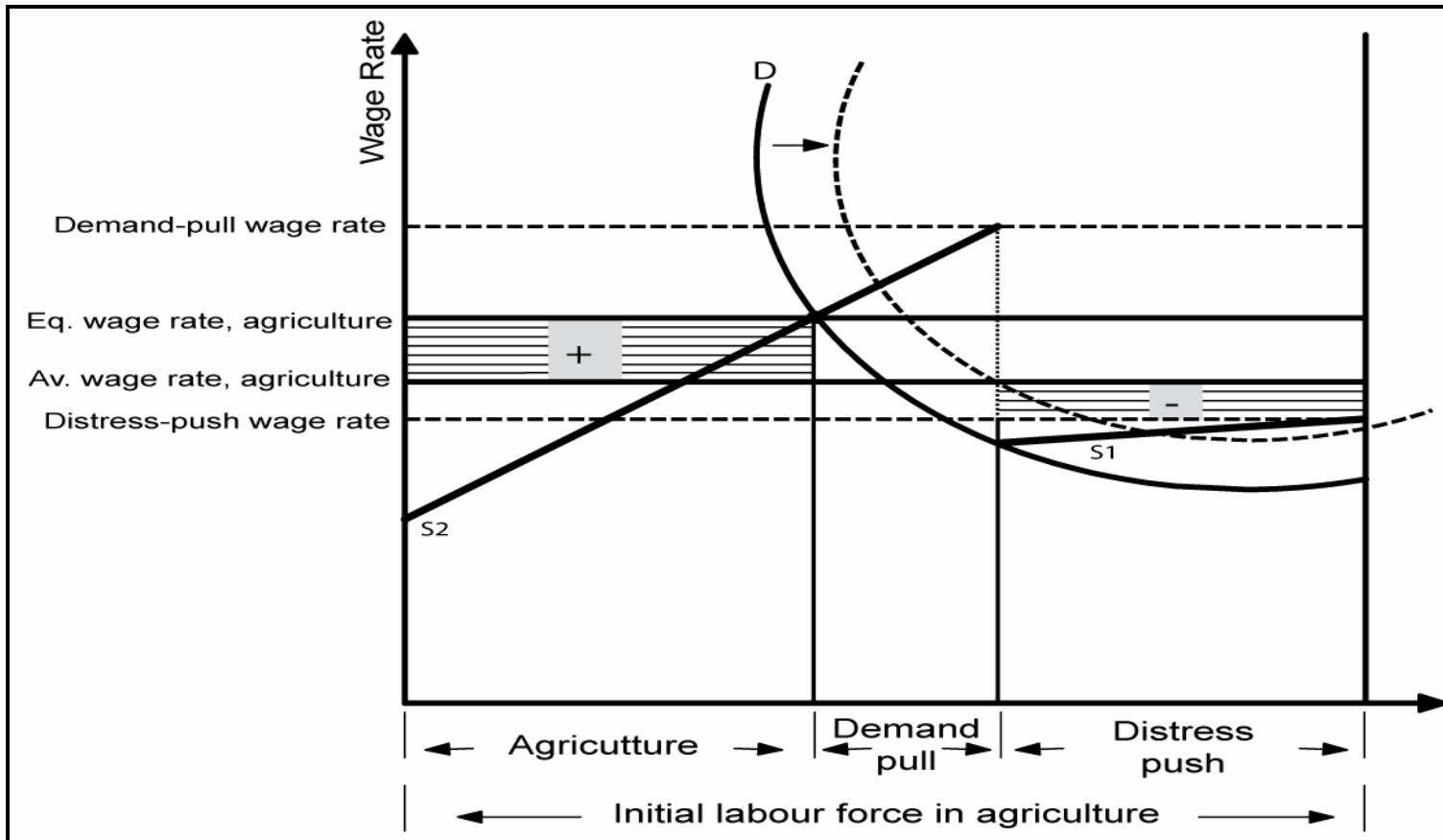

(a) Welfare gains through distress-push labour shifts

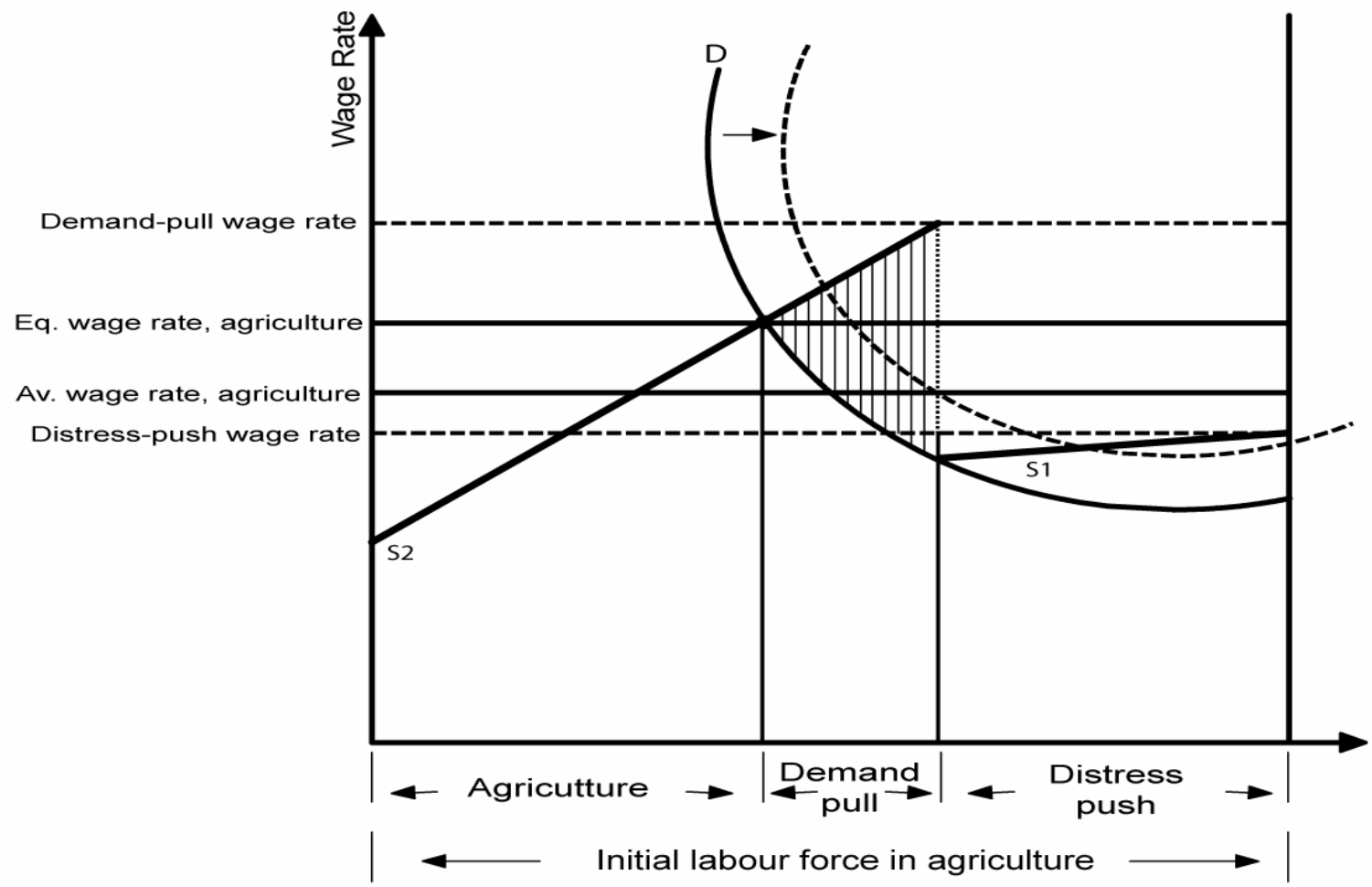

(b) Welfare gains through demand-pull labour shifts

Source: Modified after MÖLLERS \& BUCHENRIEDER, 2005 


\subsubsection{Rural Non-farm Diversification: Urban-led or Agriculture Driven}

An issue much debated in the development dialogue is whether the rural diversification is mainly agriculture-driven, or if the impulses stem from the urban economy. The failure of the industralization-led development strategies of the 50es due to their inability to tackle down to rural poor brought to surface the role of agriculture in rural development (EAPEN, 2001). This agricultureled strategy of growth advocated first by MELLOR, 1976 and later BHADURI, 1993, stressed for a more active agriculture sector with all its flexibility to absorb not only the rural labour but also to generate extensive growth. However, the limited absorptive capacity of agricultural sector requires the promotion of non-farm sector and especially small-scale manufacturing ${ }^{18}$ in the rural area.

The once neglected but potentially vast rural market for industrial goods became the ultimate target of this new development strategy. The growth of this rural non-farm stimulated by the small-scale manufacturing activities was to be largely induced by rural-urban spatial linkages resulting as a consequence a reduction in rural-urban migration. So this development strategy looked upon villages not as isolated economies but rather as dynamic autonomous entities with potential for generating employment based on their own local development priorities (EAPEN, 2001).

Putting the above discussed theory to test, EAPEN, 2001 in a study in Kerala, India examined changes in employment patterns in rural areas between 1971 and 1991. He regarded rural nonfarm employment as a critical component of rural transformation in less developed countries given the failure of the industrialization-led development strategies of the 1950s. An examination of certain socioeconomic characteristics (proxies for 'agricultural' and 'urban' linkages) for 1971 in those villages which became urban in 1991 revealed importance of both types of linkages in generating non-farm employment, depending on the location of the village vis-à-vis large urban settlements (for some of these linkages, see Box 2).

\footnotetext{
${ }^{18}$ However, there is limited possibility for the graduating of these small-scale rural manufacturing enterprises into modern large-scale manufacturing units as envisaged under 'proto-industrialization' concept (BERRY, 1987; GROSH et al., 1996 cited in EAPEN, 2001).
} 
Box 2. Reasons for Promoting Non-farming Sector

A few of the stylized reasons for promoting non-farm activities in developing world are:

- Food security: The income from non-farm activities can contribute towards better food security as it allows greater access to food.

- Farm credit support: The availability of cash income through RNF activities can support the farm sector for its credit requirements.

- Profitability of farming: The profitability of farming be increased (increased availability of inputs and improved access to market outlets) by investing in food system i.e., agro-processing, distribution and provision of farm inputs.

- Agriculture \& RNF activities linkages: Due to the direct and indirect linkages between agriculture and non-agricultural sectors, both sectors can benefits. When agriculture is dynamic due to better agricultural policies non-farm sector can also grow faster. For instance, rural agricultural and non-farm employments are closely linked through small-scale processing plants. Some of these linkages are:

o Production linkages: Production linkages turn into 'Upstream linkage', when the growth in farm sector motivate the non-farm sector to increase its investment in the farm productivity by increased and improved supply of inputs and services. The linkages between the two is 'Down stream' when non-farm sector invest (or value add) in the agro-processing and distribution services to use farm products as inputs.

o Expenditure and investment linkages: The production linkages can also result in indirect expenditure and investment linkages, where income or profits generated in one sector are spent or invested in the other sector.

Source: REARDON et al., 1998 


\subsection{Determinants of Occupational Choices}

Occupational choice plays an important role in determining earnings and success in the labour market. In the social structure of Pakistan, an occupation reflects the socio-economic status of the individual (NASIR, 2005). According to Damite \& Negatu, 2004; KurosaKi \& KhAN, 2006 and LANJOUW et al., 2001 rural households' decision to engage in various occupations takes place under the influence of several individual, household and community level factors (household size, education, age, location etc.). besides the variables related human capital, access to credit, physical, and natural capitals also influence household employment decision (BERDEGUE et al., 2001). This section will discuss some of these factors shaping household employment decisions starting with their individual characteristics.

\subsubsection{Education and Skills}

There is a positive and significant relationship ${ }^{19}$ between literacy levels and non-farm employment opportunities at the household as well as individual levels as depicted by various studies (REARDON et al., 2000; BARRETT et al., 2001b; JANVRY \& SADOULET, 2001; WANDSCHNEIDER, 2003). Besides these studies, LANJOUW et al., 2001 in peri-urban Tanzania and ZHANG et al., 2002 in China revealed education as important determinant of non-farm employment. Regarding the role of education in different employment sectors, the following trends emerges:

a) Low-income activities such as non-agricultural casual jobs have low entry barriers and do not require education achievement (BERDEGUE et al., 2000; BERDEGUE et al., 2001; SMITH et al., 2001);

b) The probability rises for an individual to work in regular formal employment with rise in education levels (SMITH et al., 2001); and

c) Involvement in self employment is usually most likely for those with some basic education, but is lower for both the illiterate and those with high levels of education (LANJOUW, 1999). Entrepreneurial capacity is stimulated by secondary education. In developing countries, an entrepreneur with an elementary education can expect to earn an income 41 percent higher than one with no education at all (ISLAM, 1997).

\footnotetext{
${ }^{19}$ Education is a significant determinant of RNF business sector success, wage levels and productivity, and it is therefore important for creating a more "egalitarian" income distribution (REARDON et al., 1998).
} 
More educated individuals have not only greater aspirations to work outside agriculture but also better education provides skills like ability to manage a business ${ }^{20}$, process relevant information, adapt to changing demand patterns, and liaise with public and private service providers facilitating successfully in non- farm activities (WANDSCHNEIDER, 2003).

Concerning the role of education in agriculture sector, although human capital augments labor productivity in theory, studies in rural developing areas have shown contradictory results

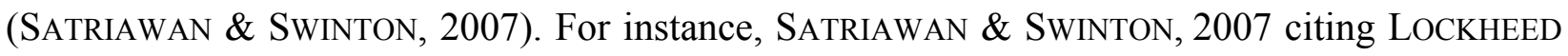
et al., 1980 and JAMISON \& LAU, 1982 linked education with significant increases in farm productivity, particularly through improved efficiency. Similarly, ScHULTZ, 1988 suggests while better educated rural labourers leave agriculture first when the returns to education are larger elsewhere, they will return to it if there is an agricultural boom.

FAFCHAMPS \& QUISUMBING, 1999 by utilizing 12 rounds of panel data in rural Pakistan revealed the insignificant effect of education on crop and livestock income. The study further concluded that households with better-educated males earn higher off-farm income. Non-farm work has a much higher return to education than does farm work and hence, JOLLIFFE, 2004 suggests that this divergence in return affects the allocation of labour in farm households between farm and non-farm.

Like most of other developing countries Pakistan has poor literacy ratio accompanied with lower quality of education and mismatch of acquired skills with the market demand resulting in lower returns on investment in human capital ${ }^{21}$. This, in turn, weakens the role of education as a catalyst in poverty reduction efforts (DAWN INTERNET EDITION, 2002).

\footnotetext{
${ }^{20}$ Education (primary and secondary) promotes the growth of the rural non-farm sector as literacy improves labor productivity and enables a worker to master skills provided through on-the-job training (ISLAM, 1997).

${ }^{21}$ The problem lies within priorities as Pakistan, like many other developing countries, spends too little on social sector programmes. During the last 60 years since independence, the number of primary and high schools in Pakistan has increased 18 and 39 times respectively, but because of the significant population growth and poor governance, over 10 million children are still not enrolled in school. Besides alarming drop out rates where less than 50 percent of enrolled students complete their primary level education, nearly two thirds of the country's population is unable to read, write or comprehend a simple letter comprised of 2-3 paragraphs. The average teacher-student ratio is 3 to 1,000. The educational budget has never been more than 1.6 percent of GDP (KHALID \& KHAN, 2006).
} 


\subsubsection{Household Composition}

Household composition (HH size, dependency ratio etc.) plays an important role in engagement in non agricultural activities. It is the population pressure, resulting into rather higher dependency, which is forcing increasing number of Pakistanis to engage in diverse economic activities. Pakistan, the 6th most populous country in the world (4th in Asia), where the slower pace of fertility transition has strong implications for economic and social development. In particular, this results into relatively higher dependency ratio. According to 1998 CENSUS OF PAKISTAN (Figure 6 ), only 32 per cent of the total population lies in the working age group (25-59), which is almost unchanged since 1981. The resulting high dependency ratio not only constraints the saving capacity of average households but it also has strong implications for their consumption pattern and overall quality of life.

Pakistan's population is mostly rural based where the cultivable land is shrinking and the growing population (majority illiterate and unskilled) have to take refuge in low paid non-agricultural sector (DAWN INTERNET EDITION, 2002). Hence, the trends in population growth and urbanization in Pakistan require an increasing labour absorption not only in agriculture but also in the non-farm sector (HUSSAIN, 1989, p. 332).

Figure 6. Population Pyramid of Pakistan, 1998

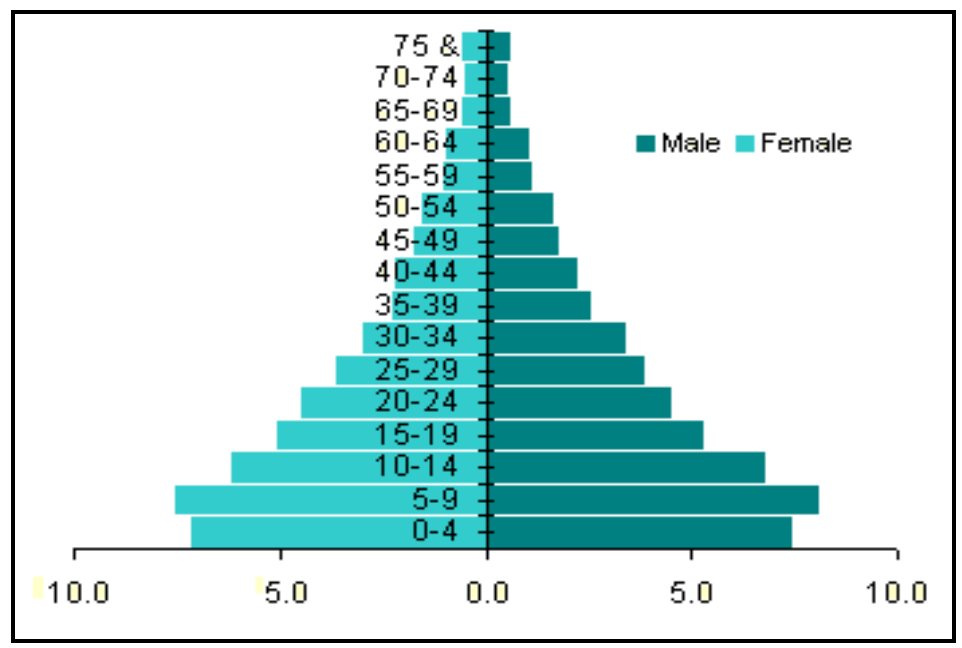

Source: Based on census report GOVERnMENT OF PAKISTAN, 2000. 


\subsubsection{Role of Gender}

The crowding hypothesis ${ }^{22}$ supports the evidence that males are generally employed in high paid jobs while females are concentrated in low paying occupations (NASIR, 2005 citing Zveglich \& Rodgers, 2004; TeO, 2003; Bayard, et al., 1999; BlaU, Ferber, and Winkler, 1999; BLAU \& KAHN, 1996). Majority of the females are working in the developing world as informal wage workers, for instance a report of ILO, 2003 states:

Many millions of women dwell in the so-called informal economy of the developing world but at the price of being unprotected and poorly-paid. This means that many remain beyond the reach and coverage of ILO Conventions and national labour laws. In India, for example, 93 percent of all workers are in the informal economy; other examples are 62 percent in Mexico and 34 percent in South Africa. Informal employment is generally a larger source of employment for women than for men.

OVERBEEK et al., 2000, p. 64 supported ILO views through an EU research in 1995-97 as marginalization of agriculture in most areas reflected the increase in women seeking non-farm employment. However, GAURAHA, 1996, p. 420 observed in his study in Raipur district, Madhya Pradesh, India that the involvement of females in non-agricultural work was low. RUBEN and BERG, 2001, p. 555 observed that female members of wealthier households were mainly involved in self-employment.

Women's economic empowerment is an essential element of sustainable development. A UN study in 2002 reveals the ground realities that despite the growing involvement of women in recognized economic activity in Pakistan (20.8\%), they continued to remain dominant in unpaid household work (33\% of total women labor force). Therefore, the economic future or financial position of a Pakistani woman is more uncertain than a man's, due to low literacy rates, traditional barriers, lack of opportunities for employment, and low-income levels (FAREEDEE, 1989, p. 2). NASIR, 2005 citing NAZLI, 2004; SidDiQUi \& HAMID, 2003; ASHRAF \& AshrAF, 1996 also states that there is occupation segregation and concentration of females in low paying occupations in Pakistan.

\footnotetext{
${ }^{22}$ The crowding hypothesis of POLACHEK \& SIEBERT, 1993 cited in NASIR, 2005 splits the occupations on the basis of social norms. Males, according to the hypothesis, have the freedom to exercise their choice of occupations whereas females are limited to choose only from the occupations labelled as the "female jobs." The entry into "female jobs" is easy for women therefore they are crowded in these occupations. This oversupply of women due to occupational segregation therefore leads to low earnings for them.
} 
To assess the economic status of women in rural Baluchistan, Pakistan, KHAN, 2000a carried out a small-scale sample survey in district Pishin and Maustang, which showed that the major factors for women's poor involvement in economic activities are social and cultural. The women give preference to home based income generating activities, the income was in their control which they mostly spent on education and health of their children. There is a need for a separate gender policy focusing on streamlining home based income generating activities and such projects should be encouraged at community level (KHAN, 2000a).

\subsubsection{Role of Credit and Financial Capital (assets)}

The lack of access to financial services for the informal, micro and small enterprise are acknowledged as constraints on potential diversification into non-farm economy activities. Lack of access to formal credits hinders individual's ability to venture into new businesses or where enterprises are planning to expand activity. For instance, the lack of access to formal credit is widespread in rural Northwest Pakistan (MANIG, 1991; KHAN, 2007) and specially those in informal sectors face particularly stringent constraints in this sphere (JAN, 2007). Similarly, ISLAM, 1997 observed in Bangladesh that 72 percent of households engaged in manufacturing, 59 percent of households engaged in trade and services, and 54 percent engaged in transport suffered from credit constraints. Access to formal credit provision ${ }^{23}$ has been found to be weak amongst many of the rural poor, despite the number of institutions engaged in this activity. Lack of knowledge about credit providers, tight repayment periods and high initial capital requirements represent barriers to access (ZELLER et al., 2003).

\footnotetext{
${ }^{23}$ Funds are provided to rural population by institutional and individual sources. Institutional sources include commercial banks, NGOs/ CBOs, co-operative societies, government programmes (e.g. Khushali bank in Pakistan) and micro-projects. While these institutions would be an important provider of finance for the rural however, they run mainly in urban areas to keep their financial viability (ZELLER et al., 2003). Similarly, individual sources consist of moneylenders, relatives, friends, and localised revolving credit systems. Individual or informal credit providers are diverse, ranging from individual moneylenders, to friends and family, sometimes based on clan or kinship groups. The benefits of informal credit include the ability to deliver the service close to poor people's homes, flexibility in capacity and needs, less bureaucratic and not necessarily dependent on formal collateral (character rather than assetbased). However, they are restricted by liquidity, or the ability to disperse larger, longer-term loans needed in times of general need (ZELLER et al., 2003). However in order to reduce the risk of loan default, according to MANIG, 1990 and AleEM, 1990 the granting of credit in rural Pakistan by a private trader also demands the following requirements or screening processes:

- the borrower has to be recommended by a trusted third party,

- the borrower has to do business with the trader on a cash basis for one or two seasons before lending takes place, and

- besides the borrower's credit history, enquiries are made in the market and, sometimes, in the borrower's village about the borrower's indebtedness and reputation in the market.
} 
REARDON et al., 2000, p. 266, based on a review of household survey evidence from Africa, Asia and Latin America, suggested that the non-farm employment and micro-enterprise programmes will not necessarily resolve rural income inequality problems and attendant social tensions nor automatically benefit the poor. Instead policymakers should be worried by substantial evidence of poor people's inability to overcome important entry barriers to many non-farm activities. The main determinants of unequal access to non-farm activities are the distribution of capacity to invest in non-farm assets and the relative scarcity of low capital entry barrier activities. Therefore, it is important for public investments and policy to favour an increase in the access of the poor to assets that allow them to overcome non-farm employment entry barriers.

\subsubsection{Role of the Infrastructure}

Infrastructure development is an important determinant for participation in the rural non-farm sector. Expanding roads, transport, and communications infrastructure leads to specialization as well as division of labor by rural households which in turn, promote developing a trade, marketing, and distribution network. When rural enterprises can readily get materials and market their products outside local areas, labor costs become the dominant factor in their location (ISLAM, 1997). So, there is a need for development of hard as well as soft infrastructure to stimulate rural non-agricultural activities.

However, the ground reality is different in majority of developing countries as the incentives for private sector investment in rural areas are largely absent. Access to services considered vital for rural growth, including transport, electrification and credit are beyond the means of most rural households (TOPFER, 2000, p. 98). The most visible ways in which rural poverty is manifested are poor shelter, infrastructure and service provision in rural settlements. There are several factors beyond household characteristics and farm income which condition the household's participation in non farm work. Some of these factors are appropriate public actions and investments in rural infrastructure which have implications for the participation of rural farm households in non-farm pursuits (ABDUALI et al., 1999).

The conventional rural versus urban debate (which has dominated development policies and aid investment priorities) is counter-productive and no longer based on reality. Instead, the focus should be on promoting urban-rural linkages. Improvements in shelter and infrastructure in rural areas can play an important role in strengthening urban-rural linkages, create non-farm employ- 
ment, manage natural resources and contribute to sustainable development of rural dominated regions. Towards this goal, the adoption of enabling policies are needed in many developing countries which decentralize political decision-making, guide private investments into rural areas, and support the initiatives of local communities (TOPFER, 2000, p. 98).

\subsubsection{Rural Town Development and Role of Government}

Closeness to cities influence the non-farm activities households engage in. In a detailed study of employment in Bouake, Cote d'Ivoire and the surrounding region, URIBE ECHEVARRIA, 1991, found that traditional activities diminished rapidly in importance close to the city. For example, basket-making, weaving and pottery comprised 6.2 percent of total employment at $25+\mathrm{km}$ from the city but only 1.9 percent within $10 \mathrm{~km}$. The central problem is that of "absorptive capacity": to what extent can the urban economy productively employ new labour force entrants and provide basic social services to accommodate them? Therefore, the rural areas are in desperate need of economic development to check the pressure on the urban centres.

Considering rural small-scale industrial development, the Chinese experience is unique as Township Enterprises (TEs) were given the tasks of producing rural non-farm employment and reducing the incidence of rural poverty. Much of the early capital came from farmers: in the form of taxes, levies, labour and cooperatives; as direct investment from surplus farm income stemming from liberalization. Initially, the TEs were confined to agro-processing but were gradually expanded into engineering, chemicals, electronics and other diverse non-agricultural enterprises. The applicability of the Chine's TE model to developing countries, the TE's competitive strength is marked by a managerial innovation, viz synergy related advantages identified and built into every industrial cluster. China's favourable conditions, such as political stability, strong macroeconomic performance, high savings rate (38\%) and disciplined, literate workforce are not prevalent in other Third World countries. It is demonstrated how Chinese TEs have adversely affected Brazilian leather, Indian silk and African small-scale manufacturing (PURUSHOTHAM, 1997).

In order to create intermediary towns to diffuse and decentralize the development of industrial activity and social infrastructure in the rural areas, 'Agrovillas' program was launched in Pakistan in the early 70es (KHAN, 1975). The rationale behind the 'Agrovillas' was to create buffer between the rural sectors and the urban industrial centres through spatial dispersion of 
social and economic facilities and to create work and income opportunities for rural inhabitants close to their homes. KHAN, 1975 argueing the revival of these these 'Agrovillas' on the basis that it will check the selective outflow of rural resources and avoid crowding industrial and services activities into a few already swelled industrial metropolises.

The permanent large increase in rural population in developing countries along with a shrinking agriculture sector requires a new orientation for rural employment policy. The limitation of agriculture sector to provide employment necessitates promoting non-farm sector along with its agri-business sector due to its substantial capacity to offer employment. The main stress on this policy are establishing a very large number of very small, small and medium-sized enterprises in rural areas (MANIG, 2006, p. 63). The basic ingredients required for this new paradigm are higly motivated and innovative entrepreneurs. These innovative entrepreneurs will invest their knowledge and capital resulting in increased productivity in the rural sectors with the ultimate consequence of generating employment and income opportunities. However, the promotion of this rural employment strategy require not only investing in the population living conditions but also addressing the overall business environment. Few of these components according to MANIG, 2006, p. 81 needed for promoting smallest to middle size enterprises in rural areas are:

a) good governance, political stability with legal certainity, and rule of law;

b) effective public administration with less role of bureaucracy; and

c) economic frame conditions along with efficient communication and transport infrastructure.

Similarly, REDDY, 2000 stressed for a separate strategy for procedures and provisions, method of implementation and administration for the rural non-agricultural sector. This sector is complex, diverse and more broad-based compared to rural industrialization and the programme for sector need to be distinguished from the programme of industrialization needs. However, then comes the question of which non agricultural activities should government promote, retail trade, services or industrial enterprises? One simple way of response for the government is to assist the needs of a particular enterprise or a group of enterprises providing the same or similar products. For example, public-sector support can be linked to government procurement of products and supplies (ISLAM, 1997). 


\subsubsection{Social Capital Dimension of Access to the Non-Farm Economy}

Social capital ${ }^{24}$ play an important role in developing countries in access to non-agricultural employment mainly because of widespread corruption and weak institutions. So, in such societies, access to the rural non-agricultural economy depends on taking part in various social institutions, social structures and social relations which are governed by rules, norms, obligations, reciprocity and trust (ALBRECHT, 1976; MANIG, 1991).

Revealing examples from the six village of rural Northwest Pakistan, RIEKEN, 1994 identified social networks as one of the main factors in getting non-agricultural employment or even creating own businesses. For instance, although the two neighbouring villages of Kochian and Gulbela had the same number of households in 1986/87 and were divided by an arterial road, there were 20 percent more people in Kochian engaged in the non-agricultural activities with one-third of those working in Peshawar. In constrast, twice as many entrepreneurs and craftmen resided in Kochian than Gulbela. The role of social networks played a major role to intiate employment in transport sector or persuing various apprentices in Kochian ${ }^{25}$. Similarly, the social contacts of the residents in tribal villages Mushtarzai and Yousafkhel allowed them to gain jobs in the big cities of Pakistan like Karachi, Lahore, and Rawalpindi. Some of the households in these villages used these informal contacts to seek jobs in gulf countries (for details, see RIEKEN, 1994).

\subsubsection{Land Ownership}

Land ownership is not only an important factor in the decision to engage in the non-agricultural sector, but in addition it is an important requirement for access to credit from the formal banking system (KHAN, 2000b). The number of owners and the area of small landholdings (less than five ha) has increased somewhat; the proportion of large landowners (more than 20 ha) has gone down from 2.7 to 2.0 per cent and their share in the total area has declined from 26 to 23 per cent.

In Pakistan, about 96 per cent of the landowners have holdings of less than 10 ha, but they own 64 per cent of the area. The highest concentration of landownership is in Sindh province. Small

\footnotetext{
${ }^{24}$ Social Capital is the sum of social resources available to individual households in the form of networks of social relations that may be used to access other productive resources and livelihood strategies (GAREN, 2001).

${ }^{25}$ Those employed in the transport sector were four times as many, and three and a half times as many apprentices came from Kochian (RIEKEN, 1994).
} 
landowners (with less than two ha) are preponderant in NWFP (96 per cent) and Punjab (80 per cent), but they own only 55 and 36 per cent of the area in the two provinces. They comprise 40 per cent of all landowners in Sindh and own less than 10 per cent of the area. The large landowners (with more than 20 ha) own 38 per cent of land in Sindh, 20 and 14 per cent in Punjab and NWFP, respectively (KHAN, 2000b).

The pattern of landownership in Pakistan and its provinces ${ }^{26}$ is highly skewed as for instance, the Gini coefficient increased from 0.66 in 1972 to 0.75 in 2000 for Pakistan. The few misguided attempts at land distribution in 1959, 1972, and 1977 had made tenancy unattractive to land owners. In order to avoid giving land to government, these landowners split their lands between their family members and in some cases, land previously sharecropped was resumed by landlords for self-cultivation. The ultimate result was capital intensive farming with the consequence of lesser employment opportunities for the landless labour (QURESHI \& QURESHI, 2004).

Pakistan, where 35 percent of total farm area is cultivated by others than the owners has been passing through fundamental changes since the last four decade in rural land ownership. KHAN, $2000 \mathrm{~b}$ mentioned the following three major changes in landownership in Pakistan since the late 1960s:

a) First, the ownership and area under small landholdings have increased mainly because of subdivision of holdings by the law of inheritance and rapid population growth, though some of it may be the result of distribution of land to the landless following the land reforms of 1972.

b) Second, there has been a significant fall in the number and area of large landholdings because of intrafamily land transfers expecting and in response to the land reforms acts of 1959 and 1972.

c) Finally, medium-size holdings (10 to 40 hectors) have gained, especially in Sindh province, both in number and area.

These trends in land ownership in Pakistan can be presented in the hypotheses of polarization and inverse switching, where the first deals with the size distribution of farms and it implications for

\footnotetext{
${ }^{26}$ Among the four provinces, NWFP presents the most inequal landownership with a Gini coefficient of 0.86 in 2000. while for the rest of provinces, the Gini coefficient is in the range of 0.67-0.71 (QURESHI \& QURESHI, 2004).
} 
labour requirement while the latter discusses a situation in which an increasing number of tenants seek supplementary wage labour, and land-owners adjust their production organization involving tied labour supply. So there is a need for institutional framework for realizing the objectives of high yields on small farms and greater employment in the off farm sector (HuSSAIN, 1989).

However, PIESSE et al., 1999 challenged the conventional wisdom which suggests that non-farm incomes make rural income distributions more equal, since it is the needy, perhaps with less land, who are forced to look for further income sources. The authors found this view to be naive, since it is those with higher farm incomes who may have either greater capacity or more choice, and are able to take advantage of non-farm employment opportunities. Their results showed that nonfarm income decreased inequality in Chiweshe, which is near Harare, Zimbabwe and increased inequality in the remote region of Gokwe. Thus, the opportunities offered by developing markets and non-farm opportunities appear to be important.

Another experience from a different continent which may be of interest is that of Nigeria where ILIYA \& SWINDELL, 1997 observed that primitive accumulation in agriculture does not necessarily lead to subsequent investment in the rural industrial sector. Based on 1989-90 households survey for two towns in Sokoto state, they found that wealthy farming households (landlords) had jobs and business connections; poor farming households (tenants) had sporadic supplementary employment while intermediate farming households (owner occupations) were limited with reliable non-farm employment.

\subsection{Transformation and Changes in Rural Employment Structure}

An important objective of the current study is to analyse the processes of change in the employment structure in the research area, thereby, justifying a brief discussion on institutions $^{27}$ and the dynamics of changes in these institutions. In the following sections, an attempt has been made to understand these institutions and the processes of institutional change in nonagricultural employment.

\footnotetext{
${ }^{27}$ The term 'institution' has a long history of usage in the social sciences, dating back at least to Giambattista Vico in his Scienza Nuova of 1725. However, even today, there is no agreement on the definition of this concept (HodGSON, 2006, p. 1).
} 


\subsubsection{Institutions and Their Role in Livelihood}

Institutions are a broadly defined concept. In the NIE literature, a distinction is made between the "institutional environment" of NORTH, 1990, 1991, 2000 and the "institutional arrangements" of WiLliamSON, 1985. The institutional environment is the underlying set of rules and regulations that govern economic interactions within a society. They include the formal laws of the state and the state organizations that uphold them; they also include informal institutions such as social customs and ideologies.

Formal institutions are conscious creations of political actors and strictly enforceable, while informal institutions - not synonymous with norms ${ }^{28}$ - are sometimes intended and sometimes the result of unintended patterns that accrue overtime based on repeated interactions (STACEY \& RITTBERGER, 2003, p. 861). Institutional arrangements, but then, are the more specific contractual arrangements that govern the way economic actors cooperate or compete. In WILLIAMSON's model, they were devised primarily for reducing transaction costs ${ }^{29}$. Examples include the firm, the commodity exchange, interlocking transactions, and other types of business contracts (SMITH et al., 1999).

There are two related but seemingly divergent aspects of the institutions, firstly, institutions are the rule of the game ${ }^{30}$; and institutions are equilibrium entities (AOKI, 2000, p. 13). The rule of the game theory places stress on the design view of institutions, whereby rule making by actors such as legislators, political entrepreneurs, economists, and so on is susceptible to con-

\footnotetext{
${ }^{28}$ Informal norms of behavior come from socially transmitted information and, thus, constitute a part of the cultural heritage. Therefore, the process of their formation and erosion must be slow and complex. The tension between politically determined formal rules and persistent informal constraints then may have important implications for the way economies change (AOKI, 2000, p. 12).

${ }^{29}$ According to NORTH, 1990 the institutional environment usually devises to serve the needs of a country's elite. It may help reduce transaction costs within the economy, but in many poor countries, it does not since lowering of transaction costs is not necessarily for the elite (SMITH et al., 1999). Some of the transaction costs viewed by SMITH et al., 1999 in their study of farm credit in Pakistan were:

- Search costs: the costs of searching suppliers or buyers in a particular market;

- Screening costs: the costs of building the trustworthiness of potential parties to a transaction;

- Negotiation costs: the bargaining cost with trading partners as well as officials controlling trade;

- Measuring costs: the costs of quality and quantity of goods or services being bought or exchanged;

- Transfer costs: the cost of transport, processing, packaging, and securing title;

- Monitoring costs: the overseeing costs to see whether the terms and conditions agreed upon are fulfilled; and

- Enforcement costs: the costs of enforcing agreements as well as seeking compensation if it is broken.

30 'Game Theory' provides a useful tool for understanding the self-enforcing nature of institutions. However, it is unlikely to provide a complete closed theory of institutions (AOKI, 2000, p. 13).
} 
scious ${ }^{31}$ design. Similarly, the equilibrium of the game view also explains the stability of institutions. Such an institution is a socially framed state from which agents are not motivated to depart as long as others do not do so (Ibid., pp. 12-13). Even institutions under equilibrium are subject to changes such as a shift from one equilibrium (sequence) to another (sequence). The elements of spontaneity, design, or both can play a role in disturbing this equilibrium (Ibid., pp. 22-23).

Closely related to institutions is the concept of organizations, that for NORTH, 1994 cited in HODGSON, 2006 are made up of groups of individuals bound together by some common purpose to achieve certain objectives. Organizations as includes political parties, firms, trade unions, and so on. It is the interaction between institutions and organizations that shapes the institutional evolution of an economy. If institutions are the rules of the game, organizations and their entrepreneurs are the players.

The neo-institutionalists' ${ }^{-}$such as NORTH, 1990, 1991 - idea of institution as a game ${ }^{32}$ was further refined by AOKI, 2007, pp. 6-7 who considered institution as self-sustaining, salient patterns of social interactions, represented by rules that every agent knows and are incorporated as agents' shared beliefs about how the game is played and to be played. He further added, 'institutions are humanly devised constructs and could be diverse, not being just a mechanical transformation of natural factors conditioned prior to game.' In this sense, institution is not an objective physical phenomenon, but a human mental construct ${ }^{33}$ (Ibid., p. 7).

\subsubsection{Institutional Change}

Institutions, the rules that govern interactions between people, change over time. Considering the process of change, institutions - the long, stable regulation of important processes in societies affect socio-economic life, and socio-economic life affects institutions (LANJOUW \& STERN,

\footnotetext{
${ }^{31}$ According to AOKI, 2000, p. 13, individual players are perfectly capable of deductive reasoning regarding a feedback mechanism between their own and other's choices.

${ }^{32}$ The 'game' concept of institution's is not new as (AOKI, 2000, p. 11) showed citing ADAM SMITH, 1775, Part 6, chapter 2 from his 'Wealth of Nations' states: 'In the great chessboard of human society, every single piece has a principle of motion of its own, altogether different from that which the legislature might choose to impress upon them'.

${ }^{33}$ For NORTH, 2000, p. 7, 'there is no such thing as laissez-faire. Milton Friedman is a great man, but we should realize that any society, economy, or polity is structured and the structure is a person-made function of the way in which we order the society.' He further says 'this structure is a complex mixture of rules, norms, conventions and behavioural beliefs, all of which together form the way in which we operate and determine how successful we are in achieving our goals.'
} 
1998). As stated earlier, institutions are subject to change, but these changes are slow, continuous, rapid, or irregular.

As a slow-moving institution ${ }^{34}$, culture - including values, beliefs, and social norms - evolves with changes in technology and scientific knowledge, which obviously plays an important role in understanding growth. Like culture, technology evolves slowly and continuously, although the pace may vary. Fast-moving institutions such as political institutions do not necessarily change often but can change more quickly - sometimes nearly overnight (ROLAND, 2004). Institutions change $^{35}$ or evolve because of various reasons, but the focus in this study is institutional response to socio-economic structures.

The increasing intrusion of modern principles of economy and a growing social mobility, new institutions become necessary as mechanisms that regulate the society, even at village level. There is always the need to examine whether the existing, mostly traditional institutionals are adequate for such adjustments, whether and in how far modern ones had been established and which driving forces accelates or hinders that change (RIEKEN, 1994).

\subsubsection{Past Studies in Changes in Rural Employment Structures}

KUMAR, 1996 documented changes in the structural and transitional aspects of distribution of land, employment, income, occupational diversification, poverty and living standards in Bhuvel village, Kheda district, Gujarat, India. This village was first surveyed in 1946 and then again in 1993. In both surveys, information was collected from all the households, adopting a census method of investigation. The survey showed declining trends in the male worker population ratio

\footnotetext{
${ }^{34}$ A multitude of exogenous and endogenous influencing factors induces the social changes. As an immanent component of the societal development processes, therefore, the institutions also undergo change. Institutions in this context mean economic, social, and political organizations, together with the rules that govern their interaction. A central concern of development economics is the analysis of changing economic and social institutions, the forces that shape them, and the outcomes in the levels and distribution of living standards. The study of change needs observation of individuals and communities at different points in time. The study of living standards involves knowledge of the circumstances of individuals. Despite their fundamental place in the process of enquiry into economic development, such data are rare. The rarity is understandable since those who would observe have finite and changing lives, and those to be observed may not stay still, remain alive, or wish to be followed (LANJOUW \& STERN, 1998).

${ }^{35}$ The way in which a society changes is a mixture of changes in formal rules, informal norms of behavior, and conventions and their enforcement characteristics (NORTH, 2000, p. 8). NORTH, 2000, p. 13, citing Russia as an example states 'In Russia, many of the formal rules were changed but there were no enforcement mechanisms, and the norms of behavior that evolved over time were inconsistent with these formal rules, producing the chaos and results that are apparent today.'
} 
but significant rise in the female worker population ratio. The major changes observed were: a reduction in the proportion of agricultural workers and increase in the non-farm employment; increasing feminization of agricultural labour; replacement of tenant and permanent labour by wage labour; within wage labour the growth of temporary and casual labour; and, inflow of migrant labour.

Chaudhry and CHAUdhry, 1992 explored the trends in rural employment and rural wages in Pakistan, and analysed the causes underlying these trends. The study concluded that growth of demand for labour in agriculture remained well above the increases in labour supplies throughout 1959-60 to 1984-85 and might have resulted in growing scarcities of labour and rapid increases in real wages in Pakistan agriculture.

RIEKEN, 1994 examining the same six villages in Northwest Pakistan as present, revealed the profound interactions and dependencies between rural development and the process of institutional change in non-agricultural employment. His study was motivated by the assumption that the increasing intrusion of modern principles of economy and a growing mobility need emerging new institutions to regulate society, even at the village level. There always remains the question whether the existing, mostly traditional institutions are adequate for such adjustment requirements, whether there exist modern ones and which driving forces are behind institutional change.

RIEKEN, 1994 study was planned as a follow-up ${ }^{36}$ of MOHNHAUPT, 1971 investigation on "Rural Population and Factory Work" concerning the same research villages in Northwest Pakistan. MoHNHAUPT, 1971 following a framework of differentiation between traditional and nontraditional occupations reported that only four percent of the labour force in the research area was employed in the industrial sector, while the fluctuation margin between the six villages was zero to fifteen percent. An immediate reason for this variance, which, to a certain extent only, was the result of distance between the residence and the place of work.

Mohnhaupt, 1971 and so as RIEKEN, 1994 observed a considerable degree of social hierarchy prevailing in the Northwest Pakistan as he states "somehow characteristic physical occupations, which are not connected with owner-cultivation, are always identified with the lowest social

\footnotetext{
${ }^{36}$ The two studies are not directly comparable as MoHNHAUPT, 1971 investigation in the area was concentrated on the extend and conditions of industrial workers while RIEKEN, 1994 took a broader approach by studying all the nonagricultural occupations in the area. The heavy industry lost its importance considerably in the 70es and 80es in Northwest Pakistan due to variety of reasons and hence to find a subject of greater structural relevance for the village level, RIEKEN, 1994 extended his investigation to include all the non-agricultural occupations not just factory workers.
} 
status." RIEKEN, 1994 further suggests that this results from "the association that an ascription of roles and status and societies characterized by agriculture only allows criteria of social position such as the amount of income to become important at a very slow pace and within the context of more radical changes in the economic framework conditions. Thus, access to traditionally known occupations which however, are connected with little prestige, is more limited than to such ones which, when taken up, require a long separation from family connections." MOHNHAUPT, 1971 also indicated several time in his study the poor prestige associated with factory work in Northwest Pakistan. According to him, this correlates with the extremely high fluctuation rate among new employees, precisely, but also among those who have been working for long, and with a high rate of absenteeism.

Exploring the reasons behind the prevailing underdevelopment in the Northwest Pakistan, RIEKEN, 1994 citing MOHNHAUPT, 1971 states "under the conditions of a completely unknown socio-structural environment, in the absence of sanction mechanisms going beyond the financial aspects- somehow a structural vacuum- even such terms as absence of contracts or products quality must lose their substance. In view of lack of mechanisms regulating the social organization, the workers' 'pressure groups' did not appear as trade unions but as 'informal groups' with autocratic leaders. Decisions made by these groups often had a greater liability for their members than eventually contrary own interests. This was reflected in the bulk enticement of whole gangs from one factory to the other."

The miserable levels of formal education and hardly available trainings as observed by MOHNHAUPT, 1971 also forced the factory managers in Northwest Pakistan to either renounce to employment qualifications or to resort to entice employees from other firms. The on-job training conducted by a few firms then were restricted only to the base necessities. Similarly, the qualified workers because of less perceived pressures and controls also preferred to work in cottage industries despite low wage and more working hours.

MOHNHAUPT, 1971 made two broad recommendations for labour market based on his study, the wage system be further differentiated according to performance and period of employment and a greater transparency for the workers in Northwest Pakistan.

MANIG, 1991 along with a team of German and Pakistani researchers analysed the results of the survey conducted in 1986/87 to highlight the institutional change processes in six villages in the vicinity of Peshawar. The survey results revealed that pure farming households lost relatively 
in significance while at the same time non-farm income earning households gained significance both absolutely and relatively in all of the six villages.

Of more than 1800 households in the six surveyed villages, approximately half derived their household income exclusively from non-agricultural jobs and around 37 percent from the combination agricultural and non-agricultural occupations. The group of non-agricultural households consists of businessmen households and the wage and salary earner households. The percentage of businessmen households increased from 14 percent to more than 17 percent.

\subsection{Conceptual Framework}

The present work apply a unique combination of cross-sectional as well as semi-longitudinal approaches to analyze the occupational structural and especially non-agricultural employment in Northwest Pakistan. The following sections consider the framework of the study starting with its cross-sectional element and followed by the theory behind processes of change in the rural employment structure in Northwest Pakistan.

\subsubsection{Framework for Cross-sectional Consideration of Empoyment Structure}

To study the livelihood strategies, the present study will focus on the livelihood income generating strategies pursued by the rural household in Northwest Pakistan. The whole study is summarized in Figure 7. The household, which is the basic unit of study, is equipped with various assets under the pressure and influence of venerability context, over which they have no or limited control. However, these households are endower differently with assets which is the main reason behind intra-household inequality.

The institutions (structure/processes) lie between the households' actual potential and their aspirations. These on one hand can make or unmake household assets and on other hand can define the range of livelihood income strategies on their disposal. Rural households' resource

allocation decisions are fundamentally constrained by conditions of livelihood assets endowment and related socio-political and institutional factors (BERHANU et al., 2007, p. 872). 
Figure 7. Conceptual Framework of the Study

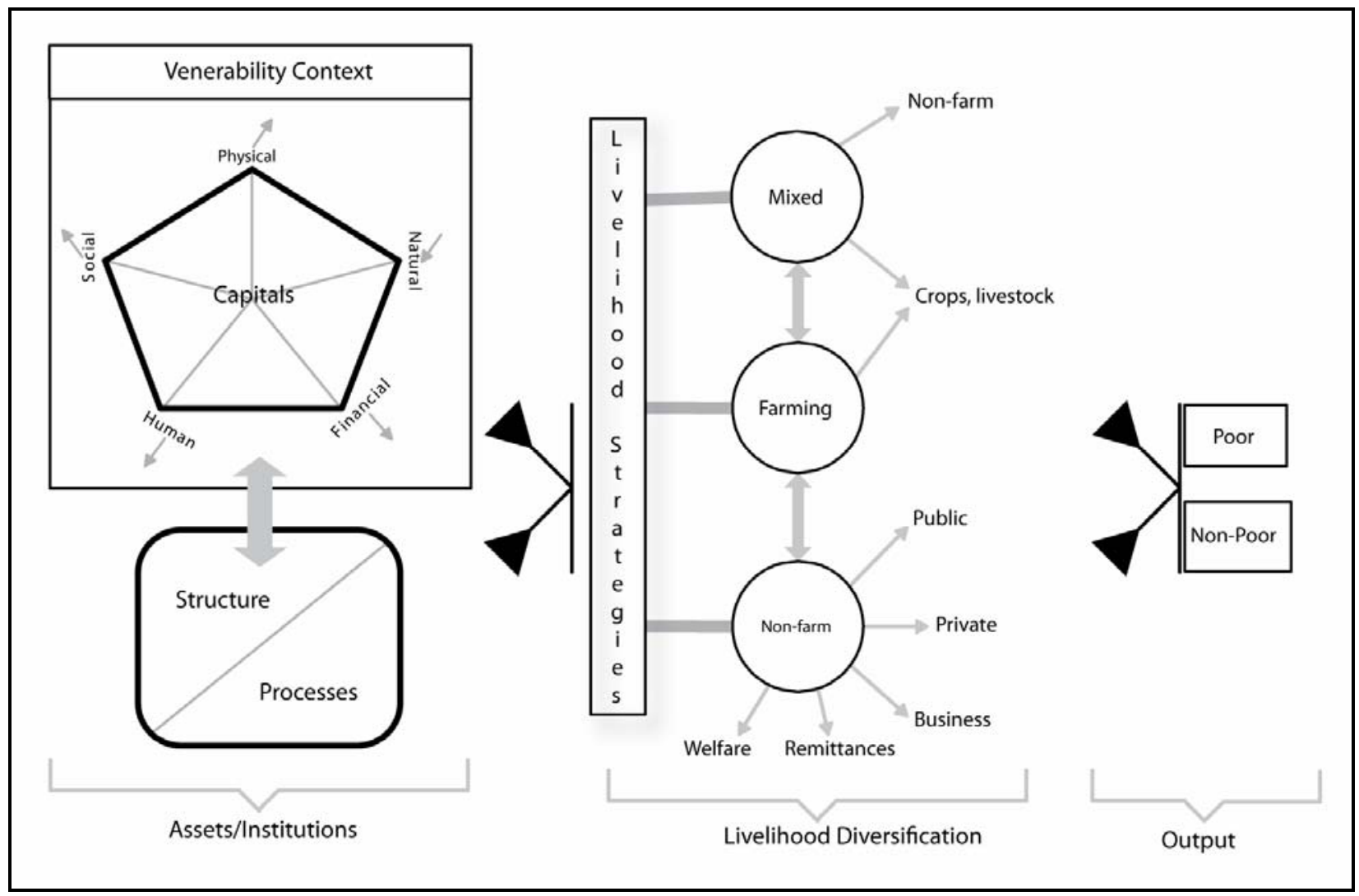

Source: Own figure

The livelihood choices pursued by the household members may be based on farm activities, nonfarm or a combination of both. The livelihood outcome is determined by the strategies pursued by the household, which in turn are defined by their assets situation. The resulting outcome (poor/non-poor) again directly influences the range of assets at their disposal.

The present study will explore the household employment strategies in rural Northwest Pakistan using a utility maximization household framework (JANVRY \& SADOULET, 1995, 2001). Using this household behavioural approach is justified on two fronts:

a) Both production and consumption decisions are interrelated at the household level (CAILlavet et al., 1994), and

b) The household characteristics within the imperfect markets play an important role in determining household behaviour (LÖFGREN \& ROBINSON, 1999). 
It is assumed that rural household, as an entity faces constrained utility maximization problem (JANVRY \& SADOULET, 1995) resulting in a labor supply function $(L)$, which depend on wages $(w)$, capital available to the household $(k)$, and household characteristics $(z)$ :

$$
L^{s}=f(w, k, z)
$$

Considering the labor supply function $(L)$, in terms of household's incentives ${ }^{37}$ and capacities (CORRAL \& REARDON, 2001), the study will analyze a variety of individual, household and community related factors, which influence one's decision to engage in a particular livelihood income generating strategy. These factors are diverse however; we limit their presence in individual, household, and village level variables in the six research villages in Northwest Pakistan. In addition, we are also examining the degree of diversification of these various income-generating activities and the emerging livelihood outcome.

Conceptually, the framework draws on the livelihoods approach ${ }^{38}$ (ELLIS, 2000), focusing on the portfolio of households' economic activities and the results of that diversity of activities in income and other measures for well-being. This approach to explore the facets of household livelihood, appear to be appropriate provided the complexity of the rural livelihoods (MANIG, 1991; AlbreCHT, 1976) in the study area Northwest Pakistan.

\subsubsection{Framework for Trend in Rural Empoyment Structure}

In rural Pakistan, there is a high degree of mutual but asymmetrical interdependency among the prevailing systems of household-family-farm and the village (MANIG, 1991). The mainly

\footnotetext{
${ }^{37}$ Following the behavioural model of CORRAL \& REARDON, 2001 households' incentives are "returns and risks" in the forms of prices of inputs and outputs, wages, and production risks. Similarly, for an incentive responding household, the capacities are assets representing household characteristics and their capitals like physical capital, social capital, and organizational capital. Households with better capabilities will response better to the available incentives. Hence, these are the incentives, which according to REARDON et al., 1998 will push or pull the individuals within the households towards labour markets.

${ }^{38}$ The conceptual framework follows the livelihood approach of DFID and other development agencies that put people at centre of development and is a way of thinking about the objectives, scope, and priorities for development. Hence people are viewed as performing in a context of vulnerability. Within this context, they have access to certain assets or poverty reducing factors. These gain their meaning and value through the prevailing social, institutional and organisational environment. This environment also influences the livelihood strategies that are open to people in pursuit of beneficial livelihood outcomes that meet their own livelihood objectives (DFID, 2001; ANNA, 2003; Steimann, 2004).
} 
privately owned production system in the traditional village system of Pakistan is based on a low degree of labour division and productivity (ALBRECHT, 1976; MANIG, 1991). The interaction under the influence of household-family-farm and the village system led to the exchange of resources such as labour, water, capital, etc. However, as already said, this interaction among different economic and social groups is asymmetrical with different bargaining powers and different advantages in their relationships. Take, for instance, the tenant-landlord relationship in rural Pakistan where inequalities are fixed in the form of institutions in the traditional village systems (MANIG, 1991; RIEKEN, 1994; SMITH et al., 1999). In the research area in Northwest Pakistan, the institutions are still general and undifferentiated (ALBRECHT, 1976; MANIG, 1991; RIEKEN, 1994) where the Pukhtun moral code 'Pukhtunwali' streamlines behavioural patterns and relations in the Pukhtun society (for explanation on 'Pukhtunwali' see Albrecht, 1976; AhMed, 1980; MAHDI, 1986; MANig, 1991; AMINEH, 2005, 2006; KHAN, 2007).

The relatively stable-looking institutional structures change ${ }^{39}$ under the influence and pressure of a multitude of factors (MANIG, 1991; RUTTAN, 2006) such as:

- demographic pressure,

- increased expectations among the population and their changes in demands,

- changing tendencies in commercialization,

- new technologies and innovations,

- government interventions and reaction-action to government policies, and

- an aggravation in the internal social tensions emerging from the interaction of the above-mentioned factors.

These intervening influential factors disturb the equilibrium of a stable-looking institutional structure forcing a change in the existing structures. Figure 8 summarizes the framework of rural institutions that, working as regulatory mechanism, governs the interaction between the people themselves and the environment surrounding them. These regulatory mechanisms enable a person to expect the answer to his behaviour and his activities (first level). This is followed by a certain degree of based behaviour and interaction patterns (second level), eventually standardizing the activities in a society (MANIG, 1991, pp. 18-19).

\footnotetext{
${ }^{39}$ According to NoRTH, 1990, p. 6. see also pp. 45, 83, 'institutional change shapes the way societies evolve through time and hence is the key to understanding historical change.' He believes that 'institutions typically change incrementally rather than in discontinuous fashion. How and why they change incrementally and why even discontinuous changes (such as revolutions or conquest) are never completely discontinuous are a result of the imbeddedness of informal constraints in societies... These cultural constraints not only connect the past with the present and future, but provide us with a key to explaining the path of historical change' (MANIG, 1991).
} 
Figure 8. Processes Behind Institutional Change

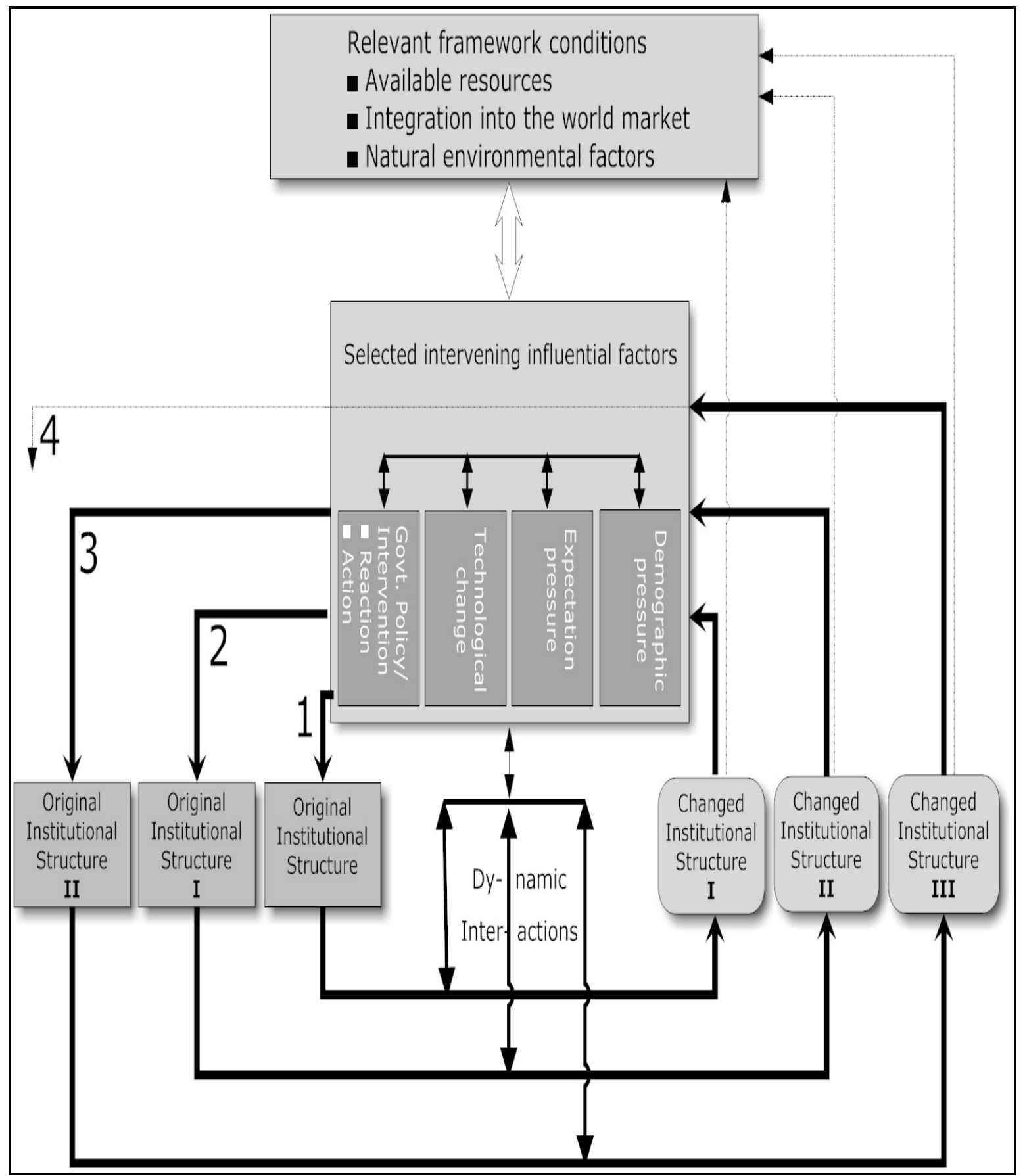

Source: Modified after MANIG, 1991, p. 20.

The 'pattern model' in Figure 9 represents through its basic elements a concise framework for the analysis of changes and transitions in a social economic system. Within this complex social 
system, the basic elements - according to MANIG, 1991, pp. 16-19 and RUTTAN, 2006 - show different modes of interdependencies such as:

- interdependence among the basic elements themselves such as technology, population, resources, and culture;

- interdependence among the basic elements and natural environment; and

- interdependence among the basic elements and other social systems.

Changes in one element induce complementary changes and adjustments in other elements, and this change process demands time (MANIG, 1991). Therefore, comparable changes in these specific elements bring about various complementary processes in diverse social systems.

Figure 9. The 'Pattern Model' Showing Basic Elements of Socio-economic System

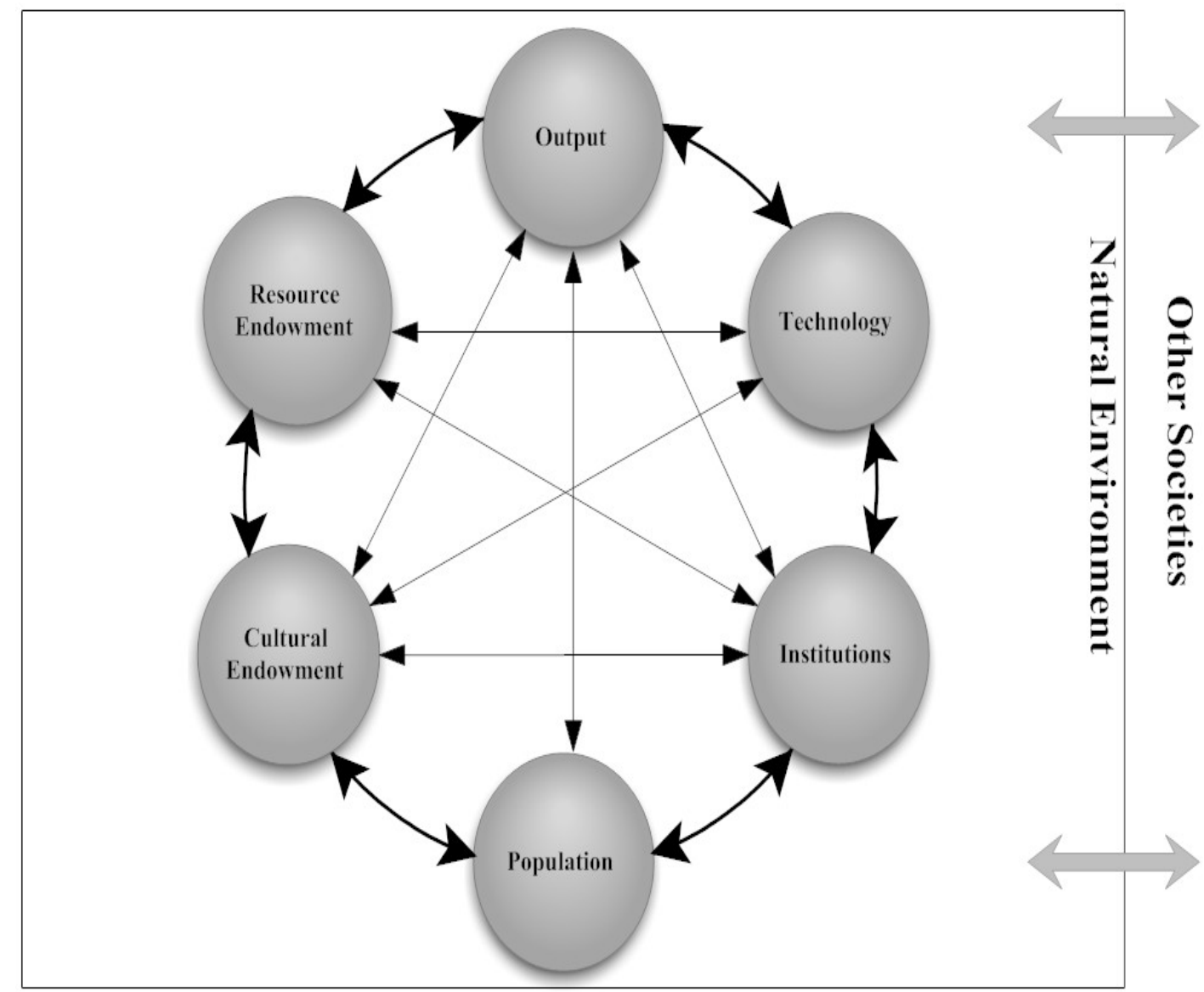

Source: Modified after MANIG 1991, p. 22 and RUTTAN, 2006, p. 264. 
Hence, the present study along with exploring the cross-sectional employment characteristics is also an inquiry into the changes in the occupational structure in rural Northwest Pakistan. As far as the sectors of production and distribution are concerned, the most important institutions should be analysed regarding their functions, structural organization, and the interactions especially between modern and old institutions ${ }^{40}$. For ascertaining and comparing these changes, the following four studies on rural institutions, carried out in 1967/68 and 1986/87, in the Peshawar district, are of particular importance:

- rual population and factory work (MOHNHAUPT, 1971),

- family, farm, and labour structure (ALBRECHT, 1976),

— stability and changes in rural institutions (MANIG, 1991), and

— institutions, culture, and non-agricultural activities (RIEKEN, 1994).

The following chapter discusses the sources on which this study is based, the basic survey, and the procedures used to collect and process the data. Further, the methodology applied to analyze the research questions is also provided at its end sections.

\footnotetext{
${ }^{40}$ With a view to characterizing development, the significane and, thus, the differences between agriculture and non-agricultural sector, but especially within the latter, will be explored regarding the production, employment, and income structure.
} 


\section{METHODOLOGY AND FIELD RESEARCH INSTRUMENTS}

This chapter covers the research methodology to investigate the objectives specified in chapter 1. The sections below starts with the discussion of field research instruments followed by demarcation of household categories, selection of villages and households, sampling procedures, and data processing details. The remaining sections in this chapter addresses the methodology used for research questions starting with the measures used for descriptive analysis of livelihood strategies in the area. Household diversity is analysed using Shannon, Simpson, and Dissimilarity indices. Descriptive analysis is also used to compare the changes in employment structure in the study villages over the years. Following sections concerns the logit and multinomial logit models applied to analyse the influencing factors on household diversity, povety, and occupational participation. The explanation of different poverty indices used in the study is also provided.

\subsection{Field Research Instruments}

The sections below describe the field surveys and the procedures the study used across the study villages. The section begins with the basic survey carried out in rural Northwest Pakistan as a part of a larger research project. The subsequent section provides a brief overview of the contents of the special survey.

\subsubsection{Basic Survey}

A large, census type rural household surveys ${ }^{41}$ were administered in six villages of district Peshawar, Northwest Pakistan. The same questions were administered to all households, but interviews were conducted in a semi-structured manner, allowing responses and follow-up questions as needed. A basic survey followed by a subject specific special survey formed the major tool for collection of primary data. The special survey was sampled based. Both of these surveys included a mix of both open-ended structured and unstructured, and closed-ended questions.

41 The basic survey was carried out in six villages of rural Northwest Pakistan as part of a larger research project. The results of this project based on basic survey appeared in KHAN, 2007. 
The basic survey starts with section on the identity and other socio-economic variables of the household head and its members (Appendix 4), while remaining ten sections are concerned with:

a) Farm status: owned land, land rented-in \& rented-out, and self cultivated;

b) Cropping structure: cultivated area along with crops grown in rabi and kharif;

c) Livestock situation: quantity of livestock owned by household;

d) Farm machinery: details of hired tractors and other farm implements;

e) Land tenancy: information about tenancy of irrigated and rain-fed land;

f) Credit profile: details of credit taken;

g) Farm products marketing: type, quantity, and location of farm product marketed;

h) Capital formation: household investment in land, housing, and machinery, etc.;

i) Agricultural employment: number of permanent or casual agricultural in a season; and

j) Non-agricultural employment: status \& duration of such jobs and multiple employment.

\subsubsection{Special Survey}

The households engaged in non-agricultural employment were interviewed intensively, in descriptive as well as explorative terms, through the Special Survey. The Special Survey was purposely designed in such a way to reveal the objectives of the present study. The investigation of trends and patterns observed in RNAE was a main objective of this study, which was revealed by the initial sections of the survey.

Data was collected on eight core topics, namely sectoral distribution of occupations, household assets profile, labour unions, education \& training, job conditions \& working relations, women employment, and information on social capital. Other areas such as migration \& remittances, housing, means of communication, are also covered in the survey.

The survey's occupational-sector component queried the household respondents about three dimensions of employment: first, their sectoral distribution; second, the characteristics of their occupations; and third, the recall of non-farm employment, particularly the reasons behind any change in employment and work related migration characteristics. An overview of the contents used in the special survey are given in Appendix 5. 


\subsection{Demarcation of the Household Categories}

Given that rural households are not homogeneous but dynamic entities, with diverse assets, capabilities and opportunities (ROVERE et al., 2006, p. 627), the categorization of households need to be simple and logical to help target our research questions. Creating socio-economic categories and types serves to structure certain phenomena in a complex social environment. As the categories are created according to predetermined criteria, there is an unavoidable loss of information about the characteristics that are not included in the categories, as well as the differentiation within the categories. By being very detailed when deciding the criteria, this loss of information can be reduced; however, this results in a weakening of the orientation character of the criteria. In a concrete situation, the creation of the categories fluctuates between these two poles, even if the goal behind the categorization is to achieve the purpose as far as possible (MANIG, 1991).

In the villages of Northwest Pakistan, it is a possible and, at the same time, an important form of economic and social differentiation to assign the individuals to certain socio-economic household categories as it also suits the social differentiation in the understanding of the people themselves. Naturally, there are also other differentiation criteria (for example, family, clan, and member of a specific lineage, among others). For the household categories to fulfill their role as an orientation and their character as a means of differentiation, the characteristics chosen for the categories have to be significant in the society being studied. As the selected household categories chosen from the analysis of the basic survey have to allow a comparison with the surveys in the same villages in 1967/68 and 1986/87, the same characteristics - which are relevant in Northwest Pakistan society - were chosen for the delimitations. An added goal was to make any qualitative ${ }^{42}$ changes between the two survey periods clear.

For the analysis of the survey in 1967/68, AlBRECHT, 1976, p. 40 classified the households in the six study villages in Northwest Pakistan according to various social and economic categories, whereby eight major characteristics played a role:

a) household organization,

b) main source of income,

c) additional income sources,

\footnotetext{
${ }^{42}$ Qualitative methods is a way to dig underneath apparent relationships derived from the quantitative data, in order to understand what the numbers are measuring or missing (ADATO et al., 2007, p. 247). Qualitative information was gathered through observational methods, informal group discussions, and key-informant individual interviews across the six villages.
} 
d) position of the earner of additional income in the household organization,

e) occupational social status of the main income earner,

f) occupational social status of the additional income earner,

g) size of the household income, and

h) types of assets.

In accordance with the characteristics and their combinations, ALBRECHT, 1976, p. 40 traced 28 different socio-economic household types; MANIG, 1991, p. 68, nevertheless, reduced it to 13 household types. As the present study is a continuity of the studies in 1967/8 and 1986/7, we used the same differentiation of household types as adopted by MANIG, 1991, whereby we wanted fewer characteristics for the delimitations. Figure 10 provides a detailed explanation of these household categories used in this study.

\section{The household categories were defined and delimited based on exclusion: 'present/not} present.' All the characteristics refer to the type of and access to land and other income sources found among the households that were combined to make up the categories:

- property rights for the land and power of disposition,

- livestock production as the main source of income, and

- non-agricultural occupations as the source of income.

Based on their livelihood diversity and strategies, local households in the research area were categorized into three major types: pure farmers who are involved in on-farm crop production or livestock rearing; mixed income earners who in addition to farming are also engaged in non-farm activities; pure non-farm households who are landless and mostly rely on wage-salary or business related activities.

The three broad categories were sub-divided based on criteria pertaining to respective category. For instance, pure farmers were split into landlords who rented all their land, households operating their own land, those running their own land along with rent-in parcels, tenants, and finally households relying only on livestock rearing. Sharecropping were given representation in the categories as they represents an important labour contract in the area where sharecroppers seasonally rent land, holding the rights over an agreed proportion of the harvest (mostly 5050 share in produce). The main characteristics of the household types and their sub-typologies are given in Figure 10. 
Figure 10. Delimitations of the Household Categories for the Study Villages

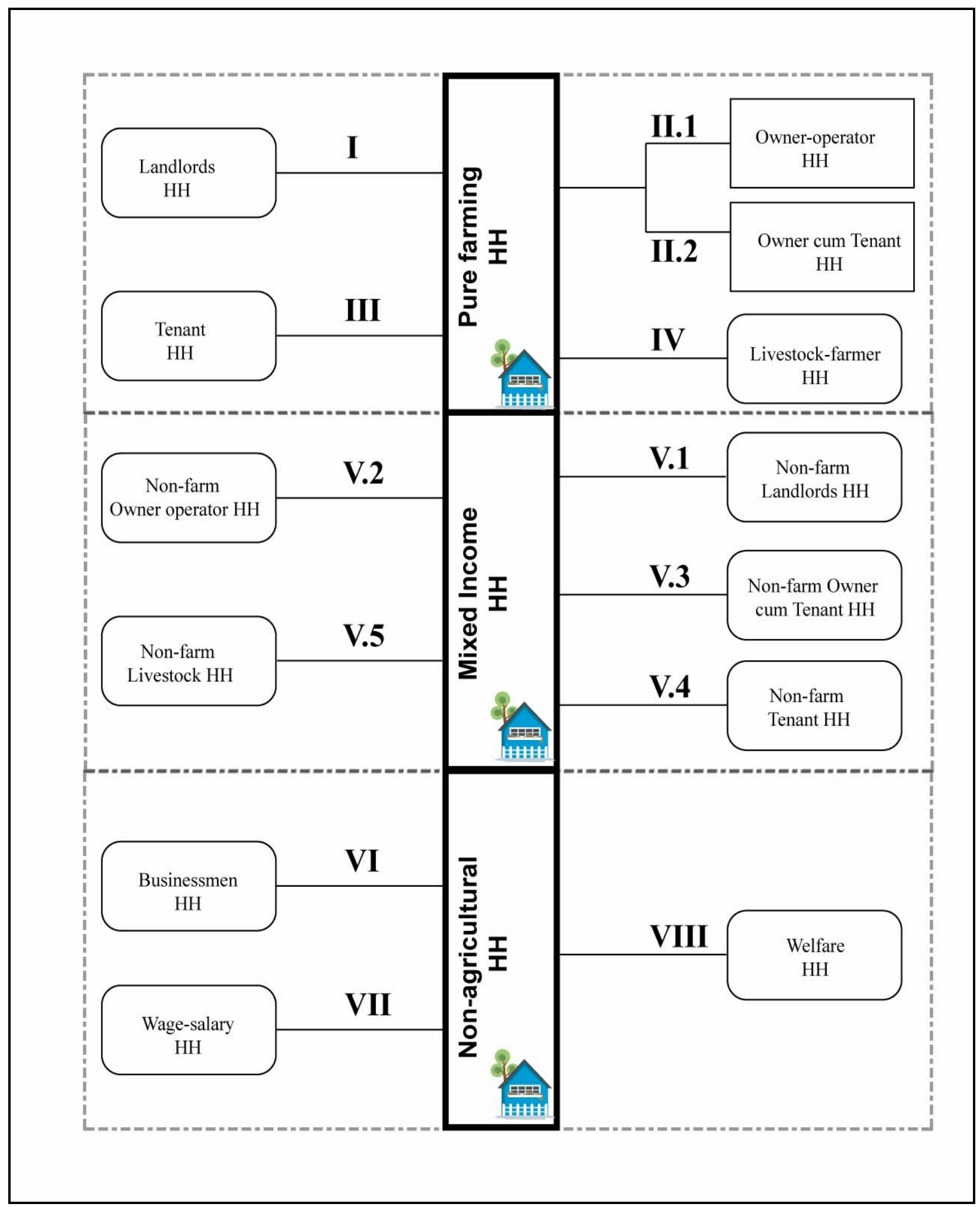

Source: Adjustment after MANIG, 1991 and ALBRECHT, 1976. 


\subsection{Selection of the study villages}

Much of the rural landscape in Northwest Pakistan still has a traditional touch at first glance, but some houses and businesses now have a comparatively prosperous appearance, both viewed from the outside and from the inside. However, the survey villages are located in a region ${ }^{43}$ characterized by a dismal performance in terms of social or economic indicators of development.

The study area includes six villages: Kukar, Dalazak, Mushtarzai, Yousafkhel, Gulbela, and Kochian in the district of Peshawar in the North West Frontier Province (NWFP ${ }^{44}$ ) of Pakistan, covering an area of 6880 acres (see Appendix 3). Peshawar is the eight biggest city in Pakistan with over one million population growing at annual rate of around 3.3 percent. Between March and September 2005, the household socio-economics were studied in the six villages in the district Peshawar, Northwest Pakistan, to explore how different households have fared over time in these regions. To adjust different fields of inquiry explored by the members of research team, it became necessary to select the research villages according to different socio-economic aspects. The six research villages in Northwest Pakistan were already selected in 1967-68 on the basis of the below-mentioned criteria:

a) role and influence of the provincial capital Peshawar in shaping the socio-economic conditions in the study villages,

b) land tenure system,

c) irrigation water supply, and

d) occupational structure.

To address the issue of geographic location variation in socio-economic context vis-à-vis livelihood opportunities, the six villages near Peshawar district were the foci of the research — two in the immediate vicinity of the major commercial area (Kukar \& Dalazak), two at mid-distance (Mushtarzai \& Yousafkhel), and the remaining two far away (Kochian \& Gulbela). Figure 11 shows the logic behind the selection of the individual villages in the district Peshawar, Northwest Pakistan. The villages were selected at different distances from and with different transportation linkages with the city of Peshawar, the economic and administrative capital of the region, to ascertain its sphere of influence (for details, see ALBRECHT, 1976; KHAN, 2007).

\footnotetext{
${ }^{43}$ The province of NWFP is among the most deprived in the country in terms of human development.

${ }^{44}$ The North West Frontier Province (NWFP) derives its name from its historical position in British India when it was carved out as a province in 1901. NWFP is the smallest of the four provinces of Pakistan and home to 15 million people (majority Pashtun) with a total area of $74,521 \mathrm{~km}^{2}$ administered by $\mathbf{2 2}$ districts.
} 
Figure 11. Criteria for the Selection of the Villages for the Surveys in Northwest Pakistan

\begin{tabular}{|c|c|c|c|c|c|c|}
\hline Selection Criteria & 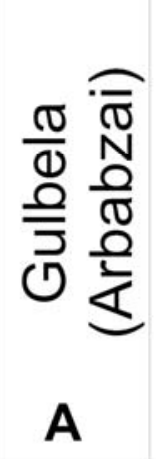 & 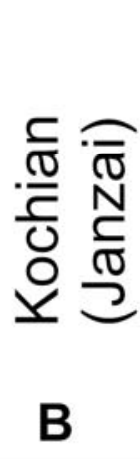 & 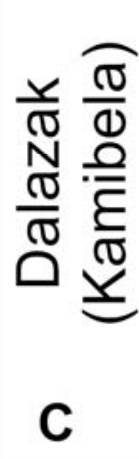 & 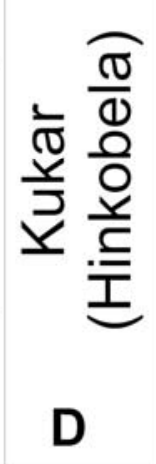 & 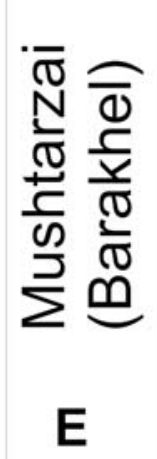 & 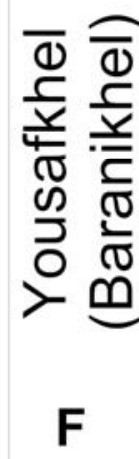 \\
\hline City Proximity: Close & 0 & O & $\nabla$ & $\nabla$ & O & O \\
\hline City Proximity: Remote & $\nabla$ & C & O & 0 & $\nabla$ & $\nabla$ \\
\hline Land Tenure: Own Operators & $\boldsymbol{\nabla}$ & 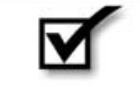 & O & 0 & $\nabla$ & ○ \\
\hline Land Tenure: Tenants & $\nabla$ & $\nabla$ & O & O & $\nabla$ & $\nabla$ \\
\hline Irrigation: Artificial & $\nabla$ & $\nabla$ & O & 0 & 0 & 0 \\
\hline Irrigation: Rainfed & 0 & 0 & 0 & 0 & 0 & $\nabla$ \\
\hline Occupation: Farming & $\nabla$ & $\nabla$ & O & O & $\nabla$ & O \\
\hline Occupation: Non-farming & 0 & 0 & $\nabla$ & $\nabla$ & 0 & 0 \\
\hline
\end{tabular}

Note: The research village names are given in vertical columns with names in brackets show their fictional names used in 1986/7 survey. Similarly, the 1967/8 survey refered to these villages with English alphabets (A-F). Source: Adjustment after MANIG, 1991 and ALBRECHT, 1976.

Two of the study villages, Kukar and Dalazak, are in the immediate vicinity (5-8 kms) of Peshawar city, while the rest of the four villages were located at a $16-23 \mathrm{kms}$ distance from the city. Transportation linkages and road conditions were very dismal in the remote tribal villages Yousafkhel and Mushtarzai. Villages were also selected on the basis of differences in the land tenure system, where Gulbela and Kochian were typical landlord villages. The average 
annual precipitation of only $400 \mathrm{~mm}$ in the area necessitated the selection of villages based on production factors such as irrigation. Finally, Kukar and Dalazak were selected in order to ascertain the role of non-agricultural employment in the rural economy.

Thus, comparing the villages might give an insight into how the local context influences the households' socio-economic conditions, their livelihoods, and the strategies for gaining these livelihoods. The six survey villages in District Peshawar, Northwest Pakistan, were not referred to by their real names in previous surveys of 1967/68 and 1986/87 to protect the data (see top row of Figure 11). Instead, fictional names were constructed and, interestingly, the name given in 1986/87 matched exactly the socio-economic, geographical, and agro-climatic conditions of these villages. For instance, Gulbela referred as Arbabzai because of presence of feudal families 'Arbabs,' while Kukar was given the fiction name 'Hinkobela' due to the prevalence of the Hindko speaking community. Similarly, Yousafkhel was named Barani khel ${ }^{45}$ because of its rainfed nature. As Mushtarzai was in the close vicinity of Bara Fort, it was given the fiction name of Bara Khel. The research team decided to use the real names for all six villages during the survey in 2004/05 in order to solve any identification problems for future research in this area.

\subsection{Unit of Study and Sampling Frame}

The household is a complex unit involved in a web of social relations and networks (ADATO et al., 2007, p. 259). In continuation with the previous surveys in Northwest Pakistan, the household, rather than the individual, was adopted as the basic unit of analysis, though data for individuals within a household was also collected (see for details ALBRECHT, 1976; MANIG, 1991). While it clearly makes more sense to take the household as a convenient basis for our study, it was necessary for analytical purposes to have figures that relate to individuals as these are the fundamental units that experience utility. The household which matches the Pathun concept of 'Kor' is defined as a group of people who live together under a common roof, use a common kitchen, are provided for from a common household budget (income pooling unit), and contribute to the common budget. While the head of household stood for that one member of a household who household members recognized him as the social-residential unit's main point of reference. When parents, brothers, and sisters comprise a household, either a parent or the eldest brother is generally reported as the head by the household. When a household consists of several related persons, either the respondent or the eldest household member is selected as the 'head.'

\footnotetext{
${ }^{45}$ Baran means rain, while Khel refers to clan in Pashto language.
} 
The basic survey was based on the voting list of the households received from the local Nazim office (Union Council) in the respective villages. A common drawback in empirical research in developing countries is the accuracy of administrative lists; as CASLEY \& LURY, 1987 mentioned, the administrative lists regularly contain flaws and suffer from the following shortcomings:

- they may include units that do not belong to population of interest (over coverage),

- exclude a unit that does belong to the population of interest (under coverage), and

- list the same unit several times.

However, for the present survey, the list was accurate because of its compilation for a popular purpose as everyone had an interest in registering for the voting list. The list was also not outdated as it was used in the recent local (Nazim) elections in the region.

\subsection{Selection of households}

There has been a major demographic growth in these villages since the last survey of 1986/7; therefore, a systematic approach was applied for the accurate administration of the basic survey questionnaire. Hence, for surveying purposes, we divided six villages into enumeration blocks, each block comprising between 100-150 households. The enumeration blocks reduced work load as the three PhD students along with locally hired enumerators were awarded certain blocks for surveying.

The use of the household as a sampling unit did not present any great difficulty as it coincides with the Pashtun concept of Kor (house). Once the Basic Survey was completed, a preliminary analysis of certain variables were made to provide an overview of the socio-economic situation of the surveyed villages and hence made us able to draw the sample for the Special Survey. Mainly due to financial and time constraints it was considered necessary to limit the size of the sample for special survey to 120 households (for details, see Table 1).

Once the Basic Survey fulfilled its purpose of identify those households engaged in pure non-agricultural employment and mixed income earning, it was followed by a Special Survey on non-agricultural employment. Now basic survey became a sampling frame for the special survey. As a first step the households in the basic survey in the six villages were divided into 
three groups or strata, namely only farming, households engaged in farming with non.farm jobs, and those involved only in non-agricultural employment. As the objective of the study was to analyse the non-agricultural employment hence we decided to select households engaged in only non-farming and farming with non-farm activities from the basic survey for all villages.

Table 1. Selection of Households for the Special Survey

\begin{tabular}{|c|ccccccc|}
\hline $\begin{array}{c}\text { Household } \\
\text { category }\end{array}$ & Dalazak & Gulbela & Kochian & Kukar & Mushtarzai & Yousafkhel & Total \\
\hline V1F & 1 & - & - & 1 & 2 & 1 & 5 \\
& $(5.0)$ & - & - & $(5.0)$ & $(10.0)$ & $(5.0)$ & $(4.2)$ \\
V1NF & - & - & - & - & 1 & - & 1 \\
& - & - & - & - & $(5.0)$ & - & $(0.8)$ \\
V2F & 3 & 1 & 1 & 1 & 3 & 3 & 12 \\
& $(15.0)$ & $(5.0)$ & $(5.0)$ & $(5.0)$ & $(15.0)$ & $(15.0)$ & $(10.0)$ \\
V2NF & 1 & - & - & - & 3 & 6 & 10 \\
& $(5.0)$ & - & - & - & $(15.0)$ & $(30.0)$ & $(8.3)$ \\
V3F & - & - & - & - & 1 & - & 1 \\
& - & - & - & - & $(5.0)$ & - & $(0.8)$ \\
V4F & 1 & - & 1 & - & - & 1 & 3 \\
& $(5.0)$ & - & $(5.0)$ & - & - & $(5.0)$ & $(2.5)$ \\
V4NF & - & 2 & 3 & 1 & 1 & - & 7 \\
& - & $(10.0)$ & $(15.0)$ & $(5.0)$ & $(5.0)$ & - & $(5.8)$ \\
VI & 5 & 3 & 4 & 6 & 2 & 1 & 21 \\
& $(25.0)$ & $(15.0)$ & $(20.0)$ & $(30.0)$ & $(10.0)$ & $(5.0)$ & $(17.5)$ \\
VIIF & 4 & 3 & 4 & 4 & 3 & 2 & 20 \\
& $(20.0)$ & $(15.0)$ & $(20.0)$ & $(20.0)$ & $(15.0)$ & $(10.0)$ & $(16.7)$ \\
VIINF & 5 & 11 & 7 & 7 & 4 & 6 & 40 \\
& $(25.0)$ & $(55.0)$ & $(35.0)$ & $(35.0)$ & $(20.0)$ & $(30.0)$ & $(33.3)$ \\
\hline Total & 20 & 20 & 20 & 20 & 20 & 20 & 120 \\
& $(100)$ & $(100)$ & $(100)$ & $(100)$ & $(100)$ & $(100)$ & $(100)$ \\
\hline
\end{tabular}

Note: Figures in the brackets represent the percentage of respective household category within a village.

For description of household categories, see Figure 10.

Source: Special survey carried out in six villages, 2004-05.

Random Sampling was used for the special survey in which the identification numbers of all the non-agricultural households were entered into SPSS and then each household category was 
awarded its due representative and proportional share in sample. The random sample utility in in SPSS (version 14) were used to select randomly 120 households for all six villages with each having equal share of 20 households in the special survey. The sample for special survey and the share of each household category within this sample is given in Table 1 which included:
a) the landlord households with non-farm jobs (hh-cat. V1F \& V1NF),
b) the non-farm owner operator households (hh-cat. V2F \& V2NF)
c) the non-farm owner cum tenant households (hh-cat V3F),
d) the non-agricultural tenant households (hh-cat. V4F \& V4NF)
e) the businessmen households (hh-cat. VI)
f) the pure non-agricultural households (hh-cat. VIIF \& VIINF)

\subsection{Sampling Weight}

Overall, a sample size of 120 was deemed sufficient to investigate the different facets of nonagricultural activities however, the number of households chosen in different villages were not proportional to the village share in total population. This required a need for using sampling weights in descriptive as well as econometric analysis with the aim to extrapolate results from sample to population in the six research villages. The weight for a village $i$ is being calculated as:

$$
W_{i}=\frac{\left[\frac{n_{i}}{N}\right]}{\left[\frac{s_{i}}{S}\right]}
$$

Where $\mathrm{n}_{\mathrm{i}}$ is the total number of sampled households in all the six villages, $\mathrm{N}$ refers to all the households in the study villages, $s_{i}$ is the number of households sampled in individual village, and $\mathrm{S}$ is the total household size in individual village. For example, based on the equation 1, one can compute the sample weight for village Kukar as:

$$
W_{i}=\frac{\left[\frac{n_{i}}{N}\right]}{\left[\frac{s_{i}}{S}\right]}=\frac{\left[\frac{120}{2825}\right]}{\left[\frac{20}{727}\right]}=1.544
$$


Table 2 provides the household size, sampled households, and their corresponding sampling fractions and weights. The use of weight corrected any issues of over or under-sampling in the random sample. These sampling weights were used in Stata $^{46}$ for descriptive as well as econometric analysis of special survey.

Table 2. Sampling Statistics of the Surveyed Villages in Northwest Pakistan

\begin{tabular}{|lccccc|}
\hline Village & $\begin{array}{c}\text { Total } \\
\text { households }\end{array}$ & $\begin{array}{c}\text { Relative fre- } \\
\text { quency in } \\
\text { population (\%) }\end{array}$ & $\begin{array}{c}\text { Surveyed } \\
\text { households }\end{array}$ & $\begin{array}{c}\text { Sampling } \\
\text { fraction }\end{array}$ & $\begin{array}{c}\text { Sampling } \\
\text { weight }\end{array}$ \\
\hline Dalazak & 380 & 13.45 & 20 & 0.053 & 0.807 \\
Kukar & 727 & 25.73 & 20 & 0.028 & 1.544 \\
Gulbela & 432 & 15.29 & 20 & 0.046 & 0.918 \\
Kochian & 459 & 16.25 & 20 & 0.044 & 0.975 \\
Mushtarzai & 539 & 19.08 & 20 & 0.037 & 1.145 \\
Yousafkhel & 288 & 10.19 & 20 & 0.069 & 0.612 \\
\hline All Villages & 2825 & 100.00 & 120 & 0.042 & \\
\hline
\end{tabular}

Note: Figures presented in the last two columns have been rounded to the next whole integer.

Source: Own calculations

\subsection{Survey Time and Response Rate}

The basic survey followed by a special survey was conducted between March 2005 and September 2005 across the six research villages. The research team was able to conduct this comprehensive survey because of the familiarity of authors with the local socio-economic conditions as all were brought up in Peshawar. The author along with two other doctoral candidates from Goettingen University Germany and four locally-hired male interviewers conducted the interviews while secondary, ${ }^{47}$ village-level socio-economic data were obtained from the local Nazim office, basic health units, school principals, and Statistics department Peshawar, Pakistan. Detailed field-notes were also taken which documented both the daily experience of the fieldwork as well as information learned through formal and informal conversations that were not included in

\footnotetext{
${ }^{46}$ Stata offers four types of weights: fweight, pweight, aweight, and iweight.

${ }^{47}$ Our interviews with the household heads were supplemented by semi-structured interviews with school teachers in Kochian and Dalazak, health officials in Gulbela, politicians, and state officials in different villages (see for details, KHAN, 2007).
} 
the interviews. The respondents (heads of the households) were interviewed in their local language Pashto ${ }^{48}$.

In order to gain support, publicize and encourage participation for interviewing local people, the research team met with the community representatives and the village notables. We enjoyed the hospitality, cooperation, and friendship of the people of the study villages from the first day. Some degree of privacy was attempted while administering the questionnaires.

The research team conducted around 2825 household interviews in all six villages, accounting for a 98 percent response rate. We had few incidents of refusal to interview mainly due to the Pashtun culture of respect for guests. Not included in the sample were fifty-two households which were either unwilling to respond or were not present at their homes or businesses when the interviewers visited. The numbers of refusal cases were distributed across the six villages as follows: Mushtarzai (20), Gulbela (12), Kukar (8), Yousafkhel (5), Dalazak (4), and Kochian (3).

The research team made every effort to gain the cooperation of the respondents by communicating the purpose of the survey and answering the respondent's questions. Luckily, the respondents were overwhelmingly willing to take part in the survey because of their awareness of the previous surveys conducted and its legitimacy. The interviews took place in both public and private settings like market places or intersections; in shops; and in hujra of influential people in the study villages ${ }^{49}$. The inquiry was mostly quantitative in nature, using a structured questionnaire. In addition, when specific topics warranted more discussion, qualitative information was also gathered. When possible, observations were also made of the respondents' living arrangements and surroundings. Discussions with men took place in both public and private locations; however, sometimes interviews with women were in or near their homes.

\subsection{Data Processing}

The data collected was checked for inconsistencies, coded, and entered into the computer using SPSS Data Entry Program, version 4 (SPSS Inc. USA). By making use of the Statistical

\footnotetext{
${ }^{48}$ Knowledge of the local language Pashto by the research team proved an invaluable asset during surveying as it removed any problem of misinterpretation.

${ }^{49}$ The research area has a strong purdah tradition, so just a handful of women were interviewed in Kukar and Gulbela. All of these interviewed women belonged to the poor households whose males were daily wage workers in other cities of NWFP.
} 
Package for Social Sciences (SPSS) program, version 15 (SPSS Inc. USA), the data were crosschecked, processed, and analyzed. The table module in SPSS was extensively used for tabulation purposes. The econometric analysis was conducted in Stata ver. 9.2 (StataCorp, USA). The majority of the graphs were constructed in Adobe Illustrator CS2, Stata, DeltaGraph ver. 5.6 (SPSS Inc. USA) and occasionally in SPSS.

The transformation of variables such as per capita income, household categories, land ownership, and poverty level were performed in SPSS and Stata. In addition, several other transformations were carried out for livestock, farm area, and income related variables. Besides descriptive statistics where necessary, relationships among the different variables were also examined through Pearson correlation ${ }^{50}$ (for further details, see RABE-HESKeth \& EveritT, 2004; HAMILTON, 2006). Econometric analysis like logit and multinomial logit regression were performed in Stata. Similarly, the post-estimation interpretation of the logit and multinomial logit models in Stata were performed using the package 'spostado' developed by LONG \& FREESE, 2001 at Indiana University, USA. Marginal effects in logit models were obtained by using the module 'prchange,' while 'fitstat' was used for other post-estimations such as fit of the model (for more details, see LONG \& FREESE, 2001, pp. 117-129). Multicollinearity diagnostic were computed by 'collin' module in Stata. Gini coefficient and Lorenz curves were constructed in Stata using modules such as 'ineqdec0,' 'Inequal7' and 'glcurve.'

\subsection{Analytical Methodology Applied to the Research Questions}

The following sections deal with the explanation of analytical methodology applied to solving the research questions outlined in chapter 1 . The applied methodology follows a mix of descriptive and econometric analysis. The beginning sections concerns the analytical procedures for household diversification and strategies in the area. Whether non-agricultural employment is agriculture-led or urban-led is the theme of subsequent sections. The descriptive profile of poverty along with econometric analysis of factors afftecting poverty is also discussed. Factors affecting employment choices is analysed using multinomial logit model. The final section addresses the methods used to trace the changes in occupational structure in the study villages.

\footnotetext{
${ }^{50}$ The Sidak adjustment method was used for p-values (justification of this method is given in HAMILTON, 2006, pp. 171-175).
} 


\subsubsection{Research Methodology for Income Generating Strategies and Livelihood Diversity}

\subsubsection{Methodology for Diversification Strategies across Households and Villages}

The first research question entails a descriptive as well as an explorative analysis portraying the diversification strategies across villages and households within villages. This enquiry will descriptively highlight the diverse economic activities performed by the households, for instance, farming, non-farm employment, mixed income earners, and self-employment. The analysis will help us in labelling the livelihood income generating strategies adopted by the members of the household in the six villages as survival or accumulation. If majority of the household members are engaged in low paid informal economy then the strategy is definitely survival.

The study will also quantitatively investigate the CHAYANOV concept of household strategies. CHAYANOV mentioned in EMIGH (2001) proposed that adults in households with high dependency ratio work longer hours and produce greater output than adults in households with a low dependency ratio. Workers in a household with a high dependency ratio must work longer to provide for other members of the households. If CHAYANOV's theory motivates household strategies, household output per worker should be greater when the dependency ratio is high than when the dependency ratio is low.

The CHAyANOV concept of household strategies demand using Pearson correlation between dependency ratio and output per worker. Dependency ratio here refers to number of consumers (dependents) divided by numbers of workers while output per worker means household monthly income divided by the number of working members in the households.

\subsubsection{Household Diversity Indices}

Diversity is used as a measure of variation for the households in the study area. There are various ways of measuring diversity; however, this section is confined to the most common of these measures, namely Simpson index, Shannon entropy, and Dissimilarity index. These measures have their roots in biology and ecology (MCBRATNEY \& MinASNY, 2007). Considering our 
objective of assessing the extent of diversity in household income, we used Simpson Index (D). The index according to MCBRATNEY \& MiNASNY, 2007 is easy to compute and interpret, as follows:

$$
D=\sum_{i=1}^{s} p_{i}^{2}
$$

With $0 \leq \mathrm{D} \leq 1$, values near zero corresponding to a highly diverse system, and values near one corresponding to more homogeneous system. So, the closer to 1 less diverse the respective household category is, in term of income.

To examine the degree of diversification across the household categories the study used the share of household category income in total household income. Shannon's entropy or diversity index is applied to reveal the diversity in household category in terms of their income. Shannon's entropy $(\mathrm{H})$ is commonly used in ecological studies to accounts for both abundance and evenness of the species present in an area (MCBRATNEY \& MinASNY, 2007). Following SCHWARZE, 2004; and SCHWARZE \& ZELLER, 2005 we adjusted to our purposes the Shannon's index as follows:

$$
H_{\text {HHincome }}=-\sum_{i=1}^{s}\left[\left(\text { incshare }_{i}\right) \cdot \ln \left(\text { incshare }_{i}\right)\right]
$$

where $\mathrm{S}$ is the number of income sources and incshare ${ }_{i}$ the share of income from activity $i$ in total household income. The Shannon index considers both, the number of income sources and their evenness. It is calculated for every household category and increases continuously with higher diversity.

Finally, Index of Dissimilarity is an indicator of segregation (SCHULZ et al., 2002). This shows the extent to which different household categories in their income are separated from one another. The index has the range of 0 to 1 , with values close to 1 showing that a household category is economically separated from the other category while the closer the value to 0 , the more the categories are mixed together. These indices were computed in Stata (ver. 9.2) using the 'ineq' module developed by NicHOLAS J. COX. 


\subsubsection{Logistic Regression for Household Diversity}

Rural livelihood diversification can imply a change from agricultural to non-agricultural activities (BODIL \& LENNART, 2001). Therefore, to explore the degree of diversification and the factors stimulating or impeding it in the six study villages, logit analysis is employed. For the households in the research villages, the dependent variable is specified as whether the household has or has not diversified (binary categorical variable). Households are classified into two types, non-diversified and diversified through non-agricultural activities. As the main interest of the study is diversification, those households engaged in pure non-farm activities were excluded from the analysis. An almost similar approach was used by SCHWARZE \& ZELLER, 2005 to investigate the determinants of household diversification in Indonesia. The independent variables were selected after a thorough review of the literature on agricultural diversification. As there are only two options, hence the logit applied for the households consider diversified households (mixed income earners) relative to non-diversifiers (pure farmers). The coefficients measure the change relative to non-diversifiers. The model can be formulated as:

$$
\operatorname{Pj}=\operatorname{Pr} o b(y=1)=\frac{e^{x \beta}}{1+e^{x \beta}}
$$

The relative probability of $\mathrm{y}=\mathrm{j}$ to the base category is calculated as:

$$
\frac{\operatorname{Pr} o b(y=j)}{\operatorname{Pr} o b(y=1)}=e^{x \beta}
$$

The results of the logit model help identify factors significantly affecting diversification, and provide general insights into farm diversification in rural Northwest Pakistan. The explanatory factors in the logistic regression of household diversification choice could be categorised as household level attributes which include household demographic characteristics, asset endowments, and access to opportunities and infrastructure represented by village dummies. To be specific these are represented by the explanatory variables of education of the household head (EDU), age of the household head (AGE), household size (MAL \& FEM), size of household workforce (HHW), household assets (LND \& LVK), and village dummies (FVL \& NVL).

It is hypothesized that the household's relative diversity status will be determined by: 
a) the household's endowments of both physical and human productive resources, the most important of which are enough supplies of farmland, and of family labour to work in the non-farm sector;

b) the formal educational attainments of household head, higher levels of which may be positively related to managerial ability on the farm as well as improved access to off-farm wage or business related employment opportunities locally or abroad;

c) the age of the household heads which proxy their experience and we further assume the younger generation to be more innovative;

d) the stock of capital assets employed on the household disposal, which may include livestock;

e) the dependency load in the household, as defined by the number of female in the households. Given the traditional nature of society in Northwest Pakistan plagued by miserable female literacy and employment we expect an increasing stress on the households with more females to diversify; and

f) the state of infrastructure and economic opportunities offered by the locality captured by village dummies will also play a decisive role in households diversification decisions.

\subsubsection{The Analysis of Agriculture and Urban-led Influences in Non-farm Employment}

The second question examines analytically an important branch of enquiry not investigated in previously projects, the role of agriculture and urban centre in shaping non-agricultural employment in the study area. For the first part of this question that is the role of agriculture, we make use of an intercorrelation matrix for the following variables at village level obtained from the basic survey:
a) Non-farm workers of all workers (NFRMLAB);
b) Employment rate in village (EMPRATE);
c) Ratio of actual farm acres/ no. of farmers (FRMFRMER);
d) Ratio of agri. laborers to farmers (AGRLAB);
e) Literacy in village (EDURATE);
f) Tropical Livestock Unit (LIVESTOCK);
g) Actual farm area in acres (FRMAREA);
h) Actual irrigated area in acres (IFRMAREA); and 
i) Distance of research village from provincial capital Peshawar in kms (URBANEF)

We selected these variables because economic theory suggests that villages which combine a high proportion of cultivated area, high cultivated area per cultivator and a high incidence of irrigation would generate relatively higher agricultural incomes, which means a higher demand (largely based on consumption behaviour of agriculturists) for goods and services produced by the local non-farm sector. Participation rate in the non-farm sector is also an indication of the role of agriculture in the village economy while surplus labour in agriculture will compel labourers to seek work outside agriculture (EAPEN, 2001, pp. 77-83). Similarly those villages close to town will be more responsive to economic stimuli than those located remotely. Hence, for the study of urban influence, we divided the research villages into 'extension', 'midlevel', and 'tribal' villages based on their distance from the provincial capital Peshawar.

\subsubsection{Methodology for Measuring Poverty in the Area}

\subsubsection{Determination of Headcount Index, Poverty Gap, and Severity Index}

Besides measuring the income inequality and Lorenz curve for the rural households, the study also attempts to calculate the incidence, severity, and depth of poverty in the research area. The headcount index $\left(\mathrm{P}_{\mathrm{o}}\right)$ is the proportion of the population with income less than the poverty line $(q / n)$. Although it is simple to construct and easy to understand nevertheless this index ignores differences in well-being between different poor households. It assumes all poor are in the same situation without taking the intensity of poverty into account. Although this index yields a measure of the prevalence of poverty by classifying households as poor or not poor, however, it does not describe the depth and severity of poverty experienced by poor households (WEISE, 2006, p. 11) necessitating the use of poverty gap index.

The depth of poverty is captured by the 'poverty gap' measure, which is the difference between the income (or consumption) of a poor individual, and the income (or consumption) poverty line as a proportion of the poverty line, aggregated for all of those in poverty and then divided by the total population (COULOMBE \& MCKAY, 1996; HARGREAVES et al., 2007). It indicates the per capita measure of shortfall in the welfare of poor from the poverty line. They show how much would have to be transferred to the poor to bring their income up to the poverty line. It has policy implications as it indicates the "minimum" cost for eliminating poverty with transfers (the 
cost to eliminate poverty with perfect targeting of the poor and no targeting costs or distortion effects). The mentioned two indices ignore the inequality among the poor and hence the poverty severity index comes into play. Squared poverty gap or simply poverty severity is a variant of the poverty gap that reflects distribution within the poor in a way that the larger gaps are given a greater relative weight in the indicator.

The headcount index, the poverty gap, and the poverty severity index all give different focuses to poverty related policies and belong to the Foster-Greer-Thorbecke class of measures (COulombe \& MCKay, 1996). These commonly used $P_{\alpha}$ classes of indices are defined as follows:

$$
P_{\alpha}=\frac{1}{n} \sum_{i=1}^{q}\left(\frac{z-y_{i}}{z}\right)^{\alpha}
$$

where individuals have been ranked from the poorest $(i=1)$ to the richest $(i=n$, where $n$ is the population size), where $y_{i}$ is the standard of living measure for individual $i, q$ is the number of individuals defined to be poor and $\alpha$ is a parameter reflecting the weight placed on the living standards of the poorest among the poor.

\subsubsection{Estimation Methodology: Logit Regression for Determinants of Poverty}

The endowment of various assets were econometrically analyzed to predict their role in the shaping of household livelihood outcome (Question 3). Instead of calculating a new poverty line to classify households as 'poor' and 'non-poor', the study followed the poverty line ${ }^{51}$ estimated by Planning Commission, government of Pakistan. In order, to analyze the asset position at household level we relied heavily on DFID assets pentagon approach ${ }^{52}$.

By controlling for many factors, multivariate analysis enables a clearer understanding of the nature and determinants of poverty than can be obtained from examination of summary poverty

\footnotetext{
${ }^{51}$ The official poverty for Pakistan is estimated on 2350 calories per adult equivalent per day. This is based on an adult equivalent intake of 2150 calories in the urban areas and 2450 calories in the rural areas. The poverty line for Pakistan for FY1999 on this basis has been defined at Rs. 670 per capita per month (ADB, 2002). After taking into consideration the inflationary changes between the said periods, the poverty line at the prices of 2004 is estimated at Rs 848.798 per adult equivalent per month (GOVERNMENT OF PAKISTAN, 2004).

${ }^{52}$ For more details visit site: http://www.livelihoods.org
} 
indices (BAULCH \& MCCULLOCH, 2002, p. 169). To test the hypothesis about the role of assets endowment on the poverty of household, the application of Binary Logistic Regression ${ }^{53}$ is considered most appropriate. To find determinants of poverty, we first need to define who the poor are. Although the definition of "poverty" has become increasingly broad and heterogeneous in international debates, and is itself the subject of many studies . Nevertheless, following a conventional income based definition of poverty, we defined a poor household ${ }^{54}$ as one whose income fall below the poverty line ${ }^{55}$. We justify the use of the income-based definition ${ }^{56}$ of poverty on three major grounds:

- Firstly, it centre on the inability to earn a certain minimum bundle of goods which lies at the core of many definitions of poverty,

- Secondly, it easily splits the population into mutually exclusive categories, and

- Finally, collecting information on income was simple compared to consumption patterns of rural households suffering from besides recall problems and a lack of clear and agreed basket of goods to construct poverty line using the cost of basic needs methods.

Using Logit model, we analyzed the static correlates of poverty in a multivariate framework. A dichotomous variable representing whether a household is poor $^{57}$ is regressed on a set of explana-

\footnotetext{
${ }^{53}$ Since the response variable is dichotomous, it is inappropriate to assume that they are normally distributed, thus most suitable method to use for analyzing such data is binary logistic regression. Similar approach was used by SteVe et al., 2002 and BAUlCH \& MCCUlLOCH, 2002 for the study of determinants of poverty in Mexico and Pakistan, respectively. A possible alternative is the Probit Model but as GreEne, 2003; MAdDALA, 1999; and WOOLDRIDGE, 2003 acknowledged that the logistic model based on the Cumulative Logistic Function is computationally easier to use than other types and hence was decided its use in this study.

${ }^{54}$ Poverty is fundamentally a phenomenon arising at the level of households and of their members, and so its measurement and characterization ideally requires the availability of a suitable, representative data set at the household level (ZELLER et al., 2006).

${ }^{55}$ To frame the conventional practice in poverty analysis 'poverty line' is simple. First, a basket of goods and services is constructed that matches with local consumption patterns to satisfy a pre-set basic needs for one person. Then this basket is valued at local consumer prices to calculate its minimum cost. The household is considered poor if their per-capita or per adult-equivalent income is below the poverty. If this does not hold true, the household is classified as being non-poor (BAULCH \& MCCULLOCH, 1998).

${ }^{56}$ The consumption as well as multi-dimensional based approaches to define poverty are also common in literature . For instance, in order to capture the multiple dimensions of poverty according to ZELLER et al., 2006 development practices based on qualitative and quantitative indicator variables suggest three major types of poverty assessment tools:

a) Computation of a poverty line and various poverty measures taking into account the way in which actual household expenditures fall short of the poverty line;

b) Ranking households by their wealth relative to other community members using rapid appraisal and participatory appraisal tools; and

c) Construction of a weighted poverty index using a range of qualitative and quantitative indicators.

${ }^{57}$ As no absolute poverty line exists currently for the research area, for this study the poverty line was set at line used by government of Pakistan in 2004-05, which was Rs. 849 per person per month. To be specific the dependent
} 
tory variables $\mathrm{X}_{\mathrm{n}}$ (Table 27). If we denote household $i$ as poor $\left(P_{i}=1\right)$ and non-poor as $P_{i}=0$, then following GREENE, 2003 and GUJARATI, 2003, the Binary Logistic Regression, where there are several predictors variables $(\mathrm{Xn})$ from which the probability of $\mathrm{Y}$ is predicted is provided by a cumulative logistic distribution function as given in equation (1).

$$
P_{i}=\mathrm{E}\left(\Upsilon=1 / \chi_{i}\right)=\frac{1}{1+e^{-z}}
$$

where $\mathrm{Z}=\beta_{0}+\beta_{1} \chi_{1}+\beta_{2} \chi_{2}+\ldots \ldots . .+\beta_{n} \chi_{n}+\varepsilon_{i}$

Where $\mathrm{P}_{\mathrm{i}}$ is the probability of $\mathrm{Y}$ occurring, $e$ is the base of natural logarithms (approx. 2.718), and other coefficients from a linear combination much the same as in multiple regression equation. If $\mathrm{P}_{\mathrm{i}}$ is the probability of being a poor household as given in equation $(2)$, then, $\left(1-P_{i}\right)$, the probability of being non-poor household, is:

$$
1-P_{i}=\frac{1}{1+e^{z}}
$$

Therefore, we can write:

$$
\frac{P_{i}}{1-P_{i}}=\frac{1+e^{z}}{1+e^{-z}}=e^{z}
$$

Where $\mathrm{P}_{\mathrm{i}} / 1-\mathrm{P}_{\mathrm{i}}$ (odd ratio) indicates the ratio of the probability of a household being 'poor' to the probability of a household being 'non-poor'. What variables should be included in $\mathrm{X}_{\mathrm{i}}$ ? Considering the economic theory and local socio-economic conditions, we assume that the determinants of poverty in the study villages are as follows:

a) Education and training: Here we used five variables: years of education of household head (EDU) and his months of training (TRBJB), number of household members with 5-8 years education (WRED58), household members with 10-12 years literacy (WRED1012), and those household members with graduation (WRED14).

variable was one for poor households (real income per household member less than Rs. 849 per month) and zero otherwise. 
b) Demography: Three variables were used: household size (HHS), household head age in years (AGE), and household dependency ratio (DEPRATIO).

c) Household labour: The diversity of household occupational structure in the study villages demanded five set of variables: number of farmers (JBFR), household members in casual jobs (JBCR), those in permanent private regular jobs (JBPE), number of businessmen at household disposal (JBOB), and finally government employees (JBGE).

d) Household assets: Household with own transport (TRANSOWN), own telephone (INASN), pacca/semi pacca house ownership (INHSL), size of house in marla (INHSS), livestock ownership in TLU (LOGLVSTKUNT). As there is a tendency to associate poverty with the landless (HUSSAIN et al., 2003; PERERA et al., 2005), so we introduced the variable on household land ownership in acres (OWNLAND).

e) Household Expenditure: Dummy of annual household expenditure in Pakistani rupees on festivities (CACRDUM).

f) Infrastructure: Village dummies were introduced for all the six research village with Mushtarzai serving as reference village to capture the numerous characteristics of a region associated with poverty. The relationship of these characteristics with poverty is village specific. We expect poverty to be high in areas characterized by geographical isolation, insecurity and internal conflicts, and a low resource base. In addition, inadequate public services, weak communications and infrastructure, as well as underdeveloped markets can also contribute to poverty.

The assumption that these variables are all exogenous to the rural poverty could be questioned. This is a matter of judgment, recognizing that dropping a variable because of a fear of possible endogeneity could create an even bigger problem of omitted variable bias. However, the model dropped the variable on household credit ${ }^{58}$ due to endogeneity problem.

\footnotetext{
${ }^{58}$ According to BANERJEE \& DUFLO (2007) rural extremely poor households in Pakistan have an outstanding debt around 93 percent with few of these households getting loans from a formal lending source.
} 


\subsubsection{Estimation Methodology for Multinomial Logit Model: Factors Influencing Occupa- tional Choices}

The fourth question is aimed at highlighting not only the occupational activities of the respondents but also the factors influencing household decision ${ }^{59}$ to engage in these diverse occupations. The previous research projects in the proposed six villages in Northwest Pakistan differentiated more than 200 jobs or occupations that were classified into different occupational categories (MANIG, 1991, p. 57). Hence, based on these studies, we considered seven broad occupations in the study area: private permanent employees; public sector employees; informal private wage labor; own enterprise activities; farming; and other remunerated activities.

Factors considered important in determining the occupational choice model are included as regressors, which in fact reflect the heterogeneity of incentives and constraints facing household occupational decisions. Some of these regressors merit comments. We expect individual characteristics (age, education) to strongly influence activity choices (although decision making may not be exclusively individual in this part of the world!). We expect the youngest to engage in non-farm sector due to its demand of muscles. We expect that after a certain age, individuals are more likely to retire, move out of the labour force. Therefore, to capture such possible nonlinearity or life cycle for participation in different occupations we also introduced the square of age. Due to prevailing cultural-religious trends ${ }^{60}$, we expect engagement in various occupations to be clearly a male activity therefore gender was not included as regresser in the analysis.

Education as a variable will reflect the stock of skills at household level. We expect a positive and significant association between education levels and jobs in the organized sector at the household levels as shown by a number of studies in different developing country contexts (REARDON et al., 2000). Better educated individuals are likely to possess skills and aspirations to working outside agriculture which facilitate successful involvement in non-farm activities. In contrast, the usefulness of formal education for successful participation in the rural labor market is not always evident as the skills required to engage in many rural activities are either very simple or acquired outside the formal school system, through relatives and friends or on-the-job training. The formal educational system of Pakistan is having a traditional and narrow focus on academic disciplines, resulting in deficient technical and life skills for students.

\footnotetext{
${ }^{59}$ SCHUTZ, 1964 as mentioned in CAMILLA et al., 2000 demonstrated that rural people in developing world considered as traditional, illiterate and steeped in irrational practice are in fact conscious and reasoning decision makers, aiming to achieve certain goals in face of a set of constraints.

${ }^{60}$ An excellent description of Pathan society is given in ALBRECHT, 1976 and MANIG, 1991.
} 
The role of household size is vague as on one hand it may supply more economically active adults but what be the case when there is a high dependency ratio? To account for the labour resources at the household level, the variable on number of economically active members is also introduced. A high wage rate in other sectors makes the farming unattractive. However, due to possible endogeneity problems, we did not consider the effect of income on economic participation. Similarly, higher landholding and livestock ${ }^{61}$ units may not only broaden the choices for households to engage in formal sectors but it may also encourage them to specialize in farming. Finally, in order to capture the effect of the geographical variation, we introduce village dummies in the econometric model. It will take account of the availability of hard as well as soft infrastructure available to individuals living in these villages.

To identify the determinants behind rural household decision to engage in various occupations in Northwest Pakistan we assume that in a given period rational ${ }^{62}$ household choose among the seven ${ }^{63}$ mutually exclusive occupational alternatives that offers the maximum utility ${ }^{64}$. Following GreEne, 2003 and KenNedy, 2003, suppose for the ith respondent faced with $\mathrm{j}$ choices, we assume the utility choice $\mathrm{j}$ as:

$$
\mathrm{U}_{\mathrm{ij}}=\mathrm{Z}_{\mathrm{ij}} \beta+\varepsilon_{\mathrm{ij}}
$$

If the respondent makes choice $\mathrm{j}$ in particular, then we assume that $\mathrm{U}_{\mathrm{ij}}$ is the maximum among the $\mathrm{j}$ utilities. Hence the statistical model is derived by the probability that choice $\mathrm{j}$ is made, which according to MADDALA, 1999 is:

$$
\operatorname{Prob}\left(\mathrm{U}_{\mathrm{ij}}>\mathrm{U}_{\mathrm{ik}}\right) \text { for all other } \mathrm{K} \neq \mathrm{j}
$$

We further assume that the random utility error terms are distributed independently and identically as log weibull distributions. Further, we have information on several characteristics of the employment decision makers therefore, we can make use of the multinomial logit model (LONG

\footnotetext{
${ }^{61}$ Livestock can also act as a substitutable asset that can be sold in order to invest in land or small businesses, and vice versa (ELLIS \& FREEMEN, 2004).

${ }^{62}$ The behavioural notion of the model may be invoked here by considering rural households in the research villages as rational decision makers.

${ }^{63}$ The research projects of 1967/68 and 1986/87 conducted by IRE, Goettingen University Germany in rural Northwest Pakistan identified these broad occupational categories. See for details MANIG, 1991. Implying the multinomial logit model will be inappropriate whenever two or more of the alternatives are close substitutes (KENNEDY, 2003) hence; we reduced the number of categories to six to avoid this situation.

${ }^{64}$ Utility is maximised by expected earning gains from adopting an activity profile choice (BERHANU et al., 2007).
} 
\& FREESE, 2001; KENNEDY, 2003). We select this model not only because of the computational ease $^{65}$ (MILLER \& VOLKER, 1985) but also multinomial logit ${ }^{66}$ analysis exhibits a superior ability to predict occupational distribution ${ }^{67}$ (KEANE, 1992). While Probit versions of these models are theoretically possible, computation and identification issues limit their use (GREENE, 2003).

The multinomial logit model can allow us to estimate a set of coefficients $\beta_{\mathrm{j}}$ corresponding to each occupational category as follows:

$$
\operatorname{Pr}(y=j \mid \chi)=\frac{e^{\beta_{j} X_{i}}}{\sum_{j=1}^{j=7} e^{\beta_{k} X_{i}}} \quad, \quad j=1,2, \ldots 7
$$

To identify the model, we impose the normalization by considering the parameter vector associated with informal non-farm employment as zero $\left(\beta_{1}=0\right)$. So, the remaining coefficients $\boldsymbol{\beta}_{\mathbf{j}}$ measures the change relative to the base group informal non-farm employment. The probabilities as, therefore,

$$
\begin{gathered}
\operatorname{Pr}(y=j \mid \chi)=\frac{e^{\beta_{j} X_{i}}}{1+\sum_{j=2}^{j=7} e^{\beta_{k} X_{i}}} \\
\text { and } \\
\operatorname{Pr}(y=1)=\frac{1}{1+\sum_{j=2}^{j=7} e^{\beta_{k} X_{i}}}
\end{gathered}
$$

\footnotetext{
${ }^{65}$ Due to its computational ease, Multinomial logit is widely used in different areas of economics, social studies, and market research (mentioned in MADDALA, 1999; GREENE, 2003).

${ }^{66}$ MNLT is a generalization of Logit Model based on the Random Utility Model (RUM) which is simply the likelihood of choosing a particular alternative (occupation) if the utility of that alternative is greater than utility of other alternatives for that respondent .

${ }^{67}$ The study of occupational choice, by SCHMIDT \& STRAUSS (1975) provides a well known application of Multinomial Logit Model (GREENE, 2003).
} 
Where $\operatorname{Pr}$ is the probability of an economic activity; $i$ indexes the individuals; $j$ represents the seven ${ }^{68}$ nominal unordered occupational categories; $e$ is the natural log; and $\mathrm{x}_{\mathrm{i}}$ vector of exogenous variables affecting employment decision of household head. The model is estimated by maximum likelihood ${ }^{69}$, where the above probabilities enter the likelihood function. For further details see LONG \& FREeSE, 2001; GREENE, 2003; and KENNEDY, 2003.

A simplification of the overall Multinomial Logit Model is as follow:

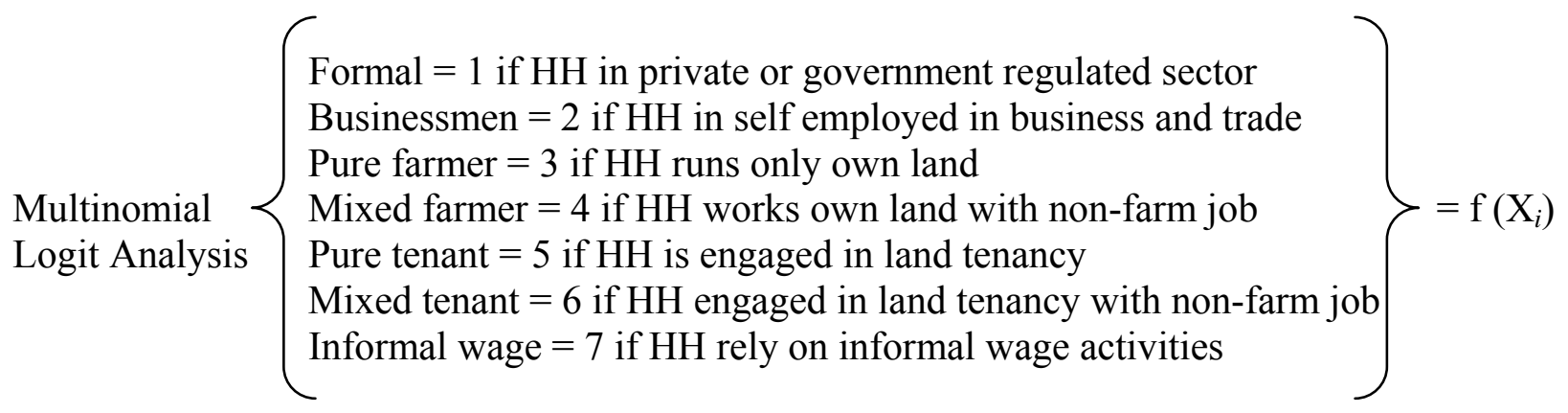

Based upon the literature studied, the explanatory variables comprise a selection of individual, household and community characteristics. The informal private wage labor (casual workers including farm labor) as the base group ${ }^{70}$ is compared with the above mentioned occupations ${ }^{71}$ (polychotomous) and this indicate whether the other occupational categories can be regarded as systematically different in any way from the comparison group.

\subsubsection{Measuring Changes in Employment Structure in the Study Villages over the Years}

Finally, the study of structural changes (somewhat institutional) in the employment pattern (Question 5) demands comparative analysis of the present period with situation prevailing in 1986/87 and 1967/68. The present study is basically employing ex-post facto research design

\footnotetext{
${ }^{68}$ Using a similar methodological approach to HENNESSY and REHMAN, 2004; DAMITE and NegATU, 2004; and AMELIE \& ZimMERMANN, 2004 seven occupational categories are identified to gain some insights as to the determinants of household activity choice.

${ }^{69}$ The maximum likelihood principle of estimation is based on the idea that the sample of data at hand is more likely to have come from a "real world" characterized by one particular set of parameter values than from a "real world" characterized by any other set of parameter values (SIMONOFF, 2003).

${ }^{70}$ Informal private employment will be kept as base group as majority of the rural dwellers in these areas were engaged in low rewarding informal economic activities.

${ }^{71}$ All these options available to the heads of the household are independent of each other. Assuming the errors in this model are independently and identically distributed with weibull distribution then the differences between the errors have a logistic distribution and the Multinomial Logit is the appropriate technique of estimation .
} 
relying on cross-sectional procedure for data collection to investigate the objectives specified in chapter 1 . However, to explore the structural changes in employment situation, the study also attempted to relate the employment situation in the research area in $1967 \& 1987$ to the present period. Similar approach was applied in Kerala, India to investigate non-farm employment by EAPEN, 2001, to compensate for the missing data. Similarly, MANIG, 1992 also restricted himself to a comparison of the 1986/87 survey data with the published interpretation of the previous findings. 


\section{RESEARCH SITES}

In this chapter we describe the setting - Northwest Pakistan - and the socio-economic conditions in the six research villages in District Peshawar. Before discussing the results of the study, it is appropriate to present briefly the geo-physical, socio-economic, cultural and political situation of North West Frontier Province, its capital Peshawar and the six research villages. This section first introduces briefly the NWFP and Peshawar district and then the detail profiles of the six research locations.

\subsection{Research Setting: North West Frontier Province}

The research area is located in North West Frontier Province (NWFP), one of the smallest (9.4 percent of all) of the four provinces of Pakistan (see Appendix 1). It has a population of around 24.5 million (16.4 percent Pakistan's population). As the name suggests, $\mathrm{NWFP}^{72}$ is situated in the north western part of Pakistan ${ }^{73}$. Until 1901, it was a division of the, then, Punjab Province consisting of the Peshawar, Hazara, and Kohat Districts. Upon its separation from Punjab in 1901, Peshawar became its capital.

Since NWFP is a land-scarce province with only a limited scope for agriculture-led growth, human capital is expected to play an important role in poverty eradication. Yet, even in terms of human development, the province is lagging behind other provinces such as Sind and Punjab. This disparity, i.e., human development poverty is more serious than income/consumption poverty, is a notorious characteristic of this region (KUROSAKI \& KHAN, 2006).

Table 3 provides a comparison of selected agricultural related statistics for Pakistan and its North West Frontier Province. NWFP accounts for one-fifth of the total number of farms in Pakistan

\footnotetext{
${ }^{72}$ Until recently NWFP was one of the two Pakistani provinces where Muttahida Majlis-i-Amal (MMA), an alliance of six Islamist parties, ran the provincial government. It won power in the province on the strength of its anti-Americanism. This appealed to the Pushtun people in NWFP who saw the war in Afghanistan as an assault on their ethnic kin and the one in Iraq as an attack on their religion (ECONOMIST, 2003).

${ }^{73}$ Pakistan is a part of South Asia where more than 500 million people or about 40 percent are estimated to live below the poverty line (WORLD BANK, 2000). The poverty line reflects a minimum necessary standard of living (or that adequate for a minimum calorie intake) and identifies those who fall below the line.
} 
while the farm area in this province makes up only one-tenth. This means that the average size of agricultural farms in NWFP is well below the average 6.2 acres for the country. Worthy of special mention is the fact that only one percent of the farm area in NWFP is over 25 acres, slightly less than the national figure of five percent. With respect to tenancy, there is not much difference between NWFP and Pakistan as around three-forths of the total farm area is selfcultivated.

\section{Table 3. Comparison of Agricultural Related Statistics between Pakistan and NWFP}

\begin{tabular}{|lll|}
\hline Characteristics & NWFP & Pakistan \\
\hline Farms & & \\
Total number & 1356234 & 6620054 \\
Farm area (acres) & 5589079 & 50425166 \\
Cultivated area (acres) & 4093619 & 40715843 \\
Average cultivated farm area (acres) & 3 & 6.2 \\
Cultivated area percent of farm area & $73 \%$ & $81 \%$ \\
Number of farms under 5 acres & $79 \%$ & $58 \%$ \\
Number of farms under 25 acres & $99 \%$ & $95 \%$ \\
Farm area & & \\
Own cultivated & $76 \%$ & $73 \%$ \\
Owner-cum tenant cultivated & $14 \%$ & $15 \%$ \\
Tenants cultivated & $10 \%$ & $12 \%$ \\
Area under major Crops & & \\
Wheat & $49 \%$ & $40 \%$ \\
Maize & $26 \%$ & $4 \%$ \\
Rice & $2 \%$ & $12 \%$ \\
Cotton & - & $14 \%$ \\
Sugar cane & $5 \%$ & $4 \%$ \\
Fodder & $3 \%$ & $11 \%$ \\
Vegetables & $3 \%$ & $2 \%$ \\
Pulses & $5 \%$ & $5 \%$ \\
Orchards & $1 \%$ & $2 \%$ \\
\hline
\end{tabular}

Source: Government of PAKISTAN, 2000; KHAN, 2007.

There are two main seasons in Pakistan's agricultural calendar: the rabi season that lasts from about November to April and the kharif season from May to October. Cotton and wheat are two of the most important crops in Pakistan, the former as a cash crop and a major source of export revenue and the latter as a staple food. Farmers in NWFP devote - due to their small pieces of land-over three-forth of their land to cereals while at the over-all country level it is grown on 56 percent area. Similarly, the role of cotton is non-existent in NWFP's economy; nevertheless it 
accounts for around 2.7 percent of total Pakistan's GDP (KHAN, 2007). During 2002-03, agriculture contributed about 20 percent to the provincial GDP while the share from employment was 44 percent.

Geography, the fallout from international tensions, inadequate investment in human capital, and a policy environment unsupportive of the private sector have made the NWFP one of Pakistan's poorest provinces. Poverty in the NWFP is widespread, in particular in rural areas. The estimated per capita provincial GDP in 2002-03 was only 60 percent of the average for the country. Women's participation in economic activities is very limited, contributing to the province's low per capita incomes. The incidence of income poverty (headcount index) in rural NWFP was estimated at 46.5 percent in 1998/99 (WORLD BANK, 2002), which is the highest in Pakistan. Since NWFP is a land-scarce province (only 30 percent of the land in the province is cultivable) with a limited scope for agriculture-led sustained growth, human capital is expected to play an important role in poverty eradication. Yet, even with respect to human development such as literacy rates and infant mortality rates, the province lags behind the other provinces of Pakistan like Sind and Punjab.

\subsection{Profile of District Peshawar}

When spring-time flushes the desert grass, Our Kafilas wind through the Khyber Pass.

Lean are the camels but fat the frails, Light are the purses but heavy the bales, As the snowbound trade of the North comes down, To the market-square of Peshawar town.

-- Rudyard Kipling

Peshawar, where the current study was conducted is located at the entrance of famous Khyber Pass $^{74}$, is the provincial capital of the North West Frontier Province (NWFP) and is the largest city in the province with a geographical area of 1257 square kilometers. The city of Peshawar lies about $163 \mathrm{~km}$ west of Islamabad, the capital of Pakistan. The total population of the district is slightly above two million (GOVERNMENT OF PAKISTAN, 2000) that is administratively divided into 92 Union Councils, four Town Councils and one Zilla council (MEHNAZ, 2005).

\footnotetext{
${ }^{74}$ The narrow route to the Khyber with its numerous Buddhist ruins and lonely British forts pass cuts through the Hindu Kush (Hindu Killer) - the rust-colored mountain range about 56 kilometer west of Peshawar, forming the most direct link between Peshawar and the Afghanistan capital, Kabul.
} 
The population growth rate is still extremely high by any standard although it declined over the years, from 3.89 in 1981 to 3.56 in 1998. Density was 1606.3 per square $\mathrm{km}$ and 8.5 persons per household in 1998. The population of the urban area is 0.983 million people (48.9\%) while 1.036 million (51.3\%) in rural area. The district presents a perfect example of SEN, 1990 'missing women' concept as for every hundred females there are 110.76 males. Around 46 percent of the total population is below 15 years of age.

Peshawar lacks considerably in human capital as more than half $(58 \%)$ of the population is illiterate while literate females are only 26 percent. Splitting the literacy rate figures into urban and rural regions, the literacy is much lower in rural area (29.2\%) of Peshawar while 54 percent of urban dwellers are literates. This disparity, i.e., human development poverty is more serious than income/consumption poverty, is a notorious characteristic of this region (KUROSAKI \& KHAN, 2006). There are around 1839 schools and colleges in the public sector with 3 universities. The private sector has many schools and colleges and a couple of universities.

\subsection{Natural Conditions of District Peshawar}

Peshawar with its subtropical climate is a water-rich valley through which flows the Kabul River that forms a long boundary of $\mathbf{4 8 . 5} \mathbf{~ k m}$ with the Indus River, eventually falling into the Arabian Sea. The surrounding region of Peshawar consists of irrigated plains, as part of a huge basin drained and irrigated by the Kabul River, and a tract covered by hills at Cherat in the southeast. The average depth of the water table in the area ranges between 30 and 45 metres. Figure 12 shows for Peshawar the year's average precipitation, average maximum daily temperature, and average minimum temperature.

The summer lasts from April to October with the minimum temperature averaging $15.7^{\circ} \mathrm{C}$ in April and $25.9^{\circ} \mathrm{C}$ in June. On the other hand, the maximum temperature averages about $29.7^{\circ} \mathrm{C}$ in April and $40.7^{\circ} \mathrm{C}$ in June. The Peshawar region receives much less rain during the period of the south-west monsoon and is wet during the winter season, which signifies a sequence of weather throughout the year more like that found in Iran, to the west. During the last 10 years, the average annual rainfall was about 400 millimeters, with the period from December through March accounting for about two thirds of the total annual rainfall (GOVERNMENT OF NWFP, 2003). 
Figure 12. Climatic Conditions in the Study Area

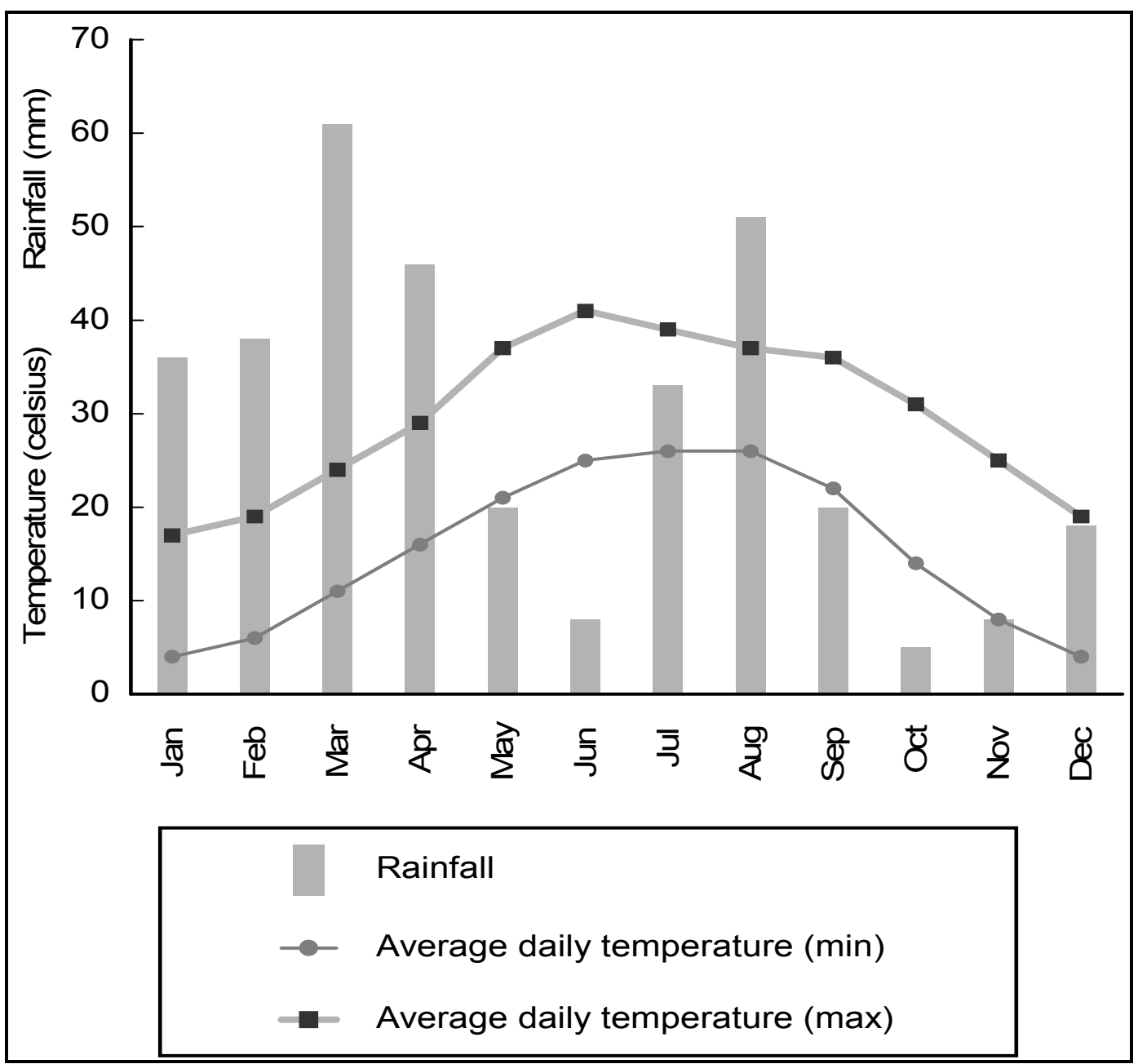

Source: Adjusted after BBC, 2006.

\subsection{Description of the Study Area}

The current study was conducted in six villages of District Peshawar Northwest Pakistan (see Table 4 for a description of study villages). The following sections explain the socio-economic conditions prevailing in these rural areas. The discussion starts with the villages in the immediate vicinity of provincial capital Peshawar followed by the Gulbela and Kochian. The last section addresses the tribal villages of Mushtarzai and Yousafkhel. 


\subsubsection{Extension Villages}

Kukar: Kukar is the largest ${ }^{75}$ village, owing to its location on the urban fringe which is proximate to both Peshawar city and the main industrial areas in the region. The village lies about 5 $\mathrm{km}$ north of Peshawar and is connected by the busy Peshawar-Charsadda Highway. One needs roughly 15 minutes of travel time to reach the provincial capital. Because of its location near a major highway, several new commercial and mercantile activities established themselves in the region. Nevertheless, the village is complex in its arrangement and the failure of the state to provide satisfactory schooling has led to the increasing emergence of privately run educational institutions. Although a state run canal serves the irrigation needs of the village agriculture, it has suffered from pollution problems in recent years.

Dalazak: Dalazak is located nearly $8 \mathrm{~km}$ east of Peshawar and is accessible by a narrow strip of recently built road. Although the village classified in 1967/68 as an 'owneroperator/tenant/businessman'-village, the development in recent years fails to justify this definition. The state canal has become increasingly polluted in recent years because of the everexpanding provincial capital Peshawar. Besides, the newly erected Peshawar-Hayatabad 'Ring Road' close to the village has opened direct links between Dalazak and other regions of Peshawar and hastened the growth of trade and service based employment in the village.

\subsubsection{Landlord, Tenant, and Labourer Villages}

Gulbela: In the 1967/68 survey, this village along with Kochian were categorized as a 'landlord/tenant/labourer'-villages due to the predominance of landlords ${ }^{76}$ who leased out land (Albrecht, 1976). Gulbela is located about $17 \mathrm{~km}$ northeast of Peshawar, close to the river Kabul (for the socio-economic conditions ${ }^{77}$ in the study villages, see Table 4). The Arbab family dominates the local landownership, owning almost all of the agricultural land in Gulbela. Nevertheless, the rapid subdivision of agricultural land has increased the economic differentiation

\footnotetext{
${ }^{75}$ In 2005, Kukar's population was 6,003, of which all were Muslims except for 21 people belonging to other religions.

${ }^{76}$ The present survey shows a declining role of these landlords in the village economy as more and more people are switching towards non-agricultural employment.

${ }^{77}$ According to the 1998 district census, like the rest of villages about 99.4 percent of the village population is Muslims, and there are only 19 people belonging to other religions.
} 
even within 'Arabs'. The landlords have their own communal irrigation system at their disposal; nevertheless, there are problems with the water supply.

Table 4. Socio-economic Characteristics across the Six Villages in Northwest Pakistan

\begin{tabular}{|l|cccccc|}
\hline Characteristics & \multicolumn{6}{|c|}{ Villages } \\
\cline { 2 - 7 } & $\begin{array}{c}\text { Kuk- } \\
\text { ar }\end{array}$ & $\begin{array}{c}\text { Dala- } \\
\text { zak }\end{array}$ & $\begin{array}{c}\text { Gul- } \\
\text { bela }\end{array}$ & $\begin{array}{c}\text { Koch- } \\
\text { ian }\end{array}$ & $\begin{array}{c}\text { Yousaf- } \\
\text { khel }\end{array}$ & $\begin{array}{c}\text { Mushtar- } \\
\text { Zai }\end{array}$ \\
\hline Demography & & & & & & \\
Population & 6003 & 2668 & 3439 & 3639 & 2620 & 4194 \\
Population density & 7.1 & 4.6 & 4.3 & 7.3 & 1.3 & 2.0 \\
No. of households & 727 & 380 & 432 & 459 & 288 & 539 \\
Average household size & 8.3 & 7.0 & 8.0 & 7.9 & 9.1 & 7.8 \\
Sex ratio (male/female) & 112 & 110 & 111 & 110 & 116 & 111 \\
Women productive age 15-49 (\%) & 44 & 44 & 43 & 41 & 42 & 43 \\
Women currently married (\%) & 30 & 31 & 29 & 29 & 31 & 31 \\
Geography and land & & & & & & \\
Distance from Peshawar (Km) & 5 & 8 & 17 & 17 & 23 & 16 \\
Area (acres) & 846 & 579 & 806 & 499 & 2045 & 2105 \\
& wheat, & wheat, & Sugar & Sugar & wheat, & wheat, \\
Main crops & maize, & maize, & cane, & cane, & maize & maize, \\
& fodder & vegetables & wheat & wheat & & vegetables \\
Housing & & & & & & \\
Hhs with Pakka house (\%) & 35 & 25 & 26 & 31 & 4 & 10 \\
Hhs with semi-pacca house (\%) & 0.3 & 0.2 & 0.2 & 2.1 & 3.8 & 2.3 \\
Hhs with Kacha house (\%) & 65 & 74 & 74 & 67 & 92 & 88 \\
Hhs with electricity (\%) & 96 & 97 & 90 & 90 & 93 & 95 \\
Hhs with portable water (\%) & 18 & 28 & 12 & 1 & 3 & 93 \\
Education & & & & & & \\
Male: 5-9 years (\%) & 10.2 & 17.0 & 14.9 & 15.4 & 15.9 & 22.8 \\
Male: 10 years and more (\%) & 10.8 & 12.9 & 10.2 & 9.3 & 5.7 & 9.8 \\
Female: 5-9 years (\%) & 2.1 & 5.0 & 3.9 & 4.5 & 1.6 & 2.8 \\
Female: 10 years and more (\%) & 3.3 & 1.3 & 0.9 & 1.2 & 0.1 & 0.4 \\
\hline
\end{tabular}

Note: 1) Population density is village population over village area in acres.

2) The sex ratio, an indicator of gender inequality in a society, mirrors gender differentials in mortality. A high sex ratio indicates premature death of females, the source of which could include poor female access to health inputs or social factors resulting in sheer neglect. Pakistan's sex ratio of 108 males per 100 females (GOVERNMENT OF PAKISTAN, 2000) means almost 8 million missing women which even surpasses South Asia's already high ratio of 106. Even compared to other low-income countries, Pakistan's sex ratio is high. SEN, 1990 brought attention to this simple but powerful sex ratio statistic to calculate the phenomenon he called "missing women." In a world with no excessive female mortality, the sex ratio would be 95 to 98 males per 100 females. The difference between this benchmark and the actual ratio translates to the number of missing women - i.e., women who could have lived but did not because of premature death (WORLD BANK, 2005).

3) Hhs refers to "households" in the study area.

Source: Basic survey carried out in six villages of Northwest Pakistan, 2004-05; KHAN, 2007; GovernMENT OF PAKISTAN, 2000. 
Gulbela hosts a 'high-school' (classes 6-10) and two 'primary-schools' (classes 1 to 5) for girls and boys. There are also two private schools initiated in the last few years which charge competitive fees for schooling. The public infrastructure was less visible in the area as there was no post office or bank and the health facilities was not more than a 'basic health unit', staffed by a doctor, a dispenser, a few lady health visitors and a gatekeeper. The research team conducted a comprehensive interview with the head of the school as well the staff at the BHU. Some of the landlord households have established commercial markets alongside the Charsadda ${ }^{78}$ highway which borders the village. Most of these are grocery shops, electronic goods sellers, and barbers.

Kochian: The village lies directly across from Gulbela on the Charsadda highway. There are two 'middle schools' in the village - one for girls and the other for boys. Due to its location directly next to the main road with intensive bus traffic, a few businesses and teahouses opened in recent years near the bus stop.

\subsubsection{Tribal Villages}

Mushtarzai: Mushtarzai lies $16 \mathrm{~km}$ south of Peshawar and became part of Peshawar Town 4 under the recent administration setup. Although the research team noted some construction work on the road passing through the village, most of the village suffers from a lack of satisfactory public infrastructure. Administration-wise, four local council members represent the village - two general councilers, one farm/labor member, and one Naib Nazim (Deputy Mayor). With property distribution, Mushtarzai is divided into five distinct regions (Khandey) - Niazey, Manzey, Sultankhel, Usmankhel, and Karamkhel. Niazey is the biggest Khandey, hosting around 170 households. A public tube-well supplies drinking water through a mutually arranged formula: 1.5 hours for every 'Khandey.' There are two middle and two primary schools in the village. Nevertheless, a couple of private schools serve the educational needs of the village within the village and in the nearby village of Mashookhel.

Traditionally, the villagers in Mushtarzai made a living from agriculture; later agriculture was combined with non-farm employment, and occasionally labourers migrate to the Gulf countries.

\footnotetext{
${ }^{78}$ The large town of Charsadda is located about $7 \mathrm{~km}$ from both Gulbela and Kochian. In the last decade the construction of Charsadda highway not only opened a number of new economic opportunities but also considerably accessible the neighbouring villages. Charsadda has an important market where villagers sell most of the grain, vegetables and gur (a brown sugar) not needed for family use.
} 
The close vicinity to the 'tribal area' leads to direct competition for the rare water with the inhabitants of the tribal land since the river flows through their land. The two villages, Mushtarzai and Yousafkhel, were categorized in previous surveys as 'owner-operator-villages' (ALBRECHT, 1976) because of predominance of owner-operator farm households.

Yousafkhel: Yousafkhel, the only rainfed village, where ecological conditions are dominated by low and unreliable rainfall. It lies $23 \mathrm{~km}$ south of Peshawar and is the poorest concerning infrastructure provision among the villages (Table 4). The village also suffers from security problems as the village setup is tribal and it is only accessible by a trodden dirt road. The road to the main Peshawar-Kohat highway was paved except for about 2 kilometers. The usually crowded bus made a single round trip daily, usually taking about an hour between Yousafkhel and the Peshawar Kohat bus station.

Water scarcity is a particular constraint as the water table has dropped to such a depth that it is no longer possible to irrigate the fields with tube-wells which were common a decade ago. The few functioning ancient Roman wells (qanat) observed in the 1986-87 survey, completely disappeared in the area. The unpredictable precipitation only allows one annual crop of cereals in the winter. Nevertheless, some farmers still cultivate their fields in summer in hope of rainfall. Many fields were levelled and surrounded by a small earth dam in order to take advantage of all the rain for farming purposes. This way, the precipitation can no longer flow off the surface. The drinking water is supplied by private wells or river water, although there are two state-owned tube-wells. ${ }^{79}$ One of the facilities was part of a bilateral rural development project.

There is limited economic activity in Yousafkhel besides a handful of grocery shops, a private dispensary, and a family-run small traditional flourmill. There is no Basic Health Unit (BHU) in the village, and the people have to travel to nearby villages such as Mathanai or, if the patient is seriously ill, to the provincial capital Peshawar. In recent years, the public sector set up a few educational institutions in Yousafkhel. There are three schools in the village- twogovernment schools for boys (primary and middle level) and a primary school for women. One of the primary school operates privately.

\footnotetext{
${ }^{79}$ As far as the two tube-wells are concerns, one has gone dry in recent years, and the other is still under construction. The villagers informed the research team that the construction started almost two years ago, but the facility is still not operational.
} 
Picture 1. Socio-economic Conditions in the Study Villages in Northwest Pakistan

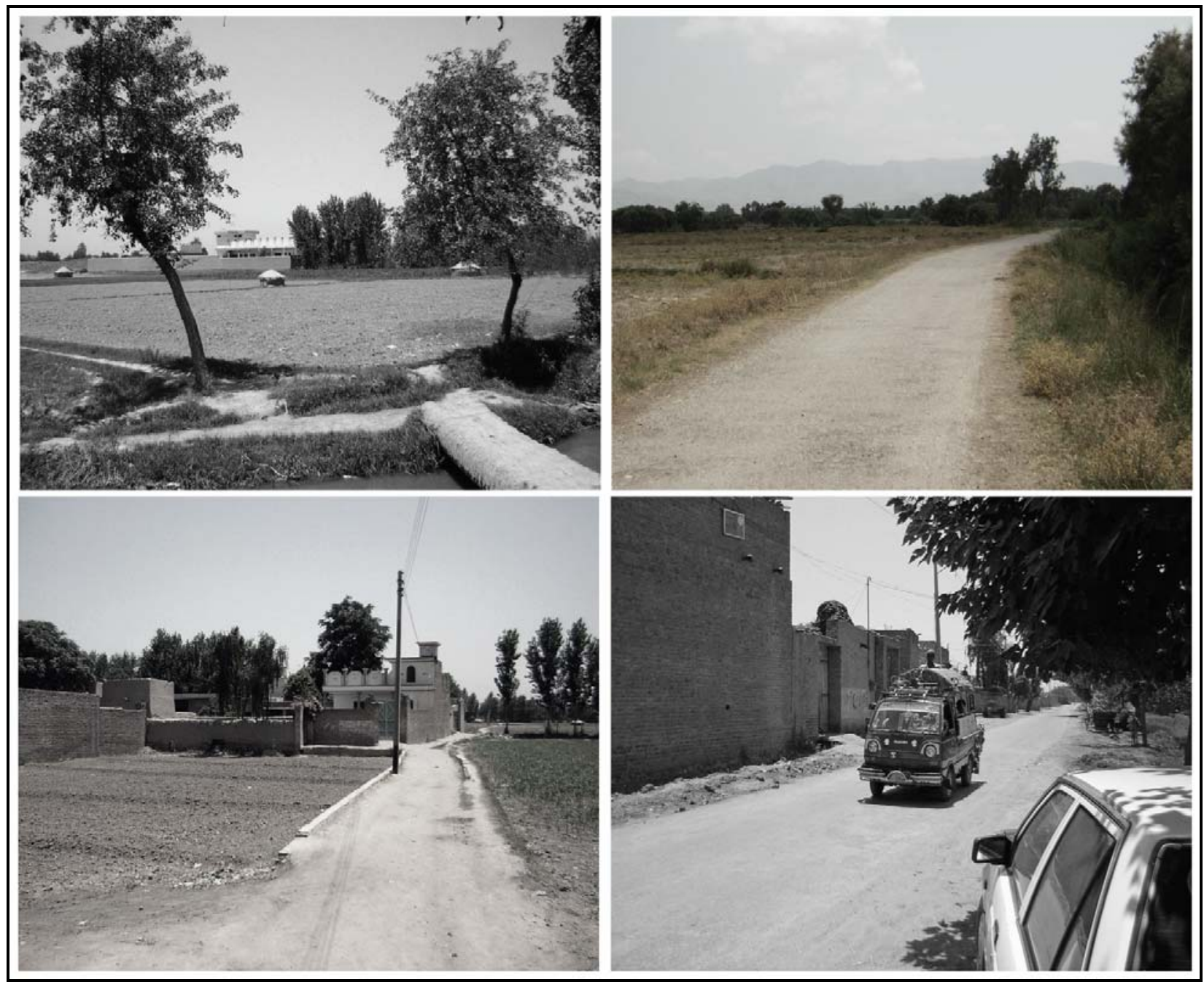

Source: Basic survey carried out in six villages of Northwest Pakistan, 2004-05 (photos by author).

The six villages discussed in the above sections have distinct population and geographical locations, yet they turn out to have much in common with respect to the social and economic circumstances that prevail within them (see Picture 1). They all have a low literacy rate, and all have poor infrastructures hindering individuals from achieving a better livelihood. All the government schools in the survey villages are poorly maintained and equipped in comparison to the privately run English-medium schools and to most of the Urdu-medium schools in Peshawar. These schools have inadequate amenities and there are few teaching materials. Despite these socio-economic conditions, there are major development projects around the study areas. For instance, a major construction work in the shape of the Islamabad-Peshawar Motor- 
way $(\mathrm{M} 1)^{80}$ is in its completion phases. The motorway will affect the socio-economic scene of the region in the near future.

The following chapters give an analysis of the basic and special surveys conducted in the above mentioned six villages of Northwest Pakistan. The analytical part is given by special topics.

${ }^{80}$ The work on the $149.3 \mathrm{~km}$ long Peshawar-Islamabad Motorway started on January 1, 2003 with a cost of Rs. 13203 million (GOVERNMENT OF PAKISTAN, 2006). 


\section{EMPIRICAL ANALYSES}

This chapter starts with a descriptive analysis of prevailing livelihoods across the six study villages with an extensive review of household asset situation. The household asset structure across the study villages is complex, however, the study limited discussion to the most important ones that shape the livelihoods in the study area.

\subsection{The Asset Status of Livelihood in the Surveyed Villages in Northwest Pakistan}

In the following sections the study describe the livelihood assets only briefly. A fuller description of the household livelihood capitals, their activities, and the results of quantitative information from basic survey in the research area appears in companion publications (see KHAN, 2007; JAN, 2007). So, these sections focus descriptively on a few livelihood assets i.e. human, natural, and physical assets of the rural households in the research area in Northwest Pakistan. The study of the prevailing assets is important as it directly influence the strategies followed by the households.

\subsection{Human Capital in the Study Area}

Human assets such as household size and literacy provide an idea on a household's quantitative and qualitative potential. A household investing into education (provided facilities are available) can increase its alternatives for income generation and might be able to find better income sources through regular salaried jobs, or start a self employed business (STEIMANN, 2004).

\subsubsection{Household Size}

The total population in the six surveyed villages was 22,563 persons distributed across 2825 households. The number of households in a village varies from a low of 288 (in Yousafkhel) to a high of 727 (in Kukar). The household size varies from an average of seven people in the Dalazak to nine persons in Yousafkhel. On the average, each household was made up of eight people across the research area. Table 5 shows the demography and distribution of households 
across the study villages according to household size classes. Almost half of the total households in the area were above the national average of seven people per household indicating the prevalence of joint and extended family system.

Table 5. Household Size Classification in the Survey Villages, 2004/05

\begin{tabular}{|l|ccc|ccccc|}
\hline \multirow{2}{*}{ Research Villages } & \multicolumn{5}{|c|}{ Demographic Characteristics } & \multicolumn{5}{|c|}{ Percentage of the Household-size Classes } \\
\cline { 2 - 8 } & Population & Mean HH & HH Range & 1 & 2 & 3 & 4 & 5 \\
\cline { 2 - 8 } & No. & No. & No. & $1-4$ & $5-7$ & $8-10$ & $11-20$ & $21-34$ \\
\hline Dalazak (n=380) & 2668 & 7.0 & $2-34$ & 25.0 & 40.5 & 22.6 & 9.7 & 2.1 \\
Gulbela (n=432) & 3439 & 8.0 & $1-32$ & 14.6 & 36.6 & 30.6 & 16.7 & 1.6 \\
Kochian (n=459) & 3639 & 7.9 & $2-26$ & 13.3 & 38.6 & 31.6 & 15.0 & 1.5 \\
Kukar (n=727) & 6003 & 8.3 & $2-27$ & 14.6 & 32.6 & 32.3 & 18.6 & 1.9 \\
Mushtarzai (n=539) & 539 & 7.8 & $2-22$ & 12.4 & 40.4 & 30.4 & 16.3 & 0.4 \\
Yousafkhel (n=288) & 2620 & 9.1 & $2-29$ & 10.1 & 30.2 & 32.3 & 24.7 & 2.8 \\
\hline All Villages (n=2825) & 22563 & 8.0 & $1-34$ & 14.9 & 36.5 & 30.3 & 16.7 & 1.6 \\
\hline
\end{tabular}

Note: 1) The number of individuals in a household classified into five groups.

2) HH refers to households

Source: Basic survey carried out in six villages of Northwest Pakistan, 2004-05.

In general, the survey findings show that males outnumber females in the study region (53 and 47 percent respectively). The proportion of females is smaller in the remote tribal village Yousafkhel (46 and 54 percent respectively). A possible reason for the low proportion of females is a desire for more male members in the households in this traditional men dominated society. The patriarchal nature of the rural population can be observed by only 26 females headed households (0.9 percent of the total households and those were mostly widows). These characteristics are important because they are often associated with socio-economic differences between households. For example, female-headed households were poorer ${ }^{81}$ than households headed by males. In addition, the size and composition of the household affects the sharing of financial and other resources among household members, which in turn influences the overall well-being of these individuals. Household size is also associated with crowding in the dwelling which can lead to unfavourable health conditions.

\footnotetext{
${ }^{81}$ The average monthly income of female-headed household was Rs. 5678, while it was Rs. 7522 for male-headed households. The bulk (73\%) of these female headed households were in Kukar and Kochian
} 


\subsubsection{Literacy and Skills}

A household's productive capacity depends on labour, land, and capital. Rural households in Northwest Pakistan invest less in human capital, as depicted by the basic survey. In the surveyed villages, about 61 percent of the households have a head ${ }^{82}$ without any education. The nearly 39 percent of the household heads who were literate had an average schooling of nine years. Analysing education of the household head, the following picture of human capital in the area emerges:

a) 19 percent of all households had from one to eight years of schooling,

b) 16 percent studied for 9 to 12 years, and

c) just over four percents were university graduate.

\subsection{Labor Endowment at Household Disposal}

Classifying different types of occupations in the research area is a Herculean task because of the labyrinthine criss-crossing of the underlying attributes. Nevertheless, a sixfold classification, namely 'farmers,' 'casual labourers,' 'permanent workers,' 'government employees,' 'businessmen,' and 'others' is used to make the analysis simple and meaningful. Table 6 presents the occupational pattern for all the working adults in the research area.

Informal sectors such as casual daily wage earners, the self-employed, and petty trades dominate the job market in the area. In addition, the jobs available to daily wagers and other low-skilled workers are often unstable, offer few benefits, and pay low wages. However, a lack of new private businesses (six percent) in Yousafkhel signals that the village is experiencing stagnation. Detailed interviews with some of the business operators (mostly grocery shops) in the village confirmed this impression. The main problems are the lack of growth in the number of local jobs, forcing people to leave the village in search of jobs in other major cities of Pakistan such as Lahore, Peshawar, Karachi, and D.I.Khan, and the lack of interest in agriculture among the people because of its rain fed (Barani) nature. The situation has become even more problematic because of the lack of work opportunities in these cities as well as the employers' stress on a more skilled workforce.

\footnotetext{
${ }^{82}$ In the study area, 99 percent of the household heads were male.
} 
Table 6. Distribution of the Household Working Members according to their Occupations

\begin{tabular}{|l|cccccc|}
\hline \multirow{3}{*}{ Villages } & \multicolumn{5}{|c|}{ Percentage working in the following fields } \\
\cline { 2 - 7 } & $\begin{array}{c}\text { indep. } \\
\text { farmer } \\
(\mathrm{n}=727)\end{array}$ & $\begin{array}{c}\text { causal } \\
\text { worker }\end{array}$ & $\begin{array}{c}\text { permanent } \\
\text { employee }\end{array}$ & $\begin{array}{c}\text { govern.- } \\
\text { employee }\end{array}$ & $\begin{array}{c}\text { own } \\
\text { business } \\
(\mathrm{n}=1391)\end{array}$ & $\begin{array}{c}\text { welfare } \\
\text { based } \\
(\mathrm{n}=1375)\end{array}$ \\
& 20.2 & 30.8 & 15.7 & 20.0 & 13.4 & - \\
\hline Mushtarzai $(\mathrm{n}=1032)$ & 15.2 & 27.5 & 37.7 & 13.5 & 6.2 & - \\
Yousafkhel (n=600) & 14.3 & 35.5 & 27.3 & 10.3 & 11.3 & 1.2 \\
Gulbela (n=812) & 17.7 & 22.1 & 24.4 & 13.3 & 21.9 & 0.7 \\
Kochian $(\mathrm{n}=821)$ & 10.2 & 18.6 & 22.0 & 23.2 & 25.9 & - \\
Dalazak $(\mathrm{n}=667)$ & 6.7 & 21.5 & 28.5 & 13.2 & 30.2 & - \\
Kukar $(\mathrm{n}=1468)$ & 13.5 & 25.8 & 25.5 & 15.3 & 19.7 & 0.3 \\
\hline All Villages $(\mathrm{n}=5400)$ & &
\end{tabular}

Source: Basic survey carried out in six villages of Northwest Pakistan, 2004-05.

Figure 13 catalogues the distribution of agricultural labourers in the research area in Northwest Pakistan. Except for Yousafkhel and Kukar, the casual agricultural wageworkers were concentrated variedly in the rest of the four research villages. The large share of casual agricultural labourers in Kochian, Gulbela, Mushtarzai, and Dalazak corresponds to the demand for these workers during the peak seasons of harvesting, sowing, and weeding for crops such as cereals, sugar cane, and vegetables. The permanent labourers made up most of the overall agricultural workers in Kukar and Yousafkhel, whereby in Kukar, only the dairy farmers hired them.

Agricultural casual wageworkers in the surveyed region are poor by any reckoning. These workers have an inadequate and uncertain number of days of employment. Although across the villages there were minor differences in the wage rates paid to casual workers, the wages paid on construction sites were higher (Rs 150 a day) than those paid for agricultural labour (Rs. 90 a day), while skilled workers may earn Rs 200-300 each day. Nearly all the members of the agricultural labour households in the study area lived below the official income-poverty line in 2004-05. In sum, the standard of living of agricultural labourers has remained backward, and deprivation and economic vulnerability mark their lives. 
Figure 13. Distribution of Agricultural Labors across the Research Area, 2004/05

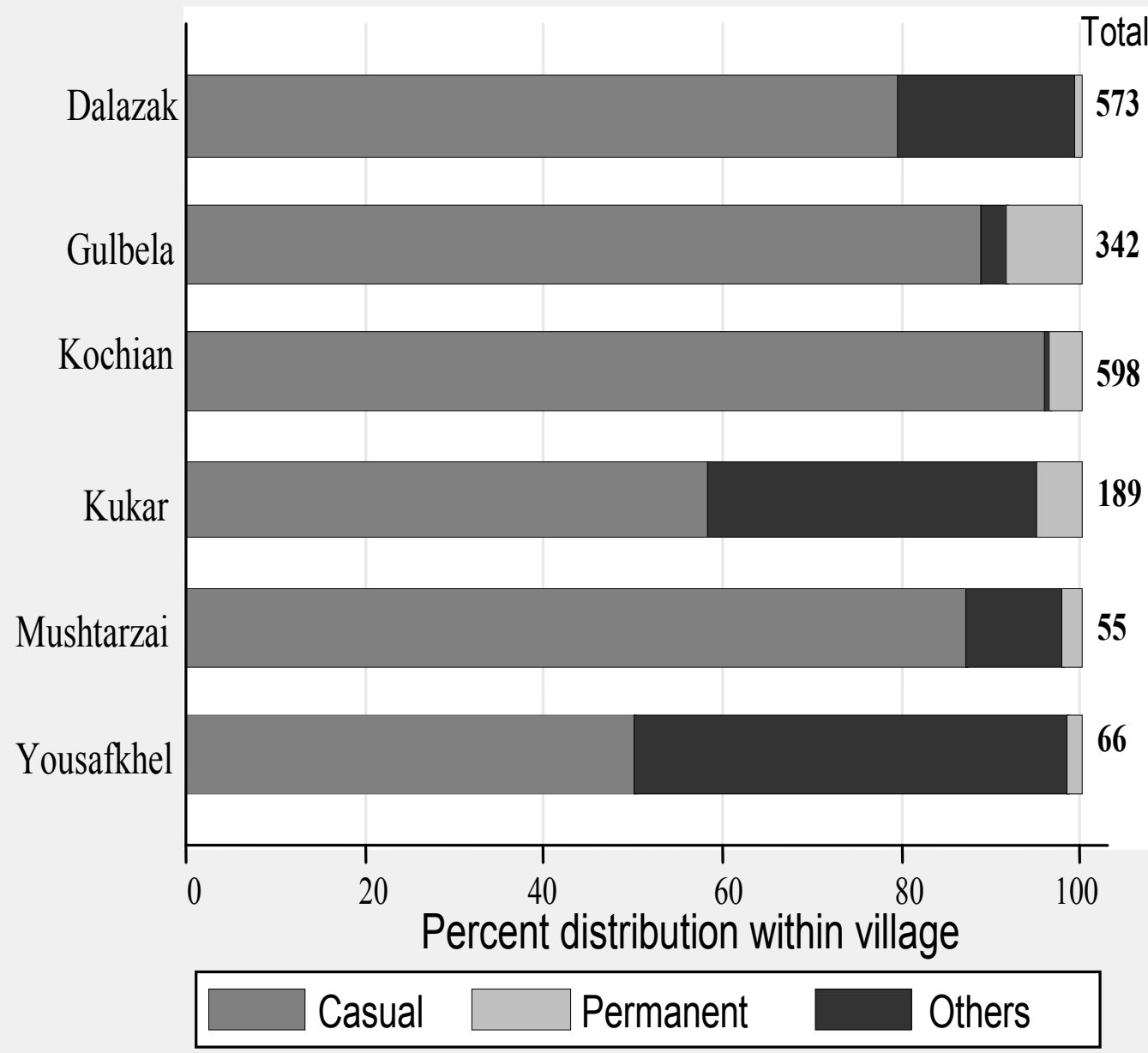

Source: Basic survey carried out in six villages of Northwest Pakistan, 2004-05.

Table 7 shows the different types of economic activities undertaken by people in the research villages in the 2005 calendar year, showing importance of various occupations in the village economy. The table encompasses a myriad of different occupations, most of which took place locally and in the provincial capital Peshawar. The high share of government employees in Dalazak (23 percent) and Mushtarzai (20 percent) is because of work offered in the provincial capital Peshawar and not by the local public sector. Nevertheless, as in Kukar, the public sector also created several new jobs in the surveyed villages by setting up and upgrading Basic Health Units (BHUs), primary and secondary schools, 'Nazim' (union council) office, and a few tube wells. However, a lack of work is still a problem in the study area. 
Table 7. Household Members with Main Occupations in the Survey Villages, 2004/05

\begin{tabular}{|c|c|c|c|c|c|c|c|}
\hline Occupations $^{1}$ & $\begin{array}{c}\text { Kuk- } \\
\text { ar }\end{array}$ & $\begin{array}{c}\text { Yousaf- } \\
\text { khel }\end{array}$ & $\begin{array}{l}\text { Gul- } \\
\text { bela }\end{array}$ & $\begin{array}{l}\text { Koch- } \\
\text { ian }\end{array}$ & $\begin{array}{c}\text { Dala- } \\
\text { zak }\end{array}$ & $\begin{array}{l}\text { Musht- } \\
\text { arzai }\end{array}$ & $\begin{array}{c}\text { All } \\
\text { Villages }\end{array}$ \\
\hline Farmers & 61 & 86 & 112 & 140 & 63 & 200 & 662 \\
\hline Buffalo owners & 38 & 5 & 4 & 5 & 5 & 8 & 65 \\
\hline Casual workers: all jobs & 236 & 130 & 163 & 76 & 90 & 241 & 936 \\
\hline Casual workers: farming & 9 & 8 & 45 & 65 & 5 & 7 & 139 \\
\hline $\begin{array}{l}\text { Casual workers: house } \\
\text { construction }\end{array}$ & 70 & 27 & 80 & 40 & 29 & 70 & 316 \\
\hline Perm. employee: welder & 7 & - & 1 & 13 & 80 & 9 & 110 \\
\hline Perm. employee: driver & 63 & 31 & 70 & 94 & 34 & 16 & 280 \\
\hline $\begin{array}{l}\text { Perm. employee: weapon } \\
\text { maker }\end{array}$ & - & 43 & - & - & - & - & 43 \\
\hline Perm. employee: servant & 35 & 4 & 8 & 13 & 3 & 5 & 68 \\
\hline $\begin{array}{l}\text { Perm. employee: } \\
\text { mechanic }\end{array}$ & 44 & 6 & 8 & 19 & 1 & 12 & 90 \\
\hline $\begin{array}{l}\text { Perm. employee: } \\
\text { electrician }\end{array}$ & 18 & 4 & 1 & 2 & 4 & 5 & 34 \\
\hline Perm. employee: overseas & 17 & 28 & 8 & 12 & 20 & 93 & 178 \\
\hline Border Patrol & 1 & 24 & 7 & 9 & 3 & 53 & 97 \\
\hline Police & 40 & 3 & 15 & 20 & 17 & 26 & 121 \\
\hline Army & 16 & 14 & 7 & 26 & 17 & 40 & 120 \\
\hline Teacher & 49 & 2 & 31 & 13 & 18 & 27 & 140 \\
\hline High Gov. employee & 36 & 6 & 6 & 5 & 19 & 7 & 79 \\
\hline Own transport enterprise & 18 & 5 & 10 & 58 & 13 & 7 & 111 \\
\hline Own grocery store & 79 & 9 & 32 & 48 & 25 & 53 & 246 \\
\hline Milk seller (ambul.) & 16 & - & 6 & 5 & - & - & 27 \\
\hline Yogurt seller (ambul.) & 25 & - & - & - & - & - & 25 \\
\hline Cloth business & 92 & 1 & 5 & 4 & - & - & 102 \\
\hline Tailor & 58 & 5 & 14 & 17 & 12 & 11 & 117 \\
\hline
\end{tabular}

Note: 1) Although the occupational structure was diverse across the six research villages in Northwest Pakistan, only the most important occupations are shown here.

Source: Basic survey carried out in six villages of Northwest Pakistan, 2004-05.

The manufacturing sector was almost non-existent in the survey villages, apart from a few small-scale enterprises such as:

a) a family run small soda factory in Kochian;

b) a handful of flour machines in Kukar and Yousafkhel;

c) a few tailoring shops widely spread across the villages - most of these tailors were specialized in male dress only; 
d) a family run Cricket bats making enterprise in Dalazak; and

e) a Coca-Cola factory near Kukar on the Peshawar Charsadda Highway employing a limited number of people from Kukar, Kochian, and Gulbela. It is relevant to mention that this factory was non-operational because of a financial crisis, and several respondents working as drivers, supervisors, and loaders in the factory reported that they had not received their salaries for the last six months.

Small businesses were equally diverse, including everything from running a grocery shop to making and selling clothes. We followed the same procedure adopted in previous surveys in classifying livelihood activities in the research villages, and self-employed skilled work was, thus, distinct from permanently hired employment. Some of the non-agricultural, selfemployment activities - or non-farm enterprises - are caste-based services such as carpenters, barbers, and blacksmiths. The traditional practice of 'ustakar' was also observed in the study villages. An 'ustakar' - for instance, a barber in a traditional village - is paid in kind by farm households twice yearly after harvest (i.e., he is not rewarded for each service separately).

Those households without any income sources have to rely on either 'zakat' from local villagers or the government. Traditionally, the feudal households in the village provide food and clothes in return for various kinds of work to a household that cannot manage to make a living on its own. However, the welfare-based households claimed that this traditional safety net is starting to break down. As an economic livelihood strategy for the welfare-based households, the government support ('zakat') represents an alternative to work and economic support from family and friends. However, as noted, the welfare ${ }^{83}$ based people in the study areas often face greater stigma, misinformation, and significant obstacles on their eligibility for the 'zakat' program.

In 2005, just over three percent of the total working members in the study area were labour migrants and of these, the majority had unskilled jobs, mostly in Gulf countries. This phenomenon was more pronounced in Mushtarzai where around nine percent of the total working force was employed in Arab Gulf countries and as a new trend, occasionally in Malaysia. Almost all the migrants transferred money or goods regularly. Nevertheless, migration rose a challenge to

\footnotetext{
${ }^{83}$ According to HUSSAIN et al. (2003, p. 56) 'zakat,' 'ushr,' 'fitrana,' and 'nazrana' (different forms of charity) have been quite significant sources of livelihood for both the extremely poor and the poor in Pakistan. This charity assistance is offered three times more in the private sector that in the public sector, and some of the non-poor are also recipients of government 'zakat,' indicating the widespread corruption generally alleged in this sphere.
} 
existing tribal social relationships and a minor introduction of new types of consumption patterns (goods or clothing).

\subsection{Female Economic Activity in the Study Area}

Women were classified as unemployed in most of the cases as rural households in the study area in general are reticent to let women work for wages outside their home. In the prevailing patriarchal Afghan society in Northwest Pakistan, women are the standards by which morality is judged and that hinders their involvement in any economic activity. This male dominated society treats its women as 'cultural bourgeoises', circumspect, decorous, and bearers of the family honor (RAHMAN, 1987). According to DUPREE, 2002 "honour is the rock upon which social status rests and the family is the single most important institution in Afghan society. The position of women is central to these values and they carry the responsibility of passing on the values of the society to younger generations." However, some women do in fact take part actively in grain storage if it is kept at home and make side revenues by producing butter, weaving, and raising minor animals such as poultry.

The special survey enquired about household female employment in the study area. Only three percent of the households reported to have economically active females. These women work on average for seven hours a day in jobs like police constables (17\%), tailoring (34\%), school teachers $(34 \%)$, or as servants $(17 \%)$ at landlords houses within the village. These results are supported by SIDDIQUI \& HAMID, 2003 cited in NASIR, 2005 that in the Pakistani society females are perceived as secondary earners and therefore are encouraged to enter into those occupations where males have the least preferences. This female work even in this traditional Pakhtoon society can be traced to the increasing need for money in a cash scarce rural economy. Also, some women do not work outside; instead they work inside their homes, tailoring and do embroidery. When asked about the reasons for not working of their adult female, the household head mentioned the following reasons:

a) nearly 47 percent of the household head considered home as the proper domain for their women, and expressed their intention based on Pakhtoon culture, to discourage their outside work;

b) 33 percent considered childcare and rearing as reason for not working; and 
c) 18 percent expressed their willingness to allow their female to work but blamed the lack of jobs in the area as for their not working.

The power relations within the Pakhtoon society play a major in the low economic activity of females in the rural Northwest Pakistan. In this predominantly patriarchal society 'Gender' in the words of SCOTT, 1991 becomes 'a primary way of signifying relationships of power'. Despite such dismal female employment situation, the study team observed no evidence of any targeted support from government or NGOs in the form of technical support or motivation to encourage female employment.

\subsection{Land Access and Tenure}

The average farm size as well as the irrigated area varies widely among villages and households within villages. As can be seen from Table 8, all households cultivate on the average only 2.8 acres. Across the villages, a high degree of land fragmentation was observed in Mushtarzai where the farm and cultivated area was less than half $(1.1$ acres $)$ of the overall village mean area. There was a slight difference of just four percent between the land cultivated and the total farm area at the household level in the study area.

For the most part, the land in the research area is irrigated; however, the entire 679 acres in Yousafkhel are rainfed. Crop production is dependent on the quantity and dispersion of rain in the rainy season in monsoon (July - October) and a brief duration in winter. It is relevant to mention that wherever irrigation of the farm area was possible, the households tried to cultivate all the land in their possession. Because of inadequate land resource endowment in the study area, the households have to take up jobs outside agriculture as a survival strategy.

Table 8 provides an account of the farming across the six villages with widespread variability. Just over a quarter of the total households belonging to the agricultural household categories (hh cat. II, III, V2, V3, and V4) have a farm. Looking at distributing farms for the aforementioned household categories in the individual villages, Yousafkhel has the highest (51 percent) of them followed by Mushtarzai (43 percent), while Kukar (10 percent) has the least. 
Table 8. Farm Area, Cultivated Area, and Number of Farms in the Survey Villages, 2004/05

\begin{tabular}{|l|cccc|cccc|}
\hline \multirow{2}{*}{ Villages } & \multicolumn{4}{|c|}{ Farm area } & \multicolumn{4}{c|}{ Cultivated area } \\
\cline { 2 - 8 } & $\begin{array}{c}\text { Mean } \\
\left(\text { acres }^{1}\right)\end{array}$ & $\begin{array}{c}\text { Total } \\
(\text { acres })\end{array}$ & $\begin{array}{c}\text { Irrigat. } \\
(\%)\end{array}$ & $\begin{array}{c}\text { Not irrigat. } \\
(\%)\end{array}$ & $\begin{array}{c}\text { Mean } \\
\text { (acres) }\end{array}$ & $\begin{array}{c}\text { Total } \\
(\text { acres })\end{array}$ & $\begin{array}{c}\text { Irrigat. } \\
(\%)\end{array}$ & $\begin{array}{c}\text { Not irrigat. } \\
(\%)\end{array}$ \\
\hline Kukar (n=75) & 2.4 & 182.4 & 98.1 & 1.9 & 2.4 & 181.4 & 98.6 & 1.4 \\
Mushtarzai (n=232) & 1.1 & 242.9 & 100 & 0 & 1.1 & 242.9 & 100 & 0 \\
Gulbela (n=79) & 5.5 & 430.5 & 79.1 & 20.9 & 5.4 & 428.5 & 79.5 & 20.5 \\
Kochian (n=131) & 2.6 & 340.9 & 100 & 0 & 2.6 & 340.9 & 100 & 0 \\
Dalazak (n=113) & 3.2 & 365.8 & 87.2 & 12.8 & 3.1 & 354.3 & 90 & 10 \\
Yousafkhel (n=148) & 4.6 & 679.1 & 0 & 100 & 4.3 & 637.3 & 0 & 100 \\
\hline All villages (n=778) & 2.9 & 2241.6 & 63.4 & 36.6 & 2.8 & 2185.3 & 65.1 & 34.9 \\
\hline
\end{tabular}

Note: Values in bracket shows the numbers of farms in the respective village.

1) Data in acres per farm, where 1 acre $=0.4047$ ha. In Northwest Pakistan, 'jerab' is the common measure for land where 2 'jerabs' $=1$ acre. In the basic survey questionnaire, the land was reported in 'jerabs' while during analysis we used acre as the unit for land.

Source: Basic survey carried out in six villages of Northwest Pakistan, 2004-05.

The average farm and cultivated area is largest (close to 5 acres) for the pure tenants while for the rest of household categories it remained close to the overall mean of around 3 acres. Relative to other household categories, the share of irrigated area for owner operators with non-agricultural jobs (Hh-cat. V2) is nearly 39 percent. Nearly 31 percent of these households come from the rainfed village Yousafkhel.

There was a predominance of small-sized holdings in the study area in 2004-05. Summarizing the farm related statistics in Table 9, the following picture of the agricultural situation in the study area in Northwest Pakistan emerges:

a) about 82 percent of the households cultivated less than five acre,

b) farms ranging 5-25 acres were cultivated by nearly 18 percent households, and

c) less than one percent cultivated more than 25 acres (Table 9).

A notable feature shown in Table 9 is that about 44 percent of the farmers households with nonagricultutal activities operated less than 5 acres of land. So, the scarcity of land motivated them towards exploring non-agicultural opportunities along with staying in farming as well. The state of the farm mechanization in the study area is evident from the fact that just three percent of 
the farming households owned 26 tractors $^{84}$. Nevertheless, 72 percent of the farming households hired tractors for land preparation for different crops at an average rate of Rs. 214/hr.

\section{Table 9. Percentile Distribution of the Farms According to Size Categories and Household Categories in the Surveyed Villages, 2004/05}

\begin{tabular}{|c|c|c|c|c|c|c|c|}
\hline \multirow{3}{*}{$\begin{array}{l}\text { Farm Size } \\
\text { Categories }\end{array}$} & \multicolumn{6}{|c|}{ Household Categories } & \multirow{3}{*}{$\begin{array}{c}\begin{array}{c}\text { Total } \\
(\mathbf{n}=778)\end{array} \\
\text { percent }\end{array}$} \\
\hline & \multicolumn{3}{|c|}{ Pure Farmers } & \multicolumn{3}{|c|}{ Farmers with Non-farm Jobs } & \\
\hline & $\begin{array}{l}\text { Owner } \\
\text { oper. } \\
(\mathrm{n}=44)\end{array}$ & $\begin{array}{c}\text { Owner- } \\
\text { cum ten. } \\
(\mathrm{n}=8)\end{array}$ & $\begin{array}{c}\text { Only } \\
\text { Tenants } \\
(\mathrm{n}=81)\end{array}$ & $\begin{array}{c}\text { Owner } \\
\text { oper. } \\
(\mathrm{n}=409)\end{array}$ & $\begin{array}{l}\text { Owner- } \\
\text { cum ten. } \\
(\mathrm{n}=32)\end{array}$ & $\begin{array}{l}\text { Mixed Tenants } \\
\quad(\mathrm{n}=204)\end{array}$ & \\
\hline Small $(n=635)$ & 4.6 & 0.9 & 6.3 & 44 & 3.7 & 22.2 & 81.7 \\
\hline Medium $(n=136)$ & 1.0 & 0.1 & 4.0 & 7.9 & 0.5 & 3.8 & 17.5 \\
\hline Large $(n=7)$ & - & - & 0.1 & 0.6 & - & 0.1 & 0.8 \\
\hline Total $(n=778)$ & 5.6 & 1.0 & 10.4 & 52.5 & 4.2 & 26.1 & 100 \\
\hline
\end{tabular}

Note: Values in bracket shows the total numbers of farms in respective category.

Values may not match in certain columns to total due to rounding.

Legend: Small $=$ below 5.0 acres Medium $=5-25$ acres Large $=$ above 25 acres

Source: Basic survey carried out in six villages of Northwest Pakistan, 2004-05.

With the exception of the landlord households (hh cat. I), in the case of the rest of the farming households, the landed property is very small units ranging from 2.3-3.8 acres. Compared to the 479 households which owned the irrigated land, nearly 169 households owned non-irrigated land. Occasionally, a household owned irrigated as well as rainfed property. Around 206 households lease out their mainly irrigated land in share tenancy (50-50 share of the produce ${ }^{85}$ ). Share tenancy was wide spread in Kochian and Gulbela, where the landlords (Arbabs) have parceled out land in small lots to tenants for cultivation. These tenants have no legal rights and the

\footnotetext{
${ }^{84}$ The traditional means of land preparation are decreasing as only four percent of the farming households used bullocks. MAHMOOD et al., 2005 mentioned the following three reasons for the increased hiring and availability of farm machinery in District Peshawar Northwest Pakistan:

a) serious scarcity of animal draught power necessitates the use of mechanical power for agricultural production activities;

b) the government, as a response to encourage the use of farm machines, withdrew the testing and standardization controls in the free market distribution; and

c) agricultural machinery is exempted from import duties.

${ }^{85}$ However, as observed by JACOBY \& MANSURI, 2007, pp. 4-5 in their study in Pakistan, the 50-50 output-sharing formula probably overstates the degree of uniformity in these contracts. For example, tenants usually borrow from their landlords, often by taking an advance for their share of the input costs, which is typically repaid at harvest time. Output and cost shares alone, thus, do not fully characterize the terms of the share-contract.
} 
landlords used supervisors (zalidar) for looking after their land affairs. The tenants provided their labour not only for cultivation but also occassionaly some services to the landlords free from any remuneration of their labour. These contracts in which the tenants provided 50 percent of produce to the landlords as rent of the land were mostly verbal and lasted in majority of cases for more than one year.

The differences about farming in the study area can be best seen by comparing crop distributions on individual household farms across the villages. As mentioned earlier, the study area has two distinct cropping seasons, namely 'kharif' (summer) and 'rabi' (winter). The region grows various tropical and subtropical crops during these cropping seasons. Obviously, food grains were the main constituents of the cropping pattern both in the 'kharif' and 'rabi' seasons in 2004-05. Wheat (47 percent) and maize (14 percent) were the two main cereals cultivated in the region.

During the 'kharif' season, besides maize (Zea mays L.) as a major crop, vegetables and fodder together accounted for about eight percent of cropped area. As stated earlier, the acreage planted with wheat (Triticum aestivum L.) was almost half the cropped area, while other 'rabi' crops such as fodder and vegetables occupied nearly the same area as during 'kharif.' The annual sugar cane crop (Saccharum officinarum L.) accounted for 21 percent of the cropped area across the villages. The agro-climatic causes also influence the cropping patterns as the rain-fed village Yousafkhel concentrate only on cereals. An increasing population pressure and expanding markets put a great demand on the natural resources; ways to increase and sustain agricultural production are, as a result, gaining greater importance in the region.

Sugar cane is a water intensive crop; therefore, in the irrigated villages of Gulbela and Kochian, almost 50 percent of the area was devoted to it where canal water (the cheapest source of water drawn from the canals built by the feudal families in these villages) is widely used. Similarly, the tenants devoted crop areas in the range of 36-39 percent to growing sugar cane. These tenant households grew wheat roughly on the same proportion of land as sugar cane, most of which is consumed within the household with little to offer for sale.

Combining these findings with those in the previous section, we can assume that with limited alternatives for earning cash income and no crop insurance, these farming households depend largely on their own production for food, feed, and fodder needs. 


\subsection{Livestock Ownership in the Area}

Except for a few dairy farms at Kukar and Gulbela kept by farming households, the livestock production in the study area took place as a household activity and seldom employed hired labour (see Table 10). Cattle were the most popular species along with buffalo; they were the species most widely kept by the livestock households (cat. IV, V5). The livestock integrates closely with the rural subsistence economy through reliance on crop residues as feed and growing fodder crops on a small-scale which fits in the cropping cycles. Of the 2825 households in the six survey villages, 41 percent of the households kept an average of $2.1 \mathrm{TLU} /$ household $^{86}$. The study area had some 883 cows, 617 buffaloes, 319 sheep, and 731 goats spread to different degrees across the villages in 2004/05. Looking at livestock possession, around 58 percent of the households in Kochian kept on the average 1.7 livestock units. Only 22 percent of the households in Kukar kept livestock but the number of animals expressed in livestock units remained highest across the study area.

Table 10. Significance of Livestock Production in the Surveyed Villages, 2004/05

\begin{tabular}{|llccccccc|}
\hline Household Categories & & $\begin{array}{c}\text { Kuk- } \\
\text { ar }\end{array}$ & $\begin{array}{c}\text { Yousaf- } \\
\text { khel }\end{array}$ & $\begin{array}{c}\text { Gul- } \\
\text { bela }\end{array}$ & $\begin{array}{c}\text { Koch- } \\
\text { ian }\end{array}$ & $\begin{array}{c}\text { Dala- } \\
\text { zak }\end{array}$ & $\begin{array}{c}\text { Musht- } \\
\text { arzai }\end{array}$ & $\begin{array}{c}\text { All } \\
\text { Villages }\end{array}$ \\
\hline Only farmers & Percent & 78 & 30 & 89 & 100 & 84 & 70 & 82 \\
(n=158) & TLU & 12.9 & 1.6 & 4.3 & 2.9 & 2.5 & 2.0 & 4.7 \\
Farmers with non- farm & Percent & 54 & 51 & 92 & 86 & 66 & 53 & 62 \\
jobs (n=780) & TLU & 5.4 & 1.9 & 3.3 & 1.9 & 2.4 & 1.8 & 2.5 \\
Only non-farm & Percent & 15 & 31 & 35 & 43 & 35 & 30 & 29 \\
(n=1887) & TLU & 1.2 & 1.1 & 1.2 & 1.1 & 1.2 & 1.4 & 1.2 \\
All Households & Percent & 22 & 42 & 47 & 58 & 46 & 43 & 41 \\
Categories (n=2825) & TLU & 4.0 & 1.6 & 2.2 & 1.7 & 1.8 & 1.7 & 2.1 \\
\hline
\end{tabular}

Legend: TLU= Tropical Livestock Unit

Source: Basic survey carried out in six villages of Northwest Pakistan, 2004-05.

\footnotetext{
${ }^{86}$ To keep the analysis consistent with previous surveys, following MANIG (1991, pp. 106-107), the various types of animals were aggregated into 'Tropical Livestock Units' (TLU). One Tropical Livestock Unit (TLU) is equal to $250 \mathrm{Kg}$. The TLU values for different species of animals is: 1 for cattle older than 3 years; 0.5 for cattle under 3 years; 0.75 for buffalo female 1-3 years; 0.5 for buffalo male 1-3 years; 1.5 for buffalo older than 3 years; 0.5 for buffalo under 1 year; 0.5 for donkey/horse/mule for cattle; 0.1 for goat/sheep (see for details on TLU, ILCA, 1992).
} 


\section{HOUSEHOLD LIVELIHOOD DIVERSIFICATION AND STRATEGIES IN THE STUDY AREA}

This chapter addresses two broad questions related to livelihoods in the research area in Northwest Pakistan: how diverse are the livelihoods in the area and whether these activities are agriculture-led or urban-led? Diversity and heterogeneity have many different dimensions. However, there is increasing agreement within the research community that development should be directed on creating more diverse opportunities for rural people. This call for an immediate focus on the household, to understand household strategies, discriminating between different types of households and identifying opportunities to lift people out of poverty (ROVERE et al., 2006). Livelihood strategies of rural households are characterised by a wide diversity in resource endowments, activity choice and the prevailing conditions for engagement in market exchange (RUBEN \& Pender, 2004). The research presented here concerns the causes and consequences of this diversity based on fieldwork conducted in six villages of Northwest Pakistan. The chapter begins with diversity of livelihood in the area and the strategies pursued by the households in earning a living. A multivariate analysis is also conducted to analyse the determinants behind household diversity.The final section explores the question that whether the non-farm activities in the study villages agricultural led or urban led.

\subsection{Diversification Strategies according to Household Structure}

This section begins by broadly looking at the household income diversification strategies in the research area (Table 11). The following sections will investigate these household strategies in individual research village in more details. For comparability as well simplicity, the household income generating strategies are classified as: S1 (only farming), S2 (farming with non-farm jobs), and S3 (only non-agricultural activities). The basic survey identified three distinct rural income diversification strategies in the area. Only a few rural households (5.6\%) depend entirely on the farming as livelihood strategy (Strategy S1). For instance, full-time farmers earn all their income from agricultural production on lands they cultivate and from livestock they own. There is little demand for agricultural wage labourers' in the study villages so even the poor are unable to depend just on the farming sector. Some household belonging to income diversification strategies combine farm and non-farm earning (27.6\%) as they draws income both from their own on-farm production and from non-agricultural activities (Strategy S2). In the research area, two- 
third of all households (almost half of these wage-salary earners) received their income only from non-farm sector (Strategy S3). Informal daily wage activities ${ }^{87}$ accounted for nearly 66 percent of the Strategy VII (wage-salary category) revealing their survival nature. In addition, the jobs available to daily wagers and other low-skilled workers are often unstable, offer few benefits, and pay low wages. Majority of these perform unskilled manual labour while other due to their better assets endowments undertake better paid jobs.

Table 11. Household Income Diversification Strategies in the Study Area, 2004-05

\begin{tabular}{|c|c|c|c|}
\hline \multirow{2}{*}{\multicolumn{2}{|c|}{ Household Income Strategies }} & \multicolumn{2}{|c|}{ All Villages } \\
\hline & & \multirow{2}{*}{$\frac{\text { Number }}{19}$} & \multirow{2}{*}{$\frac{\text { percent }}{0.7}$} \\
\hline Strategy S1: Only farming & I: Landlords & & \\
\hline & II1: Owner operators & 44 & 1.5 \\
\hline & II2: Owner-cum-tenants & 8 & 0.3 \\
\hline & III: Tenants & 81 & 2.9 \\
\hline & $I V:$ Livestock & 6 & 0.2 \\
\hline \multirow{5}{*}{$\begin{array}{l}\text { Strategy S2: Farm and non- } \\
\text { farm }(27.6 \%)\end{array}$} & V1: Landlords and non-farm jobs & 125 & 4.4 \\
\hline & V2: Owner operators with non-farm & 409 & 14.5 \\
\hline & V3: Owner-cum-tenants with non-farm & 32 & 1.1 \\
\hline & V4: Tenants with non-farm & 204 & 7.2 \\
\hline & V5: Livestock with non-farm & 10 & 0.4 \\
\hline \multirow[t]{3}{*}{$\begin{array}{l}\text { Strategy S3: Pure non-farm } \\
(66.8 \%)\end{array}$} & $\begin{array}{l}V I: \text { Business and trade (skilled and } \\
\text { unskilled) }\end{array}$ & 507 & 17.9 \\
\hline & VII: Wage-salary & 1361 & 48.2 \\
\hline & VIII: Welfare related & 19 & 0.7 \\
\hline Total Households & & 2825 & 100 \\
\hline
\end{tabular}

Note: All figures and percentages presented in this table have been rounded to the next whole integer. Source: Basic survey in the six villages of Northwest Pakistan, 2004/05.

Small businesses were equally diverse, including everything from running a grocery shop to making and selling clothes. Street vendors listed as unskilled traders have neither permanent structures nor fixed spaces for their economic activity; though some like tea stall owners have rudimentary fixed premises. Others for instance fruit or vegetable sellers are mobile as they walk with pushing their cart around the street. Most of them work alone though family members may sometimes help.

${ }^{87}$ Informal wage-salary households constituted 48 percent of all the households in the study villages. 


\subsection{Diversification Strategies according to Household Categories across the Villages}

This section continues the discussion of household diversification strategies by looking its distribution across the six research villages. Table 12 summarized the 2825 surveyed households in the six villages in Northwest Pakistan according to their household categories. Broadly speaking, the research team noted as stated in the earlier section, three main livelihood strategies among the rural households in the study area.

\subsubsection{Households with Only Farming as Livelihood Strategy}

A total of 158 households were exclusively relying on farming as a livelihood strategy in the research villages. This broad category accounted for five further subcategories:

a) Landlord households: Only 19 or 0.7 percent of the total households have leased out their entire land and live exclusively from the rent they receive (Table 12). The landlords made up about 12 percent of the total 158 pure farming households (hh cat. I-IV). Similarly, Kochian and Gulbela alone accounted for nearly 68 percent of these 19 feudal households which in the majority of the cases lease out their land in a share cropping system (50-50 share of the produce).

b) Owner-Operator households: Around 39 percent of the total owner-operator households (3.2 percent of the total households in this village) were located in Mushtarzai, while Dalazak also had a sizeable portion (30 percent) of them. A limited land endowment on part of the farming households in these villages was partly responsible for this trend.

c) Owner-cum tenant households: The share of these households across the villages was non-significant except for Mushtarzai where just seven households had rented-in land along with cultivating their own land.

d) Tenant households: Just over half of the total farming households were tenants (hh cat. III) concentrated in Gulbela and Kochian.

e) Livestock households: Livestock rearing was not a prominent strategy in the survey villages. Kukar was the only village in which such households were found. 
Table 12. Distributions of Households in the Study Area according to their Diversification

\begin{tabular}{|l|cccccc|c|}
\hline $\begin{array}{l}\text { Household } \\
\text { Strategies }\end{array}$ & $\begin{array}{c}\text { Dalazak } \\
(n=380)\end{array}$ & $\begin{array}{c}\text { Gulbela } \\
(n=432)\end{array}$ & $\begin{array}{c}\text { Kochian } \\
(n=459)\end{array}$ & $\begin{array}{l}\text { Kukar } \\
(n=727)\end{array}$ & $\begin{array}{c}\text { Mushtarzai } \\
(n=539)\end{array}$ & $\begin{array}{l}\text { Yousafkhel } \\
(n=288)\end{array}$ & $\begin{array}{l}\text { All Villages } \\
(n=2825)\end{array}$ \\
\hline I $(n=19)$ & 0.04 & 0.25 & 0.21 & 0.11 & 0.04 & 0.04 & 0.67 \\
II1 $(n=44)$ & 0.46 & 0.04 & 0.04 & 0.18 & 0.60 & 0.25 & 1.56 \\
II2 $(n=8)$ & 0.00 & 0.00 & 0.00 & 0.00 & 0.25 & 0.04 & 0.28 \\
III $(n=81)$ & 0.18 & 0.64 & 1.27 & 0.46 & 0.28 & 0.04 & 2.87 \\
IV $(n=6)$ & 0.00 & 0.00 & 0.00 & 0.21 & 0.00 & 0.00 & 0.21 \\
V1 $(n=125)$ & 0.50 & 0.18 & 0.11 & 0.81 & 2.23 & 0.60 & 4.42 \\
V2 $(n=409)$ & 2.55 & 0.35 & 0.18 & 1.31 & 5.66 & 4.42 & 14.48 \\
V3 $(n=32)$ & 0.14 & 0.00 & 0.04 & 0.07 & 0.81 & 0.07 & 1.13 \\
V4 $(n=204)$ & 0.67 & 1.77 & 3.12 & 0.64 & 0.60 & 0.42 & 7.22 \\
V5 $(n=10)$ & 0.04 & 0.04 & 0.00 & 0.14 & 0.00 & 0.14 & 0.35 \\
VI $(n=507)$ & 3.15 & 1.88 & 3.19 & 7.72 & 1.66 & 0.35 & 17.95 \\
VII $(n=1361)$ & 5.73 & 9.81 & 7.89 & 13.98 & 6.94 & 3.82 & 48.18 \\
VIII $(n=19)$ & 0.00 & 0.35 & 0.21 & 0.11 & 0.00 & 0.00 & 0.67 \\
\hline Total $(n=2825)$ & 13.45 & 15.29 & 16.25 & 25.73 & 19.08 & 10.19 & 100.00 \\
\hline
\end{tabular}

Note: Values represent the percentage of respective household category in total households.

1) For explanation of these household strategies see Table 11.

Source: Basic survey in the six villages of Northwest Pakistan, 2004/05.

\subsubsection{Households with the Strategy of Combining Farming with Non-farming Activities}

Within the mixed-income households, members including head of the households combine income from independent farming with the non-agricultural employment (category V). The mixed income earning sources are diverse, as shown in Table 12. If one puts these households according to their prevalence in the survey villages, the order becomes V2, V4, V1, V3 and V5 (see Figure 10 for an explanation of the categories).

Tenant households (V4) accounted for around one-fifth of the households in Kochian where landlords have rented out small pieces of land as a strategy of influence and pressure. However, as a survival strategy, the tenants were engaged in non-agricultural jobs working, for example, as casual workers, permanently hired workers and employees, traders, officials, or were retired people.

The group of landowners who leased out their entire land to be able to take up a non-agricultural occupation (cat. V1) account for only four percent of the total households (Table 12). Nevertheless, farmers with only small plots of land are to be found mainly in this category. For various 
reasons, they do not want to sell the land because owning land has a certain degree of security and contributes to a higher social prestige. Most of these households (43 percent) were located in Yousafkhel where the rainfed nature makes it necessary for the owners to cultivate their land themselves.

\subsubsection{Households with Only Non-agricultural Activities as Livelihood Strategy}

Two-thirds of all the households (almost half of them wage-salary earners) received their income from non-agricultural earning sources alone. The wage-salary earning households accounted for 36-64 percent of the entire households across the villages. Roughly, one-third of all the households were economically based on the dependent occupation of their members (cat. VII).

Around 78 percent of the households were landless, while the share of landlord households (cat. I and V1) was five percent (Table 12). Looking across the villages, the landless households were in the range of 90-96 percent in Gulbela, Kochian, and Kukar, while almost 73 percent in Dalazak. Only in the tribal villages of Yousafkhel and Mushtarzai did the landless make up less (in the range of 47-49 percent) than the farming households (see Table 12 ). The neighbouring villages of Gulbela and Kochian on the Charsadda highway account for two-thirds of the total landlord households (cat. I) in the surveyed villages. In contrast, the share of the landlords with nonagricultural incomes was the lowest among the survey villages. Close to one-fifth of all the households belonged to businessmen households in which at least one member of the household carried out an independent occupation. The remaining household members could also receive their income from a dependent occupational source.

\subsection{Household Strategies: Empirical Application of Chayanov Model}

This section documents an important field of enquiry by using Pearson correlation between dependency ratio and output per household worker ${ }^{88}$ to investigate quantitatively the CHAYANOV concept of household strategies. Table 13 explores if CHAYANOV's theory motivates household

\footnotetext{
${ }^{88}$ Although the households were constructed according to criteria given in Figure 10, nevertheless the beginning sections of the basic survey documented information about the income sources of the household head and its members. Hence, the study was able to construct the variables for analysis.
} 
strategies, household output per worker (household monthly income divided by its workers) should be greater when the dependency ratio is high than when the dependency ratio is low.

The Pearson's correlation coefficient showed a moderate relationship between the dependency ratio and output per worker. The strength of the correlation is different across villages and household occupational categories. The overall correlation is positive and significant $(\mathrm{p}<0.1$ $\mathrm{r}=0.16$ ) supporting the CHAYANOV's theory. Thus, except Gulbela, Mushtarzai, and Yousafkhel the rest of the villages were following CHAYANOVIAN household strategies, that is, allocating labor based on a tradeoff between the provision of household members and the drudgery of labor. There were also households that were not assigning labour in this way (for instance, cat. V2 \& V3). Thus, these households have many dependants and few workers at their disposal. However, it is important to mention that households with plentiful workers and few dependents also followed Chayanovian strategies if they had rather low output per worker.

Table 13. Correlation between Dependency Ratio and Household Output per Worker

\begin{tabular}{|l|ccccccc|}
\hline Villages & Yousafkhel & Mushtarzai & Kochian & Gulbela & Dalazak & Kukar & $\begin{array}{c}\text { All } \\
\text { Villages }\end{array}$ \\
\hline Correlation & $\begin{array}{c}-0.38 \\
(0.10)\end{array}$ & $\begin{array}{c}-0.05 \\
(0.84)\end{array}$ & $\begin{array}{c}0.36 \\
(0.12)\end{array}$ & $\begin{array}{c}-0.03 \\
(0.91)\end{array}$ & $\begin{array}{c}0.24 \\
(0.30)\end{array}$ & $\begin{array}{c}0.41 \\
(0.07)\end{array}$ & $\begin{array}{c}0.16 \\
(0.09)\end{array}$ \\
\hline $\begin{array}{l}\text { Household } \\
\text { Categories }\end{array}$ & $\mathbf{V 1}$ & $\mathbf{V 2}$ & $\mathbf{V 3}$ & $\mathbf{V 4}$ & VI & VII & All HH \\
\hline Correlation & $\begin{array}{c}0.17 \\
(0.75)\end{array}$ & $\begin{array}{c}-0.02 \\
(0.92)\end{array}$ & $\begin{array}{c}-0.99 \\
(0.99)\end{array}$ & $\begin{array}{c}0.11 \\
(0.78)\end{array}$ & $\begin{array}{c}0.57 \\
(0.01)\end{array}$ & $\begin{array}{c}0.15 \\
(0.26)\end{array}$ & $\begin{array}{c}0.16 \\
(0.09)\end{array}$ \\
\hline
\end{tabular}

Note: Output per worker refers to household monthly income divided by the number of working members in the household. Similarly, dependency ratio refers to number of consumers (dependents) divided by number of workers. The figures in brackets are the P-values.

For a description of household categories see Figure 10.

Source: Basic survey in the six villages of Northwest Pakistan, 2004/05.

\subsection{Simpson, Shannon and Dissimilarity Indices of Household Diversity}

This section by considering diversity as a measure of variation compare the monetary status of the study households in the research area. To be specific, the degree of diversification across the household categories is calculated using the share of a household category ${ }^{89}$ income in total household income. A set of some well known indices like Simpson index, Shannon entropy, and Dissimilarity index are used for this purposes.

\footnotetext{
${ }^{89}$ For details of these household categories, see Figure 10.
} 
As pointed out by the high values of Simpson Index (D) in Table 14 that income diversity is low among livestock farmers, landlords, and owner operator-cum-tenants in the study area. The pure non-agricultural households (wage and self-employment) are engaged in a mix of diverse activities as suggested by the low Simpson values. Interestingly, households combining farming with non-farming activities are monetary more diversified compared to their farming counterparts. Shannon's entropy $(\mathrm{H})$ also revealed the diversity in household category in terms of their income. This index again revealed the same trend for the monetary diversity among the comparing household categories.

Table 14. Diversity Indices for Household Categories

\begin{tabular}{|c|c|c|c|}
\hline Household Strategies & $\begin{array}{l}\text { Simpson } \\
\text { Index }\end{array}$ & $\begin{array}{l}\text { Shannon } \\
\text { Entropy }\end{array}$ & $\begin{array}{c}\text { Dissimilarity } \\
\text { Index }\end{array}$ \\
\hline I: Only Landlords $(n=19)$ & 0.241 & 2.032 & 0.507 \\
\hline II1: Owner operators $(n=44)$ & 0.046 & 3.383 & 0.365 \\
\hline II2: Owner-cum-tenants $(n=8)$ & 0.179 & 1.901 & 0.222 \\
\hline III: Tenants $(n=81)$ & 0.035 & 3.962 & 0.321 \\
\hline IV: Livestock $(n=6)$ & 0.319 & 1.375 & 0.384 \\
\hline V1: Landlords with non-farm jobs $(n=125)$ & 0.013 & 4.547 & 0.313 \\
\hline V2: Owner operators with non-farm $(n=409)$ & 0.005 & 5.684 & 0.314 \\
\hline V3: Owner-cum-tenants with non-farm $(n=32)$ & 0.059 & 3.159 & 0.300 \\
\hline V4: Tenants with non-farm $(n=204)$ & 0.007 & 5.124 & 0.239 \\
\hline V5: Livestock with non-farm $(n=10)$ & 0.150 & 2.087 & 0.274 \\
\hline VI: Business and petty trade $(n=507)$ & 0.003 & 5.984 & 0.257 \\
\hline VII: Wage-salary $(n=1361)$ & 0.001 & 6.914 & 0.287 \\
\hline VIII: Welfare related $(n=19)$ & 0.072 & 2.784 & 0.238 \\
\hline I-IV: Only farmers $(\mathrm{n}=158)$ & 0.088 & 3.687 & 0.573 \\
\hline V1-V5: Farmers with non-farm jobs $(\mathrm{n}=780)$ & 0.003 & 6.328 & 0.317 \\
\hline VI-VIII: Only Non-farmers $(\mathrm{n}=1887)$ & 0.001 & 7.252 & 0.282 \\
\hline
\end{tabular}

Note: These indices were computed in Stata (ver. 9.2) using the 'ineq' module developed by NICHOLAS J. CoX. Source: Basic survey in the six villages of Northwest Pakistan, 2004/05

Index of Dissimilarity exhibits segregation or the extent to which different household categories in their income are separated from one another. Column three in Table 14 compares the per capita income of respective category to all other categories. The higher the Index, the more a household 
category is economically separated from the other category. The lower the Index, the more the categories are mixed together. The value can range from 0 to 1 , where a value of 1 means the category is totally separate from the other categories it is being compared with, and a value of 0 means it has the same distribution as the other category.

Table 14 shows, first, that pure landlord (hh cat. I) are highly segregated from the rest of the household categories in the study area, with an average dissimilarity index of 0.507 . A dissimilarity index of 0.51 for the pure landlord household would mean that 51 percent of their income would need to move to other household categories to make landlords and these categories evenly spread across the six research villages. Second, the rest of the household categories are moderately segregated, with a dissimilarity index in the range of $0.222-0.384$. This shows a significant degree of integration among these households.

\subsection{Multivariate Analysis For Household Diversity}

The following sections concern the results of logistic regression to investigate the factors assoctiated with household diversity. After a brief account of descriptive analysis, the econometric results are discussed in the subsequent section.

\subsubsection{Descriptive Analysis for Logit Model on Household Diversity}

Table 15 reveals the descriptive statistics for logistic model on household diversity. As evident the average age of the head of the household is about 47 years, suggesting that a large percentage of decision makers were relatively well experienced. Here age is taken as proxy for experience. The household landholding as well as tropical livestock units expressed in log averages about 0.3 expressing their limited availability at household level.

The numbers of male members within a household were higher on average compared to female members. Similarly, on average there were around two working members at the disposal of a typical household. Nevertheless, these working adults were in the range of 1-8. The extension villages (Kukar \& Dalazak) located within 10 kilometers range of provincial capital Peshawar were identical in average terms to the villages Gulbela and Kochian as shown in Table 15. 
Table 15. Summary Statistics of Logit Model on Household Diversity

\begin{tabular}{|clcccc|}
\hline Dep. Var & Description & Mean & Std. Dev. & Min & Max \\
\cline { 1 - 3 } HHD & 1 if household diversified ${ }^{1}$, 0 otherwise & 0.8 & 0.3 & 0 & 1 \\
\cline { 1 - 1 } Ind. Var & & & & & \\
\cline { 1 - 2 } & Age of household head in years & 47.4 & 11.7 & 15 & 85 \\
EDU & 1 if educated matric \& above, 0 otherwise & 0.2 & 0.4 & 0 & 1 \\
MAL & Number of male members in household & 4.9 & 2.8 & 1 & 23 \\
FEM & Number of female members in household & 4.2 & 2.5 & 0 & 15 \\
HHW & Number of household members working & 2.3 & 1.4 & 1 & 8 \\
LVK & Log of Tropical Livestock Unit & 0.3 & 0.9 & -2.3 & 4.6 \\
LND & Log of acres of owned land & 0.3 & 1.1 & -3.5 & 5.1 \\
FVL & 1 if HH lives in Kochian \& Gulbela, 0 otherwise & 0.2 & 0.4 & 0 & 1 \\
NVL & 1 if HH resides in Kukar \& Dalazak, 0 otherwise & 0.2 & 0.4 & 0 & 1 \\
\hline
\end{tabular}

Note: All figures presented in this table have been rounded to the next whole integer.

Legend: Dep. Var = Dependent variable Ind. Var $=$ Independent variables $\mathrm{HH}=$ Household

1) Household diversification is measured on a binary scale with 1 representing those engaged in farming along with non-agricultural activities and 0 refers to those engaged in only farming activities.

Source: Basic survey carried out in six villages of Northwest Pakistan, 2004-05.

\subsubsection{Results: Determinants of Diversification}

Table 16 presents logistic regression results modelling the determinants of household diversification as measured by households in farming with non-farm work. The study measured diversification on the basis of household combining agriculture with non-agriculture activities as according to Schwarze, 2004; and SchwarZE \& ZELLER, 2005, the term diversification in such circumstances is often used in the sense of diversification out of the agricultural sector, i.e. as a shift of activities which are not related only to agriculture. The explanatory variables used in the model explain around 27 percent variation in diversification among the surveyed households. Moreover, the collinearity diagnostics shown in Table 18 for the model are within the acceptable range (for details, see HAMILTON, 2006).

Human capital matters. More educated household head facilitates diversification. Specifically, each another year of household head education increases nearly nine percent the likelihood for the household to diversity. Also, there is strong evidence that household diversification is positively and significantly associated with the working members in a household; that is, rather more active members typically draw a larger share of income outside cropping. This result suggests 
that households with more economically active members have more hands available for income earning off the farm, including daily wage labor or petty commerce (this is consistent with BLOCK \& WEBB, 2001).

Table 16. Logit Analysis of Factors Affecting Household Diversification in the Study Area

\begin{tabular}{|lcccc|}
\hline Variables & Coefficients & $\begin{array}{c}\text { Standard } \\
\text { Errors }\end{array}$ & $\begin{array}{c}\text { Odd } \\
\text { Ratios }\end{array}$ & $\begin{array}{c}\text { Marginal } \\
\text { Effects }\end{array}$ \\
\hline AGE & -0.006 & 0.010 & 0.994 & -0.001 \\
EDU & $1.203 * * *$ & 0.284 & 3.329 & 0.088 \\
MAL & -0.062 & 0.061 & 0.940 & -0.005 \\
FEM & 0.007 & 0.061 & 1.007 & 0.001 \\
HHW & $1.343^{* * *}$ & 0.165 & 3.831 & 0.099 \\
LVK & $-0.825^{* * *}$ & 0.136 & 0.438 & -0.061 \\
LND & $-0.363^{* * *}$ & 0.102 & 0.696 & -0.027 \\
FVL & $-1.289 * * *$ & 0.249 & 0.275 & -0.095 \\
NVL & $-0.793^{* * *}$ & 0.273 & 0.453 & -0.058 \\
Constant & 0.536 & 0.475 & & \\
Observations: 938 & R-squared: 0.266 & McFadden's Adj R ${ }^{2}: 0.242$ & \\
LR chi2(9): 225.92 & Prob $>$ chi2: 0.000 & Log likelihood: -312.34 & \\
\hline
\end{tabular}

$* * * \mathrm{p}<0.01, * * \mathrm{p}<0.05,{ }^{*} \mathrm{p}<0.1$

All figures presented in this table have been rounded to the next whole integer.

Source: Basic survey carried out in six villages of Northwest Pakistan, 2004-05.

There is also suggestive evidence that households located in the extension villages (Kukar \& Dalazak) tend to be less diversified than in the tribal villages (Yousafkhel \& Mushtarzai) mainly because of the limited role of agriculture and remittances in their economy. Similarly, although there is higher density of population, and roads and markets in Kochian and Gulbela, there is almost six percent less probability for the dwellers of these villages to diversify relative to the reference villages. Again the shrinking farming area due to growing population explains for this phenomenon. While some of the findings were consistent with expectations, a number of unexpected results also emerged. For example, age of the household was statistically insignificant contrary to findings elsewhere in the literature. Also, as expected, the positive coefficient estimates for number of females in a household suggest diversification; however, the coefficient is non-significant. The coefficient on land and livestock ownership addresses the role of assets as determinants of diversification. Both of these farm assets are associated negatively with household diversification. The level of livestock ownership is negatively and significantly associated with household diversification, resulting from their limited endowment in the area. 
Table 17 provides an intercorrelation matrix for the variables used in the logistic regression. As shown by the first column of this matrix, the seemingly weak correlation is positive and significant between those who diversified (HHD) and majority of the explanatory variables. However, for a few variables this linear correlation is nevertheless significant but negative, for instance, household assets (livestock and land ownership) and location in extension villages (Kukar \& Dalazak).

Table 17. Correlation among Variables used in Logit Model for Household Diversity

\begin{tabular}{|cccccccccccc|}
\hline & & $(1)$ & $(2)$ & $(3)$ & $(4)$ & $(5)$ & $(6)$ & $(7)$ & $(8)$ & $(9)$ & $(10)$ \\
$(1)$ & HHD & 1.00 & & & & & & & & \\
$(2)$ & AGE & 0.06 & 1.00 & & & & & & & \\
& & $(0.09)$ & & & & & & & & \\
$(3)$ & EDU & 0.05 & -0.19 & 1.00 & & & & & & \\
& & $(0.12)$ & $(0.00)$ & & & & & & & \\
$(4)$ & MAL & 0.13 & 0.34 & -0.12 & 1.00 & & & & & \\
& & $(0.00)$ & $(0.00)$ & $(0.00)$ & & & & & & \\
$(5)$ & FEM & 0.09 & 0.23 & -0.07 & 0.61 & 1.00 & & & & \\
& & $(0.01)$ & $(0.00)$ & $(0.04)$ & $(0.00)$ & & & & & \\
$(6)$ & HHW & 0.28 & 0.41 & -0.16 & 0.67 & 0.50 & 1.00 & & & \\
& & $(0.00)$ & $(0.00)$ & $(0.00)$ & $(0.00)$ & $(0.00)$ & & & & \\
$(7)$ & LVK & -0.20 & 0.14 & -0.06 & 0.16 & 0.19 & 0.17 & 1.00 & & \\
& & $(0.00)$ & $(0.00)$ & $(0.05)$ & $(0.00)$ & $(0.00)$ & $(0.00)$ & & & \\
$(8)$ & LND & -0.11 & 0.10 & 0.19 & 0.15 & 0.10 & 0.04 & 0.10 & 1.00 & \\
& & $(0.00)$ & $(0.00)$ & $(0.00)$ & $(0.00)$ & $(0.00)$ & $(0.19)$ & $(0.00)$ & & \\
$(9)$ & FVL & -0.20 & 0.05 & -0.04 & 0.05 & 0.06 & 0.02 & 0.20 & 0.03 & 1.00 \\
& & $(0.00)$ & $(0.12)$ & $(0.24)$ & $(0.15)$ & $(0.05)$ & $(0.62)$ & $(0.00)$ & $(0.32)$ & \\
$(10)$ & NVL & -0.04 & 0.04 & 0.24 & -0.04 & -0.03 & -0.01 & 0.10 & 0.03 & -0.34 & 1.00 \\
& & $(0.27)$ & $(0.18)$ & $(0.00)$ & $(0.18)$ & $(0.39)$ & $(0.77)$ & $(0.00)$ & $(0.34)$ & $(0.00)$ \\
\hline
\end{tabular}

Note: Values in the brackets shows the significance levels.

Source: Basic survey carried out in six villages of Northwest Pakistan, 2004-05.

Table 18. Collinearity Diagnostics for Logit Model on Household Diversity

\begin{tabular}{|lcccc|}
\hline Variable & VIF & SQRT VIF & Tolerance & R-Squared \\
\hline AGE & 1.27 & 1.13 & 0.7855 & 0.2145 \\
EDU & 1.18 & 1.09 & 0.8456 & 0.1544 \\
MAL & 2.26 & 1.50 & 0.4415 & 0.5585 \\
FEM & 1.66 & 1.29 & 0.6010 & 0.3990 \\
HHW & 2.01 & 1.42 & 0.4970 & 0.5030 \\
LVK & 1.15 & 1.07 & 0.8724 & 0.1276 \\
LND & 1.09 & 1.05 & 0.9141 & 0.0859 \\
FVL & 1.21 & 1.10 & 0.8232 & 0.1768 \\
NVL & 1.26 & 1.12 & 0.7917 & 0.2083 \\
Mean VIF & 1.46 & & & \\
\hline
\end{tabular}

Source: Basic survey carried out in six villages of Northwest Pakistan, 2004-05. 


\subsection{Livelihood Activities in the Research Area Agriculture Led or Urban Induced}

In this section, the study attempts to answer the research question whether the prevailing economic activity (non-farm) in the study area primary agriculture-led or the growth impulses urban based. The socio-econmic data of six research villages obtained by the basic survey serve as proxies for the presence of agriculture and urban linkages in the growth of non-agricultural activities.

Table 19 provides through an inter-correlation matrix the possible relationship between proportion of non-agricultural workers and various socio-economic variables. From the first column of Table 19, it can be seen that irrigated farmland (IFRMAREA) has the highest correlation $(\mathrm{r}=$ $0.45 \mathrm{p}<0.01$ ) with the proportion of non-agricultural workers (NFRMLAB), followed by livestock and the ratio of agricultural laborers to farmers (AGRLAB). However, the correlation is negative and significant between the proportion of non-farm workers and various socio-economic determinants. It reinforces the fact that the prevailing non-farm sector in the area is informal, requiring less in assets and human capital from the workers. Most of the determinants are correlated significantly with the distance (kms) from provincial capital, Peshawar (URBANEF). In order, to highlight the urban effect, we need to look at the individual villages.

Table 19. Correlation Matrix of Proportion of Non-Farm Workers and its Determinants

\begin{tabular}{|llccccccccc|}
\hline & & $(1)$ & $(2)$ & $(3)$ & $(4)$ & $(5)$ & $(6)$ & $(7)$ & $(8)$ & $(9)$ \\
$(1)$ & NFRMLAB & 1.00 & & & & & & & & \\
$(3)$ & EMPRATE & -0.01 & 1.00 & & & & & & \\
$(4)$ & AGRMFRMER & 0.05 & -0.13 & 1.00 & & & & & \\
$(5)$ & EDURATE & $-0.19^{*}$ & $-0.15^{* *}$ & $0.28^{*}$ & 1.00 & & & & \\
$(6)$ & LIVESTOCK & $-0.24^{*}$ & 0.01 & 0.11 & 0.08 & $-0.09^{+}$ & 1.00 & & \\
$(7)$ & FRMAREA & $-0.13^{* *}$ & -0.07 & $0.95^{*}$ & $0.27^{*}$ & -0.07 & $0.19^{*}$ & 1.00 & \\
$(8)$ & IFRMAREA & $-0.45^{*}$ & -0.00 & $0.26^{*}$ & $0.37^{*}$ & $0.13^{*}$ & $0.27^{*}$ & $0.45^{*}$ & 1.00 & \\
$(9)$ & URBANEF & $-0.15^{*}$ & $-0.06^{+}$ & $0.14^{* *}$ & -0.12 & $0.21^{*}$ & $-0.12^{*}$ & $0.12^{* *}$ & 0.01 & 1.00 \\
\hline
\end{tabular}

Note: * Significant at $1 \%, * *$ significant at $5 \%,+$ significant at $10 \%$

Legend: NFRMLAB $=$ Non-farm workers of all workers $(\%)$ EMPRATE $=$ Employment rate in village $(\%)$ FRMFRMER $=$ Ratio of actual farm acres/ no. of farmers AGRLAB $=$ Ratio of agri. laborers to farmers EDURATE $=$ Literacy in village $(\%) \quad$ LIVESTOCK $=$ Tropical Livestock Unit FRMAREA $=$ Actual farm area (acres) $\quad$ IFRMAREA $=$ Actual irrigated area (acres) URBANEF $=$ Distance of individual research village from provincial capital Peshawar (kms) Source: Basic survey of six villages in Northwest Pakistan, 2004/05. 
Table 20 further explores the urban effect by comparing the averages of various socio-economic indicators across the three categories of villages. As can be seen, the extension villages (Kukar \& Dalazak) offer more on average in non-farm employment; however, majority of these are in informal sector ${ }^{90}$ because of low literacy rate $(29 \%)$. The extension villages being part of an urban agglomeration as they are located just within $10 \mathrm{kms}$ range of provincial capital Peshawar and hence they are more responsive to the economic stimuli emerging from the metropolis. In case of the midlevel villages of Kochian and Gulbela, the economic impulses emerges partly from Peshawar as well as the neighbouring cities of Charsadda and Mardan ${ }^{91}$.

\section{The influence of agriculture is slightly more prominent in the economies of midlevel villages} as obvious from farm area, irrigation farm, farms per number of farmers, and the ratio of agriculture labourers to farmers. Similarly, because of rainfed nature of Yousafkhel, the tribal villages offer less in agriculture.

Table 20. Socio-economic Indicators Conveying Urban Effect across Villages Categories

\begin{tabular}{|lcccc|}
\hline & \multicolumn{4}{c|}{ Villages } \\
\cline { 2 - 5 } Indicators & $\begin{array}{c}\text { Extension } \\
(<=8 \mathrm{kms})\end{array}$ & $\begin{array}{c}\text { Midlevel } \\
(17 \mathrm{kms})\end{array}$ & $\begin{array}{c}\text { Tribal } \\
(<=23 \mathrm{kms})\end{array}$ & $\begin{array}{c}\text { All } \\
(5-23 \mathrm{kms})\end{array}$ \\
\hline Non-farm workers of all workers (\%) & $97.4(100)$ & $94.8(100)$ & $88.9(100)$ & $94.1(100)$ \\
Employment rate in village (\%) & $26(22)$ & $25(20)$ & $25(23)$ & $26(22)$ \\
Ratio of actual farm acres/ no. of farmers & $2.7(2.3)$ & $3.0(2.0)$ & $2.5(1.0)$ & $2.7(1.5)$ \\
Ratio of agri. laborers to farmers & $2.9(2.0)$ & $3.7(2.0)$ & $0.4(0.0)$ & $2.0(0.5)$ \\
Literacy in village (\%) & $29.4(25.7)$ & $34.2(37.4)$ & $29.1(30.8)$ & $30.8(30.8)$ \\
Tropical livestock unit & $2.9(1.1)$ & $1.9(1.0)$ & $1.7(1.5)$ & $2.1(1.1)$ \\
Actual farm area (acres) & $2.7(2.0)$ & $3.7(2.0)$ & $2.4(1.0)$ & $2.8(1.5)$ \\
Actual irrigated area (acres) & $2.7(2.0)$ & $3.2(2.0)$ & $1.1(0.63)$ & $2.3(1.0)$ \\
\hline
\end{tabular}

Legend: Extension villages $=$ Kukar+Dalazak $\quad$ Midlevel villages $=$ Gulbela + Kochian

Tribal villages $=$ Yousafkhel + Mushtarzai

The village Mushtarzai was same distance from Peshawar as the midlevel villages however, because of its tribal socio-economic setup, we considered it with Yousafkhel.

Note: Medians values in brackets.

Source: Basic survey of six villages in Northwest Pakistan, 2004/05

\footnotetext{
${ }^{90}$ The concept of informal sector was first introduced by KEITH HART's research in Accra, Ghana in 1972, and was internationalized by the work of the World Employment Mission to Kenya (KING, 2001).

${ }^{91}$ Mardan, with its 1632 sq. km fertile land and heavy industrial is a strategic district of the North West Frontier Province (NWFP). The district was named 'Mardan' in the honour of Pir Mardan Shah, a prominent religious figure of his time. It became an independent district after its detachment from District Peshawar in 1937 (GOVERNMENT OF PAKISTAN, 2000).
} 


\section{LIVELIHOOD OUTCOME: PROFILE OF POVERTY IN THE AREA}

This chapter addresses the poverty dynamics of the rural households concerning about the extensive and deep poverty in rural Northwest Pakistan, and the desire to understand the causes that contributes to the persistence of poverty, in order to transcend it. The overall research question was: What is the role of household's endowment with capitals to the outcome of their livelihood strategies for well-being? The ultimate objective is to translate this knowledge into better interventions for poverty reduction. The chapter begins with a brief descriptive summary of living standard in the research area as revealed by household survey data for 2004-05, and then uses regression analysis to study the determinants of poverty.

\subsection{Household Income Distribution}

To explore the overall household income inequality in the study area, it is essential to account for income differences across the villages and the principal household categories. Monthly mean total household income in the basic survey was estimated to be Rs. 7505, indicating a mean level of per capita income of Rs. 1058, which confirms the general poverty status of the population of Northern Pakistan (see GOVERNMENT OF PAKISTAN, 2005a).

Table 21. Percapita Monthly Household Income by Income Quartile

\begin{tabular}{|l|cccc|}
\hline \multirow{2}{*}{ Villages } & \multicolumn{4}{|c|}{ Income $^{1}$ quartiles } \\
\cline { 2 - 5 } & $\begin{array}{c}\text { Low } \\
(\mathrm{n}=589)\end{array}$ & $\begin{array}{c}2^{\text {nd }} \\
(\mathrm{n}=1041)\end{array}$ & $\begin{array}{c}3^{\text {rd }} \\
(\mathrm{n}=833)\end{array}$ & $\begin{array}{c}\text { High } \\
(\mathrm{n}=362)\end{array}$ \\
\hline Dalazak $(n=380)$ & 12.37 & 30.79 & 36.84 & 20.00 \\
Gulbela $(n=432)$ & 25.23 & 38.19 & 26.16 & 10.42 \\
Kochian $(n=459)$ & 23.75 & 39.43 & 27.45 & 9.37 \\
Kukar $(n=727)$ & 20.91 & 36.04 & 32.05 & 11.00 \\
Mushtarzai $(n=539)$ & 18.55 & 38.78 & 26.90 & 15.77 \\
Yousafkhel $(n=288)$ & 25.00 & 37.15 & 26.39 & 11.46 \\
Total $(n=2825)$ & 20.85 & 36.85 & 29.49 & 12.81 \\
\hline
\end{tabular}

Legend: Low = less than Rs. $425 \quad$ 2nd = Rs. 425-849 $\quad$ 3rd = Rs. 850-1698 $\quad$ High = more than Rs. 1698

These quartiles were constructed following the monthly poverty line of Rs. 849 per household member for Pakistan (GOVERNMENT OF PAKISTAN, 2004), hence, the lowest quartile (I) is half of this poverty line while the highest quartile is more than double of the official poverty line.

1) Data shows in percentage terms household monthly per capita income in Pakistani rupees.

Source: Basic survey in the six villages of Northwest Pakistan, 2004-05. 
Table 21 shows how income is distributed by income quartiles across the study villages. For the highest quartile, 20 percent of income comes from village Dalazak. The income shares of the second quartile are relatively well balanced across villages, demonstrating the capacity of the households to diversify. On the other hand, the share of income for the lowest quartile is relatively concentrated in Gulbela and Yousafkhel which account for together 50 percent of earnings followed by 24 percent in Kochian, 21 percent in Kukar and only 12 percent in Dalazak. Except Dalazak and Kukar, the third quartile (Rs. 850-1698) is uniformly distributed.

\section{Figure 14. Percapita Monthly Household Income Distribution}

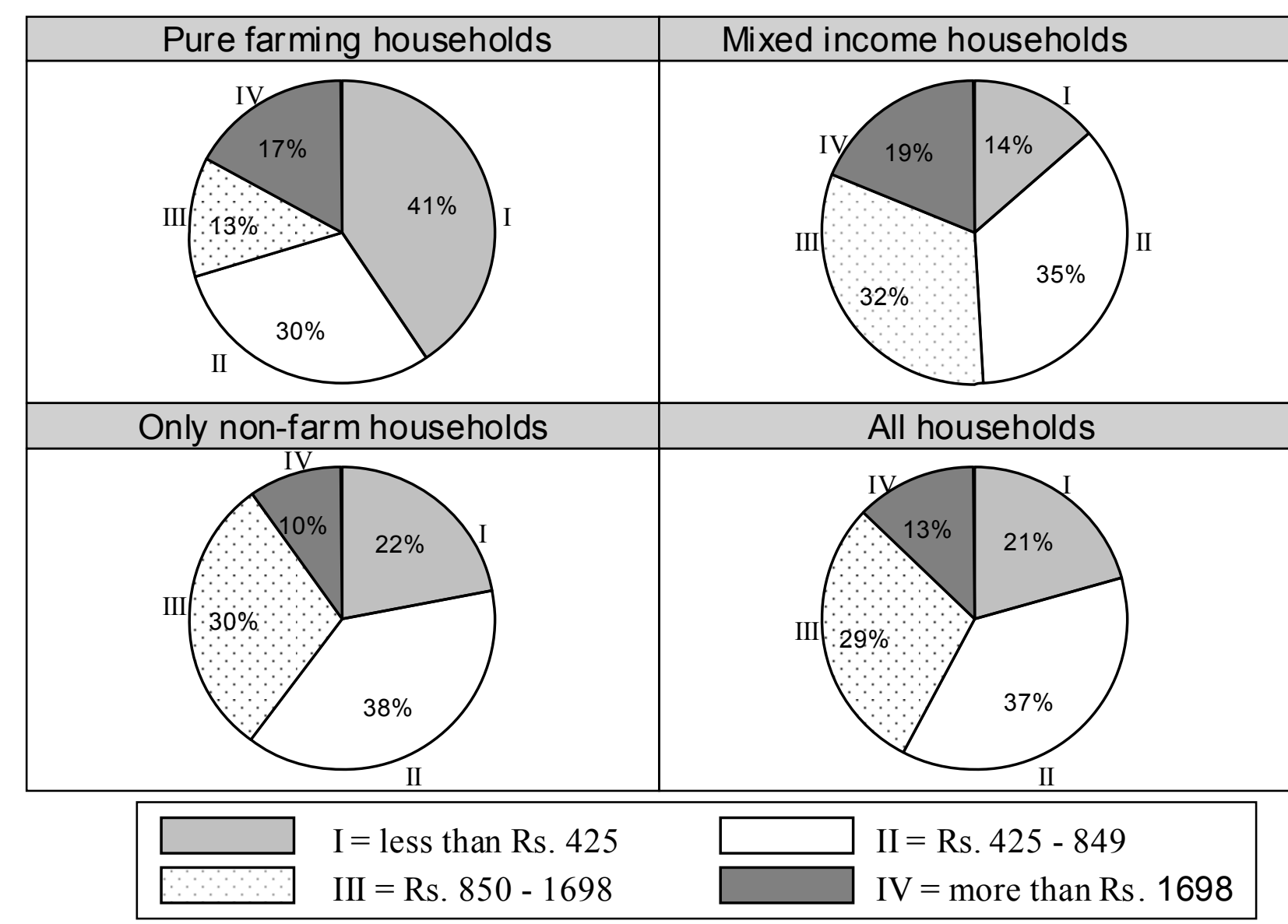

Note: 1) Data shows in percentage terms household monthly per capita income in Pakistani rupees.

Source: Basic survey in the six villages of Northwest Pakistan, 2004/05

Figure 14 sketches the distribution of the same income quartiles for the major household categories. From the figure, one can observe that all quartiles show larger variability. Households 
combining farming with non-farming activities (mixed income households) account for the highest share $(19 \%)$ of the highest quartile owing to their better assets situation and capacity to diversify. It is revealing to know in Figure 14 that 41 percent of the lowest income group belong to pure farming households compared with only 21 percent overall. The pure farming households were dominated by tenant households and this clearly highlights the dismal economic position of these tenants in the area, whose livelihoods are survival oriented based on subsistence farming.

\subsection{Poverty Indices for the Rural Households in the Research Area}

SEN, 1976 considered the possession of three major properties for a good summary index of poverty measure. Firstly, the index must be sensitive to the relative number of poor, capturing the incidence of poverty. Secondly, the index must be sensitive to the average level of income of the poor, indicating their average deprivation. Lastly, the index must be sensitive to the distribution of income among the poor, indicating their degree of relative deprivation. As the FOSTER, GREER and THORBECKE, 1984 poverty measure possesses all these three properties, hence we decided for its use to document poverty in the study villages.

Table 22 presents the results of the headcount index (Po), poverty gap (P1) and poverty severity (P2) for six research villages in Northwest Pakistan based on the poverty line of Rs. 849 as cutoff point ${ }^{92}$. The same three indices were also applied to the household categories in the area (see Table 23). The data for the poverty analysis came from the basic survey of 2825 households in the six research villages. The first glance at both of these tables (Table $22 \&$ Table 23) reveal shocking realities as in majority of the villages and the households' categories within these villages more than half of households are living below poverty line.

Based on the Rs. 849 poverty line headcount ratios, our results suggest that the village with the lowest poverty incidence is Dalazak, followed by Kukar, and Mushtarzai. Poverty is highest in Gulbela, with Kochian and Yousafkhel also showing high headcounts (Table 22).

\footnotetext{
${ }^{92}$ Although expenditure data are generally regarded as the most effective way of capturing household economic status, however, the complexity of capturing such sensitive data in a complex rural society like Northwest Pakistan where migrancy, remittance, and social capital are all important components of the context should not, however, be underestimated (see for details, AlBRECHT, 1976; KHAN, 2007; MANIG, 1991).
} 
Table 22. Poverty Indices for the Research Villages

\begin{tabular}{|lccccccc|}
\hline PovertyIndices & \multicolumn{7}{c|}{ Research Villages } \\
\cline { 2 - 8 } & $\begin{array}{c}\text { Dalazak } \\
(n=380)\end{array}$ & $\begin{array}{c}\text { Gulbela } \\
(n=432)\end{array}$ & $\begin{array}{c}\text { Kochian } \\
(n=459)\end{array}$ & $\begin{array}{c}\text { Kukar } \\
(n=727)\end{array}$ & $\begin{array}{c}\text { Mushtarzai } \\
(n=539)\end{array}$ & $\begin{array}{c}\text { Yousafkhel } \\
(n=288)\end{array}$ & $\begin{array}{c}\text { Total } \\
(n=2825)\end{array}$ \\
\hline Head count $\left(\mathrm{P}_{\mathrm{o}}\right)$ : percent & 43.2 & 63.4 & 63.2 & 57.0 & 57.3 & 62.2 & 57.7 \\
Poverty gap $\left(\mathrm{P}_{1}\right)$ : percent & 15.5 & 27.5 & 26.2 & 23.2 & 22.1 & 26.3 & 23.4 \\
$\begin{array}{l}\text { Poverty severity }\left(\mathrm{P}_{2}\right): \mathrm{x} 100 \\
\text { No. of poor }\end{array}$ & 7.6 & 14.6 & 13.8 & 12.3 & 11.2 & 14.4 & 12.3 \\
$\begin{array}{l}\text { Mean of poverty line } \\
\text { amongst poor }\end{array}$ & 164 & 274 & 290 & 414 & 309 & 179 & 1630 \\
$\begin{array}{l}\text { Mean of poverty gap } \\
\text { amongst poor }\end{array}$ & 545.0 & 480.9 & 496.5 & 503.6 & 522.5 & 490.0 & 504.8 \\
\hline
\end{tabular}

Source: Basic Survey in six villages of Northwest Pakistan, 2004-05.

Considering the pattern of poverty by household categories, the pure farmers (hh-cat. I-IV) are, by far, the most likely to be poor (Table 23). As expected, the landlord households (hh-cat. V1) with a value of $P_{o}$ of 25 percent, are least likely to be below the poverty line relative to other categories, seemingly because of their better assets.

A particularly large contribution to poverty is also made by households classified as mixed tenants (hh-cat. V4) and those engaged in only non-agricultural salary-wage activities (hh-cat. VII). As an important point of contrast, the headcount ratio $\mathbf{P}_{\mathbf{0}}$ is higher among households which are in the salary-wage employment (hh-cat. VII) than among those in self-employment (hh-cat. VI). The predominance of casual and informal nature of jobs in the non-farm wagesalary sector in the area explains this phenomenon. This view was confirmed by NOMAAN, 2000 that real wages of casual workers in Pakistan improved up to the mid 1980s, during the 1990s they declined.

Table 22 and Table 23 also signal the seriousness of poverty depth as well as its severity, suggesting that most households are living in severe poverty. This is further reinforced by the value (12.3) of severity of poverty (P2) at the village level (Table 22). Once the depth of poverty is considered in computing the poverty indices, the village and house categories differential becomes even more marked. But in other respects the pattern of poverty is similar to that described above for $\mathrm{P}_{\mathrm{o}}$. Again the largest contribution to poverty comes from agricultural households in the study area. This suggests the presence of significant inequality among the households in the area. 
Table 23. Poverty Indices for Household Categories

\begin{tabular}{|c|c|c|c|c|c|c|}
\hline \multirow{2}{*}{$\begin{array}{l}\mathrm{HH} \\
\text { Cat. }\end{array}$} & \multicolumn{6}{|c|}{ Poverty Indices } \\
\hline & $\begin{array}{l}\text { Head count } \\
\left(\mathrm{P}_{\mathrm{o}}\right): \%\end{array}$ & $\begin{array}{l}\text { Poverty gap } \\
\left(\mathrm{P}_{1}\right): \%\end{array}$ & $\begin{array}{l}\text { Poverty severity } \\
\left(\mathrm{P}_{2}\right): \times 100\end{array}$ & $\begin{array}{c}\text { No. of } \\
\text { poor } \mathrm{HH}\end{array}$ & $\begin{array}{l}\text { Mean of poverty } \\
\text { line amongst poor }\end{array}$ & $\begin{array}{l}\text { Mean of poverty gap } \\
\text { amongst poor }\end{array}$ \\
\hline I-IV & 70.3 & 37.4 & 23.1 & 111 & 397.1 & 451.9 \\
\hline V1 & 24.8 & 9.0 & 4.5 & 31 & 539.8 & 309.3 \\
\hline V2 & 46.7 & 16.6 & 7.8 & 191 & 547.3 & 301.7 \\
\hline $\mathrm{V} 3$ & 56.3 & 15.3 & 5.2 & 18 & 617.9 & 231.1 \\
\hline V4 & 67.2 & 27.0 & 13.5 & 137 & 507.2 & 341.8 \\
\hline V5 & 50.0 & 15.6 & 5.2 & 5 & 584.9 & 264.1 \\
\hline VI & 51.5 & 19.2 & 9.2 & 261 & 533.3 & 315.8 \\
\hline VII & 63.0 & 25.7 & 13.5 & 857 & 503.2 & 345.8 \\
\hline
\end{tabular}

Note: See Figure 10 for explanation on household categories.

Source: Basic Survey in six villages of Northwest Pakistan, 2004-05.

\subsection{Poverty Related Indicators Across the Study Villages}

Looking at the Table 24 gives some idea of the range of well-being described for residents of the research area, where even the basic services and opportunities are either missing or limited. Around 26 percent of the men ${ }^{93}$ hold daily wage jobs as their primary activity across the study villages $^{94}$. Majority of the wage laborers are unskilled manual workers, and just a few hold semi-skilled jobs. There are substantial differences across the villages in the distribution of these workers. For example, the proportion of wage labourers' is much higher (45\%) in Gulbela than in Dalazak, Kukar, and Kochian, where altogether they accounted for 45 percent. In Gulbela, most of them were working as construction workers at a nearby river in Naguman. The dependency ratio is 153 percent for the Kochian, 118 percent for the Dalazak and 83 percent for the households in Kukar. This pattern also holds for the other research villages with some variation.

Although two-third of the economically active household workers were illiterate, nevertheless these workers in Mushtarzai, Kochian, and Dalazak have in percentage terms, much more schooling than the rest of the villages (Table 24). There is slight variation in the size of house

\footnotetext{
${ }^{93}$ Only few women were economically active in the area due to religious and Pathun cultural constraints so in our analysis we considered it as men job.

${ }^{94}$ Majority of these wage labourers have to work long hours in bad working conditions resulting occassionaly in work place injuries. For instances, the respondents in the study area were working on average nearly 9.7 hours a day with a refreshment break of around 52 minutes. The bulk of them (64\%) were working under dirty environmental conditions resulting for work place injuries (28\%). Majority reoprted hand/leg injuries, eye problems, back injuries, electric shocks, and burnt.
} 
measured in marlas, however, there is not much difference in the number of rooms per person across the villages. Interestingly, the size of home was large (18 marlas) in Yousafkhel relative to other villages, but contrary the number of rooms per person there matched the over all mean. This village has many extended families living together in one compound reflected in the high (9.1) household size.

Interestingly simply having access to pipe water in the home suggests that water remains a key, limited resource for most households in the study area. The main drinking water sources for the study area are largely wells (45\%), followed by water delivered through taps $(27 \%)$, and electric pumps $(16 \%)$ installed at home ${ }^{95}$. The presence of vehicles (cars, vans, buses, and truck) were limited only to the wealthiest households $(3 \%)$, as it was a sign of status for these households in the area. Although half of the households owned land in Mushtarzai and Yousafkhel, however, the rainfed characteristic of Yousafkhel and the small and fragmented nature of land in Mushtarzai force the people for livelihood other than farming. There does not appear to be much difference in the livestock ownership across the villages (Table 24). Except Kukar and Gulbela with a handful of small family run dairy farms, the livestock was mostly kept for house consumption.

Table 24 indicates that ownership of dwelling varies slightly across villages. Every household own their dwellings in Yousafkhel and Mushtarzai due to the tribal nature and the limited rented markets in these villages. Ownership rates are about 90 percent in the Dalazak while for the rest of the villages it is in the range of 65-75 percent. As stated earlier, the rented market is nascent in the area as only four percent households were living in rented houses while 82 percent were house owners. Kukar and Dalazak because of their vicinity to the provincial capital Peshawar and the resulting commercialization trends represented all the rented houses. Some households (14\%) in Gulbela, Kochian, and Kukar were living in landlord provided houses (mena) free of cost.

A somewhat similar pattern is observed in the case of structure of dwellings. Just over half of the dwellings in the research area are made from permanent materials (Pakka houses). However, dwellings are less likely to be built of permanent materials in the Yousafkhel (about 5 percent and 0 percent for both floors and roofs) compared to the Kochian, Kukar, and Mushtarzai (almost 50 percent for floors and 45 percent for roofs). In the research villages, while the rural households do not differ much in the value of their dwellings, there is slight difference in the percentages of houses with better sanitary conditions and improvement made in house.

\footnotetext{
${ }^{95}$ Around eight percent households obtained their drinking water from their neighbours.
} 
Table 24. Various Socio-economic Poverty Related Indicators in the Study Area

\begin{tabular}{|lccccccc|}
\hline Indicator & $\begin{array}{c}\text { Dala } \\
\text { zak }\end{array}$ & $\begin{array}{c}\text { Gul } \\
\text { bela }\end{array}$ & $\begin{array}{c}\text { Koch } \\
\text { ian }\end{array}$ & $\begin{array}{c}\text { Kuk } \\
\text { ar }\end{array}$ & $\begin{array}{c}\text { Musht } \\
\text { arzai }\end{array}$ & $\begin{array}{c}\text { Yousaf } \\
\text { khel }\end{array}$ & $\begin{array}{c}\text { All } \\
\text { Villages }\end{array}$ \\
\hline Human capital & & & & & & & \\
Education of household head (mean) & 6 & 4 & 5 & 6 & 5 & 4 & 5 \\
Wage laborers (\%) & 15 & 45 & 15 & 15 & 40 & 30 & 26 \\
Literate workers (\%) & 41 & 27 & 41 & 33 & 44 & 27 & 36 \\
Dependency ratio (\%) & 118 & 114 & 153 & 83 & 97 & 95 & 108 \\
Dwelling & & & & & & & \\
Value of dwelling (Rs. in million) & 0.3 & 0.3 & 0.2 & 0.2 & 0.3 & 0.2 & 0.3 \\
Size of dwelling (marlas) & 11 & 9 & 9 & 9 & 10 & 18 & 10 \\
Rooms per person (No.) & 0.4 & 0.3 & 0.3 & 0.3 & 0.4 & 0.3 & 0.3 \\
Access to pipe water (\%) & 35 & 15 & 0 & 5 & 100 & 5 & 27 \\
Paved front door road (\%) & 30 & 25 & 55 & 60 & 95 & 0 & 50 \\
Wall with permanent materials (\%) & 30 & 15 & 50 & 25 & 45 & 0 & 29.5 \\
House ownership (\%) & 90 & 70 & 65 & 75 & 100 & 100 & 82 \\
House structure: Pakka (\%) & 55 & 40 & 65 & 65 & 50 & 40 & 54 \\
Cement made floor (\%) & 30 & 10 & 55 & 45 & 50 & 5 & 36 \\
Cement made roof (\%) & 25 & 10 & 50 & 45 & 40 & 0 & 32 \\
Latrines with flush system (\%) & 50 & 25 & 50 & 30 & 45 & 22 & 37 \\
Any improvement in house (\%) & 28 & 25 & 25 & 50 & 40 & 0 & 32 \\
Assets & & & & & & & \\
Household with own land (\%) & 30 & 5 & 10 & 10 & 50 & 50 & 24 \\
Tropical Livestock units (mean) & 0.4 & 0.5 & 0.6 & 0.2 & 0.7 & 0.5 & 0.5 \\
Household with telephone (\%) & 45 & 25 & 40 & 30 & 55 & 20 & 37 \\
Household with TV (\%) & 90 & 50 & 65 & 95 & 80 & 75 & 78 \\
Household with Refrigerator (\%) & 50 & 21 & 30 & 37 & 55 & 40 & 39 \\
Household with AC (\%) & 20 & 15 & 15 & 10 & 20 & 5 & 14 \\
Household with vehicle (\%) & 10 & 10 & 10 & 15 & 0 & 5 & 3 \\
\hline Note: Propotion & & & & \\
\end{tabular}

Note: 1) Proportion of household members above 10 years of education.

Source: Special survey carried out in six villages of Northwest Pakistan, 2004-05, 2004/05

Table 25 provides a matrix for the possible correlations among some important poverty related variables. While there are a few strong correlations, many of these indicators are only weakly correlated with each other. There is a clearly higher correlation between education of the household head and the literacy of his members $(r=0.71 \mathrm{p}<0.01)$. Similarly, education of household head (EDU) and his household members (EDW) are correlated with wage labours at household disposal, though the correlation is negative; this appears to be due in large part to survival nature of these jobs, which happens to be low rewarding and also had the lowest status symbol in rural areas. The farming variables related (LND \& LST) show little pair-wise correlation among themselves or with the other variables. As expected asset related variables ${ }^{96}$ except livestock (LST) are positively and significantly associated with household literacy (EDU \& EDW).

\footnotetext{
${ }^{96}$ The variables on household assets are given in rows 5-11 in the matrix.
} 
Table 25. Intercorrelation Matrix of Poverty Related Variables in the Study Area

\begin{tabular}{|lllllllllllll|}
\hline & & $(1)$ & $(2)$ & $(3)$ & $(4)$ & $(5)$ & $(6)$ & $(7)$ & $(8)$ & (9) & (10) & $(11)$ \\
EDU & $(1)$ & 1.00 & & & & & & & & & & \\
WWR & $(2)$ & $-0.40^{* *}$ & 1.00 & & & & & & & & \\
EDW & $(3)$ & $0.71^{* *}$ & $-0.33^{* *}$ & 1.00 & & & & & & & \\
DPR & $(4)$ & -0.02 & 0.07 & -0.14 & 1.00 & & & & & & \\
HSP & $(5)$ & $0.61^{* *}$ & $-0.32^{* *}$ & $0.63^{* *}$ & -0.09 & 1.00 & & & & & \\
HSS & $(6)$ & $0.37^{* *}$ & $-0.29^{* *}$ & $0.32^{* *}$ & -0.13 & $0.65^{* *}$ & 1.00 & & & & \\
HSR & $(7)$ & $0.37^{* *}$ & $-0.29^{* *}$ & $0.44^{* *}$ & $-0.24^{* *}$ & $0.66^{* *}$ & $0.63^{* *}$ & 1.00 & & & \\
HSC & $(8)$ & $0.55^{* *}$ & $-0.37^{* *}$ & $0.53^{* *}$ & -0.15 & $0.58^{* *}$ & $0.30^{* *}$ & $0.48^{* *}$ & 1.00 & & & \\
HVH & $(9)$ & $0.23^{* *}$ & $-0.18^{*}$ & $0.17^{+}$ & 0.06 & $0.48^{* *}$ & $0.37^{* *}$ & $0.48^{* *}$ & $0.29^{* *}$ & 1.00 & & \\
LND & $(10)$ & $0.21^{*}$ & -0.14 & $0.30^{* *}$ & -0.14 & $0.41^{* *}$ & $0.43^{* *}$ & $0.40^{* *}$ & $0.22^{*}$ & 0.10 & 1.00 & \\
LST & $(11)$ & -0.04 & -0.03 & 0.02 & -0.13 & 0.07 & $0.19^{*}$ & $0.21^{*}$ & -0.10 & -0.13 & $0.28^{* *}$ & 1.00 \\
\hline
\end{tabular}

Note: $* * \mathrm{p}<0.01, * \mathrm{p}<0.05,+\mathrm{p}<0.1$

Legend:

EDU $=$ Education of household head (years) $\quad$ EDW $=$ Proportion of household members with 10 years and above education

WWR $=$ Wage laborers in household $(\%) \quad$ DPR $=$ Dependency ratio (\%) $\quad$ HSP $=$ Value of dwelling (Rs.)

HSS $=$ Size of dwelling (marlas) $\quad$ HSR $=$ Rooms per person $($ No. $) \quad$ HSC $=$ Concrete $/$ brick made house

$\mathrm{HVH}=$ Household with vehicle $\quad \mathrm{LND}=$ Own land (acres) $\quad$ LST $=$ Household with livestock

Source: Special Survey in six villages of Northwest Pakistan, 2004/05.

\subsection{Inequality in the Study Area}

Real income inequality among rural households in study area in Northwest Pakistan sometimes may be imperceptible to the casual observer. Nevertheless, the details collected from across the rural households in six villages show that such income inequality is significant. Most of the population are, no doubt, absolutely poor in the sense that many basic needs goods and services are scarce in the area. We made use of the basic survey data from the six villages in Northwest Pakistan to examine income distribution within the villages. As a summary measure of inequality, we used the Gini coefficient, perhaps the most widely used indicator worldwide (see Table 26).

Income inequality across the villages does not show much difference, with the Gini coefficient ranging from 0.38 in Dalazak to 0.49 in Yousafkhel (Table 26). A Gini coefficient of a size of about 0.4 implies uneven income distribution in the study villages. The overall coefficient for all the villages at 0.44 falls outside the ideal range for development and poverty reduction, which is not surprising considering the inequality in the North West Frontier Province (GOVERNMENT OF PAKISTAN, 2005a). 
Table 26. Household Wealth Inequality in Terms of Gini Coefficient across the StudyArea

\begin{tabular}{|c|c|c|c|c|c|c|c|c|}
\hline \multicolumn{2}{|l|}{ Household Categories } & Kukar & Yousafkhel & Gulbela & Kochian & Dalazak & Mushtarzai & $\begin{array}{c}\text { All } \\
\text { Villages }\end{array}$ \\
\hline \multicolumn{9}{|l|}{ Pure Farming-Hh } \\
\hline Landlords & I & 0.24 & - & 0.27 & 0.31 & - & - & 0.43 \\
\hline Owner-Operator & II1 & 0.41 & 0.35 & - & - & 0.15 & 0.38 & 0.41 \\
\hline Owner cum Tenant & II2 & - & - & - & - & - & 0.38 & 0.38 \\
\hline Tenant & III & 0.42 & - & 0.44 & 0.44 & 0.3 & 0.30 & 0.43 \\
\hline Livestock-Farmer & IV & 0.42 & - & - & - & - & - & 0.42 \\
\hline \multicolumn{9}{|c|}{$\begin{array}{l}\text { Agricultural Hh with Non- } \\
\text { agricultural Income }\end{array}$} \\
\hline Landlord & V1 & 0.34 & 0.34 & 0.13 & 0.25 & 0.32 & 0.44 & 0.42 \\
\hline Owner-Operator & $\mathrm{V} 2$ & 0.39 & 0.46 & 0.36 & 0.12 & 0.36 & 0.44 & 0.43 \\
\hline Owner cum Tenant & V3 & 0.12 & 0.02 & - & - & 0.39 & 0.36 & 0.38 \\
\hline Tenant & V4 & 0.41 & 0.41 & 0.45 & 0.38 & 0.30 & 0.46 & 0.39 \\
\hline Livestock-Farmer & V5 & 0.30 & 0.15 & - & - & - & - & 0.42 \\
\hline \multicolumn{9}{|l|}{ Non-Agricultural-Hh } \\
\hline Businessmen & VI & 0.35 & 0.27 & 0.28 & 0.39 & 0.34 & 0.30 & 0.36 \\
\hline Wage-Salary Earners & VII & 0.42 & 0.41 & 0.39 & 0.37 & 0.39 & 0.42 & 0.40 \\
\hline Welfare based & VIII & 0.17 & - & 0.05 & 0.01 & - & - & 0.15 \\
\hline All Households & & 0.41 & 0.49 & 0.43 & 0.44 & 0.38 & 0.46 & 0.44 \\
\hline
\end{tabular}

Note: The Gini coefficient is bounded between zero (perfect equality) and one (perfect inequality), and can be represented graphically as twice the area between the Lorenz curve and the 45-degree line.

Source: Basic survey carried out in six villages of Northwest Pakistan, 2004-05.

The Gini coefficient for the earnings of businessmen households was slightly low (0.36), suggesting their rather compressed and narrow earnings differentials. The prevalence of the informal sector even in the business related activities contributes to this. It is noteworthy that the income inequality is low for the owner-operator households (Hh cat. II1) in Dalazak and that it was almost identical with the Gini coefficient $(0.15)$ for livestock with non-farm earning households (Hh cat. V5) in Yousafkhel (see Table 26). This is reassuring since there was little income from farming in these villages and so the two coefficients should have been about the same. Figure 15 provides a comparison between the farming and non-farming households in terms of their annual income in the research area. The farm related households earn more on the average compared to the non-farm households because of the survival-oriented nature of these mostly informal jobs. In Gulbela, relative to other study villages, the high earning of the landlords (Hhcat. I \& V1) and owner operators (Hh-cat. II1 \& V2) inflated the mean per capita income of farming households in that village (see Figure 15). 
Figure 15. Comparison of Income across Farming and Non-agricultural Households

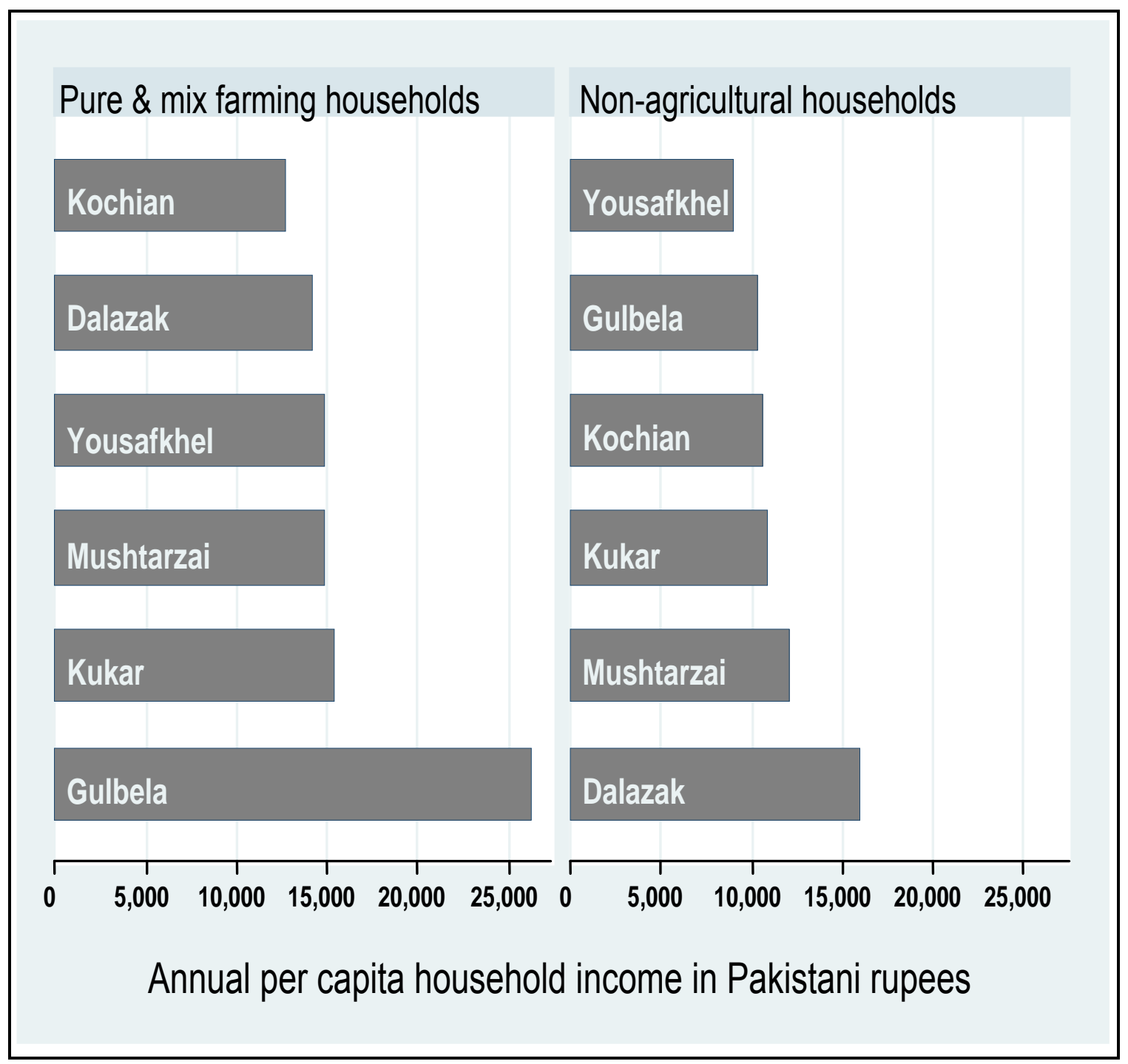

Source: Basic survey carried out in six villages of Northwest Pakistan, 2004-05.

There is not much variation in the monetary returns from businesses (Hh-cat. VI) and non-farm wage-salary activities (Hh-cat.VII) across the study villages. Much of the concern is the low earning of tenant households compared with landowners, revealing that share tenancy, which is common in the area, is a way of survival and not accumulation for the former. Even owner operators earn less in most of the villages because of the limited farming land at their disposal (see for details KHAN, 2007).

It is increasingly becoming accepted, as the WORLD BANK (2000) puts it, that "high inequality is bad for growth." As regards inequality specifically, there is considerable evidence that the higher 
the government expenditure as a percentage of the GDP, the lower the Gini coefficient of the distribution of income (WORLD BANK, 2000).

Figure 16. Lorenz Curve for Different Household Categories in the Study Villages

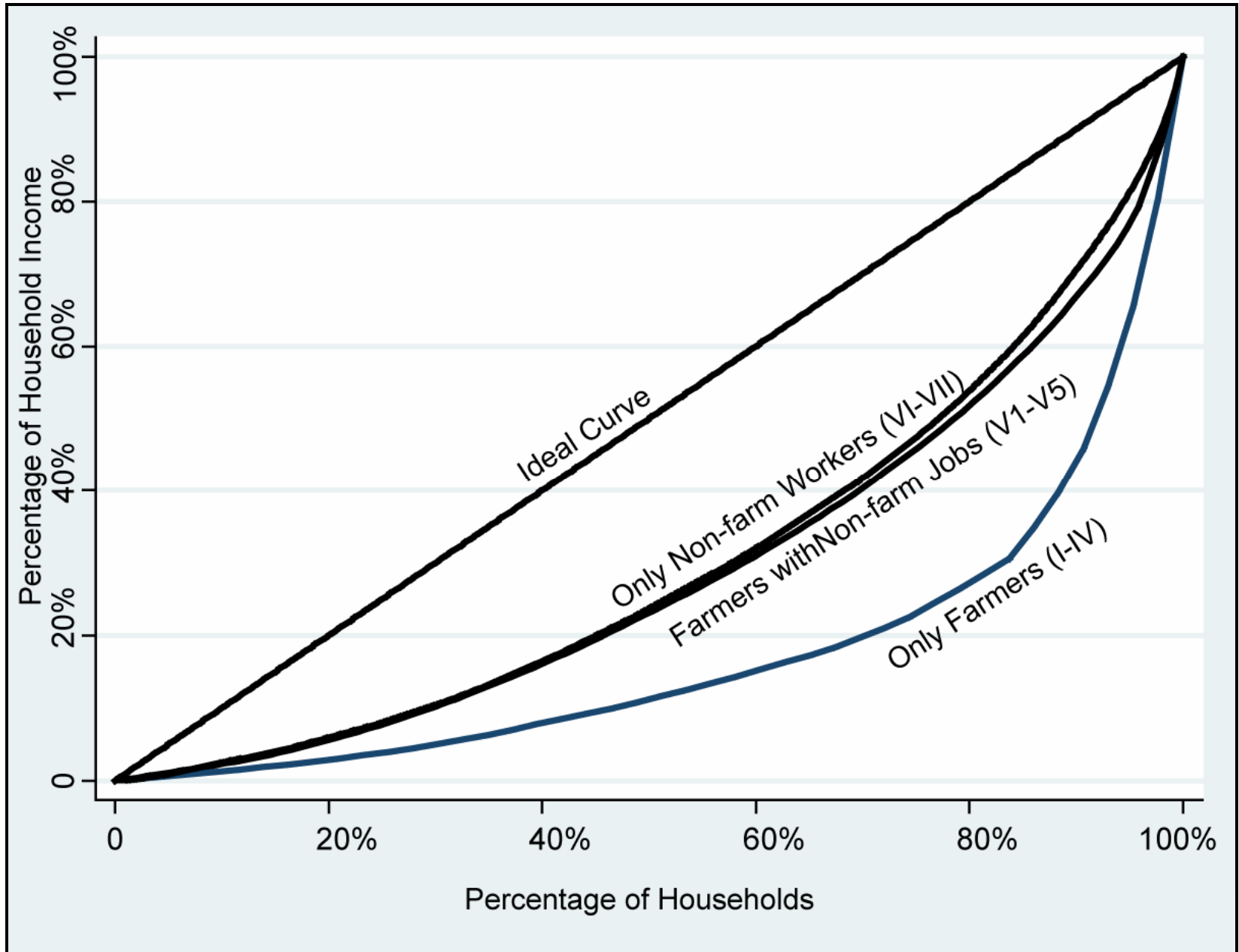

Source: Basic survey carried out in six villages of Northwest Pakistan, 2004-05.

To get a clearer picture of what the numbers in Table 26 mean, look at Figure 16. The horizontal axis measures the cumulative percent of total households, and the vertical axis measures the cumulative percent of total household income. To be specific Figure 16 depicts a Lorenz curve of the distribution of the household annual income among the household categories. A high degree of equality for the non-farm households, as suggested by the closeness of the curve to the diagonal or line of perfect equality, is clearly visible. This underlines the survival-oriented nature of the non-farm sector in the study area. 


\subsection{Empirical Results for Determinants of Poverty}

The covariates $\mathrm{X}_{1}, \mathrm{X}_{2}, \ldots, \mathrm{X}_{\mathrm{k}}$ used in the logistic model are given in Table 27 representing different types of household assets. Stata (version 9.2) is used to estimate the Binary Logistic Model based on the maximum likelihood method (see for details, LONG \& FREESE, 2001; HAMiLton, 2006). The data used in the regression came from the special survey of 120 households in six villages of Northwest Pakistan. In addition, sampling weights were used to provide representative descriptive and regression results. The collinearity ${ }^{97}$ diagnostic as shown by the mean VIF value of 2.42 are within the acceptable range (see Table 31).

\subsubsection{Descriptive Statistics for Logistic Regression on Poverty}

Sticking with the official poverty line for Pakistan, a household is considered poor if the income per household member is less than Pakistani Rs. 849 per month. In order to have some background information, the special survey also revealed interesting information about the mode of payment for the head of the household. For instance, around 46 percent of them were paid monthly, almost similar number $(44 \%)$ on daily basis, few (4\%) as weekly while the rest at the end of their contract. Nearly 29 percent received their salary in their bank account after deduction of certain taxations while majority $(69 \%)$ of them were paid for their work in cash.

Following economic theories and the ground realities in the research area in Northwest Pakistan Table 27 shows a wide range of factors that play a role in the poverty of households. About household characteristics, a typical rural household has eight members, nearly 108 percent is the dependency ratio ${ }^{98}$, and the average age of the head of household is 42 years old ${ }^{99}$. The average prejob training received by household head is low so as his formal education and of other working members within a household. A household head is educated on average till primary while only a handful of the total 249 working members were University graduates.

\footnotetext{
97 The Variance Inflation Factor (VIF) for a variable reflects the degree to which others coefficients variances are increased due to the inclusion of that variable. While Torelance $\left(1-\mathrm{R}^{2}\right)$ tells what proportion of an $\mathrm{X}$ variable's variance is independent of all other X variables. According to HAMILTON, 2006 multicollinearity becomes an issue of concern if the largest VIF is greater than 10 and the mean VIF is substantially larger than 1.

98 The dependency ratio is defined as the ratio of the number of members' dependent (not working) in a household to the number of members working. The ratio is expressed as a percentage.

99 The age served as proxy for the work experience of household head. As far work experience is concerned, household head on average worked for 13 years.
} 
Table 27. Summary Statistics for Logistic Model on Poverty

\begin{tabular}{|c|c|c|c|c|c|}
\hline $\begin{array}{l}\text { Dependent } \\
\text { Variable }\end{array}$ & Description of Variables & Mean & $\begin{array}{l}\text { Std. } \\
\text { Dev. }\end{array}$ & Min & Max \\
\hline POORDUM & $\begin{array}{l}1 \text { if poor households (real income per household member } \\
\text { less than Pakistani Rs. } 849 \text { per month), } 0 \text { otherwise }\end{array}$ & 0.48 & 0.50 & 0 & 1 \\
\hline \multicolumn{6}{|l|}{$\begin{array}{l}\text { Independent } \\
\text { Variables }\end{array}$} \\
\hline EDU & Education of household head (years) & 5.02 & 5.50 & 0 & 16 \\
\hline WRED58 & Working members with basic education (number) & 0.49 & 0.74 & 0 & 3 \\
\hline WRED1012 & Working members with Secondary education (number) & 0.58 & 0.90 & 0 & 5 \\
\hline WRED14 & Working members with Graduation (number) & 0.19 & 0.44 & 0 & 2 \\
\hline TRBJB & Training of household head (months) & 0.15 & 0.35 & 0 & 1 \\
\hline HHS & Household size (number) & 8.45 & 3.52 & 3 & 27 \\
\hline DEPRATIO & Dependency ratio (percent) & 107.74 & 86.84 & 0 & 350 \\
\hline AGE & Age of HH head (years) & 41.86 & 10.31 & 18 & 65 \\
\hline JBFR & Farmers (number) & 0.06 & 0.25 & 0 & 1 \\
\hline JBCW & Casual workers (number) & 0.28 & 0.53 & 0 & 3 \\
\hline JBPE & Permanent employees (number) & 0.80 & 1.17 & 0 & 5 \\
\hline JBOB & Businessmen (number) & 0.42 & 0.73 & 0 & 3 \\
\hline JBGE & Government employees (number) & 0.50 & 0.91 & 0 & 6 \\
\hline TRANSOWN & Own transport $(0,1)$ & 0.14 & 0.35 & 0 & 1 \\
\hline INASN & Telephone installed $(0,1)$ & 0.37 & 0.48 & 0 & 1 \\
\hline INHSL & Pacca/semi pacca house $(0,1)$ & 0.54 & 0.50 & 0 & 1 \\
\hline INHSS & Size of house (marlas) & 10.12 & 9.04 & 2 & 60 \\
\hline OWNLAND & Own land in acres & 0.60 & 1.57 & 0 & 10 \\
\hline LOGLVSTKUNT & Tropical Livestock units (log) & 0.02 & 0.51 & -2.30 & 1.10 \\
\hline CACRDUM & Expenditure on festivities $(0,1)$ & 0.31 & 0.47 & 0 & 1 \\
\hline DALAZAK & 1 if resident of Dalazak, 0 otherwise & 0.13 & 0.34 & 0 & 1 \\
\hline GULBELA & 1 if resident of Gulbela, 0 otherwise & 0.15 & 0.36 & 0 & 1 \\
\hline KOCHIAN & 1 if resident of Kochian, 0 otherwise & 0.16 & 0.37 & 0 & 1 \\
\hline YOUSAFKHEL & 1 if resident of Yousafkhel, 0 otherwise & 0.10 & 0.30 & 0 & 1 \\
\hline KUKAR & 1 if resident of Kukar, 0 otherwise & 0.26 & 0.44 & 0 & 1 \\
\hline
\end{tabular}

Source: Special survey carried out in six villages of Northwest Pakistan, 2004-05, 2004-05.

Table 27 also presents descriptive results on the distribution of the labor force (all working household members) across various types of employment by sectors. Employment types have been classified into five categories: farming, casual labor, salaried permanent private work, selfemployment, and government jobs. A total of 249 individuals for 120 households surveyed responded as participating in the labor force during the 12 months prior to the survey.

These descriptive results are indicative of important differences in type of employment in the study area. For instance, on average permanent employees in private sector jobs are wide spread 
in rural Northwest followed by government employees ${ }^{100}$ and self-employed. While salaried private sector work, as noted before, is the most important source of employment for rural households in the study area, it is farming which is the least important source for these households.

In order to examine the influence of household assets in household poverty, variables on agriculture land and livestock ownership were introduced. About 26 percent of the households in the research area reported agricultural land ownership while 36 percent of them owned livestock. The non-poor owned on average one acre of land while poor households maintained only half an acre.

Although the share of non-poor households with owned livestock was less (34 percent) compared to 38 percent for poor households, however, they owned on average more livestock units. Table 27 also provides information on the type of dwelling by poverty levels. Two types of dwelling characteristics ${ }^{101}$ are chosen for analysis: size of dwellings, and structure of dwellings. The special survey identified the structure of house based on the main materials used in the construction of the dwelling. Since the outer walls and the roof form the main part of the dwelling, information on these were utilized. Hence, houses were classified as pacca/semi-pacca and Kacha on the basis of permanent or non-permanent materials used in it. Pacca houses are those constructed from cement, concrete, or brick. Likewise, Kacha houses are those constructed from mud or unbaked bricks.

\subsubsection{Econometric Results on Poverty Correlates}

The logit model explored the roles of major factors contributing to poverty in the six research villages in Northwest Pakistan. Specifically, Table 28 regresses the binary response variable, the probability of being poor $(\mathrm{P}(\mathrm{Y}=1))$ while Table 29 presents these results in odd ratio and marginal effects.

\footnotetext{
${ }^{100}$ As revealed by the special survey of 120 households, the share of household heads in public sector jobs, which over the years, became the most secured, protected and better paid form of employment, was 27 percent. Looking at sector wise distribution of government employment, the NWFP provincial government provided 19 percent of the jobs while federal government jobs due to high entry barriers accounted only for 8 percent jobs in the area. The share of local government jobs within provincial sector was around three percent.

${ }^{101}$ As majority of dwellings were owned by the households they reside in across the villages with certain exception in Kukar, hence, we did not introduced the variable on the ownership of dwelling.
} 
Table 28. Binary Logistic Regression on Poverty in the Study Villages

\begin{tabular}{|c|c|c|c|}
\hline Explanatory Variables & Coefficients & $\begin{array}{c}\text { Robust } \\
\text { Standard error }\end{array}$ & $\begin{array}{c}\text { Z Statis- } \\
\text { tics }\end{array}$ \\
\hline Education of household head (years) & -0.148 & 0.122 & -1.21 \\
\hline Working members with basic education (number) & 0.759 & 2.050 & 0.37 \\
\hline $\begin{array}{l}\text { Working members with secondary education } \\
\text { (number) }\end{array}$ & $-2.724 * * *$ & 1.006 & -2.71 \\
\hline Working members with graduation (number) & $-3.423 *$ & 1.808 & -1.89 \\
\hline Training of household head (months) & -2.283 & 2.560 & -0.89 \\
\hline Household size (number) & $0.932 * *$ & 0.368 & 2.53 \\
\hline Dependency ratio (percent) & $-0.018 * *$ & 0.008 & -2.29 \\
\hline Age of household head (years) & -0.146 & 0.111 & -1.31 \\
\hline Farmers (number) & -2.754 & 2.348 & -1.17 \\
\hline Casual workers (number) & -0.437 & 1.008 & -0.43 \\
\hline Permanent employees (number) & $-3.412 * *$ & 1.647 & -2.07 \\
\hline Businessmen (number) & $-2.887 *$ & 1.723 & -1.68 \\
\hline Government employees (number) & $-2.086^{*}$ & 1.186 & -1.76 \\
\hline Own transport $(0,1)$ & $-5.481 * *$ & 2.777 & -1.97 \\
\hline Telephone installed $(0,1)$ & -4.429 & 3.384 & -1.31 \\
\hline Pacca/semi pacca house $(0,1)$ & -1.287 & 1.954 & -0.66 \\
\hline Size of house (marlas) & -0.066 & 0.073 & -0.90 \\
\hline Own land in acres & -0.148 & 0.459 & -0.32 \\
\hline Tropical Livestock Units (log) & $-6.296^{*}$ & 3.636 & -1.73 \\
\hline Expenditure on festivities $(0,1)$ & -2.213 & 3.048 & -0.73 \\
\hline $\operatorname{Dalazak}^{1}(0,1)$ & $5.848^{*}$ & 3.581 & 1.63 \\
\hline Gulbela $(0,1)$ & 4.595 & 3.357 & 1.37 \\
\hline $\operatorname{Kochian}(0,1)$ & $4.351 * *$ & 2.139 & 2.03 \\
\hline Yousafkhel $(0,1)$ & 2.266 & 2.969 & 0.76 \\
\hline $\operatorname{Kukar}(0,1)$ & -0.299 & 1.189 & -0.25 \\
\hline Constant & 9.780 & 6.212 & 1.57 \\
\hline $\begin{array}{l}\text { Observations }=120 \\
\text { McFadden's } \mathrm{R}^{2}=0.73 \quad \text { McFadden's Adj } \mathrm{R}^{2}=0.42 \\
\text { Wald chi }{ }^{2}(25)=63.63 \text { Prob }>\text { chi } 2=0.000 \\
\text { Log pseudolikelihood }=-22.27\end{array}$ & & & \\
\hline
\end{tabular}


These findings are in keeping with both intuition and what is already known about poverty in Pakistan (Table 28 \& Table 29). The results on household size are in keeping with generally accepted theory. A household is more likely to be poor if it has a large household size $(\mathrm{OR}=2.54$ $\mathrm{p}<0.05$ ). Although the coefficients on education of the household head and his before-job training have, the expected sign but it turned out to be non-significant. Pakistan human development record is, however, recognized to be poor (BANERJEE \& DUFLO, 2007, p. 10). The public schools are often dysfunctional in Pakistan and as a result, even the very poor parents are pulling their children out of government schools and spending money to send them to private schools (BANERJEE \& DUFLO, 2007, p. 13). The education of household head is important as when the head is illiterate himself, may have a hard time recognizing that their children are not learning much. Besides the household head, formal schooling of household members is also an asset by which the household is able to capture its maximum returns.

The household dependency ratio turn out to be significant but negatively associated with household poverty. However, we expected high dependency ratio because of its relation with household member's needs to be associated with poverty. A household is also more likely to be nonpoor if it own any land although surprisingly this is not significant. BAULCH \& MCCULLOCH, 2002 also noted similar results in their study of poverty in Pakistan. Ownership of other assets, such as livestock ${ }^{102}$ and own transport decreases the probability of a household being poor in the range of 136-157 percent. The coefficient on telephone installed within the household although have the expected sign but it turn out to non-significant.

Except the casual workers and farmers, the rest of three occupations followed by household members are significant and negative. In terms of marginal effect, the magnitude of permanent private employess is highest (85\%) followed by those in businesses or self emplyment $(72 \%)$. Similarly, government employment reduced the probability almost 52 percent for the household to be poor, however, majority of these government jobs are of lower cadres like clerks, peons, meter readers and linemen in WAPDA, and primary teachers.

Finally, the estimated coefficients differ in sign and size for the survey villages compared against the reference village, Mushtarzai (see Table 28 \& Table 29). Residence in the village Dalazak and Kochian is associated with the risk of being poor relative to Mushtarzai. The role of remittances in the economy of Mushtarzai is an immediate reason for this phenomenon. Similarly,

\footnotetext{
${ }^{102}$ KurosaKi, 1995 in a study in Punjab, Pakistan also observed that livestock holdings enable households in smoothing their incomes by decreasing their exposure to poverty risk.
} 
a dweller of Kukar is less likely to be poor than Mushtarzai, however, it turn out to nonsignificant. Kukar being located at the junction of capital city Peshawar, offer more in infrastructure and labor market.

Table 29. Odd Ratio and Marginal Effects for Logit Model on Poverty

\begin{tabular}{|c|c|c|c|}
\hline Explanatory Variables ${ }^{1}$ & $\begin{array}{l}\text { Odd } \\
\text { Ratio }\end{array}$ & $\begin{array}{c}\text { Robust } \\
\text { Standard Error }\end{array}$ & $\begin{array}{c}\text { Marginal } \\
\text { Effect }\end{array}$ \\
\hline Education of household head (years) & 0.863 & 0.106 & -0.037 \\
\hline Working members with basic education (number) & 2.137 & 4.381 & 0.188 \\
\hline Working members with secondary education (number) & $0.066 * * *$ & 0.066 & -0.677 \\
\hline Working members with graduation (number) & $0.033 *$ & 0.059 & -0.851 \\
\hline Training of household head (months) & 0.102 & 0.261 & -0.568 \\
\hline Household size (number) & $2.540 * *$ & 0.940 & 0.232 \\
\hline Dependency ratio (percent) & $0.983 * *$ & 0.008 & -0.004 \\
\hline Age of household head (years) & 0.865 & 0.096 & -0.036 \\
\hline Farmers (number) & 0.064 & 0.149 & -0.685 \\
\hline Casual workers (number) & 0.646 & 0.651 & -0.109 \\
\hline Permanent employees (number) & $0.033 * *$ & 0.054 & -0.848 \\
\hline Businessmen (number) & $0.056^{*}$ & 0.096 & -0.718 \\
\hline Government employees (number) & $0.124^{*}$ & 0.147 & -0.519 \\
\hline Own transport $(0,1)$ & $0.004 * *$ & 0.012 & -1.362 \\
\hline Telephone installed $(0,1)$ & 0.012 & 0.040 & -1.101 \\
\hline Pacca/semi pacca house $(0,1)$ & 0.276 & 0.539 & -0.320 \\
\hline Size of house (marlas) & 0.936 & 0.069 & -0.016 \\
\hline Own land in acres & 0.862 & 0.395 & -0.037 \\
\hline Tropical Livestock Units (log) & $0.002 *$ & 0.007 & -1.565 \\
\hline Expenditure on festivities $(0,1)$ & 0.109 & 0.333 & -0.550 \\
\hline $\operatorname{Dalazak}^{2}(0,1)$ & $346.377^{*}$ & 1240.249 & 1.453 \\
\hline Gulbela $(0,1)$ & 98.956 & 332.194 & 1.142 \\
\hline Kochian $(0,1)$ & $77.551 * *$ & 165.917 & 1.081 \\
\hline Yousafkhel $(0,1)$ & 9.636 & 28.605 & 0.563 \\
\hline $\operatorname{Kukar}(0,1)$ & 0.741 & 0.881 & -0.074 \\
\hline Wald $\operatorname{chi}^{2}(25): 63.63$ & \multicolumn{3}{|c|}{ Prob > chi2: 0.000} \\
\hline McFadden's Adj R ${ }^{2}: 0.42$ & \multicolumn{3}{|c|}{ Log pseudolikelihood: -22.27} \\
\hline
\end{tabular}

Note: 1) The dependent variable is 1 if a household is below the poverty line (real income per household member less than Pakistani Rs. 849 per month) and 0 otherwise.

McFadden's $\mathrm{R}^{2}$, also known as the "likelihood-ratio index," compares a model with just the intercept to a model with all parameters (HAMILTON, 2006). However, it is in no way analogous to $\mathrm{R}^{2}$ for OLS as it lacks the straight forward explained-variance interpretation of true $\mathrm{R}^{2}$ in OLS regression (see for details GREENE, 2003; HAMILTON, 2006).

2) Mushtarzai acts as reference village.

*; **; *** Significant at $10 \% ; 5 \%$; and $1 \%$ respectively

Source: Special survey carried out in six villages of Northwest Pakistan, 2004-05. 
As the poverty line is itself often debatable, the study used a wide range of poverty lines to regress it against the same explanatory variables outlined in Table 27. To be specific, Table 30 answers how robust these results are, to the choice of poverty line, as it shows the same logit regression (only significant results) for monthly poverty lines from Rs. 449 to Rs. 1349. Comparing the determinants at different poverty line, overall the logit results seem robust to the choice of poverty line. The variables, which are sensitive to the poverty lines, are those representing education, age, working as farmer, casual workers, dependency ratio, land, house size, and a few village dummies.

Table 30. Robustness of Logistic Regression at Different Level of Poverty

\begin{tabular}{|c|c|c|c|c|c|c|c|c|c|}
\hline \multirow[b]{2}{*}{ Variables } & \multicolumn{9}{|c|}{ Poverty lines in monthly Pakistani rupees } \\
\hline & 449 & 549 & 649 & 749 & 849 & 949 & 1149 & 1249 & 1349 \\
\hline EDU & $0.9 * * *$ & $0.5 * *$ & 0.4 & 0.0 & -0.1 & 0.0 & -0.2 & 0.0 & 0.0 \\
\hline WRED58 & $-6.3 * * *$ & $-4.1 * *$ & $-6.2 * * *$ & $-2.4 * *$ & 0.8 & -1.3 & $-2.9 * *$ & -1.3 & -1.1 \\
\hline WRED1012 & $-2.8 * *$ & $-2.3^{*}$ & $-4.8 * * *$ & $-2.0 * * *$ & $-2.7 * * *$ & -0.7 & -1.4 & 0.1 & 1.0 \\
\hline WRED14 & & & & -1.5 & $-3.4^{*}$ & -2.4 & $-5.7 * * *$ & $-4.6^{*}$ & $-5.4 * *$ \\
\hline TRBJB & 3.2 & -1.1 & 1.9 & -1.3 & -2.3 & -2.5 & -10.3 & 1.9 & 2.1 \\
\hline HHS & $1.1 * *$ & $1.0^{*}$ & $1.5^{* * *}$ & $0.8 * * *$ & $0.9 * *$ & 0.7 & $2.7^{*}$ & $1.6^{* * *}$ & $1.6^{* * *}$ \\
\hline DEPRATIO & 0.0 & $0.0^{*}$ & $-0.0^{*}$ & -0.0 & $-0.0 * *$ & -0.0 & $-0.0^{*}$ & -0.0 & -0.0 \\
\hline AGE & 0.3 & 0.1 & $0.1 *$ & -0.0 & -0.1 & -0.1 & 0.1 & 0.1 & $0.1 *$ \\
\hline JBFR & 7.3 & -4.6 & -0.4 & -0.5 & -2.8 & 1.8 & $-4.1 *$ & $-3.2 * *$ & $-3.9 * *$ \\
\hline JBCW & 1.1 & 0.0 & -1.8 & $-3.0 * * *$ & -0.4 & 0.1 & -6.6 & $-3.2 * *$ & $-3.3 * *$ \\
\hline JBPE & $-3.5 * * *$ & $-3.2 * *$ & $-2.1 * *$ & $-1.9 * * *$ & $-3.4 * *$ & $-2.4 * *$ & -5.5 & $-2.9 * * *$ & $-3.2 * * *$ \\
\hline JBOB & -1.3 & -2.0 & $-2.6^{*}$ & -0.9 & $-2.9^{*}$ & -1.4 & -8.6 & $-4.2^{* * *}$ & $-4.6^{* * *}$ \\
\hline JBGE & 0.1 & -3.0 & 0.2 & 0.0 & $-2.1^{*}$ & $-3.3^{*}$ & -8.4 & $-2.9 * *$ & $-3.1^{*}$ \\
\hline TRANSOWN & & & $-5.8 * *$ & $-3.5^{*}$ & $-5.5 * *$ & $-4.4 *$ & 3.6 & -0.7 & -1.4 \\
\hline INASN & $-9.8^{* * *}$ & $-4.6^{*}$ & $-6.1 *$ & $-3.3 * * *$ & -4.4 & -4.7 & $-13.6^{* *}$ & $-3.8^{*}$ & $-3.5^{*}$ \\
\hline INHSL & $-14.9 * * *$ & $-3.6^{*}$ & $-5.1 * * *$ & -1.5 & -1.3 & -0.5 & 4.5 & -1.3 & -1.4 \\
\hline INHSS & $0.6^{* *}$ & $0.4 * *$ & -0.0 & -0.2 & -0.1 & -0.2 & -0.4 & $-0.1 * * *$ & $-0.2^{* * *}$ \\
\hline OWNLAND & $-8.7 * *$ & $-2.8 * *$ & $-2.3 * *$ & -0.5 & -0.1 & 0.6 & $-3.4 *$ & $-1.3 * * *$ & $-1.2 * * *$ \\
\hline LOGLVSTKUNT & -4.9 & $-2.5^{* * *}$ & -1.3 & -0.2 & $-6.3^{*}$ & -1.6 & -1.3 & 0.0 & 0.5 \\
\hline CACRDUM & -0.2 & 1.7 & $3.3^{*}$ & 0.3 & -2.2 & -1.4 & -12.1 & $-2.6^{*}$ & $-3.7 * *$ \\
\hline DALAZAK & -5.3 & -1.6 & 2.0 & 2.0 & 5.8 & 5.6 & 2.7 & 3.5 & $5.0^{* *}$ \\
\hline GULBELA & 3.4 & $4.2 *$ & $6.1 * * *$ & $3.5^{* * *}$ & 4.6 & $4.0 * *$ & $7.4^{*}$ & 2.9 & $4.4 * *$ \\
\hline KOCHIAN & 2.1 & 3.2 & $5.0 * * *$ & 1.1 & $4.4 * *$ & 2.1 & $8.0^{*}$ & $5.3 *$ & $7.1 * *$ \\
\hline YOUSAFKHEL & 2.6 & 1.2 & 1.7 & $2.7^{*}$ & 2.3 & 8.7 & 16.6 & $5.6^{* *}$ & $6.9^{* * *}$ \\
\hline KUKAR & -1.1 & 1.0 & -1.1 & -0.7 & -0.3 & 3.0 & 2.3 & 3.8 & $5.8 * *$ \\
\hline Observations & 92 & 92 & 100 & 120 & 120 & 120 & 120 & 120 & 120 \\
\hline R-squared & 0.73 & 0.65 & 0.73 & 0.67 & 0.73 & 0.75 & 0.83 & 0.72 & 0.70 \\
\hline Prob $>$ chi 2 & 0.0000 & 0.0056 & 0.0000 & 0.0000 & 0.0001 & 0.0000 & 0.0000 & 0.0000 & 0.0000 \\
\hline
\end{tabular}

Note: $* * * \mathrm{p}<0.01, * * \mathrm{p}<0.05, * \mathrm{p}<0.1$

Source: Special survey in six villages of Northwest Pakistan, 2004/05. 
Table 31. Collinearity Diagnostic for Poverty Model

\begin{tabular}{|lcccc|}
\hline Variables & VIF & SQRT VIF & Tolerance & R-Squared \\
\hline EDU & 3.72 & 1.93 & 0.27 & 0.73 \\
WRED58 & 2.40 & 1.55 & 0.42 & 0.58 \\
WRED1012 & 3.50 & 1.87 & 0.29 & 0.71 \\
WRED14 & 2.49 & 1.58 & 0.40 & 0.60 \\
TRBJB & 1.42 & 1.19 & 0.70 & 0.30 \\
HHS & 2.81 & 1.68 & 0.36 & 0.65 \\
DEPRATIO & 1.88 & 1.37 & 0.53 & 0.47 \\
AGE & 1.69 & 1.30 & 0.60 & 0.40 \\
JBFR & 1.51 & 1.23 & 0.66 & 0.34 \\
JBCW & 2.15 & 1.47 & 0.47 & 0.53 \\
JBPE & 3.90 & 1.97 & 0.26 & 0.74 \\
JBOB & 3.60 & 1.90 & 0.28 & 0.72 \\
JBGE & 2.28 & 0.19 & 0.81 \\
TRANSOWN & 1.18 & 1.24 & 0.65 & 0.35 \\
INASN & 1.54 & 1.61 & 0.38 & 0.61 \\
INHSL & 2.59 & 1.49 & 0.45 & 0.55 \\
INHSS & 2.23 & 1.53 & 0.43 & 0.57 \\
OWNLAND & 2.36 & 1.37 & 0.53 & 0.47 \\
LOGLVSTKUNT & 1.87 & 1.11 & 0.81 & 0.19 \\
CACRDUM & 1.23 & 1.16 & 0.75 & 0.25 \\
DALAZAK & 1.34 & 1.44 & 0.48 & 0.52 \\
GULBELA & 2.06 & 1.41 & 0.50 & 0.50 \\
KOCHIAN & 2.00 & 1.51 & 0.44 & 0.56 \\
YOUSAFKHEL & 2.28 & 1.53 & 0.43 & 0.57 \\
KUKAR & 2.34 & 1.55 & 0.41 & 0.59 \\
Mean VIF & 2.42 & & & \\
Condition No. & & & & \\
\hline NOE VIF & 2.42 & & & \\
\hline
\end{tabular}

Note: VIF values greater than 10 may warrant further examination however, as shown in above table the VIF are in acceptable range (HAMILTON, 2006).

Source: Special survey carried out in six villages of Northwest Pakistan, 2004-05. 


\section{FACTORS AFFECTING OCCUPATIONAL CHOICES}

Because of the growing interest in labour market participation of rural households and limited choices and opportunities available to them, it is important to study the pattern of their choice for a particular occupation. As the choice of occupation plays a pivotal role in determining the earnings of individuals and their bargaining power in the family, it is important to examine the factors that contribute to the formation of these choices. Over the limited evidence available for Northwest Pakistan on the subject (AlBReCht, 1976; MANIG, 1991; RieKeN, 1994), the present study is an important step towards understanding the factors responsible for it to fill the gap in research. Hence, the study is pioneer in analysing econometrically the occupational choice behaviour of rural dwellers in Northwest Pakistan and the factors explaining these choices.

\subsection{Empirical Results: Multinomial Logit Regression}

To examine the factors that are associated with the likelihood of households' engagement in different occupations demands the use of econometrics analysis. Therefore, Multinomial Logit (MNLT) model is used. Further, the basic survey revealed information on several characteristics of the household ${ }^{103}$ and its decision makers (head of the households) hence we can make use of the Multinomial Logit ${ }^{104}$. A growing number of studies applied similar approach in exploring the determinants of household occupational choice (AMELIE \& ZIMMERMANN, 2004; DAMITE \& Negatu, 2004; Mitra, 2004; NASiR, 2005; JANSEN et al., 2006; Berhanu et al., 2007; HENNESSY \& REHMAN, 2007).

\subsection{Descriptive Statistics}

The empirical analysis is based on data of 2825 households obtained by basic survey in the six villages of Northwest Pakistan. The econometric analysis carried out aims at answering the research question: What determines the household decision to participate in a particular

\footnotetext{
${ }^{103}$ The household categories were defined and delimited following the same criteria mentioned in MANIG, 1991, pp. 64-65. Hence, in order to make it consistent with earlier studies, these households were not constructed just based on the employment of the head of the household but rather a certain criteria mentioned in Chapter 3 were used.

${ }^{104}$ Multivariate analysis (Multinomial Logit) is also an appropriate technique to indicate whether the motivation to enter the RNFE is demand-pull or distress-push (BERHANU et al., 2007).
} 
employment? The central concern here is to explain factors that determine the probabilities of household engagement in different economic activities. Because the dependent variables are a set of nominal unordered occupational categories, hence we used a multinomial logistic regression in our analysis. Survey respondents reflect a wide range of personal and household characteristics (Table 32). In particular, we can see at the top of the table that although the household heads are young on average (44 years) nevertheless, there is wide spread variation in the age of the household heads. The total population of the six research villages in Northwest Pakistan is nearly 23 thousands distributed into 2825 households with an average number of eight people. Thus households size is relatively large reflecting the existence of extended family system in the area. Similarly, on average there were two working members at household disposal.

The surveyed villages also have a particular miserable record when it comes to educational attainment. For instance, the average educational attainment of household head in the surveyed villages was four years of schooling (Table 32), with only four percent of the respondents being university graduate. There is little farm activity in these villages as revealed by the variables on land and livestock ownership, but what little there is, is vital to the livelihoods of the households involved in it. Farming is almost entirely subsistence as it is a survival strategy, and is not business-oriented.

Table 32. Summary Statistics of Variables Used in Multinomial Logit Model

\begin{tabular}{|llcccc|}
\hline Variables & Description & Mean & Std. Dev. & Min & Max \\
\hline AGE & Age of HHH (years) & 44.29 & 12.24 & 15 & 88 \\
EDU & Education of HHH (years) & 3.55 & 4.82 & 0 & 16 \\
HHS & Household size (no.) & 7.99 & 3.99 & 1 & 34 \\
HHW & Workers within HH (no.) & 1.91 & 1.23 & 0 & 8 \\
logowlndTot & Land owned by HH (log acres) & 0.09 & 0.62 & -3.47 & 5.08 \\
logLvStkUnt & Tropical Livestock Units (log no.) & 0.08 & 0.67 & -2.29 & 4.61 \\
Dalazak & Dalazak (dummy) & 0.13 & 0.34 & 0 & 1 \\
Gulbela & Gulbela (dummy) & 0.15 & 0.36 & 0 & 1 \\
Kochian & Kochian (dummy) & 0.16 & 0.37 & 0 & 1 \\
Kukar & Kukar (dummy) & 0.26 & 0.44 & 0 & 1 \\
Mushtarzai & Mushtarzai (dummy) & 0.19 & 0.39 & 0 & 1 \\
\hline
\end{tabular}

Note: 1) Village Yousafkhel served as reference village.

Legend: $\mathrm{HH}=$ Household $\mathrm{HHH}=$ Household head

Source: Basic survey carried out in six villages of Northwest Pakistan, 2004-05. 
Table 33 further expands Table 32 indicating the seven distinct household occupational categories highlighting a comprehensive picture of the prevailing livelihood structure in the surveyed villages. The means and standard deviations of dependent variables of rural households along with explanatory variables are compared in Table 33 .

Starting with the seven dependent variables, slightly over 32 percent of the total 2825 households were engaged in wage employment that was exclusively informal (unregistered) in nature. Similarly, around 17 percent of the households find their livelihood in non-farm formal sector (organized government and private sector) offering not only higher pays but more prestige and social status, as well.

The combined share of the only farmer and tenant households in the employment pie was as little as six percent. Besides these around 20 percent of the rural households have combined agriculture with non-agricultural activities to spread risk and utilize available resources (both human and material) as much as possible. The share of those engaged in businesses (petty trade and self employment) was around 18 percent.

Considering the explanatory variables for the seven occupational categories, the statistics reveals that the average age of the household head is higher (50 years) for tenants with non-agricultural activities compared to almost 42 years for informal wage earners (Table 33). Household heads belonging to tenant and informal wage households are found to less educated that the other contrasting occupational categories. Informal wage earning households along with pure farmers and those in formal sector jobs have relatively smaller household size (seven members) compared to the rest of household categories.

Another interesting observation is the lower land and livestock ownership of the contrasting households. Tenants with non-farm jobs have the highest number of working members on average (nearly 3) followed by farmers with non-agricultural activities and self-employed households. As far as businessmen, formal sector earning, and informal wage households are concerned, these were higher on average in Kukar. Pure farmers and those combining farming with non-farm jobs were more in Mushtarzai. Tenancy was more wide spread in Kochian and Gulbela due to the dominance of the landlords in these villages. 
Table 33. Summary Statistics of Variables in Multinomial Logit Model

\begin{tabular}{|c|c|c|c|c|c|c|c|}
\hline \multirow[b]{2}{*}{ Indep. Variables } & \multicolumn{7}{|c|}{ Dependent Variables } \\
\hline & $\begin{array}{l}\text { Wage } \\
(1) \\
\end{array}$ & $\begin{array}{c}\text { Formal } \\
(2)\end{array}$ & $\begin{array}{c}\text { Businessmen } \\
\text { (3) } \\
\end{array}$ & $\begin{array}{c}\text { Purefarmers } \\
(4) \\
\end{array}$ & $\begin{array}{c}\text { Mixedfarmers } \\
(5) \\
\end{array}$ & $\begin{array}{c}\text { Puretenants } \\
(6)\end{array}$ & $\begin{array}{c}\text { Mixedtenants } \\
(7)\end{array}$ \\
\hline \multirow[t]{2}{*}{ Age (years) } & 41.51 & 43.50 & 44.21 & 45.42 & 46.91 & 46.57 & 50.04 \\
\hline & $(12.2)$ & (11.4) & $(12.7)$ & $(12.4)$ & (11.4) & $(11.0)$ & $(12.1)$ \\
\hline \multirow[t]{2}{*}{ Education (years) } & 1.75 & 6.63 & 3.36 & 4.99 & 4.76 & 1.35 & 1.99 \\
\hline & $(3.3)$ & $(5.2)$ & $(4.6)$ & $(5.6)$ & $(5.4)$ & $(3.3)$ & (3.9) \\
\hline \multirow{2}{*}{$\begin{array}{l}\text { Household size } \\
\text { (no.) }\end{array}$} & 7.01 & 7.50 & 8.09 & 7.45 & 8.98 & 8.19 & 10.55 \\
\hline & $(3.2)$ & $(3.2)$ & $(4.0)$ & $(4.3)$ & $(4.4)$ & $(4.4)$ & $(5.4)$ \\
\hline \multirow[t]{2}{*}{ Workers (no.) } & 1.66 & 1.77 & 1.83 & 1.36 & 2.31 & 1.52 & 2.81 \\
\hline & $(1.0)$ & $(1.2)$ & $(1.2)$ & $(0.6)$ & $(1.3)$ & $(0.8)$ & $(1.5)$ \\
\hline \multirow[t]{2}{*}{ Land (log acres) } & 0 & 0 & 0 & 1.08 & 0.29 & 0 & 0 \\
\hline & $(-)$ & $(-)$ & $(-)$ & $(1.7)$ & (1.1) & $(-)$ & $(-)$ \\
\hline \multirow[t]{2}{*}{ Livestock (log no.) } & -0.06 & -0.04 & -0.01 & 0.59 & 0.18 & 0.84 & 0.49 \\
\hline & $(0.5)$ & $(0.4)$ & $(0.5)$ & $(1.1)$ & $(0.8)$ & $(0.9)$ & $(0.7)$ \\
\hline \multirow[t]{2}{*}{ Dalazak $(1,0)$} & 0.11 & 0.14 & 0.18 & 0.18 & 0.16 & 0.06 & 0.09 \\
\hline & $(0.3)$ & $(.3)$ & $(0.4)$ & $(0.4)$ & $(0.4)$ & $(0.2)$ & $(0.3)$ \\
\hline \multirow[t]{2}{*}{ Gulbela $(1,0)$} & 0.24 & 0.15 & 0.10 & 0.10 & 0.03 & 0.22 & 0.25 \\
\hline & $(0.4)$ & $(0.4)$ & $(0.3)$ & $(0.3)$ & $(0.2)$ & $(0.4)$ & $(0.4)$ \\
\hline \multirow[t]{2}{*}{ Kochian $(1,0)$} & 0.17 & 0.16 & 0.18 & 0.09 & 0.02 & 0.44 & 0.43 \\
\hline & $(0.4)$ & $(0.4)$ & $(0.4)$ & $(0.3)$ & $(0.1)$ & $(0.5)$ & $(0.5)$ \\
\hline \multirow[t]{2}{*}{ Kukar $(1,0)$} & 0.29 & 0.30 & 0.43 & 0.18 & 0.12 & 0.16 & 0.09 \\
\hline & $(0.5)$ & $(0.5)$ & $(0.5)$ & $(0.4)$ & $(0.3)$ & $(0.4)$ & $(0.3)$ \\
\hline \multirow[t]{2}{*}{ Mushtarzai $(1,0)$} & 0.12 & 0.19 & 0.09 & 0.32 & 0.43 & 0.10 & 0.08 \\
\hline & $(0.3)$ & $(0.4)$ & $(0.3)$ & $(0.5)$ & $(0.5)$ & $(0.4)$ & $(0.3)$ \\
\hline Observations & 913 & 467 & 507 & 77 & 576 & 81 & 204 \\
\hline
\end{tabular}

Note: Figures in brackets represents standard deviation.

Source: Basic survey carried out in six villages of Northwest Pakistan, 2004-05.

\subsection{Diagnostics Tests for Multinomial Logit Model}

Before discussing the results of multinomial logit model, it is appropriate to mention some of the required diagnostic measures for this model. The following sections begins with the details of Independence of Irrelevant Alternatives (IIA), followed by WALD and LR tests for combining dependent categories and finally the collinearity diagnostics.

\subsubsection{Independence of Irrelevant Alternatives}

The multinomial logit model makes the assumption known as the independence of irrelevant alternatives (IIA). According to IIA, in a multinomial logit model, the (log-) odds of one level of response versus another do not depend on any of the other levels; that is, other possible outcomes are not relevant. 
Following LONG \& FREESE, 2001 IIA in multinomial logit model is,

$$
\frac{\operatorname{Pr}(y=m \mid x)}{\operatorname{Pr}(y=n \mid x)}=\exp \left(x\left[\beta_{m \mid b}-\beta_{n \mid b}\right]\right)
$$

IIA or the odds do not depend on other alternatives that are available, is commonly investigated in multinomial logit model using two tests ${ }^{105}$, HAUSMAN \& MCFADDEN test ${ }^{106}$ and SMALL \& HSIAO test (LONG \& FREESE, 2001). However, as a rule of thumb, multinomial logit should only be used in situations where IIA is reasonable, such as when the different response categories are distinct and dissimilar.

The study carried out the HAUSMAN and MCFADDEN test as well as the SMALL \& HSiAO test to investigate the violation of IIA. Both of these tests given in Table 34 \& Table 35 revealed that the assumption of IIA has not being violated. Furthermore, four of the test statistics in HAUSMAN test are negative, again evidence of non-violation of IIA (SCHMIDT \& STRAUSS, 1975; AMELIE \& ZIMMERMANN, 2004). Hence, we are confident to state that the occupational categories are distinct and cannot be substituted for one another. For a nice description of tests concerning IIA in multinomial logit model, see CHENG \& LONG, 2007 and HAUSMAN \& MCFADDEN, 1984.

\footnotetext{
${ }^{105}$ As a word of caution, these tests according to LONG \& FREESE, 2001 often give inconsistent results and provide little guidance to violations of the IIA assumption. Hence, MCFADDEN, 1973 mentioned in LONG \& FREESE, 2001 suggested that IIA implies that the multinomial should only be used in cases where the outcome categories "can plausibly be assumed to be distinct and weighed independently in the eyes of each decision maker." Similarly, AMEMIYA, 1981 cited by LONG \& FREESE, 2001 suggests that the MNLM works well when the alternatives are dissimilar.

${ }^{106}$ The Hausman test of IIA was calculated following LONG \& FREESE, 2001 in the following three steps:

a) Estimation of full model with all $J$ outcomes included, with estimates in $\hat{\beta}_{F}$.

b) Estimation of a restricted model by eliminating one or more outcome categories, with estimates in $\hat{\beta}_{R}$.

c) Then considering $\hat{\beta}_{F}^{*}$ as a subset of $\hat{\beta}_{F}$ after eliminating coefficients not estimated in the restricted model. The test statistic becomes,
}

$$
H=\left(\hat{\beta_{R}}-\hat{\beta}_{F}^{*}\right)^{\prime}\left[\widehat{\operatorname{Var}}\left(\hat{\beta_{R}}\right)-\widehat{\operatorname{Var}}\left(\hat{\beta}^{*}\right)\right]^{-1}\left(\hat{\beta_{R}}-\hat{\beta}_{F}^{*}\right)
$$

where $\mathrm{H}$ is asymptotically distributed as chi-squared with degrees of freedom equal to the rows in $\hat{\beta}_{R}$ if IIA is true. Significant values of $\mathbf{H}$ indicate that the IIA assumption has been violated. 
Table 34. Hausman Test for Assumption of Independence of Irrelevant Alternatives

\begin{tabular}{|lcccc|}
\hline Category & chi2 & df & P>chi2 & Evidence \\
\hline Formal & -114.66 & 60 & 1.0000 & for Ho \\
Businessmen & -4.02 & 60 & 1.0000 & for Ho \\
Purefarmer & 17.29 & 60 & 1.0000 & for Ho \\
Mixedfarmer & 49.93 & 60 & 0.8198 & for Ho \\
Puretenant & -6.01 & 60 & 1.0000 & for Ho \\
Mixedtenant & -28.42 & 60 & 1.0000 & for Ho \\
\hline
\end{tabular}

Note: Ho: Odds (Outcome-J vs. Outcome-K) are independent of other alternatives

Insignificant values of Hausman test indicate that the IIA assumption has not been violated.

Source: Basic survey carried out in six villages of Northwest Pakistan, 2004-05.

Table 35. Small-Hsiao Tests of IIA Assumption for Multinomial Logit Model

\begin{tabular}{|lcccccc|}
\hline Category & $\operatorname{lnL}(\mathbf{f u l l})$ & $\operatorname{lnL}(\mathbf{o m i t})$ & chi2 & df & P>chi2 & Evidence \\
\hline Formal & -1313.563 & -1288.456 & 50.214 & 65 & 0.912 & for Ho \\
Businessmen & -1270.279 & -1239.639 & 61.280 & 65 & 0.608 & for Ho \\
Purefarmer & -1742.317 & -1712.164 & 60.306 & 65 & 0.642 & for Ho \\
Mixedfarmer & -1363.124 & -1325.315 & 75.618 & 65 & 0.173 & for Ho \\
Puretenant & -1742.346 & -1708.834 & 67.025 & 65 & 0.407 & for Ho \\
Mixedtenant & -1580.125 & -1549.245 & 61.761 & 65 & 0.591 & for Ho \\
\hline
\end{tabular}

Note: Ho: Odds (Outcome-J vs. Outcome-K) are independent of other alternatives.

The small-Hsiao test provides the evidence that IIA has not been violated. For detail explanation of these tests see LONG \& FREESE, 2001.

Source: Basic survey carried out in six villages of Northwest Pakistan, 2004-05.

\subsubsection{Tests for Combining Dependent Categories}

In order to investigate that the outcomes are distinguishable, we carried out WALD and LR tests for combining the dependent occupational categories. As can be seen in Table 36 these two tests provide very similar results. We can reject the hypothesis that our variables do not differentiate between categories. Therefore, we cannot combine any occupational category. If two outcomes are indistinguishable with respect to the variables in the model, then one can obtain more efficient estimates by combining them (LONG \& FREESE, 2001). 
Table 36. Wald and LR Tests for Combining Alternatives

\begin{tabular}{|lcccccccc|}
\hline \multirow{2}{*}{ Alternatives tested } & \multicolumn{3}{c}{ Wald test } & & \multicolumn{3}{c|}{ LR test } \\
\cline { 2 - 3 } \cline { 7 - 9 } & chi2 & df & P $>$ chi2 & & chi2 & df & P $>$ chi2 \\
\hline Formal-Businessmen & 165.8 & 12 & 0.00 & & 188.6 & 12 & 0.00 \\
Formal-Purefarmer & 150.7 & 12 & 0.00 & & 213.6 & 12 & 0.00 \\
Formal-Mixedfarmer & 282.1 & 12 & 0.00 & & 399.9 & 12 & 0.00 \\
Formal-Puretenant & 182.8 & 12 & 0.00 & & 263.5 & 12 & 0.00 \\
Formal-Mixedtenant & 238.1 & 12 & 0.00 & & 334.1 & 12 & 0.00 \\
Formal-Wage & 353.8 & 12 & 0.00 & & 460.9 & 12 & 0.00 \\
Business-Purefarmer & 164.3 & 12 & 0.00 & & 236.7 & 12 & 0.00 \\
Business-Mixedfarmer & 429.4 & 12 & 0.00 & & 709.0 & 12 & 0.00 \\
Business-Puretenant & 148.8 & 12 & 0.00 & & 198.2 & 12 & 0.00 \\
Business-Mixedtenant & 208.5 & 12 & 0.00 & & 291.3 & 12 & 0.00 \\
Business-Wage & 169.2 & 12 & 0.00 & & 197.5 & 12 & 0.00 \\
Purefarm-Mixedfarmer & 103.2 & 12 & 0.00 & & 160.6 & 12 & 0.00 \\
Purefarmer-Puretenant & 70.4 & 12 & 0.00 & & 126.8 & 12 & 0.00 \\
Purefarmer-Mixedtenant & 125.6 & 12 & 0.00 & & 244.5 & 12 & 0.00 \\
Purefarmer-Wage & 203.8 & 12 & 0.00 & & 298.5 & 12 & 0.00 \\
Mixedfarmer-Puretenant & 230.7 & 12 & 0.00 & & 390.8 & 12 & 0.00 \\
Mixedfarmer-Mixedtenant & 289.1 & 12 & 0.00 & & 499.3 & 12 & 0.00 \\
Mixedfarmer-Wage & 585.9 & 12 & 0.00 & & 1074.0 & 12 & 0.00 \\
Puretenant-Mixedtenant & 65.2 & 12 & 0.00 & & 100.7 & 12 & 0.00 \\
Puretenant-Wage & 177.6 & 12 & 0.00 & & 213.0 & 12 & 0.00 \\
Mixedtenant-Wage & 271.0 & 12 & 0.00 & & 365.0 & 12 & 0.00 \\
\hline
\end{tabular}

Ho: All coefficients except intercepts associated with a given pair of alternatives are 0 (i.e., alternatives can be combined).

Source: Basic survey carried out in six villages of Northwest Pakistan, 2004-05.

\subsubsection{Collinearity Diagnostics}

Multicollinearity occurs when variables are so highly correlated with each other that they actually convey the same information and it becomes difficult to come up with reliable estimates of their individual regression coefficients (see for details GREENE, 2003; GUJARATI, 2003; Wooldridge, 2003; Hamilton, 2006). The post estimation Stata command 'collin' was used to compute the collinearity diagnostics ${ }^{107}$ given in Table 37. According to HAMILTON, 2006 multicollinearity becomes an issue of concern if the largest Variance Inflation Factor (VIF) is greater than 10 and the mean $\mathrm{VIF}^{108}$ is substantially larger than 1 . The current study encounters no problem of collinearity as indicated by Table 37.

\footnotetext{
${ }^{107}$ One can also use the 'VIF' command in Stata to perform collinearity diagnostics (LONG \& FREESE, 2001).

${ }^{108}$ The VIF reflects the degree to which other coefficients variances are increased due to the inclusion of that predator (HAMILTON, 2006).
} 
Table 37. Collinearity Diagnostics for Variables used in Multinomial Logit Model

\begin{tabular}{|lcccc|}
\hline Variable & VIF & SQRT-VIF & Tolerance $^{1}$ & R-Squared \\
\hline AGE & 1.34 & 1.16 & 0.75 & 0.25 \\
EDU & 1.11 & 1.06 & 0.90 & 0.10 \\
HHS & 1.75 & 1.32 & 0.57 & 0.43 \\
HHW & 1.81 & 1.35 & 0.55 & 0.45 \\
logowlndTot & 1.19 & 1.09 & 0.84 & 0.16 \\
logLvStkUnt & 1.06 & 1.03 & 0.94 & 0.06 \\
Dalazak & 2.14 & 1.46 & 0.47 & 0.53 \\
Gulbela & 2.26 & 1.50 & 0.44 & 0.56 \\
Kochian & 2.32 & 1.52 & 0.43 & 0.57 \\
Kukar & 2.88 & 1.70 & 0.35 & 0.65 \\
Mushtarzai & 2.61 & 1.62 & 0.38 & 0.62 \\
Mean VIF =1.86 & & & & \\
Condition Number $=14.24$ & & & \\
\hline
\end{tabular}

Note: 1) Tolerance or $\left(1-\mathrm{R}^{2}\right)$ tells what proportion of an $\mathrm{x}$ variable's variance is independent of all other $\mathrm{x}$ variables (HAMilTON, 2006).

Source: Basic survey carried out in six villages of Northwest Pakistan, 2004-05.

\subsection{Factors Affecting Labor Participation: Results and Discussion of Multinomial Logit Model}

This study has considered factors that determine household decision to participate in rural labor market in Northwest Pakistan using multinomial logit model. The results for the multinomial logit model are presented in terms of logit coefficients and odd ratio ${ }^{109}$ in Table 38 and Table 39 respectively. Since direct interpretation of coefficient (Table 38) is difficult for the estimates from multinomial logit model, the odd ratio (risk ratio) is used to describe the impact of variables on employment choices (Table 39). We use non-farm informal sector as the comparison group, which happens to be the dominant (33\%) employment strategy in the study area. Stata (ver. 9.2) is used to estimate the multinomial logit model. The chi-square for the model is significant at 1 percent level, and more importantly, pseudo $\mathrm{R}^{2}$ explains over 28 percent of the variance among the groups.

\footnotetext{
${ }^{109}$ It makes more sense to report the results of multinomial logit model in odd ratios than marginal effects as the MNLT is a multi-equation model and sometime the coefficients switches sign between raw coffiicients and its counterparting marginal effects (see for details on these issues, GREENE, 2003; LONG \& FREESE, 2001).
} 
Table 38. Multinomial Logit Regression for Occupational Categories

\begin{tabular}{|c|c|c|c|c|c|c|}
\hline Explanatory variables & $\begin{array}{c}\text { Formal } \\
\text { (1) }\end{array}$ & $\begin{array}{c}\text { Businessmen } \\
\text { (2) }\end{array}$ & $\begin{array}{c}\text { Purefarmer } \\
\text { (3) }\end{array}$ & $\begin{array}{c}\text { Mixedfarmer } \\
\text { (4) }\end{array}$ & $\begin{array}{c}\text { Puretenant } \\
\text { (5) }\end{array}$ & $\begin{array}{c}\text { Mixedtenant } \\
\text { (6) }\end{array}$ \\
\hline Age (years) & $\begin{array}{c}0.145 * * * \\
(0.033)\end{array}$ & $\begin{array}{c}0.040 \\
(0.029)\end{array}$ & $\begin{array}{c}0.102 \\
(0.071)\end{array}$ & $\begin{array}{c}0.245 * * * \\
(0.037)\end{array}$ & $\begin{array}{l}0.143^{*} \\
(0.078)\end{array}$ & $\begin{array}{l}0.106^{* *} \\
(0.048)\end{array}$ \\
\hline AgeSq (years) & $\begin{array}{c}-0.001 * * * \\
(0.000)\end{array}$ & $\begin{array}{l}-0.000 \\
(0.000)\end{array}$ & $\begin{array}{l}-0.001 \\
(0.001)\end{array}$ & $\begin{array}{c}-0.002 * * * \\
(0.000)\end{array}$ & $\begin{array}{l}-0.001 \\
(0.001)\end{array}$ & $\begin{array}{l}-0.001 * \\
(0.000)\end{array}$ \\
\hline Education (years) & $\begin{array}{c}0.278^{* * *} \\
(0.015)\end{array}$ & $\begin{array}{c}0.117 * * * \\
(0.015)\end{array}$ & $\begin{array}{c}0.152 * * * \\
(0.033)\end{array}$ & $\begin{array}{c}0.292 * * * \\
(0.017)\end{array}$ & $\begin{array}{l}-0.006 \\
(0.041)\end{array}$ & $\begin{array}{c}0.097 * * * \\
(0.024)\end{array}$ \\
\hline Household size (no.) & $\begin{array}{l}0.044^{*} \\
(0.023)\end{array}$ & $\begin{array}{c}0.099 * * * \\
(0.021)\end{array}$ & $\begin{array}{c}0.077 \\
(0.049)\end{array}$ & $\begin{array}{l}0.051 * * \\
(0.023)\end{array}$ & $\begin{array}{l}0.083^{*} \\
(0.044)\end{array}$ & $\begin{array}{c}0.101 * * * \\
(0.027)\end{array}$ \\
\hline Workers (no.) & $\begin{array}{c}0.087 \\
(0.073)\end{array}$ & $\begin{array}{l}-0.102 \\
(0.067)\end{array}$ & $\begin{array}{c}-1.075 * * * \\
(0.245)\end{array}$ & $\begin{array}{c}0.342 * * * \\
(0.074)\end{array}$ & $\begin{array}{c}-0.849^{* * *} \\
(0.195)\end{array}$ & $\begin{array}{c}0.402 * * * \\
(0.087)\end{array}$ \\
\hline Land (log acres) & $\begin{array}{l}-0.014 \\
(0.147)\end{array}$ & $\begin{array}{c}0.020 \\
(0.160)\end{array}$ & $\begin{array}{c}1.527 * * * \\
(0.186)\end{array}$ & $\begin{array}{c}0.538 * * * \\
(0.132)\end{array}$ & $\begin{array}{l}-0.074 \\
(0.365)\end{array}$ & $\begin{array}{l}-0.279 \\
(0.212)\end{array}$ \\
\hline Livestock (log no.) & $\begin{array}{c}0.107 \\
(0.109)\end{array}$ & $\begin{array}{c}0.101 \\
(0.099)\end{array}$ & $\begin{array}{c}1.579 * * * \\
(0.202)\end{array}$ & $\begin{array}{c}0.773 * * * \\
(0.114)\end{array}$ & $\begin{array}{c}2.094 * * * \\
(0.184)\end{array}$ & $\begin{array}{c}1.276 * * * \\
(0.146)\end{array}$ \\
\hline $\operatorname{Dalazak}^{1}(1,0)$ & $\begin{array}{l}-0.117 \\
(0.295)\end{array}$ & $\begin{array}{c}1.925 * * * \\
(0.375)\end{array}$ & $\begin{array}{c}0.432 \\
(0.553)\end{array}$ & $\begin{array}{c}-1.276^{* * *} \\
(0.254)\end{array}$ & $\begin{array}{c}1.202 \\
(1.128)\end{array}$ & $\begin{array}{l}-0.004 \\
(0.428)\end{array}$ \\
\hline Gulbela $(1,0)$ & $\begin{array}{c}-0.947 * * * \\
(0.286)\end{array}$ & $\begin{array}{c}0.461 \\
(0.377)\end{array}$ & $\begin{array}{c}-2.089 * * * \\
(0.735)\end{array}$ & $\begin{array}{c}-4.100 * * * \\
(0.342)\end{array}$ & $\begin{array}{c}1.488 \\
(1.058)\end{array}$ & $\begin{array}{l}-0.313 \\
(0.383)\end{array}$ \\
\hline Kochian $(1,0)$ & $\begin{array}{l}-0.393 \\
(0.283)\end{array}$ & $\begin{array}{c}1.371 * * * \\
(0.368)\end{array}$ & $\begin{array}{l}-1.283 * \\
(0.694)\end{array}$ & $\begin{array}{c}-4.052 * * * \\
(0.404)\end{array}$ & $\begin{array}{c}2.708 * * * \\
(1.044)\end{array}$ & $\begin{array}{c}0.988 * * * \\
(0.367)\end{array}$ \\
\hline Kukar $(1,0)$ & $\begin{array}{l}-0.387 \\
(0.265)\end{array}$ & $\begin{array}{c}1.673 * * * \\
(0.356)\end{array}$ & $\begin{array}{l}-0.145 \\
(0.545)\end{array}$ & $\begin{array}{c}-2.677 * * * \\
(0.245)\end{array}$ & $\begin{array}{c}0.857 \\
(1.077)\end{array}$ & $\begin{array}{c}-1.603 * * * \\
(0.432)\end{array}$ \\
\hline Mushtarzai $(1,0)$ & $\begin{array}{c}0.618^{* *} \\
(0.284)\end{array}$ & $\begin{array}{c}1.276^{* * *} \\
(0.390)\end{array}$ & $\begin{array}{c}1.955^{* * *} \\
(0.512)\end{array}$ & $\begin{array}{l}0.415^{*} \\
(0.226)\end{array}$ & $\begin{array}{c}1.645 \\
(1.097)\end{array}$ & $\begin{array}{l}-0.138 \\
(0.441)\end{array}$ \\
\hline $\begin{array}{l}\text { Observations }=2825 \\
\text { Log-likelihood }=-3599 \\
\text { LR chi2 }(72)=2323 \\
\text { Prob }>\text { chi } 2=0.000 \\
\text { McFadden's } R^{2}=0.24 \\
\text { McFadden's Adj } R^{2}=0.2 \\
\text { Model predicted correctl }\end{array}$ & $51 \mathrm{p}$ & & & & & \\
\hline
\end{tabular}

Note: Those engaged in informal wage activities serve as base group.

Standard errors in parentheses

$* * * \mathrm{p}<0.01, * * \mathrm{p}<0.05, * \mathrm{p}<0.1$

1) Village Yousafkhel served as reference village.

Source: Basic survey carried out in six villages of Northwest Pakistan, 2004-05. 
Table 39. Odd Ratios for Multinomial Logit Regression for Household Occupations

\begin{tabular}{|c|c|c|c|c|c|c|}
\hline Explanatory variables & $\begin{array}{c}\text { Formal } \\
(1)\end{array}$ & $\begin{array}{c}\text { Businessmen } \\
\text { (2) }\end{array}$ & $\begin{array}{c}\text { Purefarmer } \\
\text { (3) }\end{array}$ & $\begin{array}{c}\text { Mixedfarmer } \\
\text { (4) }\end{array}$ & $\begin{array}{c}\text { Puretenant } \\
\text { (5) }\end{array}$ & $\begin{array}{c}\text { Mixedtenant } \\
(6)\end{array}$ \\
\hline Age (years) & $\begin{array}{c}1.16 * * * \\
(0.04)\end{array}$ & $\begin{array}{c}1.04 \\
(0.03)\end{array}$ & $\begin{array}{c}1.11 \\
(0.08)\end{array}$ & $\begin{array}{c}1.28 * * * \\
(0.05)\end{array}$ & $\begin{array}{l}1.15^{*} \\
(0.09)\end{array}$ & $\begin{array}{l}1.11 * * \\
(0.05)\end{array}$ \\
\hline AgeSq (years) & $\begin{array}{c}1.00 * * * \\
(0.00)\end{array}$ & $\begin{array}{c}1.00 \\
(0.00)\end{array}$ & $\begin{array}{c}1.00 \\
(0.00)\end{array}$ & $\begin{array}{c}1.00 * * * \\
(0.00)\end{array}$ & $\begin{array}{c}1.00 \\
(0.00)\end{array}$ & $\begin{array}{l}1.00^{*} \\
(0.00)\end{array}$ \\
\hline Education (years) & $\begin{array}{c}1.32 * * * \\
(0.02)\end{array}$ & $\begin{array}{c}1.12 * * * \\
(0.02)\end{array}$ & $\begin{array}{c}1.16^{* * *} \\
(0.04)\end{array}$ & $\begin{array}{c}1.34 * * * \\
(0.02)\end{array}$ & $\begin{array}{c}0.99 \\
(0.04)\end{array}$ & $\begin{array}{c}1.10 * * * \\
(0.03)\end{array}$ \\
\hline Household size(no.) & $\begin{array}{l}1.04^{*} \\
(0.02)\end{array}$ & $\begin{array}{c}1.10 * * * \\
(0.02)\end{array}$ & $\begin{array}{l}1.08 \\
(0.05)\end{array}$ & $\begin{array}{l}1.05 * * \\
(0.02)\end{array}$ & $\begin{array}{l}1.09 * \\
(0.05)\end{array}$ & $\begin{array}{c}1.11 * * * \\
(0.03)\end{array}$ \\
\hline Workers (no.) & $\begin{array}{c}1.09 \\
(0.08)\end{array}$ & $\begin{array}{c}0.90 \\
(0.06)\end{array}$ & $\begin{array}{c}0.34 * * * \\
(0.08)\end{array}$ & $\begin{array}{c}1.41 * * * \\
(0.10)\end{array}$ & $\begin{array}{c}0.43 * * * \\
(0.08)\end{array}$ & $\begin{array}{c}1.50 * * * \\
(0.13)\end{array}$ \\
\hline Land (log acres) & $\begin{array}{c}0.99 \\
(0.15)\end{array}$ & $\begin{array}{c}1.02 \\
(0.16)\end{array}$ & $\begin{array}{c}4.61 * * * \\
(0.86)\end{array}$ & $\begin{array}{c}1.71 * * * \\
(0.23)\end{array}$ & $\begin{array}{c}0.93 \\
(0.34)\end{array}$ & $\begin{array}{c}0.76 \\
(0.16)\end{array}$ \\
\hline Livestock (log no.) & $\begin{array}{c}1.11 \\
(0.12)\end{array}$ & $\begin{array}{c}1.11 \\
(0.11)\end{array}$ & $\begin{array}{c}4.85 * * * \\
(0.98)\end{array}$ & $\begin{array}{c}2.17 * * * \\
(0.25)\end{array}$ & $\begin{array}{c}8.12 * * * \\
(1.49)\end{array}$ & $\begin{array}{c}3.58 * * * \\
(0.52)\end{array}$ \\
\hline $\operatorname{Dalazak}^{1}(1,0)$ & $\begin{array}{c}0.89 \\
(0.26)\end{array}$ & $\begin{array}{c}6.86 * * * \\
(2.57)\end{array}$ & $\begin{array}{c}1.54 \\
(0.85)\end{array}$ & $\begin{array}{c}0.28 * * * \\
(0.07)\end{array}$ & $\begin{array}{c}3.33 \\
(3.75)\end{array}$ & $\begin{array}{c}1.00 \\
(0.43)\end{array}$ \\
\hline Gulbela $(1,0)$ & $\begin{array}{c}0.39 * * * \\
(0.11)\end{array}$ & $\begin{array}{c}1.59 \\
(0.60)\end{array}$ & $\begin{array}{c}0.12 * * * \\
(0.09)\end{array}$ & $\begin{array}{c}0.02 * * * \\
(0.01)\end{array}$ & $\begin{array}{c}4.43 \\
(4.68)\end{array}$ & $\begin{array}{c}0.73 \\
(0.28)\end{array}$ \\
\hline Kochian $(1,0)$ & $\begin{array}{c}0.68 \\
(0.19)\end{array}$ & $\begin{array}{c}3.94 * * * \\
(1.45)\end{array}$ & $\begin{array}{l}0.28^{*} \\
(0.19)\end{array}$ & $\begin{array}{c}0.02 * * * \\
(0.01)\end{array}$ & $\begin{array}{c}15.00 * * * \\
(15.66)\end{array}$ & $\begin{array}{c}2.68 * * * \\
(0.99)\end{array}$ \\
\hline Kukar $(1,0)$ & $\begin{array}{c}0.68 \\
(0.18)\end{array}$ & $\begin{array}{c}5.33 * * * \\
(1.90)\end{array}$ & $\begin{array}{c}0.87 \\
(0.47)\end{array}$ & $\begin{array}{c}0.07 * * * \\
(0.02)\end{array}$ & $\begin{array}{c}2.36 \\
(2.54)\end{array}$ & $\begin{array}{c}0.20 * * * \\
(0.09)\end{array}$ \\
\hline Mushtarzai $(1,0)$ & $\begin{array}{l}1.85 * * \\
(0.53)\end{array}$ & $\begin{array}{c}3.58 * * * \\
(1.40)\end{array}$ & $\begin{array}{c}7.06 * * * \\
(3.62)\end{array}$ & $\begin{array}{l}1.51 * \\
(0.34)\end{array}$ & $\begin{array}{c}5.18 \\
(5.68)\end{array}$ & $\begin{array}{c}0.87 \\
(0.38)\end{array}$ \\
\hline $\begin{array}{l}\text { Observations }=2825 \\
\text { Log-likelihood }=-3599 \\
\text { LR chi2 }(72)=2323 \\
\text { Prob }>\text { chi } 2=0.000 \\
\text { McFadden's } R^{2}=0.24 \\
\text { McFadden's Adj } R^{2}=0 . \\
\text { Model predicted correct }\end{array}$ & $\begin{array}{l}3 \\
y=51 \text { per }\end{array}$ & ent & & & & \\
\hline $\begin{array}{l}\text { Note: The coefficients fo } \\
\text { Standard errors in paren } \\
\text { 1) Village Yousafkhel s } \\
* * * \mathrm{p}<0.01, * * \mathrm{p}<0.05\end{array}$ & $\begin{array}{l}\text { each occ } \\
\text { eses } \\
\text { ved as r } \\
<0.1\end{array}$ & ations meast & odd rati & ive to info & age ac & \\
\hline
\end{tabular}

\subsubsection{Role of Human Capital in Labor Participation}

Our results support the human capital hypothesis. The year of education variable is significant and positive in almost all comparisons $(\mathrm{OR}=1.10-1.34 \mathrm{p}<0.01)$. Additional years of education prompt the respondents into occupations other than non-farm informal sector, ceteris paribus (see Table 39). Nevertheless, the size of education coefficient is highest (odd ratio in 
range of 32-34\%) for farmers with non-agricultural jobs (mixed farmers) and formal sector earners. Results are in congruence with earlier findings (SCHMIDT \& STRAUSS, 1975; AMELIE \& ZIMMERMANN, 2004).

Age of the household head as proxy for experience, turn out to positive and significant for nearly all categories $(\mathrm{OR}=1.11-1.28 \mathrm{p}<0.01-0.1)$. Contrary to expectations, the likelihood of sticking to pure farming and own businesses as compared to informal wage activity is not generally influenced by age of the household head ${ }^{110}$. Older household heads are expected to be involved in occupations other than informal wage earning since they have higher accumulated experience. The negative sign of age square variable indicates the nonlinearity in age (Table 38). There are a few possible reasons for this phenomenon:

a) Firstly, it was observed in the study area that majority of those employed in the formal sector were in lower cadre jobs, increasing the likelihood for their early retirement.

b) Secondly, the introduction of 'Golden Handshake Scheme' in Pakistan under the influence of international financial institutions during the structural adjustment programme era motivated a large number of formal sector workers to retire early for getting benefits; and

c) Lastly, the joint family system is more common among farming households in rural Pakistan and so elders don't work so often. Similar results were reported by ARIF et al., 2000 in their study in Pakistan.

As expected the household size turn out to be positive and significant for majority of the constrasting occupational categories $(\mathrm{OR}=1.04-1.11 \mathrm{p}<0.01-0.1)$. A large household because of dependency problems, make it necessary on part of the household to diversify their income sources and strive for occupations that are more rewarding than informal wage jobs. In addition, in a Pashtun society, household composition also affects the types of employment its members enter, as well as how or by whom decisions are taken (ALBRECHT, 1976; MANIG, 1991). The variable on working members in a household showed mixed picture. It turned out to be negative and significant $(\mathrm{OR}=0.34-0.43 \mathrm{p}<0.01)$ for the pure farmer and pure tenant categories relative to reference group. However, the reverse $(\mathrm{OR}=1.41-1.50 \mathrm{p}<0.01)$ was true for those enaged in mixed farming and mixed tenancy compared to informal wage jobs. This reveals that

\footnotetext{
${ }^{110}$ Younger household members with better education could have a better paid job, however, we considered only the age of the household head. The study do acknowledge the limitations of these results.
} 
as a strategy of survival, majority of the household members within the informal wage earning household have to work.

\subsubsection{Role of Household Assets in Labor Participation}

As expected ownership of land and livestock, stimulate households to farming (Table 39). Except those in own businesses and formal sector jobs, the probability (odds) increases significantly for livestock ownership for the rest of alternative occupational categories $(\mathrm{OR}=2.17-8.12$ $\mathrm{p}<0.01)$. Turning to land ownership, Table 39 indicates that in odds, it matters almost 2-5 times more for the households to be involved in pure or mixed farming than in informal wage activities $(\mathrm{OR}=1.71-4.61 \mathrm{p}<0.01)$. Wealth, defined here as household per capita income is expected to matter a lot in the likelihood of pursuing occupations other than informal work in the study area. However, because of possible endogeneity problems, the variables on income and credit were dropped from the model.

\subsubsection{Role of Geographical Location and Infrastructure in Labor Participation}

Finally comparing the six villages in term of labor market, we find that relative to Yousafkhel, the probability increases for the rest of villages, that households pursue businesses or work as tenants than informal wage works (Table 39). However, for the rest of occupation categories, except Mushtarzai majority of the results are negative and significant. Tenancy is strong in Kochian $(\mathrm{OR}=2.68-15.0 \mathrm{p}<0.01)$, where the landlord rent-out their land in small parcels on share cropping based on 50-50 share in produce.

Working as businessmen or independent trader is normally adopted by those (village Kukar \& Dalazak) around the provincial capital Peshawar, or near the main road Charsadda highway (village Kochian). This on one hand allows for easy commuting and on other hand satisfies the service demands of the urban dwellers in the provincial capital Peshawar as well as the city of Charsadda. However, in case of Mushtarzai, the demand for business related activities is mostly local driven where the remittance from abroad played a major role in setting up or initiating self employment. 
Being a resident of Dalazak, Gulbela, Kochian, and Kukar decreases the likelihood of involvement in formal sector jobs (regulated jobs in government and private sectors) and mixed farming as opposed to the base category. Nevertheless, the coefficient for Mushtarzai is statistically positive $(\mathrm{OR}=1.51-1.85 \mathrm{p}<0.05-0.1)$ for these occupational categories. The less probability for formal sector jobs in the villages near the provincial capital Peshawar points towards two main realities in the area:

a) It shows an emerging positive tendency on part of the dwellers in the tribal village Yousafkhel with its rainfed nature to find their livelihood in more secure, permanent, and high return occupations. Due to their agro-climatic conditions, the working adults in Yousafkhel and also in Mushtarzai either work in gulf countries or moved for permanent jobs to big metropolis in Pakistan like Karachi, Lahore, and Islambad.

b) The dwellers of Yousafkhel and Mushtarzai being located at the tribal belt have more chances to qualify for working in armed forces in Pakistan and border patrol jobs due to the quota system for FATA. 


\section{CHANGES IN THE EMPLOYMENT STRUCTURE}

The main purpose of this chapter is to make a comparative review and analysis of change and development in employment structure, comparing six villages in Northwest Pakistan over 37 years, 1967-2005. Although our review of the trends in occupational structure is extensive, the study cannot do justice to all the livelihood aspects and are by necessity selective. The following sections therefore examine the changing role of agriculture in rural livelihoods with the continued and increasing relevance of rural households on non-farming employment opportunities. The socio-economic structures in the study area are complex; however, in order to trace the process of change, we can identify a few major driving forces. Hence, before explaining the details of changes in the occupational structure in the six research villages, it is relevant to highlight the changes in the farming structure and demographic transition that have a direct consequence for the emergence of non-farm sector in the area.

\subsection{Changes in the Demography and Education over Time in the Study Villages}

The change process in the study area since 1967-68 is revealed by transition in the household demography and literacy. As an important driving force for change in the study area, the demographic structure reveals that in the last four decades between the first study (1967-68) and the latest (2004-05), the population in the study villages increased almost 200 percent (Table 40). It is worth mentioning that in the last four decades, the population increased by 255 percent in Kukar largely is the result of people moving to the village due to its prime location ${ }^{111}$.

There was an increase of around 128 percent in the number of households since 1967-68 which emphasizes the fact that the villages as a whole have made no progress so far in terms of the demographic transition from high to low fertility rates and explains the growth in population in the survey villages. Nevertheless, the average household size of 7.9 observed in 1986/8 remained the same for in the last two decades in the study regions (see Table 40).

\footnotetext{
${ }^{111}$ The favourable location with respect to easily accessible transport opportunities to reach Peshawar, the provincial capital, as well as the growth of a number of business activities along the Peshawar-Charsadda highway has induced a number of new settlers to move to that village. Due to the establishment of these entirely new settlements, the village boundaries stretched to the limit giving the impression of an urban quarter.
} 
Table 40. Demographic and Other Structural Changes over the Years in the Surveyed Villages in North-west Pakistan

\begin{tabular}{|c|c|c|c|c|c|c|c|c|c|}
\hline \multirow[b]{2}{*}{ Parameters } & \multirow[b]{2}{*}{ Year } & \multicolumn{8}{|c|}{ Research Villages } \\
\hline & & $\begin{array}{l}\text { Kuk- } \\
\text { ar }\end{array}$ & $\begin{array}{l}\text { Yous- } \\
\text { afkhel }\end{array}$ & $\begin{array}{l}\text { Gul- } \\
\text { bela }\end{array}$ & $\begin{array}{l}\text { Koc- } \\
\text { hian }\end{array}$ & $\begin{array}{l}\text { Dala- } \\
\text { zak }\end{array}$ & $\begin{array}{l}\text { Mush- } \\
\text { tarzai }\end{array}$ & $\begin{array}{c}\text { All } \\
\text { Villages }\end{array}$ & $\begin{array}{l}\text { Percent } \\
\text { Change }\end{array}$ \\
\hline \multirow{3}{*}{$\begin{array}{l}\text { Inhabitants } \\
\text { (Number) }\end{array}$} & $1967 / 68$ & 1687 & 693 & 1218 & 1362 & 888 & 1837 & 7685 & - \\
\hline & $1986 / 87$ & 3082 & 1368 & 1999 & 2140 & 2389 & 3323 & 14301 & +86.1 \\
\hline & $2004 / 05$ & 6003 & 2620 & 3439 & 3639 & 2668 & 4194 & 22563 & +57.8 \\
\hline \multirow{3}{*}{$\begin{array}{l}\text { Households } \\
\text { (Number) }\end{array}$} & $1967 / 68$ & 271 & 116 & 200 & 219 & 136 & 295 & 1237 & - \\
\hline & $1986 / 87$ & 372 & 159 & 276 & 281 & 296 & 435 & 1819 & +47.1 \\
\hline & $2004 / 05$ & 727 & 288 & 432 & 459 & 380 & 539 & 2825 & +55.3 \\
\hline \multirow{3}{*}{$\begin{array}{l}\text { HH Size } \\
\text { (Person./Hh) }\end{array}$} & $1967 / 68$ & 6.2 & 6.0 & 6.1 & 6.2 & 6.5 & 6.3 & 6.2 & - \\
\hline & $1986 / 87$ & 8.3 & 8.6 & 7.2 & 7.6 & 8.1 & 7.6 & 7.9 & +27.4 \\
\hline & $2004 / 05$ & 8.2 & 9.1 & 7.9 & 7.9 & 7.0 & 7.7 & 7.9 & 0 \\
\hline \multirow{3}{*}{$\begin{array}{l}\text { Any schooling }{ }^{1} \\
\text { over } 4(\%)\end{array}$} & $1967 / 68$ & 13.7 & 5.5 & 17.2 & 14.4 & 14.5 & 10.7 & 12.7 & - \\
\hline & $1986 / 87$ & 23.9 & 19.6 & 23.4 & 20.7 & 25.1 & 22.2 & 22.8 & +79.5 \\
\hline & $2004 / 05$ & 25.7 & 25.8 & 30.8 & 37.4 & 36.6 & 30.8 & 31.2 & +36.8 \\
\hline
\end{tabular}

Note: 1) In the previous research projects in 1967-8 and 1986-7, very limited data was available on the female literacy rate as in those times only few girls went to school. Therefore, only the educational level of the male population was used in the comparison (MANIG, 1991). However, the research team observed during the field study in these villages that more and more families are stressing female education.

Source: Basic survey carried out in six villages of Northwest Pakistan, 2004-05; MANIG, 1991.

The growth in the other villages is located more or less at the mean on the growth scale with the exception of Dalazak (Table 40). A variety of reasons can have contributed to the drop in the average household size in Dalazak; for instance, high literacy rate (37\%) among the research villages and also the village as the hub of family planning projects and studies in the last two decades. Returning to the other villages, the increase in household size was more pronounced in Yousafkhel, a trend continued from the previous surveys.

The literacy rate, judged on males who attended school for a period of four years or more, exhibits a similar picture across the villages. However, we must realize that in Yousafkhel, a remote village, in 1967/68 only 5.5 percent of the male population had visited a school for a minimum of at least four years; in 2004/05, however, it was already nearly 26 percent (Table 40). The literacy in Kukar since 1986/87, even if it did not decline, made little improvement. Although a number of public and private educational institutions were established in Kukar over the years, the literacy rate changed only from almost 24 percent in 1986/87 to around 26 
percent in 2004/05. This phenomenon becomes more disturbing when we look at the locality of the village, as it is only five kilometers away from the provincial capital Peshawar. However, we must realize two main facts which could have contributed to this low literacy rate: firstly, a large number of illiterate Afghan refugees settled in the village and secondly, uneducated rural families migrated from places like Charsadda, Shabqadar, Mohmand agency, and other neighbouring villages during the last two decades.

The literacy rate improved slightly between the dates of the three surveys; nevertheless, a sizeable portion of the male population is still illiterate in the study area (Table 40). This low stock of skills and labor quality at the village level clearly explains the dominance of the informal labor market at the village level.

The non-availability of data since the previous two surveys hindered the comparison of the female literacy rate in the six villages. Definitely only a few girls went to school at that time as in 1986/87, merely 156 females ${ }^{112}$ had visited a school for at least four years (MANIG, 1991). During the present survey, there was an increase in the stress on education for girls; however, the economically backward households still lagged behind in that front due to a variety of reasons. The Pakhtoon institution of 'purdah' was a major obstacle to woman education in the study areas, followed by the economic difficulties of the households.

\subsection{Changes in the Farm Structures in the Villages}

Changes in household ownership of farms in the surveyed villages between 1967-8 and 2004-5 took various forms (Table 41). The change in the number of farms also accompanied a transition in the size of the farms. In 1967-8, about 58 percent of the households had farms which reduced to 41 percent in 1986-7, reaching 28 percent in 2004-5. In contrast, in the last four decades, the absolute number of farms increased almost eight percent; that highlights the fragmentation of farms and the increase in the rural population in the study area (Table 41). Overall, the average farm size decreased from 4.1 acres in 1986-87 to 2.9 acres in 2004-05; the process of land fragmentation ${ }^{113}$ was observed in all of the villages.

\footnotetext{
${ }^{112}$ In addition, some 219 female villagers visited a school for less than four years (for details, see MANIG, 1991).

${ }^{113}$ The Islamic Law of Inheritance also plays an important role in shrinking of cultivatable land.
} 
Table 41. Transition in Household Farm Related Statistics over the Years

\begin{tabular}{|l|l|cccccc|cc|}
\hline \multirow{3}{*}{ Parameters } & \multirow{2}{*}{ Year } & \multicolumn{8}{|c|}{ Research Villages } \\
\cline { 3 - 10 } & & $\begin{array}{c}\text { Kuk- } \\
\text { ar }\end{array}$ & $\begin{array}{c}\text { Yous- } \\
\text { afkhel }\end{array}$ & $\begin{array}{c}\text { Gul- } \\
\text { bela }\end{array}$ & $\begin{array}{c}\text { Koc- } \\
\text { hian }\end{array}$ & $\begin{array}{c}\text { Dala- } \\
\text { zak }\end{array}$ & $\begin{array}{c}\text { Mush- } \\
\text { tarzai }\end{array}$ & $\begin{array}{c}\text { All } \\
\text { Villages }\end{array}$ & $\begin{array}{c}\text { Percent } \\
\text { Change }\end{array}$ \\
\hline Agricultural & $1967 / 68$ & 100 & 78 & 102 & 144 & 79 & 219 & 722 & - \\
Farms (No.) & $1986 / 87$ & 112 & 75 & 105 & 108 & 113 & 229 & 742 & +2.8 \\
& $2004 / 05$ & 75 & 148 & 79 & 131 & 113 & 232 & 778 & +4.9 \\
\cline { 2 - 10 } Farm Size & $1967 / 68$ & 4.8 & - & 3.3 & 3.0 & 3.0 & 2.0 & - & - \\
(Acres) & $1986 / 87$ & 3.7 & 9.3 & 6.1 & 3.7 & 3.7 & 2.1 & 4.1 & - \\
& $2004 / 05$ & 2.4 & 4.6 & 5.5 & 2.6 & 3.2 & 1.1 & 2.9 & -29.3 \\
\hline
\end{tabular}

Source: Basic survey carried out in six villages of Northwest Pakistan, 2004-05; MANIG, 1991.

The changes in the number of farms deviated in the individual villages. The increasing trend in the number of farms viewed in 1987/ 88 reversed in 2004/05 in Kukar and Gulbela (Table 41). In the last two decades, there was less of an increase in Mushtarzai (1.3 percent), while for Yousafkhel and Kochian, the number of farms increased strongly in the range of 21-97 percent. In the present survey, the number of farms in Dalazak remained constant, halting the increasing phenomenon experienced in the 1986/87 survey (see Table $41 \&$ Table 42).

Table 42. Changes in Farm Area, Cultivated Area, and Number of Farms in Study Area

\begin{tabular}{|c|c|c|c|c|c|c|c|c|}
\hline \multirow[b]{2}{*}{ Villages } & \multirow[b]{2}{*}{ Year } & \multicolumn{3}{|c|}{ Farm area (acres) } & \multicolumn{3}{|c|}{ Cultivated area (acres) } & \multirow{2}{*}{$\begin{array}{c}\text { Number } \\
\text { of } \\
\text { Farms }\end{array}$} \\
\hline & & Total & Irrigat. & Not irrigat. & Total & Irrigat. & Not irrigat. & \\
\hline \multirow{2}{*}{ Kukar } & $2004-05$ & 182.4 & 178.9 & 3.5 & 181.4 & 178.9 & 2.5 & 75 \\
\hline & $1986-87$ & 427 & 410 & 20 & 410 & 410 & 3 & 112 \\
\hline \multirow{2}{*}{ Mushtarzai } & $2004-05$ & 242.9 & 242.9 & 0 & 242.9 & 242.9 & 0 & 232 \\
\hline & $1986-87$ & 488 & 393 & 96 & 394 & 393 & 2 & 229 \\
\hline \multirow{2}{*}{ Gulbela } & 2004-05 & 430.5 & 340.5 & 90 & 428.5 & 340.5 & 88 & 79 \\
\hline & $1986-87$ & 687 & 451 & 236 & 687 & 451 & 236 & 105 \\
\hline \multirow{2}{*}{ Kochian } & 2004-05 & 340.9 & 340.9 & 0 & 340.9 & 340.9 & 0 & 131 \\
\hline & $1986-87$ & 403 & 393 & 3 & 401 & 393 & 0 & 108 \\
\hline \multirow{2}{*}{ Dalazak } & 2004-05 & 365.8 & 318.8 & 47 & 354.3 & 318.8 & 35.5 & 113 \\
\hline & $1986-87$ & 432 & 262 & 170 & 286 & 262 & 24 & 113 \\
\hline \multirow{2}{*}{ Yousafkhel } & 2004-05 & 679.1 & 0 & 679.1 & 637.3 & 0 & 637.3 & 148 \\
\hline & $1986-87$ & 696 & 190 & 506 & 683 & 190 & 493 & 75 \\
\hline \multirow{2}{*}{ All villages } & $2004-05$ & 2241.6 & 1422 & 819.6 & 2185.3 & 1422 & 763.3 & 778 \\
\hline & $1986-87$ & 3132 & 2099 & 1031 & 2859 & 2099 & 757 & 742 \\
\hline
\end{tabular}

Source: Basic survey carried out in six villages in 2004-05; MANIG, 1991. 
The average farm size decreased in all of the surveyed villages, with Yousafkhel experiencing a drastic reduction of 51 percent over the past two decades. This transition as stated before speaks for the pressure on land because of population growth, which justifies the fragmentation of land resulting in an increased number of farms (for a review of changes in the farm sizes and number of farms, see Figure 17).

Figure 17. Changes in Farm Size in the Study Area since 1986-87

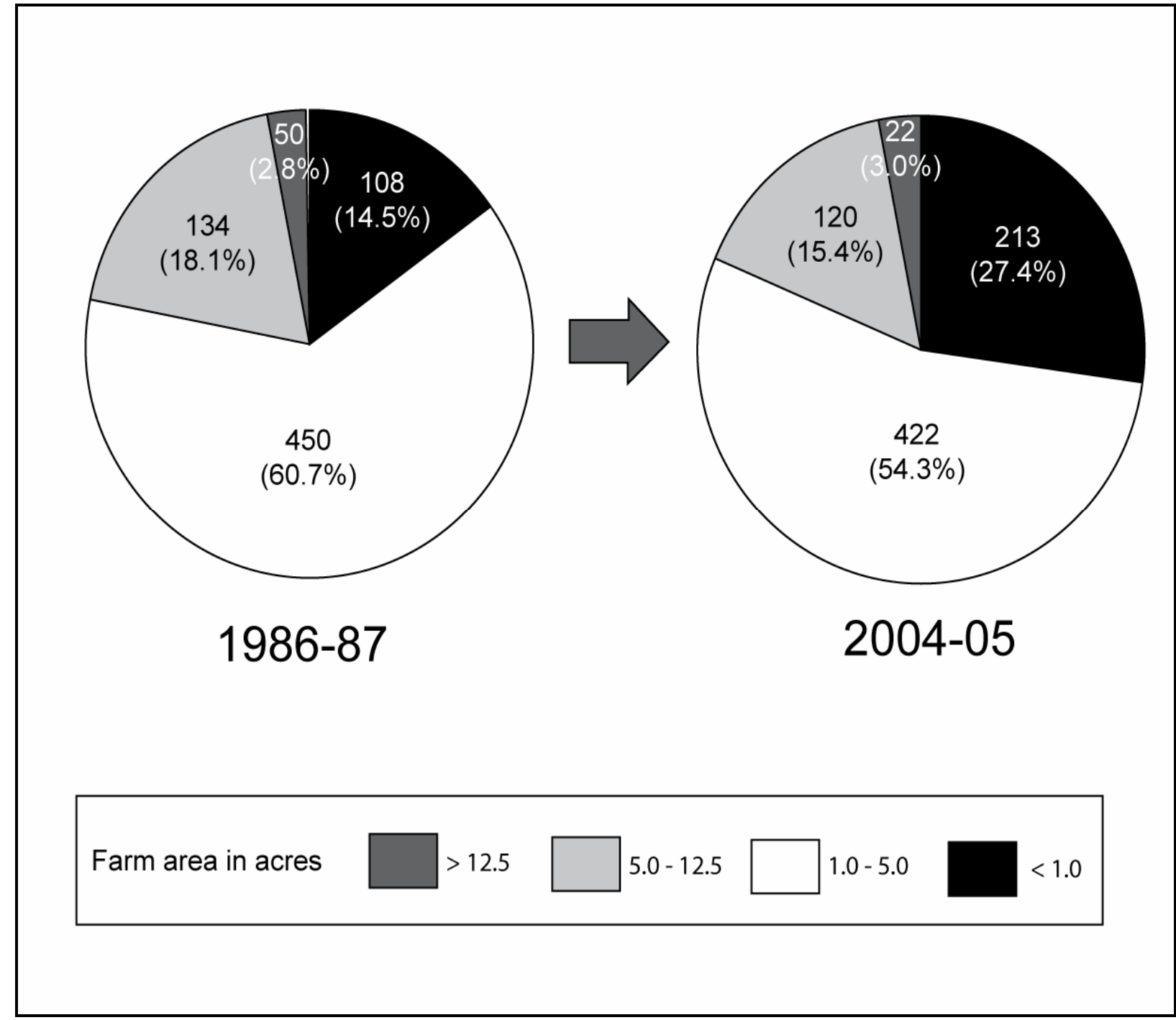

Note: Figures above the percentages (farm area) show the total number of farms in a particular farm size category. Source: Basic survey carried out in six villages of Northwest Pakistan, 2004-05; MANIG, 1991.

Wherever land tenancy was observed, it was based on share tenancy (50-50 share of the agricultural produce) while the usufructuary mortgage observed in previous studies (ALBRECHT, 1976; 
MANIG, 1991) is almost non-existent currently in the study area. Although sharecropping is a complex arrangement, a typical sharecropping contract requires that the tenant not only bear half the cost of tillage and land preparation, but also half the cost of seeds, fertilizer, and pesticides. In exchange, the tenant receives a 50 percent share in the output from which the share of the costs and any other debts are subtracted. The 'zamindar' (landlord) often provides consumption loans to the tenant, and the tenant household provides additional labor services to the 'zamindar' in return. Using this as a strategy, the landlords usually provide land to large households.

\subsubsection{Pattern of Livestock Rearing in the Study Villages}

The previous section revealed that there is little farm activity in the study villages, but what little there is, is vital to the livelihoods of the households involved in it. Farming is almost subsistence farming as it is a survival strategy and is not business-oriented. This section further takes this discussion by revealing the trends in livestock ownership ${ }^{114}$ over the years in the study area.

In some villages, changes in the cropping patterns from subsistence to cash crops and converting pasture land had contributed to a significant fall in the number of livestock (Figure 18). In Mushtarzai, however, the meagre average livestock units of 1.7 remained the same since the last survey in 1986/87; however, the share of households in livestock production decreased to 43 percent (see Figure 18). In Kochian, livestock remained an integral part of the farming and livelihood strategies.

Although the livestock related jobs increased in the last two decades. The fall in livestock farmers in Yousafkhel is mainly because of the rainfed nature of the village. Across the study villages, livestock was an important livelihood asset for the poor. Livestock not only provided meat, milk, fuel, and transport but, also, it acts as a store on which poor people could draw in times of emergencies or economic shocks.

\footnotetext{
${ }^{114}$ Livestock ownership plays a re-enforcing role in virtuous spirals of accumulation, just as its absence contributes to the inability of poorer households to climb onto the first rung of the 'ladder' leading out of poverty (KUROSAKI, 1995; ADAMS, 1996; CAIN et al., 2007).
} 
Figure 18. Changes in Household Livestock Ownership over the Years

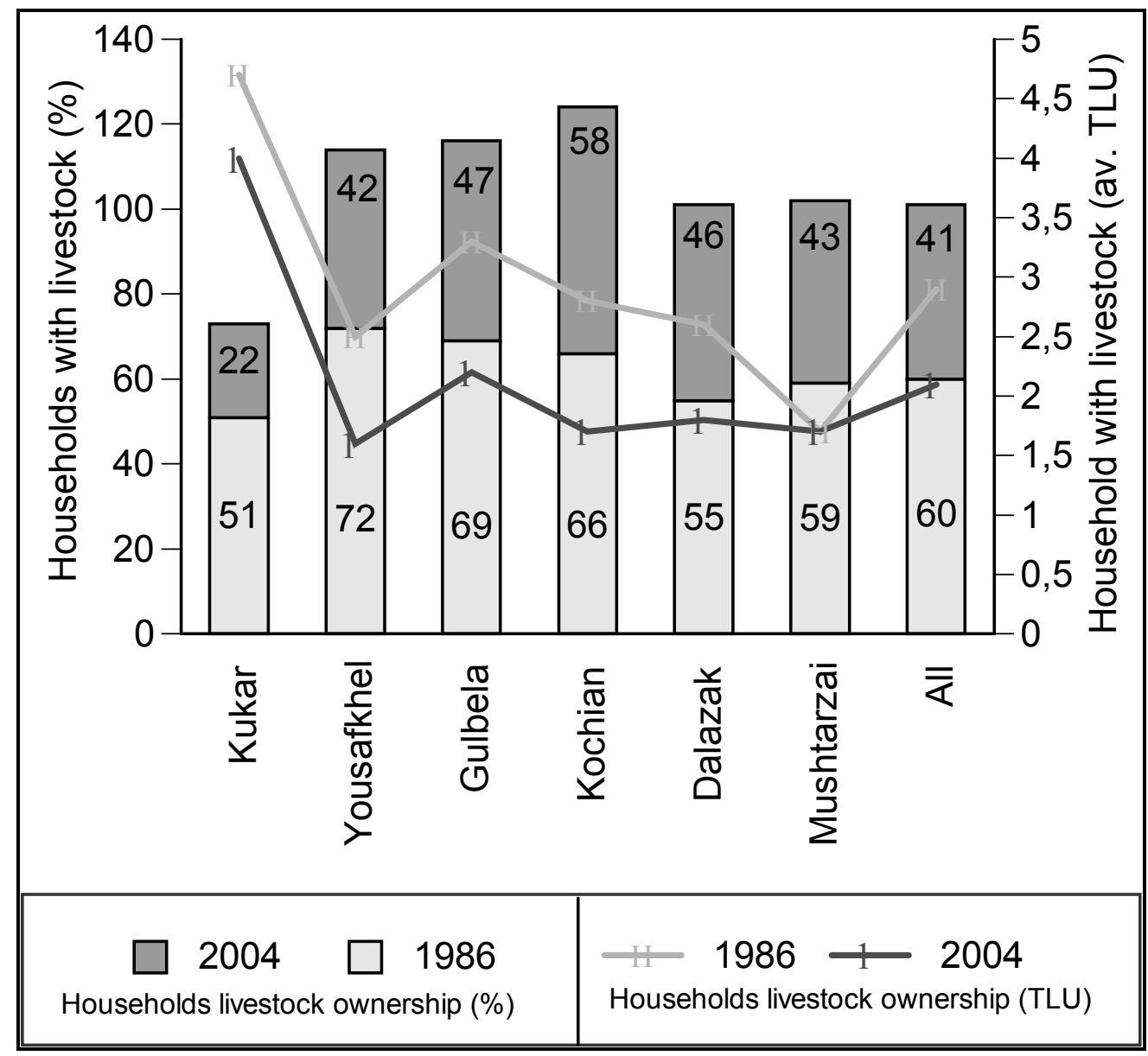

Note: A Tropical Livestock Unit (TLU) matches roughly a large cattle unit assuming beef cattle. For details on how to calculate the Tropical Livestock Unit, see Chapter 5.

Source: Basic survey carried out in six villages of Northwest Pakistan, 2004-05; MANIG, 1991.

\subsubsection{Changes in Crop Production Patterns}

The crop production changed considerably over the years in the study villages, as there emerged a decline in traditional crops such as wheat and maize and an increase in 'kharif' crops such as vegetables and fodder (for an extensive review of previous farm structure in the area, see AlBRECHT, 1976; MANIG, 1991). Over the years, fruit plantations had almost disappeared from the study villages that formerly grew them as significant cash crops. Ironically, the research area had been a locality for cultivating fruit (MANIG, 1991). Fruit growing has lost its importance as for instance just a single household operated orchards in the area. The villagers stated appearing pests (fruit flies and aphids) and marketing problems as the main causes behind disappearing 
orchards in the area. Similar reasons were behind the decline in vegetable cultivation (especially chilies), once a major source of cash income for the rural economy of Dalazak.

The foregoing discussion reveals that the the farm economy is not in a position fully to support the dense population of the region. The high population growth saw in the study area decreases landholding as land has to be continuously subdivided ${ }^{115}$. Land is not as dynamic as the population entails a shortage of land with the increased population. Because of the pressure on land, importance of non-agricultural work is steadily increasing. The fact the farmers cannot support their families by farming alone compels the farmers engaging in non-agricultural jobs to supplement farm income and support themselves.

\subsection{Occupational Pattern in the Research Area: A Comparative Perspective}

Looking at the employment pattern in the last four decades, there is a continuous process of disengagement from main stream agriculture as it increasingly becomes difficult for the rural households to fully dependent on agriculture for their livelihood. A comparison of present employment structure in the study with the 1967-68 and 1986-87 surveys conducted by Goettingen University reveals that the share of pure farming households reduced from 31 percent to only 6 percent (Table $43 \&$ Appendix 2). This disengagement from agriculture takes a variety of forms, ranging from diversification of income on or off the farm to the exit of the farmers altogether from agriculture. Hence we observed in the study area that majority of the households depend only marginally, or not at all, on employment related directly to agriculture.

Moreover, except Yousafkhel, where an increase of six percent occurred since 1986/87, the strategy of pluriactivity based on both agriculture and non-farm sources at household level have a declining trend in the last two decades (Appendix 2). For instance, although mixed income earning households across the villages increased from 13 percent in 1967/68 to 37 percent in 1986/7 however, in current survey it reduced to 28 percent (Table 43; see also for graphical display Appendix 2). This rising tendency on part of the mixed income earners to disassociate themselves from agriculture for non-farm activities can be explained by reducing farm size in the study area, which is economically non-productive. Similarly another important cause for this trend is the deteriorating terms of trade for the farming sector, as in the last few decades there is a continuous rise in the cost of inputs and a relative fall in the price of outputs, a process

\footnotetext{
${ }^{115}$ Islamic law of inheritance play a major role in this subdividion of land.
} 
resulting in declining net income from agriculture (see KHAN, 2007; JAN, 2007). In addition, an improved transportation infrastructure have facilitated the access and commuting of rural dwellers to employment in the urban centre like Peshawar.

Table 43. Changes in the Livelihood Strategies of the Rural Household (Data in Percent)

\begin{tabular}{|c|c|c|c|c|c|c|c|c|c|}
\hline \multirow{2}{*}{\begin{tabular}{l}
\multicolumn{1}{c}{ Household } \\
Occupational \\
Categories
\end{tabular}} & \multirow[b]{2}{*}{ Years } & \multicolumn{6}{|c|}{ Villages } & \multicolumn{2}{|c|}{ Total } \\
\hline & & $\begin{array}{c}\text { Kuk- } \\
\text { ar }\end{array}$ & $\begin{array}{l}\text { Yousa- } \\
\text { fkhel }\end{array}$ & $\begin{array}{l}\text { Gul- } \\
\text { bela }\end{array}$ & $\begin{array}{l}\text { Koc- } \\
\text { hian }\end{array}$ & $\begin{array}{c}\text { Dala- } \\
\text { zak }\end{array}$ & $\begin{array}{l}\text { Mush- } \\
\text { tarzai }\end{array}$ & $\%$ & No. \\
\hline \multirow{3}{*}{$\begin{array}{l}\text { Only Land- } \\
\text { lords } \\
\text { (I) }\end{array}$} & $1967 / 68$ & 4.1 & 0.9 & 2.5 & 4.1 & 0.7 & - & 2.2 & 27 \\
\hline & $1986 / 87$ & 1.3 & 1.3 & 1.4 & 0.7 & 0.7 & 0.5 & 0.9 & 17 \\
\hline & $2004 / 05$ & 0.4 & 0.3 & 1.6 & 1.3 & 0.3 & 0.2 & 0.7 & 19 \\
\hline \multirow{3}{*}{$\begin{array}{l}\text { Owner } \\
\text { occupants } \\
\text { (II) }\end{array}$} & $1967 / 68$ & 8.9 & 34.5 & 2.5 & 1.8 & 24.3 & 37.6 & 17.5 & 217 \\
\hline & $1986 / 87$ & 5.4 & 10.0 & 6.5 & 1.5 & 4.7 & 8.7 & 6.0 & 110 \\
\hline & $2004 / 05$ & 0.7 & 2.7 & - & 0.2 & 3.4 & 1.3 & 1.9 & 52 \\
\hline \multirow{3}{*}{$\begin{array}{l}\text { Only } \\
\text { Tenants } \\
\text { (III) }\end{array}$} & $1967 / 68$ & 10.7 & 3.5 & 11.5 & 11.8 & 10.3 & 7.5 & 9.5 & 118 \\
\hline & $1986 / 87$ & 3.8 & - & 11.2 & 5.0 & 2.8 & 2.5 & 4.3 & 78 \\
\hline & $2004 / 05$ & 1.8 & 0.3 & 4.2 & 7.8 & 1.3 & 1.5 & 2.9 & 81 \\
\hline \multirow{3}{*}{$\begin{array}{l}\text { Only livstock } \\
\text { rearers } \\
\text { (IV) }\end{array}$} & $1967 / 68$ & 5.9 & 4.3 & - & - & 1.5 & 1.4 & 2.2 & 27 \\
\hline & $1986 / 87$ & 0.5 & 1.3 & - & - & 1.7 & 0.2 & 0.6 & 10 \\
\hline & $2004 / 05$ & 0.8 & - & - & - & - & - & 0.2 & 6 \\
\hline \multirow{3}{*}{$\begin{array}{l}\text { Farmers with } \\
\text { non-farm jobs } \\
\text { (V) }\end{array}$} & $1967 / 68$ & 7.8 & 12.9 & 13.0 & 13.2 & 12.5 & 17.3 & 12.9 & 159 \\
\hline & $1986 / 87$ & 31.2 & 49.7 & 22.5 & 33.1 & 33.4 & 52.1 & 37.3 & 676 \\
\hline & $2004 / 05$ & 11.7 & 55.6 & 15.3 & 21.2 & 29.0 & 48.9 & 27.6 & 780 \\
\hline \multirow{3}{*}{$\begin{array}{l}\text { Only Self } \\
\text { employed } \\
\text { (VI) }\end{array}$} & $1967 / 68$ & 24.0 & 6.0 & 11.5 & 17.4 & 22.8 & 4.7 & 14.4 & 178 \\
\hline & $1986 / 87$ & 29.6 & 12.6 & 10.9 & 29.2 & 14.5 & 7.8 & 17.5 & 319 \\
\hline & $2004 / 05$ & 30.0 & 3.5 & 12.3 & 19.6 & 23.4 & 8.7 & 17.9 & 507 \\
\hline \multirow{3}{*}{$\begin{array}{c}\text { Only Salary- } \\
\text { wage earners } \\
\text { (VII) }\end{array}$} & $1967 / 68$ & 35.8 & 37.1 & 59.0 & 47.5 & 25.0 & 30.5 & 39.3 & 486 \\
\hline & $1986 / 87$ & 27.2 & 23.9 & 46.4 & 28.5 & 41.6 & 28.0 & 32.5 & 592 \\
\hline & $2004 / 05$ & 54.3 & 37.5 & 64.1 & 48.6 & 42.6 & 36.4 & 48.2 & 1361 \\
\hline \multirow{3}{*}{$\begin{array}{l}\text { Welfare } \\
\text { dependents } \\
\text { (VIII) }\end{array}$} & $1967 / 68$ & 3.0 & 0.9 & - & 4.1 & 2.9 & 1.0 & 2.0 & 25 \\
\hline & $1986 / 87$ & 1.1 & 1.3 & 1.1 & 2.1 & 0.7 & - & 0.9 & 17 \\
\hline & $2004 / 05$ & 0.4 & - & 2.3 & 1.3 & - & - & 0.7 & 19 \\
\hline \multirow{3}{*}{$\begin{array}{l}\text { Number of } \\
\text { Households }\end{array}$} & $1967 / 68$ & 271 & 116 & 200 & 219 & 136 & 295 & - & 1237 \\
\hline & $1986 / 87$ & 372 & 159 & 276 & 281 & 296 & 453 & - & 1819 \\
\hline & $2004 / 05$ & 727 & 288 & 432 & 459 & 380 & 539 & - & 2825 \\
\hline
\end{tabular}

Source: Basic survey carried out in six villages in 2004-05; MANIG, 1991.

The share of wage-salary earning households experienced a significant increase across villages, as almost half of the total households were engaged in formal and informal jobs (Table 43). Nevertheless, the labor force in non-farm activities increased in occupations, which are predominantly unskilled. Around 178 households (14\% of total) were in businesses in 1967/68, which rose to 507 (18\%) in 2004/05 (see Table 43). However, the state of prevailing informal businesses signals that this obvious rise is not a sign of a healthy labor market rather a sign of distress, not development. 
Table 44. Distribution Trend of the Household Workers in Different Occupational Fields

\begin{tabular}{|c|c|c|c|c|c|c|c|c|c|c|}
\hline \multirow{3}{*}{ Villages } & & \multirow{3}{*}{ Year } & \multicolumn{8}{|c|}{ Percentage working in the following fields } \\
\hline & & & \multirow{2}{*}{$\begin{array}{l}\text { indep. } \\
\text { farmer }\end{array}$} & \multirow{2}{*}{$\begin{array}{c}\text { causal } \\
\text { worker }\end{array}$} & \multirow{2}{*}{$\begin{array}{c}\text { perman. } \\
\text { job }\end{array}$} & \multirow{2}{*}{$\begin{array}{l}\text { gov. } \\
\text { job }\end{array}$} & \multirow{2}{*}{$\begin{array}{c}\text { own } \\
\text { business }\end{array}$} & \multirow{2}{*}{ other } & \multicolumn{2}{|c|}{ Total } \\
\hline & & & & & & & & & $\%$ & No. Pers. \\
\hline \multirow{2}{*}{\multicolumn{2}{|c|}{ Mushtarzai }} & 1987 & 26.4 & 19.8 & 13.1 & 25.1 & 11.5 & 3.4 & 100 & 870 \\
\hline & & 2004 & 20.2 & 30.8 & 15.7 & 20.0 & 13.4 & - & 100 & 1032 \\
\hline \multirow{2}{*}{\multicolumn{2}{|c|}{ Yousafkhel }} & 1987 & 28.9 & 12.9 & 24.2 & 16.8 & 13.5 & 3.9 & 100 & 356 \\
\hline & & 2004 & 15.2 & 27.5 & 37.7 & 13.5 & 6.2 & - & 100 & 600 \\
\hline \multirow{2}{*}{\multicolumn{2}{|c|}{ Gulbela }} & 1987 & 28.0 & 32.6 & 14.3 & 11.0 & 13.4 & 1.6 & 100 & 511 \\
\hline & & 2004 & 14.3 & 35.5 & 27.3 & 10.3 & 11.3 & 1.2 & 100 & 812 \\
\hline \multirow{2}{*}{\multicolumn{2}{|c|}{ Kochian }} & 1987 & 17.0 & 22.6 & 20.4 & 10.7 & 26.2 & 2.0 & 100 & 540 \\
\hline & & 2004 & 17.7 & 22.1 & 24.4 & 13.3 & 21.9 & 0.7 & 100 & 821 \\
\hline \multirow{2}{*}{\multicolumn{2}{|c|}{ Dalazak }} & 1987 & 19.6 & 17.3 & 29.6 & 15.8 & 17.9 & 0.6 & 100 & 621 \\
\hline & & 2004 & 10.2 & 18.6 & 22.0 & 23.2 & 25.9 & - & 100 & 667 \\
\hline \multirow{2}{*}{\multicolumn{2}{|c|}{ Kukar }} & 1987 & 19.4 & 14.4 & 21.2 & 14.7 & 30.2 & 1.9 & 100 & 788 \\
\hline & & 2004 & 6.7 & 21.5 & 28.5 & 13.2 & 30.2 & - & 100 & 1468 \\
\hline \multirow{4}{*}{$\begin{array}{l}\text { All } \\
\text { Villages }\end{array}$} & $\%$ & 1987 & 22.9 & 20.0 & 19.7 & 16.2 & 19.2 & 2.2 & 100 & \\
\hline & $\%$ & 2004 & 13.5 & 25.8 & 25.5 & 15.3 & 19.7 & 0.3 & 100 & \\
\hline & No. & 1987 & 843 & 738 & 726 & 602 & 699 & 81 & & 3686 \\
\hline & No. & 2004 & 727 & 1391 & 1375 & 828 & 1063 & 16 & & 5400 \\
\hline
\end{tabular}

Source: Basic survey in six villages of Northwest Pakistan, 2004/05; MANIG, 1991.

The households in the research area were not homogeneous ${ }^{116}$ in occupational terms as it encompassed a wide variety of job types and workers. Table 44 gives a picture of the percentage of household members involved in different occupations. Kukar has been far ahead in this regard when compared to other villages. Household occupational structure changed in the last two decades in such a way that the number of farmers diminished, while the share of non-agricultural activities grew. Data gathered by basic survey about the pattern of occupation suggests that there is a clear shift of occupation from agriculture to non-agriculture over the years. This shows that agriculture is no longer a prime occupation for most people as pointed out by its decline from nearly 23 percent in 1986-87 to almost 14 percent in 2004-05. One of the major reasons for this is the scarcity of cultivatable land and the population increase in the area. If the same trend persists over the years, majority of the farming households will be forced to strive for non-

\footnotetext{
116 The highly diversified and heterogeneous activities within the rural non-farm economy have been widely recognised (HARGREAVES et al., 2007)
} 
agricultural occupations to maintain their livelihood. The drop in the size of the land will have serious implications in the livelihood choices of the agrarian households. One of the immediate outcomes would be the tendency to aspire for supplementary occupations or leaving farming altogether.

It was common to find different types of workers within particular households in the study area. This occupational heterogeneity on part of the household members to engage in diverse types of occupations can be conceived as a coping mechanism against temporary unemployment of some members. For the poor households, combining income sources and the prevalence of different types of workers within households were because of not only low wages but also the outcome of the need to include several incomes to carry out survival.

Besides the occupations mentioned in Table 45, the rural dwellers were engaged in widest range of income-generating activities across the villages. Listing all those occupations pursued by the household members is a cumbersome task however, based on their prevalence some of the occupations were: horse cart (Tanga) operators, fruit/vegetable sellers, barbers, butchers, bus/van conductors, cobblers, security guards, meter readers and linemen (WAPDA and Sui-gas), icecream sellers, carpet maker, painters, break makers, cooks (kebab makers), gardeners, tube-well operators, waiters, carpenters, brick makers in kilns, goldsmiths, sweet and music shops operators, property dealers, engineers, and doctors. In order, to put it simple, some of the research villages in the course of time became specific in certain occupations like:

a) Kukar: tailoring, casual daily wage workers, cloth merchants, yogurt and milk selling, grocery shops, mechanic, electrician, and police.

b) Kochian: independent farmers, agricultural labourers, drivers, and transporters.

c) Gulbela: house construction workers, and drivers.

d) Dalazak: welders.

e) Mushtarzai: independent farmers, casual daily wage workers, house construction workers, overseas jobs, border patrol, and police.

f) Yousafkhel: weapon maker, and casual daily wage workers. 
Table 45. Changes in th e Household Members Occupations over the Years

\begin{tabular}{|c|c|c|c|c|c|c|c|}
\hline Occupations $^{1}$ & $\begin{array}{l}\text { Kuk- } \\
\text { ar }\end{array}$ & $\begin{array}{c}\begin{array}{c}\text { Yousaf- } \\
\text { khel }\end{array} \\
\end{array}$ & $\begin{array}{l}\text { Gul- } \\
\text { bela }\end{array}$ & $\begin{array}{l}\text { Koch- } \\
\text { ian }\end{array}$ & $\begin{array}{c}\text { Dala- } \\
\text { zak }\end{array}$ & $\begin{array}{c}\text { Musht- } \\
\text { arzai }\end{array}$ & $\begin{array}{c}\text { All } \\
\text { Villages }\end{array}$ \\
\hline Farmers & $\begin{array}{c}61 \\
(143)\end{array}$ & $\begin{array}{c}86 \\
(95)\end{array}$ & $\begin{array}{c}112 \\
(143)\end{array}$ & $\begin{array}{l}140 \\
(92)\end{array}$ & $\begin{array}{c}63 \\
(112)\end{array}$ & $\begin{array}{c}200 \\
(221)\end{array}$ & $\begin{array}{c}662 \\
(806)\end{array}$ \\
\hline Buffalo owners & $\begin{array}{c}38 \\
(10)\end{array}$ & $\begin{array}{c}5 \\
(8)\end{array}$ & $\begin{array}{c}4 \\
(-)\end{array}$ & $\begin{array}{l}5 \\
(-)\end{array}$ & $\begin{array}{c}5 \\
(10)\end{array}$ & $\begin{array}{c}8 \\
(9)\end{array}$ & $\begin{array}{c}65 \\
(37)\end{array}$ \\
\hline Casual workers: all jobs & $\begin{array}{l}236 \\
(88)\end{array}$ & $\begin{array}{l}130 \\
(38)\end{array}$ & $\begin{array}{l}163 \\
(50)\end{array}$ & $\begin{array}{c}76 \\
(34)\end{array}$ & $\begin{array}{c}90 \\
(70)\end{array}$ & $\begin{array}{c}241 \\
(118)\end{array}$ & $\begin{array}{c}936 \\
(398)\end{array}$ \\
\hline Casual workers: farming & $\begin{array}{c}9 \\
(6)\end{array}$ & $\begin{array}{c}8 \\
(3)\end{array}$ & $\begin{array}{c}45 \\
(82)\end{array}$ & $\begin{array}{c}65 \\
(38)\end{array}$ & $\begin{array}{c}5 \\
(2)\end{array}$ & $\begin{array}{c}7 \\
(5)\end{array}$ & $\begin{array}{c}139 \\
(136)\end{array}$ \\
\hline $\begin{array}{l}\text { Casual workers: house } \\
\text { construction }\end{array}$ & $\begin{array}{l}70 \\
(18)\end{array}$ & $\begin{array}{l}27 \\
(5)\end{array}$ & $\begin{array}{c}80 \\
(19)\end{array}$ & $\begin{array}{l}40 \\
(24)\end{array}$ & $\begin{array}{c}29 \\
(14)\end{array}$ & $\begin{array}{l}70 \\
(25)\end{array}$ & $\begin{array}{l}316 \\
(105)\end{array}$ \\
\hline Perm. employee: welder & $\begin{array}{l}7 \\
(2)\end{array}$ & $\begin{array}{l}- \\
(-)\end{array}$ & $\begin{array}{l}1 \\
(-)\end{array}$ & $\begin{array}{l}13 \\
(-)\end{array}$ & $\begin{array}{c}80 \\
(38)\end{array}$ & $\begin{array}{c}9 \\
(2)\end{array}$ & $\begin{array}{l}110 \\
(42)\end{array}$ \\
\hline Perm. employee: driver & $\begin{array}{l}63 \\
(8)\end{array}$ & $\begin{array}{l}31 \\
(23)\end{array}$ & $\begin{array}{c}70 \\
(14)\end{array}$ & $\begin{array}{c}94 \\
(27)\end{array}$ & $\begin{array}{c}34 \\
(21)\end{array}$ & $\begin{array}{l}16 \\
(6)\end{array}$ & $\begin{array}{l}280 \\
(99)\end{array}$ \\
\hline $\begin{array}{l}\text { Perm. employee: weapon } \\
\text { maker }\end{array}$ & $\begin{array}{c}- \\
(1)\end{array}$ & $\begin{array}{l}43 \\
(23)\end{array}$ & $\begin{array}{l}- \\
(-)\end{array}$ & $(-)$ & $\begin{array}{l}- \\
(-)\end{array}$ & (24) & $\begin{array}{c}43 \\
(49)\end{array}$ \\
\hline Perm. employee: servant & $\begin{array}{l}35 \\
(31)\end{array}$ & $\begin{array}{c}4 \\
(1)\end{array}$ & $\begin{array}{c}8 \\
(14)\end{array}$ & $\begin{array}{l}13 \\
(8)\end{array}$ & $\begin{array}{l}3 \\
(2)\end{array}$ & $\begin{array}{l}5 \\
(4)\end{array}$ & $\begin{array}{c}68 \\
(60)\end{array}$ \\
\hline Perm. employee: mechanic* & 44 & 6 & 8 & 19 & 1 & 12 & 90 \\
\hline Perm. employee: electrician* & 18 & 4 & 1 & 2 & 4 & 5 & 34 \\
\hline Perm. employee: overseas & $\begin{array}{l}17 \\
(-)\end{array}$ & $\begin{array}{c}28 \\
(11)\end{array}$ & $\begin{array}{l}8 \\
(-)\end{array}$ & $\begin{array}{l}12 \\
(-)\end{array}$ & $\begin{array}{l}20 \\
(3)\end{array}$ & $\begin{array}{c}93 \\
(11)\end{array}$ & $\begin{array}{l}178 \\
(25)\end{array}$ \\
\hline Border Patrol & $\begin{array}{c}1 \\
(6)\end{array}$ & $\begin{array}{c}24 \\
(23)\end{array}$ & $\begin{array}{c}7 \\
(5)\end{array}$ & $\begin{array}{c}9 \\
(13)\end{array}$ & $\begin{array}{l}3 \\
(-)\end{array}$ & $\begin{array}{l}53 \\
(97)\end{array}$ & $\begin{array}{c}97 \\
(144)\end{array}$ \\
\hline Police & $\begin{array}{l}40 \\
(8)\end{array}$ & $\begin{array}{c}3 \\
(10)\end{array}$ & $\begin{array}{l}15 \\
(7)\end{array}$ & $\begin{array}{l}20 \\
(6)\end{array}$ & $\begin{array}{l}17 \\
(9)\end{array}$ & $\begin{array}{l}26 \\
(24)\end{array}$ & $\begin{array}{l}121 \\
(64)\end{array}$ \\
\hline Army & $\begin{array}{l}16 \\
(-)\end{array}$ & $\begin{array}{l}14 \\
(6)\end{array}$ & $\begin{array}{c}7 \\
(1)\end{array}$ & $\begin{array}{l}26 \\
(1)\end{array}$ & $\begin{array}{l}17 \\
(7)\end{array}$ & $\begin{array}{l}40 \\
(26)\end{array}$ & $\begin{array}{l}120 \\
(41)\end{array}$ \\
\hline Teacher & $\begin{array}{l}49 \\
(5)\end{array}$ & $\begin{array}{c}2 \\
(-)\end{array}$ & $\begin{array}{c}31 \\
(11)\end{array}$ & $\begin{array}{l}13 \\
(6)\end{array}$ & $\begin{array}{l}18 \\
(7)\end{array}$ & $\begin{array}{l}27 \\
(17)\end{array}$ & $\begin{array}{l}140 \\
(46)\end{array}$ \\
\hline High Gov. Employee & $\begin{array}{l}36 \\
(31)\end{array}$ & $\begin{array}{c}6 \\
(5)\end{array}$ & $\begin{array}{l}6 \\
(6)\end{array}$ & $\begin{array}{c}5 \\
(4)\end{array}$ & $\begin{array}{c}19 \\
(19)\end{array}$ & $\begin{array}{c}7 \\
(5)\end{array}$ & $\begin{array}{c}79 \\
(70)\end{array}$ \\
\hline Own transport enterprise & $\begin{array}{c}18 \\
(24)\end{array}$ & $\begin{array}{c}5 \\
(2)\end{array}$ & $\begin{array}{l}10 \\
(6)\end{array}$ & $\begin{array}{c}58 \\
(59)\end{array}$ & $\begin{array}{c}13 \\
(14)\end{array}$ & $\begin{array}{c}7 \\
(22)\end{array}$ & $\begin{array}{c}111 \\
(127)\end{array}$ \\
\hline Own grocery store & $\begin{array}{c}79 \\
(32)\end{array}$ & $\begin{array}{c}9 \\
(6)\end{array}$ & $\begin{array}{c}32 \\
(17)\end{array}$ & $\begin{array}{c}48 \\
(25)\end{array}$ & $\begin{array}{c}25 \\
(20)\end{array}$ & $\begin{array}{c}53 \\
(31)\end{array}$ & $\begin{array}{c}246 \\
(131)\end{array}$ \\
\hline Milk seller (ambul.) & $\begin{array}{c}16 \\
(28)\end{array}$ & $\begin{array}{l}- \\
(-)\end{array}$ & $\begin{array}{c}6 \\
(1)\end{array}$ & $\begin{array}{c}5 \\
(1)\end{array}$ & $\begin{array}{c}- \\
(2)\end{array}$ & (2) & $\begin{array}{c}27 \\
(34)\end{array}$ \\
\hline Yogurt seller (ambul.) & $\begin{array}{c}25 \\
(44)\end{array}$ & $(-)$ & - & $\begin{array}{l}- \\
(-)\end{array}$ & $(-)$ & - & $\begin{array}{c}25 \\
(44)\end{array}$ \\
\hline Cloth business* & 92 & 1 & 5 & 4 & - & - & 102 \\
\hline Tailor* & 58 & 5 & 14 & 17 & 12 & 11 & 117 \\
\hline
\end{tabular}

Note: 1) As the occupational structure was diverse in the study area, so only the most important occupations are shown here. Figures in brackets represent number of respective occupations in 1986-87 while * represents those occupations which were not mentioned separately in 1986-87 survey but because of their prevalence in the study villages, the present survey considered them.

Some of the other occupations in the area included: carpenters, beadwork, making traditional garments.

Source: Basic survey carried out in six villages of Northwest Pakistan, 2004-05; RIEKEN, 1994; MANIG, 1991. 
This village-specific trend of non-agricultural employment that emerged over the years merits certain explanation (Table 45). The prevalence of weapen makers in Yousafkhel is due to two main reasons: firstly, the long traditional experience and talent of certain people in these skills, and secondly the village vicinity to the tribal area famous for armament production. This informal learning is spread over generations and requires no formal education, but rather specific skills. These skilled people however, in order to keep their monopoly on such jobs provide apprenticeship only to their relatives and in a few cases to their friends and acquaintances. This give rise to a trend in which specific villages concentrate on certain occupations. Almost similar explanation hold true for the rise of the welders in Dalazak. Most of these welders or to be specific bus body makers were working in big cities of Pakistan like Karachi, Hyderabad, Rawalpindi, and a handful stationed in Peshawar. Similarly another important aspect of switching from agriculture to non-agricultural employment was the emergence of 'innovators ${ }^{117}$, in certain villages. For instance, the persistence of transporters (mostly Rickshaw owners) in Kochian over the years can be attributed to this phenomenon.

\subsubsection{Agricultural Labours in the Study Villages}

The basic survey also gathered details about the employment of agricultural labourers in the study villages (Figure 19). The role of family labour is increasing obvious in carrying out farming in the area as their proportion increased from five percent in 1986-87 to 13 percent in 2004-05. Due to the prevalence of fragmented and marginal family farms in the area, the mean of production was planned in a manner that would enable the families to carry out most of the farm work without recourse to hired labor; a trend resulted in lower number of hired agricultural labor in the study area as compared to previous studies.

The owner operators with additional occupations (hh-cat. V2) operated nearly half of the total 233 family labours in 2004-05 while tenants with non-farming jobs accounted for nearly one-fifth of the total. Over the years, the share of permanent employees reduced in the study villages (Figure 19). Permanent labourers were hired exclusively by the landlords and owner operator households with additional income (hh-cat. V2). The dairy farmers in village Kukar and Gulbela also hired eight percent of the workers on fixed terms in 2004-05.

\footnotetext{
${ }^{117}$ Villagers who were looking outside their own village for work in the non-farm sector mobilize as 'innovators' other villagers to desert agriculture if their search was successful. This mediation of income possibilities by the 'innovators' took place with decreasing intensity in the village social system along the axis of relatives, friends, and acquaintances (RIEKEN, 1988 cited in MANIG, 1991).
} 
Although casual workers still form most of the hired labours for agricultural tasks, their share reduced 9 percent in the last two decades. The frequency of employment of 1527 casual workers in 2004-05 spans from occasionally to several times per cropping season. As revealed by the basic survey, tenants hired half of the total casual workers followed by owner-operators $(27 \%)$ and landlords $(12 \%)$. Concerning payments to casual labourers working on daily wage contracts, in the research villages, the typical mode was a combination of cash and kind. Occasionally, piece-rate contracts were also observed especially during harvest and weeding time. As in most other parts of rural Pakistan, the wage rate for agricultural casual labour, within the villages were uniform but considerably lower than wage in non-farm casual sector. In rural Pakistan, the mobility of adolescent young women is highly constrained, making it difficult for them to seek employment.

Figure 19. Changes in Hired Agricultural Labour in the Study Area

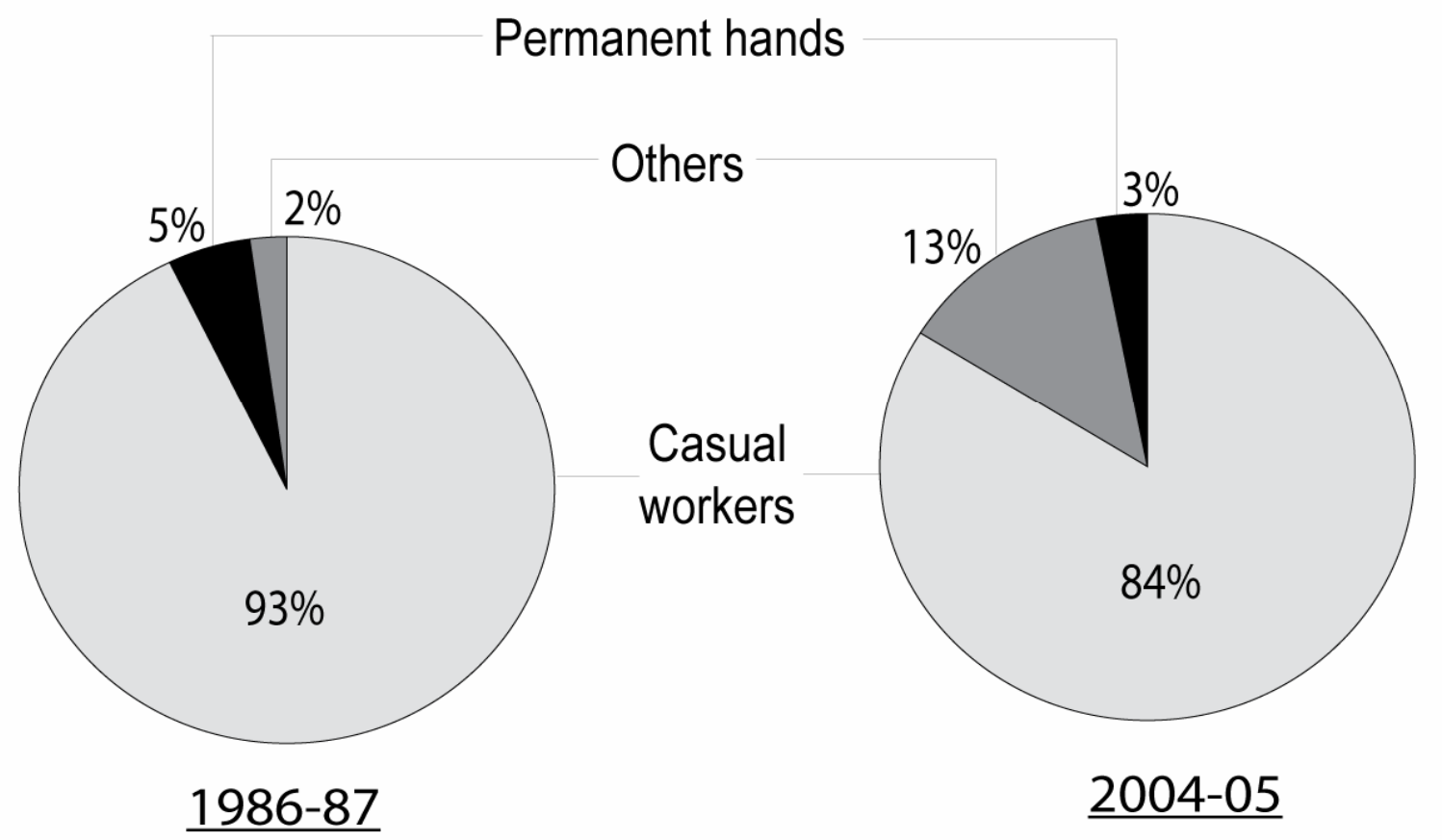

Note: Permanent hands refer to permanent hired labours who work on a farm on whole time basis and are employed for longer periods. Casual workers are employed occasionally on daily wage basis for a specific agricultural task. Others include mostly household members who do any agricultural work on permanent or part-time basis on their holding.

Source: Basic survey in six villages of Northwest Pakistan, 2004/05; MANIG, 1991. 


\subsubsection{Casual Labours, Self Employment and Petty Trade}

The rise of almost six percent in casual labourers (see Table 44) since 1986-87 speak not only for the limited employment opportunities in productive sector in the area but also points to their low human capital. Casual labour activities were widespread in the study area, which are important sources of income for the rural poor. Most household casual labour earning is obtained from daily wage work. The work that casual labourers perform in the informal labour market is usually manual and low paying. Hence, individuals with poor endowments of capital or knowledge crowd these markets.. Possibly as much as a quarter of the work force, in this way, is currently engaged in poorly paid work. As far as permanent employees in the non-farm sector are concerned, not only has this sphere not shrunk, though since the last two decades it expanded $(6 \%)$.

Casual workers and permanent employees together accounted for slightly over half of all the working population in the six study villages in 2004-05, an increase of almost 12 percent since 1986-87 (Table 44). In Kukar, the local work opportunities had increased, reflecting the increased number of casual jobs (22\%) in the village because of its status as an economic subcentre (see Table 44). This expansion occurred during a time-span that saw a series of development interventions - from industrial-led growth in 60es to market-led expansion during the 80es, and finally an era of market liberalization and privatization at the beginning of twenty first century. Nevertheless, manual, unskilled, unorganized, insecure, informal and earning a wage that changes slowly and is not regulated - these characteristics seems to define the rural labourers Northwest Pakistan, in 2005 almost as well as in 1967.

Apart from wages, the rural household economies in the study villages over the years also relied heavily on other income sources such as the product of petty commodity production and petty trade. For instance, self-employment increased slightly as the relative attraction of independent work grew with the decline in farming jobs. However, in percentage terms the growth was low as the number of household members in businesses comprised only 19.2 percent in 1986-87, in comparison to 19.7 percent in 2004-05. The rising trend was observed only in Dalazak (8\%) and Mushtarzai $(2 \%)$ while for the rest of the villages the number of persons operating businesses either declined or remained static. The numbers of shops increased and new businesses were established in the village such as hair salons, tailoring services, hotels, restaurants, bakeries, a Compressed Natural Gas (CNG) station, a petrol pump, and a few internet cafes. Majority of these small enterprises (firms) were sole proprietorships, with most of the hired labour being 
apprentices ${ }^{118}$. The population growth in Kukar has obviously created a market for private enterprises in the service sector. Nevertheless, there is not much difference in the enterprises running in the villages as most lack formal premises or what could be termed 'factory' conditions (Picture 2). Dressmakers, tailors and hairdressers mainly occupied kiosks and residential buildings, whilst some of blacksmiths and woodworkers operated either in open spaces or in wooden or iron sheds.

\section{Picture 2. Self-employment in the Study Villages}

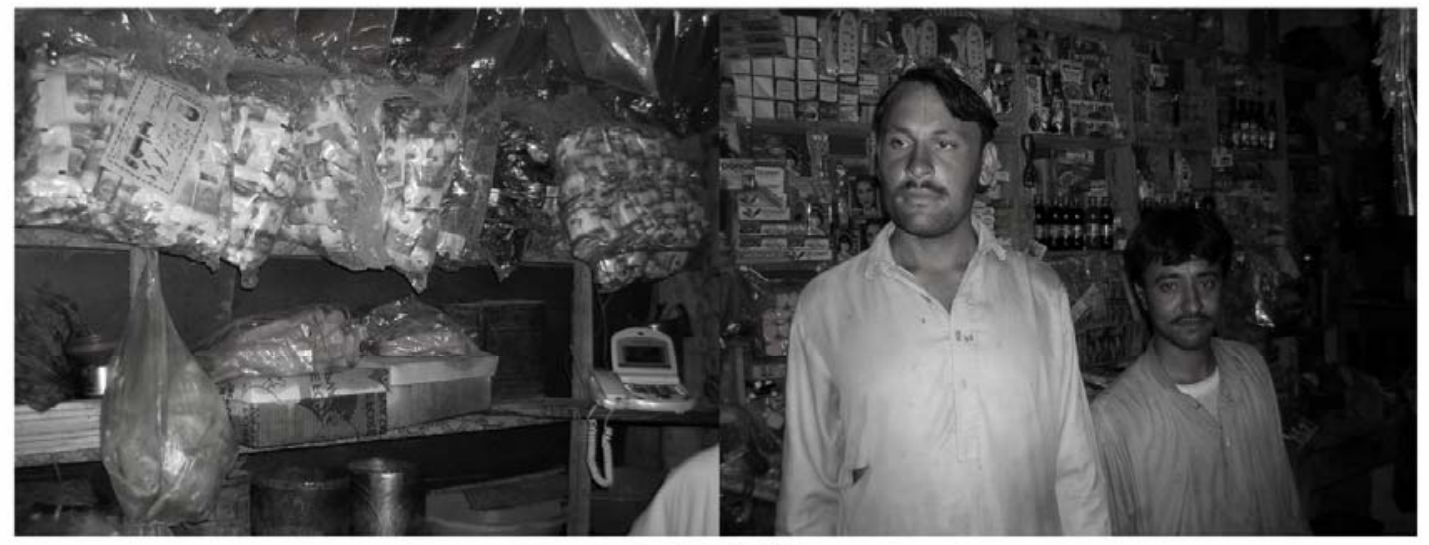

Grocery Shops in the Study Villages

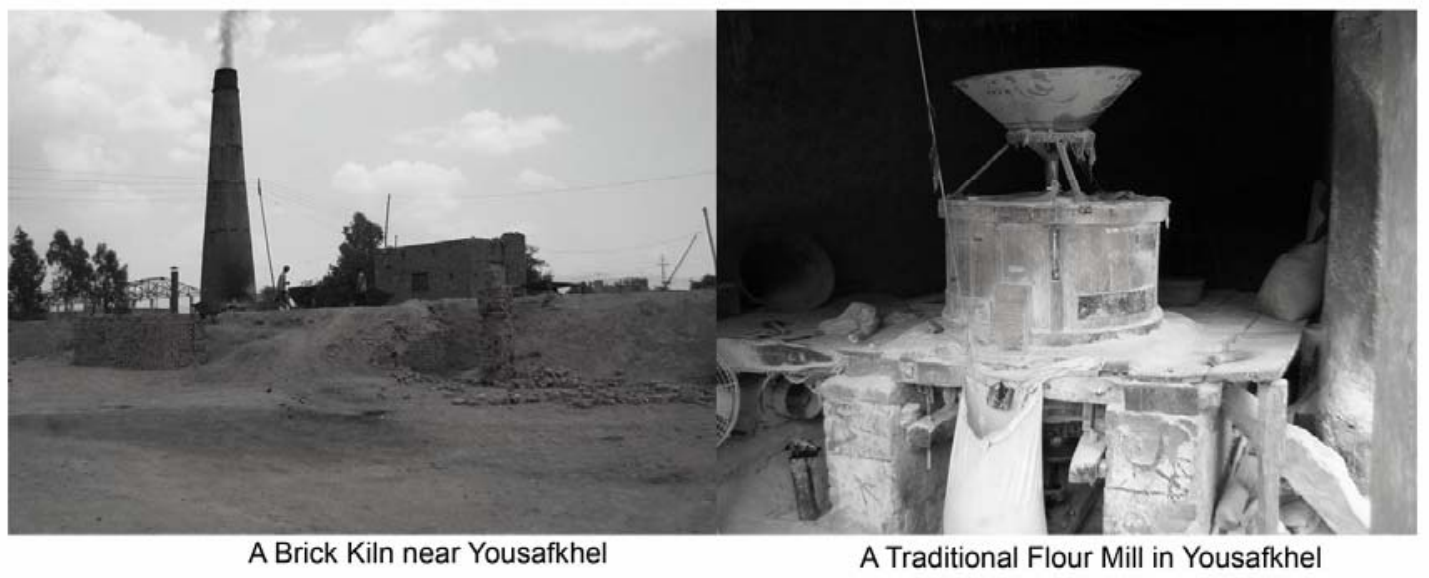

Source: Basic survey in six villages of Northwest Pakistan, 2004/05 (photos by author).

Grocery stores remained especially an important income source for the villagers as their number almost doubled over the years (Table 45). The milk sellers in Kukar reduced as the dairy

${ }^{118}$ The informal apprenticeship system is common among certain occupations like mechanics, electricians, and mechanics. This informal apprenticeship system (ustaad shagrid ${ }^{118}$ ) has many elements which make it attractive in terms of cheap on-the-job training, however, the cost in terms of quality and productivity is high (AMJAD, 2005). 
farmers in the village instead of supplying to local traders now sell their products in bulk to contractors in provincial capital Peshawar. In addition, a growing number of people now use packet milk because of quality concerns reducing the number of local milk sellers. A large number of Afghan refugees, speaking the same language of community Pashto, settled in the village Kukar in the last two decades. These newly settled Afghans were mostly engaged in business related activities like cloth selling or working as tea merchants. The bulk of these informal businesses operated outside the village economy.

This mixed pattern of businesses growth in some villages with peak rate two decades ago and a decline in recent time seems to have been influenced by both external and internal factors. External factors included the structural adjustment programmes launched under the guidance of international monetary institutions which hard hit the small businesses (GERA, 2007). Internal factors included increased labour and input costs with the withdrawal of subsidies following the initial wave of privatization and liberation of economy in the early 90es. However, we must admit that these set of factors are characteristic not only for the research area, but also for whole Pakistan.

\subsubsection{Patterns of Rural Migration}

The area has also seen other important livelihood trends, including an increased role for off-farm labour migration which are less dependent on local resources. As off-farm, non-rural opportunities in areas are limited, young men leaving their families behind in these villages migrate either to other Pakistani cities (majority Karachi or Lahore) or to the oil-rich gulf countries. Overseas employment emerged as an important source of household income in the Mushtarzai village and to a limited extent in Yousafkhel (Table 45). While the capacity of jobs in gulf countries ${ }^{119}$ is declining, the locals mostly with formal education are driven in recent years towards other destinations like Malaysia, Europe, and North America. Similarly, the region can also benefit from trade with Afghanistan and other Central Asian countries once there is stability in Afghanistan. For instance, as a new trend, several respondents earned their living by working as construction workers in Afghanistan. The main attraction was the high pay in the otherwise wartorn and unstable Afghanistan.

\footnotetext{
${ }^{119}$ The export of manpower from Pakistan for employment in the Middle East has risen dramatically since the oil boom of the mid-1970s. As a consequence, remittances, which constitute the major gain from migration, have become an important source of Pakistan's foreign exchange. Remittances have enabled these households to significantly increase current consumption and purchase assets with the potential of improving their future income stream.
} 
Much of the labour response from the research villages has been spontaneous, not Government sponsored. An extensive network of private licensed agents, play a major role in processing these labour contracts. Nevertheless based on discussions with a number of respondents in the study villages, the bulk of emigration is channeled through direct contacts with overseas employers. It cost around Rs. 80,000 to obtain the documents necessary for employment overseas. Majority of migrants finance these transaction costs by borrowing. The need to borrow these substantial amounts makes it difficult for the poorest to finance their departure. There is no change in an important aspect of these overseas jobs, as the typical migrant is a male, leaving wife and family behind for a couple of years. Although these overseas works like drivers, mechanics, electricians have long years of experience on their jobs, most of them have little or no formal vocational training.

\subsubsection{Formal Sector Jobs}

Formal $^{120}$ employment opportunities although limited in their scale were normally available to those individuals with some education. There is a slight increase in number of high government officials ${ }^{121}$ hailing from the research villages; nevertheless, except Kukar $^{122}$ their number remained static for the rest of the villages (Table 45). As nearly all the development policies and projects are significantly affected by the aspiration of bureaucracy in Pakistan (MANIG, 1991), this goes against the development scenario in the study villages.

Although increasing number of people are engaged in police department (Table 45), however, majority of this work is of low cadre (majority constables). Social contacts played a significant role for households in recruiting in police in the village Kukar. The persons employed in border patrol or army evidence the role of federal government in local job creation. Three factors play a role for the divergent trends for army jobs and working as border patrol officer in the study villages:

\footnotetext{
${ }^{120}$ Formal workers, whose principal job is formal, predominate in the most regulated sectors: the civil service, financial institutions and public activities. A major part of industry with the exception of a few multinationals and a few large-scale employers in Peshawar and other metropolitans depends upon informal channels to recruit and train its work force.

${ }^{121}$ Public sector employment is essentially governed by the Civil Servants Act 1973, the Essential Services (maintenance) Act 1952 \& 1958, and various Federal and Provincial "Efficiency and Discipline Rules." The various forms of Contracts in the state employment are derived from the said laws and rules (NOMAAN, 2000).

${ }^{122}$ The government opened several new jobs in Kukar by setting up educational institutions and health units.
} 
- firstly, limited and decline induction in the border patrol jobs by the government in the last two decades,

- secondly, more and more people in the area were observed to consider army jobs as economically more rewarding than border patrol, and

- finally, a notable competition by the households in the tribal villages (Yousafkhel \& Mushtarzai) with the rest of the four settled villages to strive for military jobs.

\subsection{Changes in Institutions Organizing Non-agricultural Employment}

As revealed by the beginning sections of this chapter, the demographic growth along with the declining capacity of agriculture sector to absorb additional labour resulted in the demand for non-agricultural employment. This changing pattern of the rural economy from simple to complex needs the adjustment in social behavoiurs that ultimately requires the emergence of new institutions. Hence, this give rise to a clash of traditional behavoiural patterns with the increasing demand for impersonal relations (RIEKEN, 1994). The following sections are more or less a coherent and historical narration of this complex process dealing with some of the major institutions regulating non-agricultural employment.

\subsubsection{Changes in the Labour Organization in the Study Area}

Although the standard of living of ordinary worker changed little in the long run, labour institutions changed. If we take a long view like the last four decades, these institutions changed to a reasonable extent in the research area in Northwest Pakistan. The proportion of wage-labourers in the work force increased through much of the last four decades. Landless increased along those engaged in self employment. The only institution that remained somewhat static over the years was the proportion of women in rural work force. The Pakhtun institution of 'pukhtunwali' with its integral code of 'purdue' is directly responsible for this economic inactivity of females. Women employment is also discouraged on religious grounds, a trend appeared strongly in the 80es due to the government sponsored Islamization move under General Zia regime. During his era (1978-88) besides Islamization of every institution, certain discrementry laws (hudod) were enacted against women. 
Considering the line dividing the degree of institutionalization between the formal and informal sectors, the current study observed negligible changes compared to situation observed by Mohnhaupt, 1971 and RIEKEN, 1994. The formal sector as before is still subordinated to government labour regulations while within the informal sector all employment relations are regulated by oral agreements. Looking at the common aspects of formal sector jobs, there is almost no change over the years. For instance, the eight hours working day, the six day week, and the regulations governing period of absence are very much the same as observed in earlier studies in the area (for details, see MOHNHAUPT, 1971; RIEKEN, 1994).

The instiutions of paid leave and period of sick leave are common for the permanent employees of major industrial enterprises and government sector. In contrast to the formal sector in the informal sector, daily wage is still the predominant mode of payment, usually paid at the evening of the working day. The wage rate for a casual labourer like construction worker increased from merely Rs. 2 a day in 1967-68 (ALBRECHT, 1976) to a daily wage of almost Rs. 150 in 2004-05. Similarly in 1967-68, those in public sector like civil servants, clerks earned around Rs. 150 per month which rose in 2004-05 to a monthly salary of rougly Rs. 7000 . Besides the low pay, the manual labour is still considered a less prestigious job because of the same fact observed by ALBRECHT, 1976 decades ago 'a daily wager dirties his hands for others'. The government jobs due to the attached elements of authority are valued high in the research area. However, over much of the last four decades, the more things changed in terms of new income opportunities, the more they remained the same in terms of the structure of employment.

There is also little change in the institution of constract workers to be paid only after they have terminated the amount of work to be done. Their pay don't include any perks. Monthly payment is still the rule in the formal sector with additional allowances like old-age pension, health and accidental insurance. The trend or somewhat obligation of employing someone belonging to a retiring employee's family in an enterprise noted in 1967-68 is no longer existent in the area.

The customary forms of caste-based labours and services like 'ustakars' previously common in the area began to decline. These 'ustakars' were mostly found in the tribal village Yousafkhel, Gulbela, and Kukar. Unable to maintain themselves by heredity means of likelihood, the members of these ustakars families were compelled to give them up altogether, or to adopt other occupations as subsidiary means of likelihoods. Thus occupational choice ${ }^{123}$ became more

\footnotetext{
${ }^{123}$ These were not always a matter of choice but in some instances these were strategies to resist marginalization on part of the households.
} 
market-driven in the research area over the years. Hence, through the long run, even as unskilled casual and poorly paid labour dominated the rural labor force in Northwest Pakistan, the worksites, work arrangements and strategies of labour allocation by household changed.

\subsubsection{Changes in Employment Relations}

The need for rural dwellers in Northwest Pakistan to survive and to compete in the rapidly complex economy has led to the emergence of new patterns of employment relations which are distinctively different from those observed in the earlier studies (see MoHNHAUPT, 1971; ALBRECHT, 1976; MANIG, 1991; RiEKEN, 1994). This section explores the ways key elements of employment relations may have changed and what the impact has been on workers of the new form of employment relations. Here, the term employment relations is used to include a broad range of issues.

The institutions that are responsible for establishment of employment relations vary according to the nature of the enterprise or government post (RIEKEN, 1994). Starting with recruitment for the non-agricultural employment, certain patterns were observed over the years in the research area. There is little change in the recruitment procedures for the public sector employment since the previous studies. The posts are properly advertised in the local newspapers and all formal procedures are followed to fill these posts. In recent time, the prerequisite like education, training, and experience for these government jobs increased considerably. Almost similar procedures are followed in the medium and large scale enterprises that are subject to legislation on industry and labour laws. However, majority of these large scale enterprises are located outside (for instance, Hayatabad industrial zone) the study villages. Nevertheless, there is still high demand for these formal sector jobs owing to their high prestige, better social security and material renumeration.

As observed by RIEKEN, 1994, the high officials at these enterprises in Northwest Pakistan still have the privilege of proposing people of their choice for the vacant post. This institution of favour and privilege is the main reason behind the recuirement of relatives or a large number of people from a few island areas. For instance, this was principal cause behind the hiring of considerable number of people from Kochian and Gulbela as drivers in Khazana Sugar Mill and Coca Cola factory located near Kukar. The similar institution is responsible for the increase of lower ranking police jobs like constables in Kukar (see Table 45). 
The recruitment situation of the casual wage labourers also changed little over the years as they are still at the mercy of open labour market locally or in other big cities of Pakistan ${ }^{124}$. These casual labourers are poorly qualified in terms of formal educations and skills which limit their chances of finding better paid secure jobs. They usually first attempt to take advantage of farm related seasonal opportunities ${ }^{125}$ befor embarking on finding work in the informal day labourers' market.

The institution of contractors hiring workers on contract (mostly construction workers in building sector) is mostly intact in the research area. These workers usually wait in their villages to be employed by a group of contractors, with whom they have close contacts. However, it was observed that even these contract workers look for alternative non-agricultural occupations at the time of seasonal unemployment. The number of contract workers increased in Gulbela over previous surveys as majority of them were hired for the construction work at the nearby river Naguman (see Table 45). Similarly, the craftmen also still follow their traditional apprenticeship but they have the choice between deciding for an autonomous occupation or opening their own business. As stated earlier, there are no written contracts in the informal sector so everything run under oral agreements. Therefore, the relationship between employer and employee lack social security - are charcteristised by the employee's marked dependence upon the entreprenear's personal decisions and altitudes as well as upon situation regarding orders.

In the preceding sections we documented that that the government has played a relatively minor role in promoting labour standards in the research area. Even we are justified to state that the low wages and poor working conditions are the direct result of government neglect of labour standards. Although the 'modern' wage employment sector outside government employment has grown over time, it is still too small to significantly affect wages and working conditions of the majority of the work force. This has resulted in the emergence of a kind of gap between the formal sector workers and casual workers, who observe no labour standard laws at their work place.

\footnotetext{
${ }^{124}$ If the manual labour is not available in the respective villages, they usually visit other neighbouring cities before going searching jobs in Karachi, Lahore, or Rawalpindi/Islamabad.

${ }^{125}$ Some of the common seasonal agricultural related jobs are: crop cultivation, harvesting, sugarcane processing, and straw transportation.
} 


\section{CONCLUSION}

\subsection{Summary and Conclusion}

The objectives of the study presented here was to analyse the livelihood strategies and employment structure of people living in the six rural villages of North West Frontier Province, a land scarce region in Northwestern Pakistan characterized by widespread poverty, social, and market marginalization. Most of the past studies in the area only briefly consider quantitatively the livelihood diversification strategies and behaviour of rural households. The current study, therefore, tried to fill this gap by considering different livelihood diversification strategies and examining their determinants under the context of rural Northwest Pakistan.

The six study villages, covering an area of 6880 acres, in district Peshawar NWFP Pakistan were predetermined based on surveys in 1967/68 and 1986/87 by Goettingen University. The current study was population-based and used previously validated instruments. We wanted villages close enough to Peshawar to provide information about the extend of non-agrucultural employment opportunities for the villagers and yet distant enough to retain its village character. We conducted a house-to-house survey of six villages of Northwest Pakistan. The villages were approximately 7-23 km from the provincial capital Peshawar.

Between March and September 2005, we conducted basic survey of 2825 households ranging from 288-727 across villages, followed by a special survey of 120 households in the area. Quantitative and qualitative approaches were employed during long periods of fieldwork in 2004-05. This included visiting for a period of several months in each of six villages, providing the opportunity to gain a deeper knowledge and understanding of these communities, as well as to become familiar with the villagers and establish mutual trust. The research team consisted of three $\mathrm{PhD}$ students from Goettingen University Germany and four locally hired male enumerators.

The questionnaire used for the basic survey is the same as used in the 1967/68 and 1986/87 surveys. It was a quick snapshot of information related to the household and household head, resource base, credit, investment and sources of income. For the special survey, 120 households (20 in each village) belonging to non-farm and mixed income earning households were selected at random from the basic survey and interviewed. Households defined here as consisting of people who shared a dwelling and kitchen and who ate together. Out of 120 sample households, 
60 were non-farm wage-salary earner households, 21 engaged in businesses while 'mixed-income earner' formed the remaining 39 households.

To understand the diversity and dynamics among rural livelihoods, households in the study villages were classified according to the sector from which they generate their income. Five of the categories were related only to agriculture: (a) pure landlords, who rent-out all of theirfrequently small-land, (b) owner operator farmers, (c) owner-cum-tenants, (d) tenants, and (e) livestock farmers. Five more categories were created in line with those specified for pure farmers for households combining farming with non-farming activities. Finally households, which subsisted exclusively on earnings from non-agricultural activities, were classified as: (h) only wage earners households, (i) microentrepreneurs and traders, and (j) welfare based households. Based on the present study we conclude that informal sectors like casual daily wage earners, selfemployed and petty trades dominate the job market in the area. The logistic regression on household diversity revealed that the number of household members who work and with educated household head have a positive and significant effect on the probability of belonging to a diversified household (mixed income earner category).

The study using basic survey data also investigated the role of agriculture and urban linkages in the prevalence of non-agriculture activities in the study area. The Pearson correlation turned out to be significant but negative between proportion of non-agricultural workers and irrigated farmland, livestock, and proximity to urban centre. The influence of provincial capital Peshawar was more pronounced for the extension villages (Kukar \& Dalazak) as there economy offered more on average in non-farm employment than the rest of the study villages. However, the prevailing non-farm sector in the study villages is informal, requiring less in assets and human capital from the workers.

This study also presented a profile of poverty in Northwest Pakistan for 2004. It assessed the magnitude of poverty and its distribution across the research villages and household categories, provided information on the characteristics of the poor, and helped identify empirical correlates of poverty. All three classes of poverty indices FOSTER, GREER and THORBECKE, 1984 were used: the head-count, poverty gap, and squared poverty gap. The rural only farming households (HH cat. I-IV) have a very high incidence of poverty followed by the tenants with non-farm jobs (HH cat. V4) and those in only non-agricultural wage-salary earning activities (HH cat. VII). These households are at the bottom end of the range of human capital and physical assets categories. Casual workers constitute one of the poorest sections of the pure non-farming households 
and, given that farm related jobs had declined in the area and casual labour increased (see MANig, 1991; ALBRECHT, 1976; RieKEN, 1994), these workers likely to be a growing section of the rural poor.

Considering the determinants of household poverty, the logit estimates confirm that the key factors distinguishing the poor from nonpoor are: household size, education of working adults, dependency ratio, and access to permanent jobs, government employment and self-employment. Some of the other variables strongly explaining the likelihood of being poor are ownership of assets such as livestock and transport and location of households. The likelihood of being poor is greater in Dalazak and Kochian where there is limited opportunity for productive and secured employment and income. The remittances sent home by the migrated labour from the reference village Mushtarzai played a major role there in decreasing the incidence of poverty.

The multinomial logit model reveals the importance of individual, household and community related variables like education, age, income, household size, working members and location in household employment decisions. The non-farm informal wage activity mix being currently most common activity across the research villages is taken as a base for comparison. The likelihood of working in the formal sector (regulated jobs) versus working as informal wage worker is significantly and positively determined by age, education, household size, and residence of village Mushtarzai. The probability of choosing self employment significantly increases with education, household size, and all village dummies except Gulbela. With respect to informal wage employment, the probability of farming related activity significantly increases with land and livestock ownership, other things being equal. The likelihood of remaining in mixed farming and mixed tenancy increase with age and education of the household head. Despite the limited opportunities, the current younger generation in the research area shows a higher propensity to hunt for alternatives outside traditional farming for their survival with little to do with wealth accumulation. The coefficient on age square is negative and significant for those engaged in formal jobs, mixed farming and land tenancy pointing to the non-linear effect of age of household head. In Northwest Pakistan, nonfarm activities have become increasingly important.

This study is an attempt to catalogue the present employment structure as well as the changes in income earning strategies between 1967 and 2005 in six villages of Northwest Pakistan. It also identified the broad features and direction of change that are transforming the research area overtime. Farming is no longer a major livelihood strategy as more and more households are switching towards non-agricultural employment. Majority of these non-farm activities are 
survival oriented and have little to do with wealth accumulation. Over four decades the share of households engaged only in farming declined from 31 percent to 6 percent, while the share of non-farm activities rose from 54 percent to 66 percent. Similarly, those combining farming with non-farm activities rose from 13 percent in 1967/68 to 28 percent in 2004/05. There is not only a continuous perceptive shift in the rural occupational structure towards non-agricultural activities since the last few decades but also the shift away from agriculture is intense. The casual workers and those in permanent private jobs still dominate the village economy while the percentage of household members engaged in own businesses across the six villages have been more or less consistent through the decades. The share of those engaged in regulated government sector declined for all villages except Kochian and Dalazak. However, majority of these public sector employments constituted the lower cadre jobs. To summarize, the following processes and trends were observed across these rural villages in Northwest Pakistan:

- Occupations and livelihoods in the six study villages are diversifying with occupational multiplicity becoming more pronounced;

- Livelihoods are increasingly becoming delinked from farming resulting in greater number of household engaged in non-farm activities;

- Majority of the non-farm occupations are insecure, low-skilled, casual and aimed at survival of the households rather than wealth accumulation; and

- International as well as internal remittances start playing a growing role in household income because of mobile and delocalized livelihoods.

\subsection{Policy Implications}

The implication of the study is that rural non-farm sector needs it due share in development policies as it has the potential to uplift the rural areas. More precisely, the informal sector that is the main source of survival for rural poor is in urgent need of support. Besides the traditional focus on development programs for promoting small manufacturing enterprises, there is also a need for giving attention to wage employment in the rural service sector. To raise the capacity of rural poor to participate in better paid non-farm jobs, we need to focus on improving job related skills through better training and education, and provision of rural infrastructure and credit schemes. Several studies on promoting non-farm employment in developing countries reached the same conclusion (CHAPLIN et al., 2004). 
There is a need for improving economic opportunities and accessibility in disadvantaged rural regions. To deal with decreasing demand for agricultural labour and the marginalisation of small-scale farming, an adjustment strategy is required to develop alternative sources of income (RUBEN \& PENDER, 2004). Besides these understanding the sources and consequences of rural household diversity is of importance for successful development interventions. Diversity is economically rewarding, since it facilitates gains from specialization and market exchange, according to the theory of comparative advantage (ROVERE et al., 2006). Therefore, policies for poverty alleviation and sustainable development in the area should take the existing diversity among rural households and the heterogeneity in resources as a useful starting point.

Research villages in Northwest Pakistan present a dismal picture. Educational and other social services are not adequate. Rural infrastructure, including roads, telecommunications, water, and waste management, is in need of upgrading. There is inadequate support for business in the form of information and mutual organization. These challenges like education, infrastructure, and services for livelihoods in Northwest Pakistan need to be addressed at the policy levels. Investing in skills development and education, for instance, is important to give people the chance to access and create non-farm opportunities, as long as it is accompanied by job creation. Enhancing non-farm employment demands suitable policies and public sector investment on education, ${ }^{126}$ training, and technical support (RUBEN \& VAN DEN BERG, 2001).

Despite a strong patriarchal tradition and sharp gender segregation in rural Northwest Pakistan, there is an urgent need for promoting involvement of women in paid labour force. Research suggests that economically active female can bring stability to the income flow into the household which as consequence will enhance women's decision making power within the family (KABEER, 1995 cited in PRYER, 2002). The present study also supports increasing the availability of public girls' schools and improving their quality in the villages where girls' public schools already exist as suggested by LLOYD et al., 2005 in their study on Pakistan.

Finally, the poverty statistics displays a large degree of inequality across villages. Location does make a difference in the well-being of many rural people. Therefore, when targeting the poor, both villages and households should be considered. As shown by the study labour quality is

\footnotetext{
${ }^{126}$ The lack of funds for education is usually considered as a valid excuse for the negligible progress but authorities should heed former Harvard University President Derek Bok's advice cited in KHALID \& KHAN, 2006: if education is a costly affair, try ignorance!
} 
positively related to income level within village, improving rural education plays a positive role in achieving both equity and efficiency. 


\section{REFERENCES}

Abduali, A., Delgado, C.L., Peters, G.H., and Braun, J. 1999. Determinants of Time Spent in Non-Farm Employment by Farmers in Northern Ghana. In: Food Security, Diversification, and Resource Management: Refocusing the Role of Agriculture? Proceedings of the Twenty-third International Conference of Agricultural Economists, Sacramento, California, USA.

ACHARYA, S. 1998. Labour Supply and Job Choice in an Agrarian Economy: Some Results from Maharashtra. Development Policy Review, Vol. 16, No. 2, pp. 153-171.

ADAMS, R.H. 1996. Livestock Income, Male/Female Animals, and Inequality in Rural Pakistan. Discussion Paper No. 21. Food Consumption and Nutrition Division, International Food Policy Research Institute, Washington, D.C., USA.

AdAto, M., Lund, F., and Mhlongo, P. 2007. Methodological Innovations in Research on the Dynamics of Poverty: A Longitudinal Study in Kwazulu-Natal, South Africa. World Development, Vol. 35, No. 2, pp. 247-263.

ADB. 2002. Poverty in Pakistan Issues, Causes and Institutional Responses. Publication Stock No. 070302. Asian Development Bank, Pakistan Resident Mission, Islamabad, Pakistan.

Ahmed, A.G.M., Azeze, A., BAbIKer, M., and Tsegaye, D. 2002. Post-Drought Recovery Strategies among the Pastoral Households in the Horn of Africa: A Review. Development Research Report Series No. 3. OSSREA (Organization for Social Science Research in Eastern and Southern Africa), Addis Ababa, Ethiopia.

AHMED, A.S. 1980. Pukhtun Economy and Society. Routledge and Kegan Paul, London, UK.

AlbReCHT, H. 1976. Living Conditions of Rural Families in Pakistan. Socioeconomic Studies on Rural Development, Vol. 3. Verlag der SSIP-Schriften, Saarbrücken, Germany.

ALEEM, I. 1990. Imperfect Information, Screening, and the Costs of Informal Lending: A Study of a Rural Credit Market in Pakistan. The World Bank Economic Review, Vol. 4, No. 3, pp. 329-349.

Amelie, C., and Zimmermann, K.F. 2004. Occupational Choice across Generations. Discussion Paper No. 395. German Institute for Economic Research, Berlin, Germany.

AmineH, A. 2005. Death and Celebration among Muslim Women: A Case Study from Pakistan. Modern Asian Studies, Vol. 39, No. 4, pp. 929-980.

AmineH, A. 2006. Sorrow and Joy among Muslim Women: The Pukhtuns of Northern Pakistan. Cambridge University Press, Cambridge, UK. 
AMJAD, R. 2005. Skills and Competitiveness: Can Pakistan Break out of the Low-Level Skills Trap? The Pakistan Development Review, Vol. 44, No. 4, pp. 387-409.

AnNA, T. 2003. Exploring Sustainable Livelihoods Approaches in Relation to Two Interventions in Tanzania. Journal of International Development, Vol. 15, No. 6, pp. 771-781.

AOKI, M. 2000. Institutional Evolution as Punctuated Equilibria. In: Institutions, Contracts and Organizations: Perspectives from New Institutional Economics (edited by MENARD, C.). Edward Elgar, Cheltenham, UK.

AOKI, M. 2007. Endogenizing Institutions and Institutional Changes. Journal of Institutional Economics, Vol. 3, No. 1, pp. 1-31.

ARIF, G.M., NAZLI, H., and HAQ, R. 2000. Rural Non-Agricultural Employment and Poverty in Pakistan. The Pakistan Development Review, Vol. 39, No. 4, pp. 1089-1110.

BANERJEe, A.V., and DuflO, E. 2007. The Economic Lives of the Poor. Journal of Economic Perspectives, Vol. 21, No. 1, pp. 141-167.

Barrett, C.B., Bezuneh, M., and ABoud, A. 2001a. Income Diversification, Poverty Traps and Policy Shocks in Cote D'ivoire and Kenya. Food Policy, Vol. 26, No. 4, pp. 367-384.

Barrett, C.B., Bezuneh, M., Clay, D.C., and Reardon, T. 2005. Heterogeneous Constraints, Incentives and Income Diversification Strategies in Rural Africa. Quarterly Journal of International Agriculture, Vol. 44, No. 1, pp. 37-60.

Barrett, C.B., Reardon, T., and WeBb, P. 2001b. Nonfarm Income Diversification and Household Livelihood Strategies in Rural Africa: Concepts, Dynamics, and Policy Implications. Food Policy, Vol. 26, No. 4, pp. 315-331.

Baulch, B., and McCulloch, N. 1998. Being Poor and Becoming Poor: Poverty Status and Poverty Transitions in Rural Pakistan. IDS Working Paper N0. 79. Institute of Development Studies University of Sussex, Brighton, UK.

Baulch, B., and McCulloch, N. 2002. Being Poor and Becoming Poor: Poverty Status and Poverty Transitions in Rural Pakistan. Journal of Asian and African Studies, Vol. 37, No. 2, pp. 168-185.

BECKER, G.S. 1976. The Economic Approach to Human Behavior. University of Chicago, Chicago, USA.

Belay, K., Beyene, F., and MANig, W. 2006. Coping with Drought among Pastoral and AgroPastrol Communities in Eastern Ethiopia. Journal of Rural Development, Vol. 28, No. JRD28-2-05, pp. 185-210.

Berdegue, J., Reardon, T., Escobar, G., and Echeverri, R. 2000. Policies to Promote Non-Farm Rural Employment in Latin America. Natural Resource Perspectives, No. 55. Overseas Development Institute, London, UK. 
Berdegue, J.A., Ramirez, E., Reardon, T., and Escobar, G. 2001. Rural Nonfarm Employment and Incomes in Chile. World Development, Vol. 29, No. 3, pp. 411-425.

Berhanu, W., Colman, D., and Fayissa, B. 2007. Diversification and Livelihood Sustainability in a Semi-Arid Environment: A Case Study from Southern Ethiopia. Journal of Development Studies, Vol. 43, No. 5, pp. 871 - 889.

Bhaduri, A. 1993. Alternative Development Strategies and the Rural Sector. In: The World Economic Crisis and Agriculture in the Third World in the Eighties: The Changing Role of Agriculture in Economic Development (edited by Singh, A. \& TABATABAI, H.). International Labour Organisation, Geneva, Switzerland.

Block, S., and Webb, P. 2001. The Dynamics of Livelihood Diversification in Post-Famine Ethiopia. Food Policy, Vol. 26, No. 4, pp. 333-350.

Bodil, E., and LennarT, O. 2001. Livelihood Diversification: Continuity and Change in the Sahel. GeoJournal, Vol. 19, No. 4 pp. 491-505.

BuChENRIEDER, G. 2005a. Determinants and Effects of Non-Farm Rural Employment. Quarterly Journal of International Agriculture, Vol. 44, No. 1, pp. 1-2.

BuChENRIEDER, G. 2005b. Non-Farm Rural Employment - Review of Issues, Evidence and Policies. Quarterly Journal of International Agriculture, Vol. 44, No. 1, pp. 3-18.

Caillavet, F., Guyomard, H., and Lifran, R. 1994. Agricultural Household Modelling and Family Economics. In: Developments in Agricultural Economics (edited by CAILlAVET, F., Guyomard, H. \& Lifran, R.). Elsevier, Amsterdam, The Netherlands.

Cain, P., Anwar, M., and Rowlinson, P. 2007. Assessing the Critical Factors Affecting the Viability of Small-Scale Dairy Farms in the Punjab Region of Pakistan to Inform Agricultural Extension Programmes. Agricultural Systems, Vol. 94, No. 2, pp. 320-330.

Camilla, T., Rebeca, L., Karen, B., Ngolo, C., Grace, C., and Data, D. 2000. Diversification of Livelihoods: Evidence from Mali and Ethiopia. Report No. 47. Institute of Development Studies, Sussex, UK.

Casley, D.J., and LuRY, D.A. 1987. Data Collection in Developing Countries. Oxford University Press, Oxford, UK.

Chambers, R., and Conway, G.R. 1991. Sustainable Rural Livelihoods: Practical Concepts for the 21st Century. IDS Discussion Paper No. 296. Institute of Development Studies, Brighton, UK.

Chaplin, H., Davidova, S., and Gorton, M. 2004. Agricultural Adjustment and the Diversification of Farm Households and Corporate Farms in Central Europe. Journal of Rural Studies, Vol. 20, No. 1, pp. 61-77. 
Chaudhry, G., and Chaudhry, G.M. 1992. Trends of Rural Employment and Wages in Pakistan: Labor Absorption in Pakistan Agriculture. In: Pakistan Agricultural Economics. National Book Foundation, Islamabad, Pakistan.

Chayanov, A.V. 1966. On the Theory of Peasant Economy (English version translated and edited by Thorner et al.). Richard D. Irwin, Inc., Illinois, USA.

Cheng, S., and Long, J.S. 2007. Testing for IIA in the Multinomial Logit Model. Sociological Methods Research, Vol. 35, No. 4, pp. 583-600.

CORRAL, L., and REARdon, T. 2001. Rural Nonfarm Incomes in Nicaragua. World Development, Vol. 29, No. 3, pp. 427-442.

Coulombe, H., and MCKAY, A. 1996. Modeling Determinants of Poverty in Mauritania. World Development, Vol. 24, No. 6, pp. 1015-1031.

DAMite, D., and Negatu, W. 2004. Determinants of Rural Livelihood Diversification: Evidence from Southern Ethiopia. Quarterly Journal of International Agriculture, Vol. 43, No. 3, pp. 267-288.

Dawn Internet Edition. 2002. Factors That Contribute to Poverty. In: Dawn, English Newspaper Karachi, Pakistan.

Delali, B.K.D., WiTKowski, E.T.F., and Charlie, M.S. 2005. Monetary Valuation of Livelihoods for Understanding the Composition and Complexity of Rural Households. Agriculture and Human Values, Vol. 22, No. 1, pp. 87-103.

DE HAAn, L., and Zoomers, A. 2005. Exploring the Frontier of Livelihoods Research. Development and Change, Vol. 36, No. 1, pp. 27-47.

DFID. 2001. Sustainable Livelihoods Guidance Sheets. The Department for International Development (DFID), London, UK.

Dharmawan, A.H. 2001. Farm Household Livelihood Strategies and Socio-Economic Changes in Rural Indonesia. Socioeconomic Studies on Rural Development, Vol. 124. Wissenschaftsverlag Vauk, Kiel, Germany.

DuPREE, N.H. 2002. Cultural Heritage and National Identity in Afghanistan. Third World Quarterly, Vol. 23, No. 5, pp. 977-989.

EAPEN, M. 2001. Rural Non-Farm Employment: Agricultural Versus Urban Linkages - Some Evidence from Kerala State, India. Journal of Peasant Studies, Vol. 28, No. 3, pp. 67-89.

ECONOMIST. 2003. Making a Virtue of Necessity. In: Economist, p. 40. Economist Newspaper Limited, USA.

Ellis, F. 1998. Survey Article: Household Strategies and Rural Livelihood Diversification. Journal of Development Studies, Vol. 35, No. 1, pp. 1-38. 
ELLIS, F. 2000. Rural Livelihoods and Diversity in Developing Countries. Oxford University Press, UK.

Ellis, F., and Freemen, H.A. 2004. Rural Livelihoods and Poverty Reduction Strategies in Four African Countries. The Journal of Development Studies, Vol. 40, No. 4, pp. 1-30.

Ellis, F., and Mdoe, N. 2003. Livelihoods and Rural Poverty Reduction in Tanzania. World Development, Vol. 31, No. 8, pp. 1367-1384.

EMIGH, R.J. 2001. Theorizing Strategies: Households and Markets in 15th-Century Tuscany. The History of the Family, Vol. 6, No. 4, pp. 495-517.

FAfChAMPS, M., and Quisumbing, A.R. 1999. Human Capital, Productivity, and Labor Allocation in Rural Pakistan. Journal of Human Resources, Vol. 34, No. 2, pp. 369-406.

FAREedeE, F. 1989. Women and Handicrafts in Punjab. Survey Report Part 2, Training and Marketing, in collaboration with and under supervision of ASR. Applied Socio-Economic Research, Islamabad, Pakistan.

Foster, J., Greer, J., and Thorbecke, E. 1984. A Class of Decomposable Poverty Measures. Econometrica, Vol. 52, No. 3, pp. 761-765.

Fuwa, N., Ito, S., Kubo, K., Kurosaki, T., and Sawada, Y. 2006. Introduction to a Study of Intrahousehold Resource Allocation and Gender Discrimination in Rural Andhra Pradesh, India. The Developing Economies, Vol. 44, No. 4, pp. 375-397.

GaURAHA, A.K. 1996. Farm and Non-Farm Employment: A Case Study. Bihar Journal of Agricultural Marketing, Vol. 4, No. 4, pp. 417-425.

GERA, N. 2007. Impact of Structural Adjustment Programmes on Overall Social Welfare in Pakistan. South Asia Economic Journal, Vol. 8, No. 1, pp. 39-64.

Geran, J.M. 2001. Growth, Crisis and Resilience: Household Responses to Economic Change in Rural Southeast Asia: Evidence from Northern Thailand. Working Paper No.1. University of Wisconsin-Madison, USA.

GreENE, W.H. 2003. Econometric Analysis, 5th ed. Prentice Hall, USA.

GuJARATI, D.N. 2003. Basic Econometrics, 4th ed. McGraw-Hill, USA.

HAAN, A.D. 2000. Urban Livelihoods and Labor Markets. 2020 Focus No. 03, Brief 04. International Food Policy Research Institute, Washington, D.C., USA.

HAMILTON, L.C. 2006. Statistics with Stata. Thomson Brooks/Cole, USA.

Hargreaves, J.R., Morison, L.A., Gear, J.S.S., Makhubele, M.B., Porter, J.D.H., Busza, J., Watts, C., KiM, J.C., and Pronyk, P.M. 2007. "Hearing the Voices of the Poor": Assigning Poverty Lines on the Basis of Local Perceptions of Poverty. A Quantitative Analysis of Qualitative Data from Participatory Wealth Ranking in Rural South Africa. World Development, Vol. 35, No. 2, pp. 212-229. 
Hausman, J., and MCFadden, D. 1984. Specification Tests for the Multinomial Logit Model. Econometrica, Vol. 52, No. 5, pp. 1219-1240.

Hennessy, T.C., and ReHman, T. 2007. An Investigation into Factors Affecting the Occupational Choices of Nominated Farm Heirs in Ireland. Journal of Agricultural Economics, Vol. 58, No. 1, pp. 61-75.

HERBOn, D. 1988. Existenzsicherung in der Agrargesellschaft: Entscheidungen und Handlungen aus mikro- und systemtheoretischer Sicht. Sozilökonomische Schriften zur Ruralen Entwicklung, Vol. 78. Alano Verlag, Aachen, Germany.

Herbon, D. 1994. Socio-Economic Dynamics in Rural Bangladesh: The Individual and Societal Effects of Opportunities and Obstacles. Aldershot, Avebury, UK.

Hodgson, G.M. 2006. What Are Institutions? Journal of Economic Issues, Vol. 40, No. 1, pp. $1-25$.

Hussain, A. 1989. Labor Absorption in Pakistan's Agriculture. Pakistan Agricultural Economics Series. National Book Foundation, Islamabad, Pakistan.

Hussain, A., Kemal, A.R., Hamid, A.I., Ali, I., Mumtaz, K., and QutUb, A. 2003. Pakistan National Human Development Report 2003: Poverty, Growth and Governance. United Nations Development Programme, Islamabad, Pakistan.

IlAHI, N., and JAFAREY, S. 1999. Guestworker Migration, Remittances and the Extended Family: Evidence from Pakistan. Journal of Development Economics, Vol. 58, No. 2, pp. 485-512.

ILCA. 1992. Livestock Production System. International Livestock Center for Africa, Addis Ababa, Ethiopia.

ILIYA, M.A., and SwindelL, K. 1997. Winners and Losers: Household Fortunes in the Urban Peripheries of Northern Nigeria. In: Farewell to Farms: De-Agrarianisation and Employment in Africa (edited by BRYCESON, D.F. \& JAMAL, V.). Ashgate, Aldershot, UK.

ILO. 2003. Facts on Women at Work. Retrieved April, 2006, from http://www.ilo.org/public/english/bureau/inf/download/women.

ISLAM, N. 1997. The Non-Farm Sector and Rural Development: Review of Issues and Evidence. Discussion Paper No. 22. International Food Policy Research Institute, Washington, D.C., USA.

JACOBy, H.G., and MAnSURI, G. 2007. Incentives, Supervision, and Sharecropper Productivity. World Bank Policy Research Working Paper No. 4125. World Bank, Washington, D.C., USA. 
JAN, I. 2007. Institutional Changes in Agricultural Support Services in Rural Northwest Pakistan. Changes in the Socio-Economic Structures in Rural North-West Pakistan, Vol. 140. Wissenschaftsverlag Vauk, Kiel KG, Germany.

Janvry, A.D., and Sadoulet, E. 1995. Quantitative Development Policy Analysis. Johns Hopkins University Press, Baltimore, USA.

JANVRY, A.D., and SAdoulet, E. 2001. Income Strategies among Rural Households in Mexico: The Role of Off-Farm Activities. World Development, Vol. 29, No. 3, pp. 467-480.

Jansen, H.G.P., Rodriguez, A., Damon, A., Pender, J., Chenier, J., and Schipper, R. 2006. Determinants of Income-Earning Strategies and Adoption of Conservation Practices in Hillside Communities in Rural Honduras. Agricultural Systems, Vol. 88, No. 1, pp. $92-110$.

JoLlifFE, D. 2004. The Impact of Education in Rural Ghana: Examining Household Labor Allocation and Returns on and Off the Farm. Journal of Development Economics, Vol. 73, No. 1, pp. 287-314.

Keane, M.P. 1992. A Note on Identification in the Multinomial Probit Model. Journal of Business and Economic Statistics, Vol. 10, pp. 193-200.

KenNedy, P. 2003. A Guide to Econometrics, 5th ed. Blackwell Publishing, USA.

KHALID, S.M., and KHAN, M.F. 2006. Pakistan: The State of Education. The Muslim World, Vol. 96, No. 2, pp. 305-322.

KHAN, A.R. 2000a. Involvement of Rural Women in the Economic Activities of Baluchistan. Journal of Rural Development and Administration (Pakistan), Vol. 31, No. 2, pp. 105-109.

KHAN, D.A. 1975. Central Place Theory as Basis for the Spatial Reorganization of Pakistan's Rural Landscape. Verlag der SSIP-Schriften, Saarbrücken, Germany.

KHAN, M.A. 2007. Changes in the Socio-Economic Structures in Rural North-West Pakistan. Socioeconomic Studies on Rural Development, Vol. 141. Wissenschaftsverlag Vauk, Kiel, Germany.

KHAN, M.H. 2000b. Duality in the Countryside In: Dawn Internet Edition Karachi, Pakistan.

KIM, B.Y. 2005. Poverty and Informal Economy Participation. Evidence from Romania. The Economics of Transition, Vol. 13, No. 1, pp. 163-185.

KING, K. 2001. Africa's Informal Economies: Thirty Years On. SAIS Review, Vol. 21, No. 1, pp. $97-108$.

KNIGHT, J. 1992. Institutions and Social Conflict. Cambridge University Press, Cambridge, UK.

Krishna, A. 2006. Pathways out of and into Poverty in 36 Villages of Andhra Pradesh, India. World Development, Vol. 34, No. 2, pp. 271-288. 
Kuhnen, F. 1985. Multiple Employment in Asian Agriculture. The Journal of Development Studies, Vol. VII, pp. 1-8.

KUMAR, B.L. 1996. Changes in the Composition of Rural Labor Force: Some Evidence from a Village Resurvey. Indian Journal of Labor Economics, Vol. 39, No. 4, pp. 809-816.

KUROSAKI, T. 1995. Risk and Insurance in a Household Economy: Role of Livestock in Mixed Farming in Pakistan. The Developing Economies, Vol. 33, No. 4, pp. 479-483.

KUROSAKI, T. 1997. Production Risk and Advantages of Mixed Farming in the Pakistan Punjab. The Developing Economies, Vol. 35, No. 1, pp. 28-47.

Kurosaki, T., and Khan, H. 2006. Human Capital, Productivity, and Stratification in Rural Pakistan. Review of Development Economics, Vol. 10, No. 1, pp. 116-134.

LANJOUW, P. 2001. Nonfarm Employment and Poverty in Rural El Salvador. World Development, Vol. 29, No. 3, pp. 529-547.

LANJOUw, P. 1999. The Rural Non-Farm Sector: A Note on Policy Options. Mimeo, Vol. 4. World Bank, Washington, D.C., USA.

Lanjouw, P., Quizon, J., and Sparrow, R. 2001. Non-Agricultural Earnings in Peri-Urban Areas of Tanzania: Evidence from Household Survey Data. Food Policy, Vol. 26, No. 4, pp. 385-403.

LAnjouw, P., and Stern, N. 1998. Economic Development in Palanpur over Five Decades. Oxford University Press, New York, USA.

LefERVRe, A. 1999. Kinship, Honour and Money in Rural Pakistan: Subsistance Economy and the Effects of Internal Migration. Curzon, Richmond.

Lloyd, C.B., Mete, C., and Sathar, Z.A. 2005. The Effect of Gender Differences in Primary School Access, Type, and Quality on the Decision to Enroll in Rural Pakistan. Economic Development \& Cultural Change, Vol. 53, No. 3, pp. 685-710.

Löfgren, H., and Robinson, S. 1999. To Trade or Not to Trade: Non-Separable Farm Household Models in Partial and General Equilibrium. TMD Discussion Paper No. 37. International Food Policy Research Institute, Trade and Macroeconomics Division, Washington, D.C., USA.

LONG, J.S., and FreEse, J. 2001. Regression Models for Categorical Dependent Variables Using Stata. Stata Press, College Station, Texas, USA.

MacPherson, S., and Silburn, R. 2000. The Meaning and Measurement of Poverty. In: Poverty: A Persistent Global Reality (edited by DiXON, J. \& MACAROV, D.). Routledge, Taylor \& Francis Group, London

MAdDALA, G.S. 1999. Limited Dependent and Quantitative Variables in Econometrics. Cambridge University Press, UK. 
MAHDI, N.Q. 1986. Pukhtunwali: Ostracism and Honor among the Pathan Hill Tribes. Ethology and Sociobiology, Vol. 7, No. 3, pp. 295-304.

Mahmood, Z., Sultan, K., and Samiullah. 2005. Status of Farm Mechanization in Peshawar and Mardan Division of North West Frontier Province of Pakistan. Sarhad Journal of Agriculture, Vol. 21, No. 2, pp. 157-164.

MANIG, W. 1990. Formal and Informal Credit Markets for Agricultural Development in Developing Countries - the Example of Pakistan. Journal of Rural Studies, Vol. 6, No. 2, pp. 209-215.

MANIG, W. 1991. Stability and Changes in Rural Institutions in North Pakistan. Socioeconomic Studies on Rural Development, Vol. 85. Alano Verlag, Aachen, Germany.

MANIG, W. 1997. Differenzierungsstrategien in Ländlichen Haushalten zur Ernährungssicherung in Nord Pakistan. Göttinger Beiträge zur Land- und Forstwirtschaft in den Tropen und SubTropen. Heft 115. Goettingen, Germany.

MANIG, W. 2006. Employment Creation by Promoting the Non-Farm Economy in Rural Regions. Journal of Entrepreneurship Research, Vol. 1, No. 1, pp. 63-86.

MaXwell, D., and Wiebe, K. 1999. Land Tenure and Food Security: Exploring Dynamic Linkages. Development and Change, Vol. 30, No. 4, pp. 825-849.

McBratney, A., and Minasny, B. 2007. On Measuring Pedodiversity. Geoderma, Vol. 141, No. 1-2, pp. 149-154.

MdumA, J.K., and Wobst, P. 2005. Determinants of Rural Labor Market Participation in Tanzania. African Studies Quarterly, Vol. 8, No. 2, pp. 32-47.

MehNAZ, G. 2005. Finding Influentials in Decision Making Process of Local Governemnt: A Study of Two Union Councils in Peshawar Disctrict of Pakistan. In: M.Phil thesis, Department of Administration and Organisation Theory, pp. 58-69. University of Bergen, Bergen, Norway.

MeindertsMA, D. 1997. Income Diversity and Farming Systems: Modeling of Farming Households in Lombok, Indonesia. Royal Tropical Institute, Amsterdam, The Netherlands.

Mellor, J.W. 1976. The New Economics of Growth: A Strategy for India and the Developing World. Cornell University Press, Ithaca, NY, USA.

Miller, P.W., and Volker, P.A. 1985. On the Determination of Occupational Attainment and Mobility. Journal of Human Resources, Vol. 20, No. 2, pp. 197-213.

MitrA, A. 2004. Informal Sector, Networks and Intra-City Variations in Activities: Findings from Delhi Slums. Review of Urban \& Regional Development Studies, Vol. 16, No. 2, pp. 154-169. 
Mohnhaupt, P. 1971. Landbevölkerung und Fabrikarbeit in Westpakistan: Berufswechsel und Anpassung Ländlicher Bevölkerungsgruppen aus vier Pakistanischen Dörfern im Peshawar-Distrikt an Fabrikarbeit. Vol. 5. Verlag der SSIP-Schriften Breitenbach, Saarbrücken, Germany.

Möllers, J., and BuChenrieder, G. 2005. Theoretical Concepts for the Analysis of NonFarm Rural Employment. Quarterly Journal of International Agriculture, Vol. 44, No. 1, pp. 19-36.

NASIR, Z.M. 2005. An Analysis of Occupational Choice in Pakistan: A Multinomial Approach. The Pakistan Development Review, Vol. 44, No. 1, pp. 57-79.

NomaAn, M. 2000. Pakistan: Employment, Output and Productivity. Discussion Paper No. 33. International Labor Organization, Geneva, Switzerland.

NoRTH, D.C. 1990. Institutions, Institutional Change and Economic Performance. Cambridge University Press, Cambridge, UK.

NoRTH, D.C. 1991. Institutions. Journal of Economic Perspectives, Vol. 5, No. 1, pp. 97-112.

NoRTH, D.C. 2000. Understanding Institutions. In: Institutions, Contracts and Organizations (edited by MENARD, C.). Edward Elgar, Cheltenham, UK.

Overbeek, G., Hillebrand, H., Goetgeluk, R., and Hetsen, H. 2000. Labour Situation of Farm Women in Rural (Urban) Areas. Report No. 4. Landbouw Economisch Institut (LEI), The Hague, The Netherlands.

Pakistan, Gov. OF. 2000. District Census Report of Pakistan. Census Publication, Report No. 33. Statistics Division, Islamabad, Pakistan.

Pakistan, Gov. OF. 2004. Economic Survey of Pakistan. Finance Division, Economics Advisor's Wing, Islamabad, Pakistan.

Pakistan, Gov. OF. 2005a. Economic Survey of Pakistan. Finance Division, Economics Advisor's Wing, Islamabad, Pakistan.

Pakistan, Gov. OF. 2005b. Labor Force Survey of Pakistan. Federal Bureau of Statistics, Islamabad, Pakistan.

Pakistan, Gov. OF. 2006. Poverty Reduction Strategy Paper: Annual Progress Report 2005-06. PRSP Secretariat, Finance Division, Islamabad, Pakistan.

Perera, S., Skully, M., and Wickramanayake, J. 2005. Human Progress in South Asia: A Multifaceted Analysis. South Asia: Journal of South Asian Studies, Vol. 28, No. 3, pp. 437-456.

Piesse, J., Thirtle, C., and Simister, J. 1999. Modernisation, Multiple Income Sources and Equity in the Communal Lands of Zimbabwe. Agrekon, Vol. 38, No. SPI/1, pp. 243-258. 
Portocarrero, J.V., Young, T., and Colman, D. 2006. Non-Farm Rural Activities in a Peasant Economy: The Case of the North Peruvian Sierra. Journal of International Development, Vol. 18, No. 2, pp. 207-221.

PrYer, J.A. 2002. Poverty and Vulnerability in Dhaka Slums: The Urban Livelihood Study. Ashgate Publishing Ltd, Aldershot, UK.

Purushotham, P. 1997. China's Township Enterprises. China Report, Vol. 33, No. 4, pp. 543-551.

QURESHI, M.G., and QURESHI, S.K. 2004. Impact of Changing Profile of Rural Land Market in Pakistan on Resource Allocation and Equity. The Pakistan Development Review, Vol. 43, No. 4, pp. 471-492.

RAhman, M. 1987. Women and Rural Development in Pakistan. Journal of Rural Studies, Vol. 3, No. 3, pp. 247-253.

ReArdon, T., Berdegue, J., and Escobar, G. 2001. Rural Nonfarm Employment and Incomes in Latin America: Overview and Policy Implications. World Development, Vol. 29, No. 3, pp. 395-409.

Reardon, T., Stamoulis, A., Balisacan, M.E., Berdegue, J., and Banks, B. 1998. The State of Food and Agriculture: Rural Non-Farm Income in Developing Countries. Food and Agriculture Organization of the United Nations, Rome, Italy.

Reardon, T., Taylor, J.E., Stamoulis, K., Lanjouw, P., and Balisacan, A. 2000. Effects of Non-Farm Employment on Rural Income Inequality in Developing Countries: An Investment Perspective. Journal of Agricultural Economics, Vol. 51, No. 2, pp. 266-288.

REDDY, E.S. 2000. Rural Non-Farm Employment in Developing Economies-Theoretical Formulation and Empirical Evidence. Journal of Rural Development (JRD), Vol. 19, No. 1, pp. 131-145.

RIEKEN, J. 1994. Institutionen, Kultur und Erwerbstätigkeit in Nordwest-Pakistan: Eine Studie zum Institutionellen Wandel im nicht-landwirtschaftlichen Erwerb. Socioeconomic Studies on Rural Development, Vol. 107. Alano Verlag, Aachen, Germany.

RoLAND, G. 2004. Understanding Institutional Change: Fast-Moving and Slow-Moving Institutions. Studies in Comparative International Development, Vol. 38, No. 4, pp. 109-131.

Rovere, R.L., Aw-Hassan, A., Turkelboom, F., and Thomas, R. 2006. Targeting Research for Poverty Reduction in Marginal Areas of Rural Syria. Development and Change, Vol. 37, No. 3, pp. 627-648.

Ruben, R., and Pender, J. 2004. Rural Diversity and Heterogeneity in Less-Favoured Areas: The Quest for Policy Targeting. Food Policy, Vol. 29, No. 4, pp. 303-320. 
RUbeN, R., and VAN DEN BERG, M. 2001. Nonfarm Employment and Poverty Alleviation of Rural Farm Households in Honduras. World Development, Vol. 29, No. 3, pp. 549-560.

RutTan, V.W. 2006. Social Science Knowledge and Induced Institutional Innovation: An Institutional Design Perspective. Journal of Institutional Economics, Vol. 2, No. 3, pp. 249-272.

SATTAR, K.A. 2004. Non-Farm Employment Opportunities in Rural Areas in Asia. Report of the APO Seminar in Philippines, 24-29 September 2001. Asian Productivity Organization, Tokyo, Japan.

SATRIAwAN, E., and Swinton, S.M. 2007. Does Human Capital Raise Farm or Nonfarm Earning More? New Insight from a Rural Pakistan Household Panel. Agricultural Economics, Vol. 36, No. 3, pp. 421-428.

SCHMidT, P., and Strauss, R. 1975. The Prediction of Occupation Using Multiple Logit Models. International Economic Review, Vol. 16, No. 2, pp. 471-486.

SchUlTZ, T.P. 1988. Education Investment and Returns. In: Handbook of Development Economics, Vol. 1 (edited by Chenery, H. \& SRInivasan, T.N.). Elseveir, Amsterdam, The Netherlands.

SChulz, A.J., Williams, D.R., ISRAel, B.A., and LeMPERT, L.B. 2002. Racial and Spatial Relations as Fundamental Determinants of Health in Detroit. The Milbank Quarterly, Vol. 80, No. 4, pp. 677-707.

SCHWARZE, S. 2004. Determinants of Income Generating Activities of Rural Households: A Quantitative Study in the Vicinity of the Lore-Lindu National Park in Central Sulawesi/Indonesia. In: Institute of Rural Development. Georg-August-University, Goettingen, Germany.

SCHWARZe, S., and Zeller, M. 2005. Income Diversification of Rural Households in Central Sulawesi, Indonesia. Quarterly Journal of International Agriculture, Vol. 44, No. 1, pp. 61-73.

SCOONES, I. 1998. Sustainable Rural Livelihoods: A Framework for Analysis. Working Paper No. 72. Institute of Development Studies, Sussex, UK.

ScotT, J. 1991. Gender a Useful Category of Historical Analysis. In: Womens's Studies International. Nairobi and Beyond (edited by ARUNA, R.). Feminist Press, New York, USA. pp. 13-37.

SEN, A. 1976. Poverty: An Ordinal Approach to Measurement. Econometrica, Vol. 44, No. 2, pp. 219-231.

SEN, A. 1990. More Than 100 Million Women Are Missing. The New York Review of Books, Vol. 37, No. 20, pp. 61-66. 
SimonofF, J.S. 2003. Analyzing Categorical Data. Springer-Verlag New York.

SMith, D.R., Gordon, A., Meadows, K., and ZwICK, K. 2001. Livelihood Diversification in Uganda: Patterns and Determinants of Change across Two Rural Districts. Food Policy, Vol. 26, No. 4, pp. 421-435.

Smith, L.E.D., Stockbridge, M., and Lohano, H.R. 1999. Facilitating the Provision of Farm Credit: The Role of Interlocking Transactions between Traders and Zamindars in Crop Marketing Systems in Sindh. World Development, Vol. 27, No. 2, pp. 403-418.

StaCeY, J., and RitTBerger, B. 2003. Dynamics of Formal and Informal Institutional Change in the EU. Journal of European Public Policy, Vol. 10, No. 6, pp. 858-883.

START, D. 2001. The Rise and Fall of the Rural Non-Farm Economy: Poverty Impacts and Policy Options. Development Policy Review, Vol. 19, No. 4, pp. 491-505.

Steimann, B. 2004. Livelihood Strategies in North-West Pakistan. Results from the Sustainable Livelihoods Survey 2004, North-West Frontier Province (Pakistan). NCCR IP6 Working Paper No.5. Department of Geography, University of Zurich, Switzerland.

Steve, W., Nicola, K., Kerry, P., Sharon, P., Gladys Rivera, H., and Gregoria RodRíguez, M. 2002. Agricultural Policy Reform and Rural Livelihoods in Central Mexico. The Journal of Development Studies, Vol. 38, No. 4, pp. 179-202.

TOPFER, K. 2000. Rural Poverty, Sustainability and Rural Development in the Twenty-First Century: A Focus on Human Settlements. Zeitschrift fur Kulturtechnik und Landentwicklung, Vol. 41, No. 3, pp. 98-105.

UPTON, M. 1996. The Economics of Tropical Farming Systems. Cambridge University Press, UK.

UptOn, M. 1999. The Economics of Tropical Farming Systems. Cambridge University Press, UK.

WANDSCHNEIDER, T. 2003. Determinants of Access to Rural Non-Farm Employment: Evidence from Africa, South Asia and Transition Economies. Report No. 2758. Natural Resources Institute, UK.

WeISE, J. 2006. Experiences with Poverty Targeting in Asia: An Overview. In: Poverty Targeting in Asia (edited by WEISE, J.). Edward Elgar Publishing Limited, Cheltenham, UK

Williamson, O.E. 1985. The Economic Institutions of Capitalism. The Free Press, New York, USA.

WoOLDRIDGE, J.M. 2003. Introductory Econometrics: A Modern Approach, 2nd ed. SouthWestern College Publishing, United Kingdom. pp. 211-241. 
WORLD BANK. 2000. World Development Report 2000/2001: Attacking Poverty. Oxford University Press, New York, USA.

WORLD BANK. 2007a. Doing Business in South Asia 2007. The World Bank, Washington, D.C., USA.

WORLD BANK. 2007b. Pakistan Promoting Rural Growth and Poverty Reduction. Report No. 39303-PK. Sustainable and Development Unit South Asia Region, The World Bank, Washington, D.C., USA.

Zeller, M., Sharma, M., Henry, C., and lapenu, C. 2006. An Operational Method for Assessing the Poverty Outreach Performance of Development Policies and Projects: Results of Case Studies in Africa, Asia, and Latin America. World Development, Vol. 34, No. 3, pp. 446-464.

Zeller, M., Sharma, M., Henry, C., and Lapenu, C. 2003. Microfinance Poverty Assessment Tool. Technical Tools Series No. 5. International Food Policy Research Institute, Washington, D.C., USA.

Zhang, L., Huang, J., and Rozelle, S. 2002. Employment, Emerging Labor Markets, and the Role of Education in Rural China. China Economic Review, Vol. 13, No. 2-3, pp. 313-328.

Zoomers, A. 1999. Linking Livelihood Strategies to Development: Experiences from the Bolivian Andes. Royal Tropical Institute, Centre for Latin American Research, Amsterdam, The Netherlands. 


\section{APPENDICES}


Appendix 1. Map of North West Frontier Province (NWFP), Showing its Districts

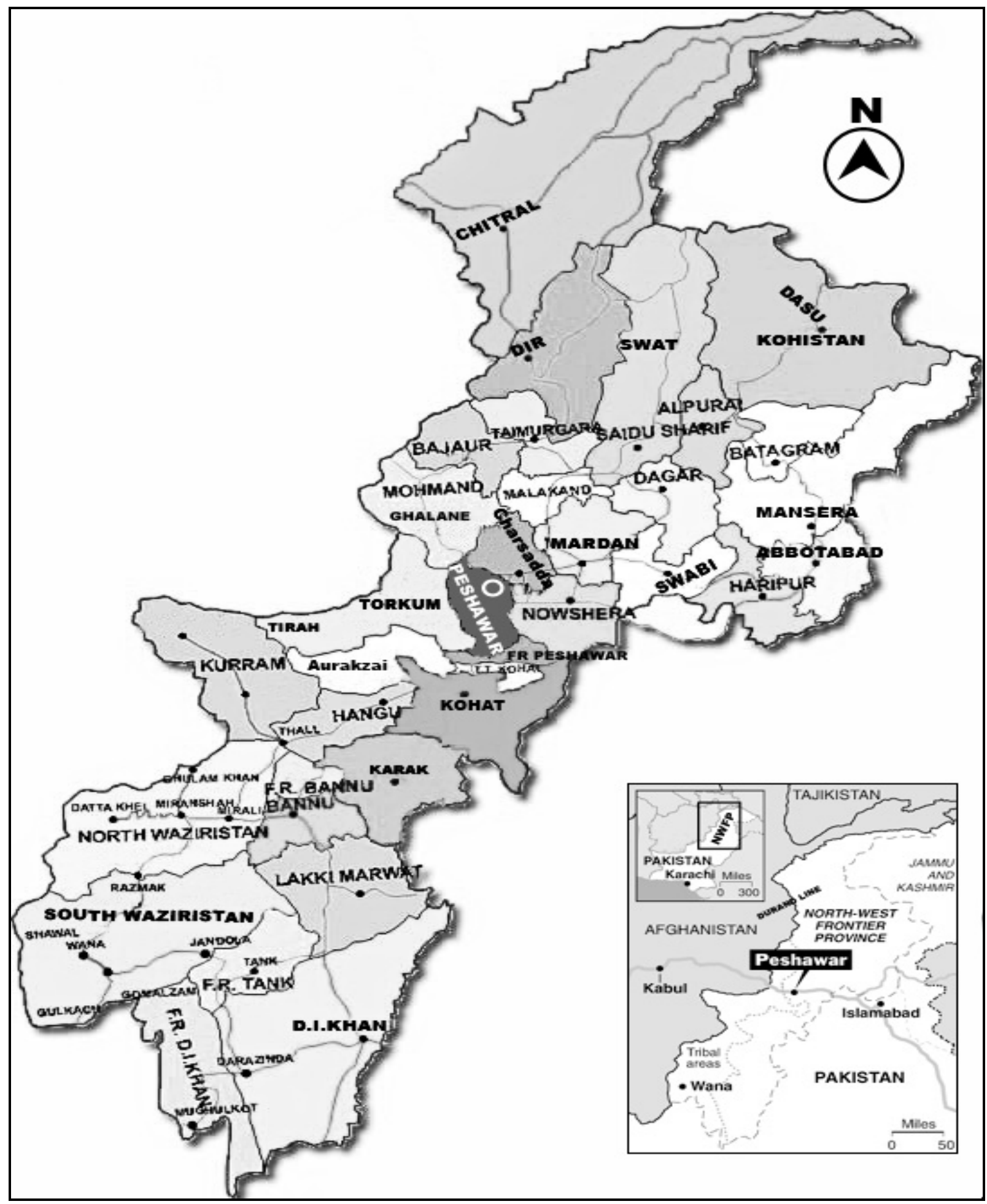

Source: GOVERNMENT OF NWFP, 2006. 
Appendix 2. Changes in the Employment Structures in the Study Area

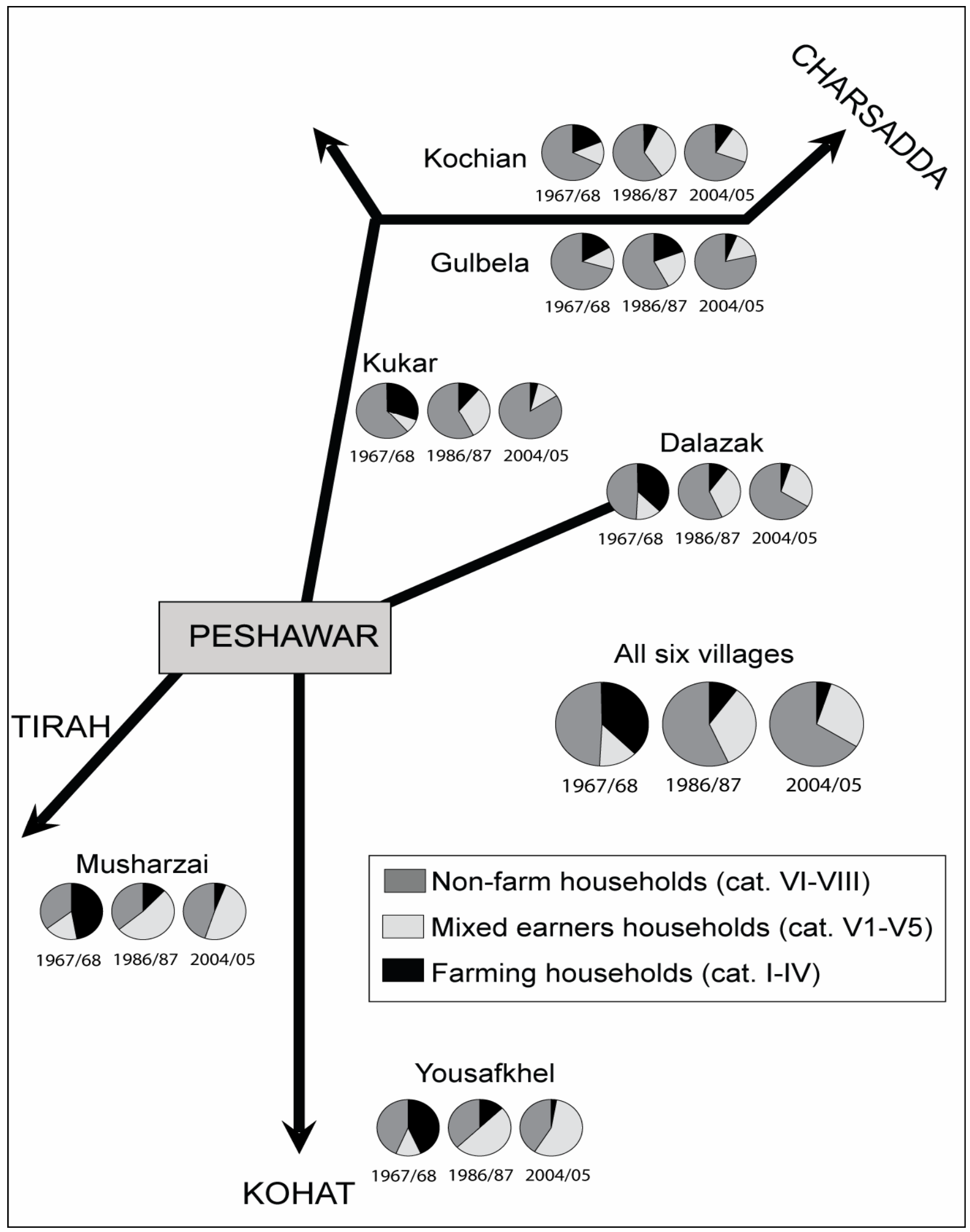

Source: Basic survey in six villages of Northwest Pakistan, 2004/05; MANIG, 1991. 
Appendix 3. Location of the Study Areas in Northwest Pakistan

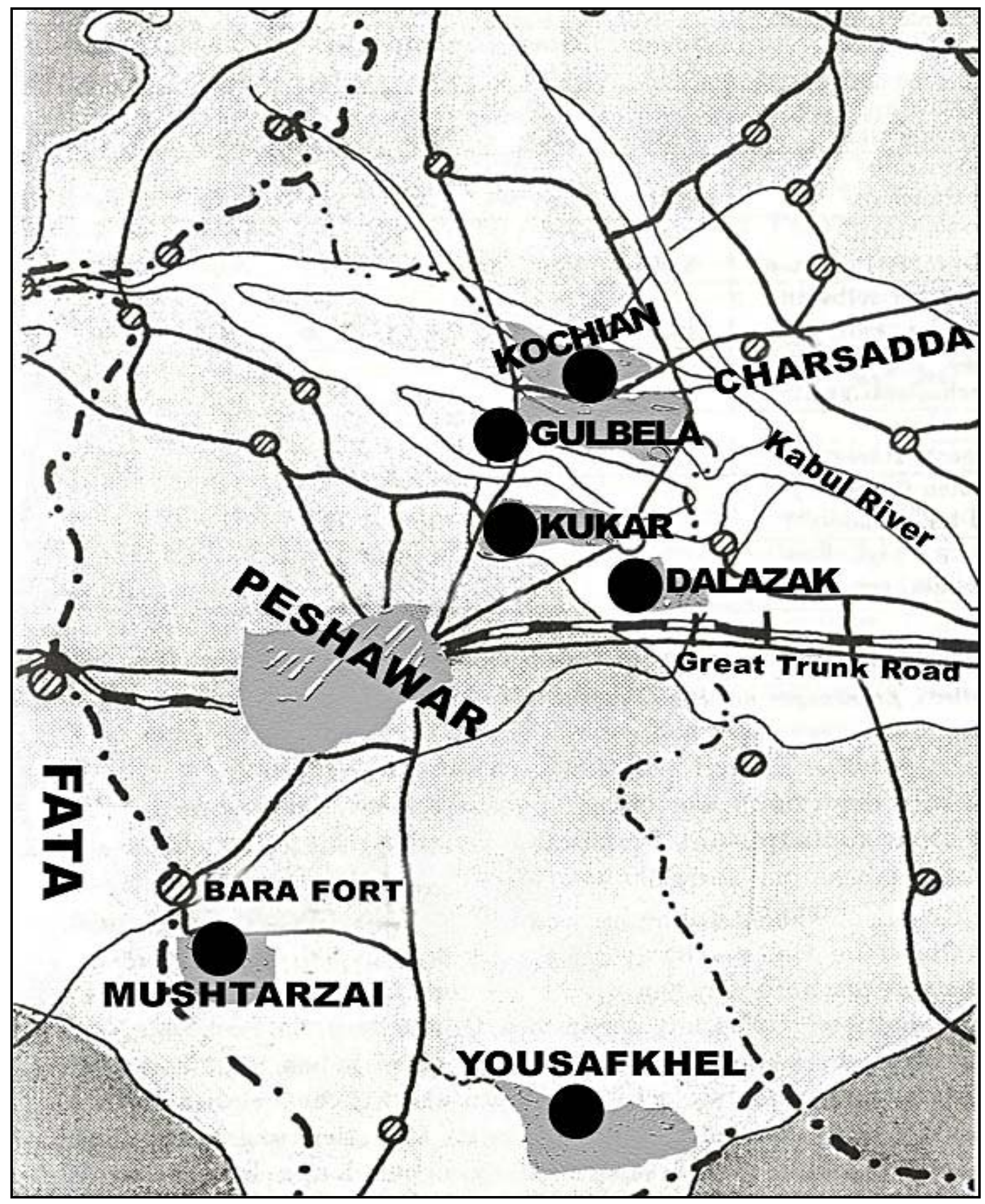

Source: Adjustment after MANIG, 1991. 
Appendix 4. Basic Survey Questionnaire of All Rural Households

\begin{tabular}{|c|c|c|c|c|c|c|c|c|c|c|c|c|}
\hline \multicolumn{2}{|c|}{ Village: } & \multicolumn{2}{|l|}{ ujra: } & \multicolumn{4}{|c|}{ Name of family head: } & \multicolumn{2}{|l|}{ Tribe/Caste: } & Survey period: & & Interviewer: \\
\hline \multirow[t]{2}{*}{ No. } & \multirow[t]{2}{*}{ Name } & \multirow[t]{2}{*}{ Sex } & \multirow[t]{2}{*}{ Age } & \multirow[t]{2}{*}{$\begin{array}{l}\text { Relation to } \\
\text { head }\end{array}$} & \multirow[t]{2}{*}{$\begin{array}{l}\text { Marriage } \\
\text { status }\end{array}$} & \multicolumn{2}{|c|}{$\frac{\text { Education }}{\text { studied }}$} & \multirow{2}{*}{$\begin{array}{l}\text { Occupations/ } \\
\text { Activities } \\
\text { Actual (specify) }\end{array}$} & \multirow{2}{*}{$\begin{array}{l}\text { Working } \\
\text { outside } \\
\text { Where? }\end{array}$} & \multirow[t]{2}{*}{$\begin{array}{l}\text { Distance to } \\
\text { village }\end{array}$} & \multirow[t]{2}{*}{$\begin{array}{l}\text { Income of employment, yearly.... } \\
\text { Accumul. Rs. }\end{array}$} & \multirow[t]{2}{*}{$\begin{array}{l}\text { Source of } \\
\text { Existence }\end{array}$} \\
\hline & & & & & & $\begin{array}{l}\text { Up to } \\
\text { years }\end{array}$ & In & & & & & \\
\hline 1 & & & & from head & & & & & & & & \\
\hline \multicolumn{13}{|l|}{2} \\
\hline \multicolumn{13}{|l|}{3} \\
\hline \multicolumn{13}{|l|}{4} \\
\hline \multicolumn{13}{|l|}{5} \\
\hline \multicolumn{13}{|l|}{6} \\
\hline \multicolumn{13}{|l|}{7} \\
\hline \multicolumn{13}{|l|}{8} \\
\hline \multicolumn{13}{|l|}{9} \\
\hline \multicolumn{13}{|l|}{10} \\
\hline \multicolumn{13}{|l|}{11} \\
\hline \multicolumn{13}{|l|}{12} \\
\hline \multicolumn{13}{|l|}{13} \\
\hline 14 & & & & & & & & & & & & \\
\hline
\end{tabular}

Remarks: 


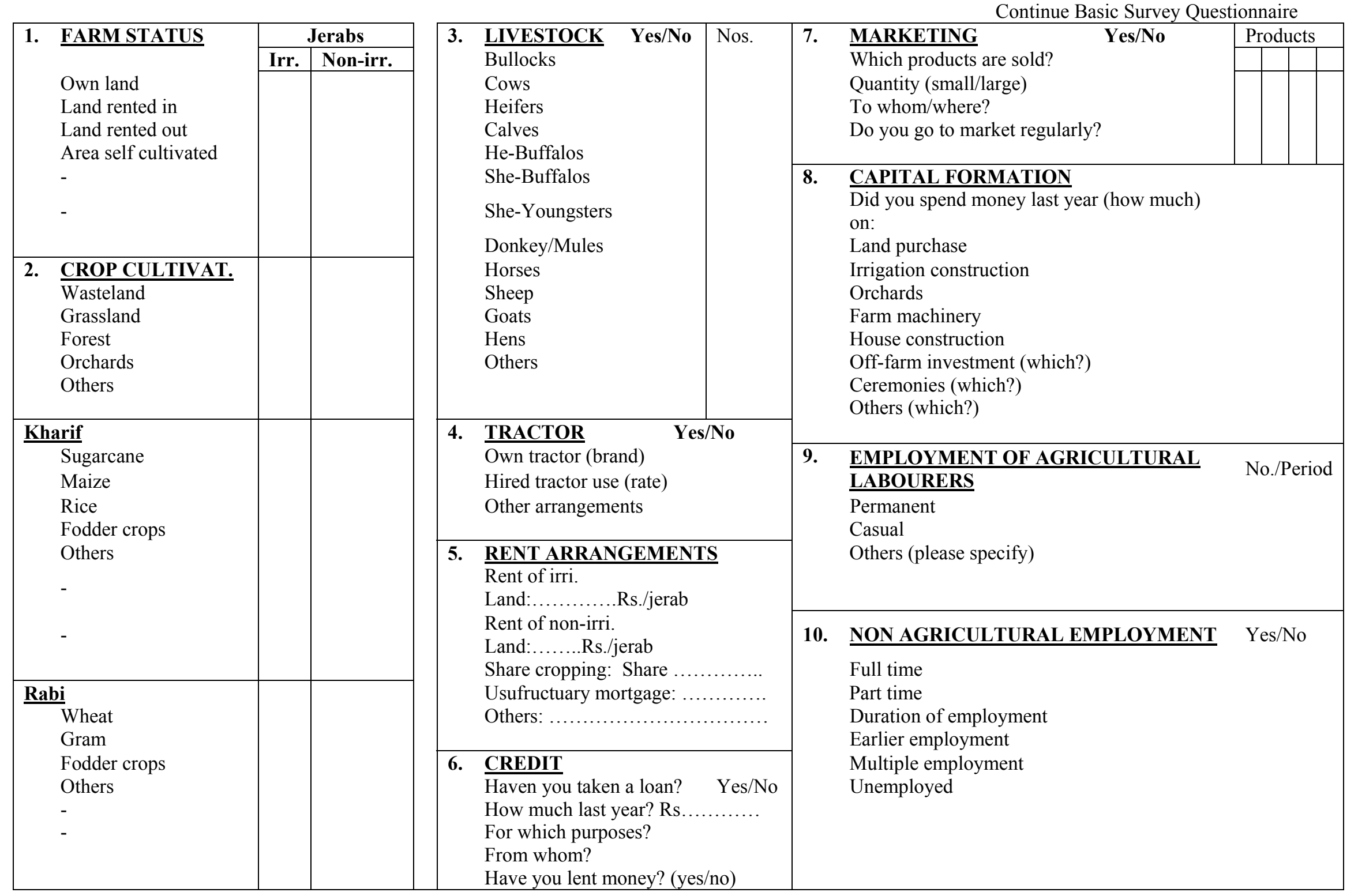


Appendix 5. Content Outline of Special Survey Questionnaire

\section{Block A: Household identification information}

A1 Identification details (village and household codes, survey period)

Block B: Occupational characteristics and pattern of employment

B1 Principal activities during last year (duration, changes, status, sector of employment, migration)

B2 Occupation details (duties performed, test/interview for job,)

\section{Block C: Household income characteristics}

C1 Income details (number of persons in employment/business, monthly income of household, mode of payment (daily, weekly, monthly, and end of contract), allowances paid

\section{Block D: Working terms and conditions}

D1 Working Conditions (hours of work/day, work place environment, injuries at work, vacations allowed, working relations with employer, labour unions)

Block E: Training characteristics

E1 Training and education (details of formal education \& training)

Block F: Infrastructure characteristics and asset based indicators

F1 Shelter/Housing (house ownership status, house size and structure, no. of rooms, roofing and flooring condition, toilet and kitchen, water supply sources (well, pipe, water pump, neighbour), access to electricity, gas, telephone)

F2 Other physical assets (land, livestock, transport, telephone etc.)

\section{Block G: Means of communication}

G1 Communication details (distance and time to place of employment, mode of transportation used)

Block H: Women and their economic activities

H1 Female engagement in economic activity (duration, nature, hours of work, amount paid, reasons for not to be economically active) 